\title{
LAS OBLIGACIONES ESTATALES Y LA RUTA CRÍTICA DE LAS MUJERES EN EL PARTIDO DE LA PLATA
}

Sofía Ballesteros

Tesis final de Maestría

Directora Dra. Manuela G. González, UNLP.

Maestría en Derechos Humanos. 
A Sebi, por tanto. A Emi y Lauti por ser.

A mi mamá por la incondicionalidad.

A mi familia grande por el respaldo.

A las "feministas compañeras" por los caminos recorridos.

A Ixs compamigxs de siempre por ser brújula en las tormentas. 
ÍNDICE

PRIMERA PARTE: APERTURA Y PRESENTACION

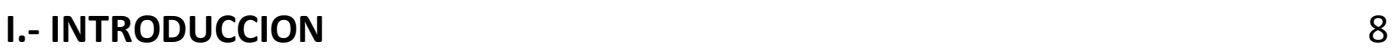

1.- Situándome 8

2.- El problema en cuestión 9

3.- Nuestro desafío 15

$\begin{array}{ll}\text { 4.- Metodología de investigación } & 16\end{array}$

$\begin{array}{ll}\text { 4.1.- Las entrevistas } & 18\end{array}$

4.2.- Las observaciones participantes 19

4.3.-Análisis de documentos $\quad 20$

5.- A modo de advertencia 21

II.- ¿DE QUÉ HABLAMOS CUANDO HABLAMOS DE...?

1.-...Violencias 23

2.-...Perspectiva de género 25

3.-...Estereotipos 26

$\begin{array}{ll}\text { 4.-...Acceso a la justicia } & 28\end{array}$

5.-...La(s) mujer(es) $\quad 30$

6.-...Ruta crítica 31

$\begin{array}{ll}\text { 7.-...Interseccionalidad } & 32\end{array}$

8.-...Maternidad (obligatoria) 34

9.-...Derechos Humanos 37

SEGUNDA PARTE: EL DERECHO DE LAS MUJERES A UNA VIDA LIBRE DE VIOLENCIA Y 
III.- EL DERECHO DE LAS MUJERES A UNA VIDA LIBRE DE VIOLENCIA: SU RECONOCIMIENTO INTERNACIONAL $\quad 42$

1.- Introducción 42

2.-Las grandes herramientas internacionales de protección: la CEDAW y la CBDP $\quad 45$

2.1.- La CEDAW 45

2.1. a.- Mecanismos de protección: el Comité CEDAW 47

2.1. b.- Las Recomendaciones Generales 48

2.1. c.- El Protocolo facultativo y los casos individuales 52

2.2.- La Convención de Belém Do Pará 53

2.2. a- Mecanismos de protección 55

2.2. b.- La Corte Interamericana y la CBDP: el caso "Campo Algodonero" 56

2.2. b. 1.-La competencia de la Corte IDH para entender en violaciones al artículo 7 de la CBDP 57

2.2.b.2.-Las obligaciones reforzadas. La relación entre la Convención Americana y la CBDP 58

IV. LA DEBIDA DILIGENCIA Y LA RESPONSABILIDAD ESTATAL EN PREVENIR, INVESTIGAR, SANCIONAR Y REPARAR LA VIOLENCIA DE GÉNERO CONTRA LAS MUJERES

60

1.- La debida diligencia para prevenir, investigar, sancionar y reparar la violencia de género contra las mujeres

60

1.1.- El abordaje del principio de la Debida diligencia por los órganos de protección y los especializados 61

2.- La debida diligencia y la responsabilidad estatal por actos de particulares

V.- LAS OBLIGACIONES ESTATALES: RESPETAR Y GARANTIZAR 72

1.- Introducción: Respetar y Garantizar 72

2.- Prevenir 74

3.- Proteger 76 
4.- Investigar, juzgar y sancionar 77

5.- Reparar 81

TERCERA PARTE: LAS RESPUESTAS DEL ESTADO EN EL PARTIDO DE LA PLATA

VI.- LA NORMATIVA VIGENTE Y LA NOMINACIÓN DEL SUFRIMIENTO DE LAS MUJERES

VII.- LAS POLÍTICAS PÚBLICAS EN EL PARTIDO DE LA PLATA 92

1.- La línea 144 de la Provincia de Buenos Aires 93

1.1.- La atención de las llamadas telefónicas: "el call” 94

1.2.- Las tensiones entre la cantidad y la calidad 97

1.3.- El equipo de seguimiento 98

1.4.- Las condiciones de trabajo y de vida de las trabajadoras de "la 144" 99

2.- Los Centros de atención primaria de Salud de la Municipalidad de La Plata 101

3.-La Dirección General de Género y Diversidad de la Municipalidad de

La Plata (ex DPG) 102

3.1.- Las tensiones entre la cantidad y la calidad 104

3.2.- Las condiciones de vida y de trabajo de las trabajadoras de la DGGyD 104

4.- La debilidad y la protección 105

$\begin{array}{ll}\text { VIII.- LAS COMISARIAS } & 108\end{array}$

1.- Las idas y vueltas 109

2.- Cuando la respuesta es un no 110

3.- Hagamos como si... 111

4.- Ante la violencia... más violencia 111

$\begin{array}{ll}\text { IX.-LAS INSTANCIAS JUDICIALES } & 113\end{array}$

1.- Juzgados de Protección contra la Violencia Familiar, Niñez y Salud Mental 114

1.1.- ¿Yo señor (a)? No señor (a) 115

1.2.- Una vuelta más... 116 
1.3.- Poniendo el cuerpo

1.4.- ¿Cuándo? ¿Cómo? ¡¿Cuándo?!

1.5.- Poniendo el cuerpo otra vez más...

1.6. - Y otra vuelta más, seguro que nos vamos a marear

1.7.- Y después ¿Qué?

1.8.- La prohibición de mediación

1.9.- Pedazos para armar

2.- Área de Procesos Urgentes (APUR)

2.1.- ¿Y por casa cómo andamos?

3.- Fuero Penal. Las Fiscalías Especializadas

4.- Acerca de la coordinación

1.- A modo de repaso

2.- Desde lejos no se ve

3.- Hecha la ley

4.--¿¿Los lentes violetas?

5.- Todos los caminos conducen a...

6.- Se hace camino al andar

7.- El rompecabezas

8.- ¿Pero entonces quien lo tiene?

9.- Un techo para vivir

10.- El dinero sí importa

11.- ¿Y con Ixs pibxs que? 
PRIMERA PARTE

APERTURA Y PRESENTACION 


\section{I.-INTRODUCCION}

\section{1.- Situándome}

Empecé a diseñar los primeros trazos de estas tesis hace casi 10 años, al calor de la lucha. Acompañada de muchxs ${ }^{1}$ compas imprescindibles. En esos años íbamos y veníamos, debatíamos mucho, nos reuníamos, construíamos nuevos espacios y redes. Llovían los llamados para ver qué hacer ante las situaciones de violencia que emergían, probamos con esto y aquello: cartillas, talleres, charlas, el POP, las mesas locales, denuncias, la casa de la mujer, talleres de artesanías, de redes, de herramientas jurídicas, de autocuidado, comisiones de mujeres, de género, documentos, los Encuentros de mujeres, la Campaña Nacional contra las violencias. Desde "La Ciega", "La Caldera”, “Aquelarre”, “Desde el Fuego", “COB La Brecha”, las identidades políticas eran múltiples pero la convicción una: luchar contra el capitalismo y el patriarcado por un mundo nuevo sin opresiones.

La calle, el puente, la plaza, la facu, el centro comunitario, el galpón, albergaron nuestros debates, nuestras ganas sinceras, nuestro poner el cuerpo, la cabeza, el corazón. Nos indignamos tanto, pero también fuimos felices. Hicimos talleres por todos lados, siempre movilizantes, algunas veces muy duros, jamás indiferentes. Las experiencias de las compañeras, y las preguntas que surgían en ese marco me impulsaron a elaborar el plan de tesis: ¿qué hacer?, ¿a dónde ir?, ¿qué existe?, ¿qué respuestas dan?, ¿alcanza?: el Estado es responsable.

Casi 10 años después extraño mucho de aquello, tal vez con una mirada un tanto romántica de esos tiempos.

\footnotetext{
${ }^{1}$ Cuando pretendo incluir a hombres, mujeres e identidades disidentes utilizaré el símbolo " $x$ " en la palabra correspondiente. Parto de que el uso del masculino para generalizar es un sesgo sexista en el lenguaje. Dejo de lado la opción de utilizar los géneros gramaticales "os/as" ya que es una formulación que no contempla a aquellas personas cuya identidades se ubican por fuera del binarismo hetoronormado varón/mujer.

Siguiendo a la Unesco (1999) entiendo que "El lenguaje no es una creación arbitraria de la mente humana, sino un producto social e histórico que influye en nuestra percepción de la realidad" (p. 2). En el mismo sentido en el texto "Hecha la ley" se señala: "Resulta importante que el lenguaje refleje la existencia autónoma de todas las personas, en la búsqueda de que todxs podamos apropiarnos de nuestro destino y ser protagonistas del mismo" (AAVV, 2015: 15).
} 
Entiendo vigentes muchas de esas preguntas, las reformulo y pongo manos a la obra, feminista ${ }^{2}$ convencida de corazón rojo y a la izquierda.

Este es mi lugar... lo explicito, aquí me sitúo y desde aquí escribo... ${ }^{3}$

\section{2.- El problema en cuestión}

Una de las formas más habituales de violencia que sufren las mujeres a nivel mundial es la violencia en el interior de su familia (COHRE, 2010:8) y la más común es la violencia dentro de la pareja (Secretario General ONU, 2006: párr. 112). Lxs expertxs señalan que en América Latina este problema, lejos de disminuir, va en ascenso (COHRE, 2010; Femenías y Soza Rossi 2009: 44).

La violencia doméstica ha sido definida como toda conducta que por acción u omisión tenga por objeto causar daño o dolor a la pareja mujer, ya sea psicológico, físico o sexual (Rioseco, 1999: 577). En un contexto donde esta violencia reconoce su causa en la desigualdad histórica de las relaciones de poder entre hombres y mujeres (Salvioli, 2007:149) y al ser las mujeres las principales afectadas (Teodori, 2015: 58) se suele utilizar el término como equivalente a "violencia hacia la mujer en el contexto doméstico".

Estas formas de violencias son una epidemia social a escala global y no un problema individual de una mujer o de un grupo de mujeres (González y Galletti, 2012: 20; Femenías y Soza Rossi 2009: 58). Es un grave problema social (Velázquez, 2003:224), tal es así que se ha hablado de terrorismo conyugal, creado y perpetuado por el esposo maltratante en el ámbito intrafamiliar (Dohmen, 2006: 105).

\footnotetext{
2Utilizo en este trabajo el termino feminista como "etiqueta descriptiva" (Bartlett, 1990) "en el sentido amplio que rodea a una postura crítica auto-consciente hacia el orden existente en cuanto a las muchas maneras en que dicho orden afecta a diferentes mujeres 'como mujeres'" (p. 3) y, agrego, a las identidades disidentes.

El feminismo es una interpretación política y una lucha (Gordon, apud Bartlett, 1990: 3). Es rico en producción teórica e intervención política, actualmente se utiliza el término "los feminismos" para dar cuenta de su heterogeneidad y cuestionar el feminismo hegemónico (Ballesteros y Colanzi, 2015:231).

Me sitúo en un feminismo no hegemónico (González y Galletti, 2014), un feminismo disidente y popular "heredero de las experiencias emancipatorias, pero que toma aquella experiencia de manera crítica y la multiplica, la socializa, la difunde, la cuestiona y la transforma" (Korol, 2013:11).

${ }^{3}$ Siguiendo los planteos de Haraway (1995) y su "conocimiento situado": "Yo quisiera una doctrina de la objetividad encarnada que acomode proyectos de ciencia feminista paradójicos y críticos: la objetividad feminista significa, sencillamente, conocimientos situados" (p. 324).
} 
La violencia doméstica comienza a ser visibilizada y denunciada, en Latinoamérica, como un problema de gran magnitud y graves consecuencias sociales, en la década de los años ochenta (Sagot, 2000), y esto se debe, en gran medida, al intenso trabajo de las organizaciones de mujeres de la sociedad civil (Rioseco, 1999: 575).

Ha sido caracterizada como un problema de salud pública y de derechos humanos, hoy en día existe consenso en la comunidad internacional sobre este punto (Rioseco, 1999:578). En los años noventa, la comunidad mundial reconoció oficialmente la violencia contra las mujeres como una violación de los Derechos Humanos ${ }^{4}$ (Sagot, 2000: 19). En nuestra región la Asamblea General de la Organización de Estados Americanos (en adelante OEA) adoptó la Convención Interamericana para Prevenir, Sancionar y Erradicar la violencia contra la mujer (en adelante "Convención de Belem Do Para" o CBDP) en 1994. Esta convención es el primer instrumento internacional en el mundo que reconoce el derecho a las mujeres a vivir una vida libre de violencia (Camacho, 2003:71) y $^{5}$ ha sido ratificado por el Estado Argentino.

El abordaje de una problemática tan compleja como la violencia doméstica hacia las mujeres debe ser integral (Dohmen, 2006: 229; Birgin y Gherardi, 2008: 242) esta necesidad ha sido reconocida por la normativa vigente y se constituye en una obligación para el Estado Argentino (Ballesteros, Cisneros y Barcaglioni, 2012:11). Así, la Corte Interamericana de Derechos Humanos (en adelante Corte IDH) (2009) ha resuelto que los Estados deben adoptar una estrategia de prevención y protección integral para cumplir con la obligación de debida diligencia en casos de violencia contra las mujeres (párr. 258).

Se ha afirmado que el que un país ratifique esta Convención no representa un cambio automático en la vida de las mujeres maltratadas, ni en los recursos de que disponen, pues para ello cada Estado debe aprobar políticas públicas y legislación específica que

\footnotetext{
${ }^{4}$ En la Conferencia Mundial de la ONU sobre Derechos Humanos, realizada en Viena en 1993.

${ }^{5}$ Esta Convención establece obligaciones para los Estados, son muchos los de nuestra región que la han ratificado. Sin embargo, se ha afirmado que la violencia intrafamiliar afecta a una de cada tres mujeres en América y que aunque, como resultado de los acuerdos internacionales, la mayoría de los países de la región formularon legislaciones para enfrentarla, no en todos ellos se han concretado reglamentaciones, instrumentos, recursos y políticas que hagan efectivas tales medidas (Sagot, 2000: 6).
} 
establezcan normas y procedimientos claros (Sagot, 2000:19) ${ }^{6}$.

Argentina ha sancionado legislación en consecuencia, así la Ley Nacional 26.485 de Protección Integral para Prevenir, Sancionar y Erradicar la Violencia contra las Mujeres en los ámbitos en que se desarrollen sus relaciones personales ${ }^{7}$.

Actualmente en la Provincia de Buenos Aires la interpretación armónica de la normativa vigente establece un alto estándar de protección y prevención contra la violencia hacia las mujeres. Sin embargo no hay una relación directa de causa-efecto entre leyes y prácticas (Segato, 2011: 2). Así múltiples estudios revelan la existencia de una gran brecha entre la legislación vigente y la concreción de medidas efectivas que repercutan en la vida de las mujeres en situación de violencia (Sagot, 2000; Comisión Interamericana de Derechos Humanos, 2007; Hollweck y Urbancic Baxter, 2006; Sernam, 2009; Barcaglioni, s/f). Esta brecha ha sido advertida por el Comité para la Eliminación de la Discriminación Contra la Mujer (en adelante Comité CEDAW ${ }^{8}$ ) (2010) en sus observaciones al Estado Argentino. El diseño e implementación de políticas públicas integrales, adecuadas y efectivas es una necesidad apremiante (Birgin y Gherardi, 2008:242; Urtazun y Delmas, 2012; Gonzalez y Galletti, 2012). Un acceso adecuado a la justicia y una respuesta judicial efectiva implican la obligación de hacer accesibles recursos judiciales sencillos, rápidos, idóneos e imparciales de manera no discriminatoria (CIDH, 2007: 3), y requieren una actuación intensa para vencer, eliminar o mitigar los obstáculos existentes (Reglas de Brasilia, 2008).

Según los datos del Registro Nacional de Femicidios de la Justicia Argentina ${ }^{9}$ (2018), en el año 2017 se relevaron 251 víctimas directas de femicidios ${ }^{10}$. Si a esa cifra se suman

\footnotetext{
${ }^{6}$ En un estudio coordinado por Sagot (2000), realizado en 10 países de Latinoamérica sobre la "ruta crítica" que recorren las mujeres para salir de la situación de violencia en la que se encuentran inmersas, los diez habían adherido a la Convención de Belém do Pará entre diciembre de 1994 y noviembre de 1996 y al momento de realizarse la investigación ocho de los diez países habían aprobado leyes específicas sobre violencia doméstica o intrafamiliar, y sin embargo en ese estudio se concluía que en todos los países las historias de las mujeres revelaban la existencia de una gran brecha entre "el discurso de la democracia formal" y "la concreción de una verdadera justicia social para las afectadas por la violencia intrafamiliar" (Sagot, 2000:8).

${ }^{7}$ Sancionada el 11 de marzo de 2009 y promulgada de hecho el 1 de abril de 2009.

${ }^{8}$ Por sus siglas en inglés.

${ }^{9}$ A cargo de la Oficina de la Mujer de la Corte Suprema de Justicia de la Nación.

${ }^{10}$ Podemos definir el concepto de femicidio en los siguientes términos: "muerte violenta de mujeres/mujeres trans/travestis (niñas, adolescentes y/o adultas) perpetradas por varones por razones asociadas a su género hayan sido o no tipificadas como femicidio, ya sea que tenga lugar dentro de la
} 
los femicidios vinculados y vinculados por interposición en línea de fuego ${ }^{11} \mathrm{el}$ número de muertes asciende a $273^{12}$. El 93 por ciento de los victimarios eran varones con quienes las víctimas tenían algún vínculo o a quienes conocían. En el 59 por ciento de los casos esos varones eran sus parejas o ex parejas. El 80 por ciento de los femicidios se cometió en espacios privados, y el 71 por ciento de ellos, en las casas de las víctimas. Se afirma en el informe que "casi el $80 \%$ del total de los vínculos encuadra en el perfil de situaciones incluidas en lo que la legislación nacional define como 'violencia doméstica' (Ley 26.485) y que requiere dispositivos de abordaje específico por los tres poderes del Estado"13 (p.11).

En Argentina en los últimos años el movimiento feminista logró visibilizar las múltiples violencias que padecen las mujeres. La violencia física y su expresión más extrema, el femicidio, son cada vez más rechazadas. Expresión de este repudio, bronca e impotencia generalizada fueron las masivas movilizaciones del 3 de junio de 2015 en varios puntos del país, convocadas por el Colectivo Ni Una Menos ${ }^{14}$. Bidaseca (2015) sostiene que "Ni una menos es el símbolo de la sensibilidad de esta época que condensa una estructura de sentimientos y de lucha contra los Feminicidios en América Latina" (p. 203).

El 3 de junio se ha convertido en un hito importante del movimiento feminista, no es una expresión de indignación aislada sino que se enmarca en un proceso abierto, "no se trata de una acción nacida de un tuit. Tiene una genealogía" señala Bidaseca (2015: 204). En este mismo sentido se ha sostenido que:

familia, unidad doméstica o en cualquier otra relación interpersonal; en la comunidad, por parte de cualquier persona, o que sea perpetrada o tolerada por el Estado y sus agentes, por acción $u$ omisión" (CSJN, 2018:4). La Ley 26.791 (2012) modifico el artículo 80 del Código Penal Argentino incorporándose las figuras de femicidio y femicidio vinculado, aunque sin nominarlas expresamente.

${ }^{11}$ Los femicidios vinculados han sido definidos como "aquellos homicidios cometidos contra una o varias personas (niñas, niños, adolescentes, mujeres, varones, trans, travesti), a fin de causarle sufrimiento a una mujer, mujer trans o travesti" (CSJN, 2018: 1). Los femicidios vinculados por interposición en línea de fuego ha sido definido como "aquellos casos en que el homicidio se comete contra una o varias personas (niña, niño, adolescente, mujer, varón, trans, travesti) que se interpone/n o intenta/n evitar un femicidio" (CSJN, 2018:1).

${ }^{12}$ Estas cifras provienen del relevamiento de causas judiciales que se iniciaron entre el 1 de enero y el 31 de diciembre de 2017 en las 23 jurisdicciones provinciales y en la Ciudad de Buenos Aires.

${ }^{13}$ Sólo en el $4 \%$ de los casos no hubo ningún conocimiento previo entre víctima y sindicado/imputado. Y en un $3 \%$ no se tiene información al respecto (p. 11).

${ }^{14}$ Miles de personas conmovidas por la seguidilla de femicidios pusieron el cuerpo en marcha y llenaron las plazas y las calles. 
Es importante que pensemos este 3 de junio como un mojón más en la larga lucha que venimos dando las mujeres y las personas LGTTBIQ en contra del hetero-patriarcado capitalista. Un mojón importante, que nos emociona, nos contagia, nos empodera y nos carga de energía para continuar caminando, poniendo nuestros cuerpos en la calle, exigiendo que se respeten nuestros derechos y nuestra autonomía. (Corriente de Organizaciones de Base La Brecha, 2015: 238)

Con respecto a la "ruta crítica" de las mujeres, no son muchos los estudios que se han realizado. Entre los existentes podemos ${ }^{15}$ mencionar el estudio que hemos referido anteriormente, coordinado por Sagot (2000) y titulado "Ruta crítica de las mujeres afectadas por la violencia intrafamiliar en América latina (estudios de caso de diez países) ${ }^{16 \prime \prime}$. En él se realiza un recuento de las experiencias de mujeres en 16 comunidades y las respuestas de prestatarios de servicios de salud, judicial, policial y social en estas comunidades. Se afirma que una de las características de la violencia doméstica es su "invisibilidad", y que uno de los factores que inciden en que el nivel de denuncia de estos hechos sea bajo es la percepción de las mujeres de que no hay servicios o respuestas sociales para apoyarlas a resolver su problema, o que los servicios existentes son poco eficientes, inadecuados y hasta dañinos (Sagot, 2000).

En otro estudio realizado en Chile por el Servicio Nacional de la Mujer (Sernam) (2009), se trabajó sobre las historias de 6 mujeres chilenas dando un papel primordial a su experiencia subjetiva en su vivencia de la violencia y en su recorrido por la ruta crítica, poniendo el acento en la descripción y análisis de las situaciones de violencia y en cuales fueron los factores que impulsaron a estas mujeres a accionar para poder salir del circulo de violencia en el que se encontraban inmersas, así como también en su recorrido por las instituciones.

En Argentina, en la provincia de Tucumán, el Observatorio de la Mujer del Hospital Centro de Salud J. Z. Santillán realizó un estudio sobre la "ruta critica" (s./f.). En el informe pertinente se afirma que en nuestro país no se habían realizado con anterioridad estudios sobre este tema. Se sistematizan y analizan los datos obtenidos de los testimonios prestados por las mujeres en el marco del trabajo cotidiano de

\footnotetext{
${ }^{15}$ De aquí en más enunciaré mi voz en plural, ya que me facilita y vuelve más cómoda la escritura.

${ }^{16}$ Nicaragua, Panamá, Perú, El Salvador, Ecuador, Belice, Costa Rica, Bolivia, Guatemala y Honduras.
} 
atención de mujeres víctimas de violencia por el Observatorio, reconstruyéndose así la "ruta crítica" recorrida por esas mujeres, y se arriba a la construcción de conclusiones en torno a los escenarios de la Ruta Crítica (accesibilidad, disponibilidad y calidad) de los diferentes Sectores (Salud, Educación, Policía, Justicia).

Barcaglioni (s./f.) aborda las dificultades con las que se encuentran las mujeres para acceder a la justicia, en casos de violencia contra la mujer ${ }^{17}$. Se analiza la comisaría de la mujer, los primeros pasos que se pueden tomar en el ámbito judicial: medidas cautelares y las posibilidades de un convenio o mediación.

Berto, González, Sarmiento y Veiga (2017), trabajadoras de la Línea 144 Nación $^{18}$, analizan su propia intervención profesional en el trabajo cotidiano, así como el proceso de realización de la denuncia en la Comisaría y solicitud de medidas protectorias en sede judicial en la Ciudad Autónoma de Buenos Aires. Afirman que muchas veces son las primeras personas con las que la mujer se anima a hablar y sostienen que "al menos la mitad de las mujeres que se contactaron con la Línea 144, vuelven a comunicarse porque se encontraron con inconvenientes u obstáculos" (p. 5).

El estudio cualitativo "La Ruta Crítica de las mujeres que sufren violencia en las relaciones de pareja" $(2017)^{19}$, realizado en la ciudad de Santa Fé, analiza los relatos de 12 mujeres víctimas de violencias de género ${ }^{20}$. Indaga sobre los factores que impulsan a las mujeres a buscar ayuda y sobre los recorridos que ellas realizan por las distintas instituciones y las respuestas que obtienen. Se efectúan mapeos y gráficos por demás interesantes.

Teodori (2015) describe el proceso emprendido por mujeres y analiza las respuestas que obtienen en la Ciudad de Buenos Aires. Pone particular énfasis en el plano de la salud. Su trabajo de campo se desarrolla en un Hospital de referencia de la Ciudad Autónoma de Buenos Aires (en adelante CABA).

\footnotetext{
${ }^{17}$ A partir de un diagnóstico realizado por "Mujeres al Oeste" en el Departamento Judicial de Morón, Provincia de Buenos aires, y un femicidio ocurrido en la ciudad de La Plata.

${ }^{18}$ En su artículo "Violencia de género y ruta crítica. ¿El Estado siempre presente? Una experiencia desde la Línea 144".

${ }^{19}$ Elaborado por el equipo de la Defensoría del Pueblo de la Provincia de Santa Fe Zona Norte. Publicado como "Octavio Bassó .et al.".

${ }^{20}$ Que acudieron para su atención al Centro de Asistencia a la Víctima y al Testigo del Delito de la Defensoría del Pueblo de la Provincia de Santa Fé Zona Norte.
} 
En "Mujeres que rompen el silencio" (2017) las autoras ${ }^{21}$ analizan la ruta crítica en la CABA, a partir de la realización de 22 entrevistas a mujeres en situación de violencia. Abordan los escenarios y actorxs involucradxs "con el propósito de identificar, revisar y repensar los modelos de prevención y atención existentes a fin de contar con insumos para el diseño de políticas públicas" (p. 7 y 8 ).

Junto a De La Vega (2012) hemos analizado la ruta crítica recorrida por una mujer en el Municipio de Florencio Varela, haciendo énfasis en el rol desempeñado por la organización social en la que ella participaba.

Para la realización de esta tesis hemos revisado ${ }^{22}$ el Repositorio Institucional de la Universidad Nacional de La Plata (SEDICI), analizando la totalidad de las tesis de maestría, doctorado y los trabajos de especialización de las Facultades de Ciencias Jurídicas y Sociales, Humanidades y Ciencias de la Educación y Trabajo Social. Ninguno de esos trabajos aborda el tema de la ruta crítica de las mujeres en situación de violencia, así como tampoco las obligaciones y respuestas estatales en esta temática. Lo cual, por un lado, nos sorprende y por otro renueva nuestro entusiasmo y compromiso con la temática que definimos y el desafío que nos proponemos.

\section{3.- Nuestro desafío}

Es en este marco, y retomando las líneas de los últimos estudios referidos, que planteamos el desarrollo de nuestro trabajo.

Partiendo de que el Estado Argentino ha asumido internacionalmente compromisos tendientes a prevenir, sancionar y erradicar la violencia contra las mujeres y que, para cumplir con dicha obligación, los distintos niveles estatales deben implementar políticas públicas que garanticen una respuesta efectiva a aquellas mujeres que pretenden salir de la situación de violencia en la que se encuentran. Nos propusimos indagar en la ruta crítica de las mujeres en situación de violencia doméstica en el Municipio de La Plata. En particular en las respuestas que obtienen de parte de los dispositivos estatales involucrados. Teniendo como referencia las obligaciones

\footnotetext{
${ }^{21}$ Bengochea, Juen, Parola, Suzal, y Grillo, en el marco de la Dirección General de La Mujer del Ministerio de Desarrollo Humano y Hábitat de CABA.

${ }^{22}$ Durante el mes de julio de 2018.
} 
asumidas internacionalmente por el Estado Argentino en esta temática.

Este análisis nos permite reflexionar sobre cómo se traducen en lo concreto los compromisos del Estado y sobre el cumplimiento, o no, de parte del Estado Argentino de las obligaciones que ha asumido al ratificar tratados de Derechos Humanos relacionados con la temática.

El objetivo general de nuestra investigación es el siguiente:

Indagar la ruta crítica de las mujeres que deciden salir del círculo de violencia doméstica en el que se encuentran inmersas en el Partido de La Plata (Provincia de Buenos Aires), teniendo como referencia las obligaciones asumidas internacionalmente por el Estado Argentino en relación a las prácticas de violencia contra las mujeres.

Los objetivos específicos consisten en:

I.- Analizar, desde una perspectiva de género y derechos humanos, las obligaciones asumidas internacionalmente por el Estado Argentino en relación a las prácticas de violencia contra las mujeres.

II.- Describir las acciones emprendidas por las mujeres víctimas de violencia doméstica y la ruta seguida por ellas para encontrar atención y solución a sus problemas de violencia.

III.- Indagar las respuestas obtenidas por estas mujeres de parte de los organismos estatales.

En el plan de tesis nos formulamos las siguientes preguntas para orientar nuestro trabajo: ¿Cuál es el proceso de la "ruta crítica" seguido por las mujeres en situación de violencia doméstica? ¿Cuáles son las respuestas estatales que obtienen en el Partido de La Plata? ¿Cumple el Estado con las obligaciones asumidas internacionalmente en relación a la violencia doméstica, en tanto respeto y protección de los Derechos Humanos de las mujeres en este aspecto?

\section{4.- Metodología de investigación}

Para la investigación hemos seleccionado la metodología cualitativa, esto ya que nos permite observar, describir, y analizar de mejor manera el fenómeno en cuestión 
(Sernam, 2009). La misma nos proporciona herramientas para trabajar datos descriptivos: las propias palabras de las personas, habladas o escritas y su conducta observable. La investigación cualitativa permite descripciones detalladas, de situaciones, personas, interacciones y comportamientos (Barcaglioni, s/f).

Se ha dicho que los datos cualitativos permiten preservar el ritmo cronológico de los eventos, comprenderlos dentro del contexto mismo en el que acontecieron y derivar de ello explicaciones fuertemente enraizadas en la realidad socio-cultural que se estudia. La investigación cualitativa permite entender los fenómenos sociales desde la propia perspectiva del actor (Sagot, 2000).

Las técnicas de recolección de datos que hemos utilizado en esta investigación son:

Entrevistas semiestructuradas: a informantes clave, que son los actores involucrados en el proceso de la "ruta crítica": prestatarixs de servicios, integrantes de organizaciones de la sociedad civil, mujeres en situación de violencia, en el ámbito geográfico seleccionado: el Municipio de La Plata.

Observación participante: en talleres o grupos de reflexión con integrantes de organizaciones de la sociedad civil que trabajen sobre esta temática, y mujeres en situación de violencia.

Análisis de documentos: de los organismos internacionales pertinentes, las instituciones, organismos públicos y organizaciones de la sociedad civil; así como de bibliografía, normativa y material periodístico relacionados con la temática.

Con respecto a la técnica de análisis de la información obtenida se utilizó el análisis de discurso (ACD).

También se utilizará la sistematización en matrices de datos cualitativas con los procedimientos de saturación teórica y método comparativo constante (Glasser y Strauss, 1967).

El trabajo de campo fue desarrollado en el partido de La Plata ${ }^{23}$, es la Capital de la Provincia de Buenos Aires, por lo que allí se encuentran las cabeceras de los organismos administrativos y judiciales de la misma.

\footnotetext{
${ }^{23}$ La ciudad de La Plata se encuentra al sur de la Región Metropolitana de Buenos Aires, está ubicada a 56 km de la Ciudad Autónoma de Buenos Aires. Las localidades del partido son: Abasto, City Bell, El Peligro, Joaquín Gorina, Lisandro Olmos, La Plata (Capital), Los Hornos, Manuel B. Gonnet, Melchor
} 
Para la elaboración del presente trabajo hemos efectuado las siguientes tareas:

-Realizamos 9 entrevistas.

-Efectuamos 10 observaciones participantes.

-Relevamos Ixs actorxs internacionales pertinentes.

-Relevamos Ixs actorxs institucionales en relación a la temática en el Municipio de La Plata.

-Analizamos las políticas públicas existentes en el Municipio de La Plata.

-Recopilamos y analizamos documentos y material pertinente.

\section{1.- Las entrevistas}

La entrevista, "comunicación con finalidad", "por sobre todo una conversación de a dos" (Minayo, 2016: 162), permite captar la perspectiva del actor, entendida como una versión a interpretar, como un texto a ser construido mediante un proceso de negociación (Teodori, 2015: 77).

Realizamos entrevistas de carácter semiestructurado a informantes clave: integrantes de organizaciones de la sociedad civil, actorxs estatales con pertinencia en la temática y mujeres que se habían encontrado en situación de violencia.

A efectos de resguardar la identidad de las personas entrevistadas utilizaremos, a lo largo de este trabajo, la primer letra de su nombre de pila para identificarlxs, en los casos en los que los nombres de dos entrevistadxs comiencen con la misma letra, en uno de ellos la acompañaremos con la primer letra del apellido.

Entre los meses de septiembre y diciembre de 2018 entrevistamos a:

P., trabajadora social de los centros de salud $n \circ 8$ y $n$ ㅇ 41 ubicados en el Barrio Altos de San Lorenzo de La Plata. Integrante de la Campaña Nacional contra las violencias hacia las mujeres.

E., psicóloga, trabajadora de la oficina de atención de la Dirección General de Género y Diversidad de la Municipalidad de La Plata.

Romero, Ringuelet, Tolosa, Villa Elvira y Villa Elisa (fuente: Observatorio metropolitano, http://www.observatorioamba.org/planes-y-proyectos/partidos-rmba/la-plata, fecha de consulta: 21/01/2019). Cuenta con una población total de 654.324 habitantes (fuente: Censo Nacional de Población, Hogares y Viviendas 2010, INDEC); y con un total de 221.313 hogares (fuente: Censo Nacional de Población, Hogares y Viviendas 2010, INDEC). 
EG., abogada, especialista en violencia de género. Acompañante y asesora de organizaciones sociales y feministas. Integrante del colectivo de Abogadxs populares La Ciega.

S., ex trabajadora del centro de atención telefónica y del equipo de seguimiento de la Línea 144 Provincia. Activista. Integrante de la Corriente Social y Política Marabunta.

SL., fotógrafa, docente del Bachillerato Popular "El Llamador" (ubicado en "El Galpón de Tolosa"). Integrante de la comisión de Géneros del Frente de Organizaciones en Lucha.

D., comunicadora social, integrante del Centro comunitario "Compartamos la lucha" ubicado en el barrio San Carlos de La Plata. Integrante de la comisión de Géneros del Frente de Organizaciones en Lucha.

B., trabajadora de una empresa de limpieza, quien había estado en situación de violencia.

A., docente, quien se había encontrado en situación de violencia.

PM., abogado, empleado en una Defensoría oficial del fuero penal del Departamento Judicial de La Plata.

\section{2.- Las observaciones participantes}

La observación participante ha sido descripta por Minayo (2016) como "parte esencial del trabajo de campo en la investigación cualitativa" (p. 170). La autora cita a Schwartz \& Schwartz (1955) quienes la definen como

un proceso a través del cual se mantiene la presencia del observador en una situación social, con la finalidad de realizar una investigación científica (...) el observador es parte del contexto bajo observación, al mismo tiempo modificando y siendo modificado por este contexto. (p. 170-171)

Realizamos observaciones participantes en las siguientes instancias:

-En el "Taller sobre violencias" en el marco del Encuentro de Formación de la Campaña Nacional contra las violencias hacia las mujeres, realizado en Pompeya, donde participaron mujeres de distintas localidades bonaerenses, entre ellas La Plata.

-En el taller "Mujeres, acceso a la justicia y estrategias de acompañamiento y contención" en el marco del 33 Encuentro Nacional de Mujeres realizado en Trelew. 
-En los talleres sobre Herramientas Jurídicas realizados en los Centros comunitarios "Expropiemos el Futuro" de Altos de San Lorenzo, "Oga Guazú" de Barrio Aeropuerto, "El Galpón de Tolosa" de Tolosa y "Awkache” ubicado en la zona céntrica de la ciudad. -En los 4 “Encuentros de actualización del POP ${ }^{24 ”, ~ r e a l i z a d o s ~ e n ~ e l ~ c i u d a d ~ d e ~ L a ~ P l a t a . ~}$

\section{3.-Análisis de documentos}

Revisamos bibliografía y artículos científicos y periodísticos pertinentes.

Abordamos la normativa nacional e internacional y la analizamos a la luz de los estándares producidos por los mecanismos de control e interpretación correspondientes.

Realizamos un relevamiento de los actores internacionales con pertinencia en la temática, y un análisis de los documentos que producen. Entre ellos podemos mencionar: las Recomendaciones Generales e informes en casos individuales del Comité CEDAW, los informes temáticos de la Relatora Especial, las sentencias de la Corte IDH, los informes de la CIDH.

Realizamos un relevamiento de los actores institucionales con funciones sobre la temática en el partido de La Plata.

Analizamos documentos producidos por estos actores, entre ellos: cartillas institucionales ("Protocolo de atención telefónica de casos-Línea 144”, “Acompañantes en red", "Sistema Integrado Provincial para el Abordaje de la Violencia Familiar y de Genero", "Mesas locales intersectoriales"), Acordadas de la Suprema Corte de Justicia de la Provincia de Buenos Aires, Resoluciones de la Procuración General de la Suprema Corte de Justicia de la Provincia de Buenos Aires, Formulario único de denuncia.

También abordamos numerosos recurseros ${ }^{25}$, centrándonos en el elaborado por el Instituto Nacional de las Mujeres (INAM), por tratarse de un material de actualización

\footnotetext{
${ }^{24} \mathrm{El}$ "Protocolo para Organizaciones Populares (POP). Violencia contra las mujeres en relaciones de pareja. Violencia sexual" (2013), La Plata, Pixel Editora, es un material de producción colectiva en cuya elaboración hemos participado.

${ }^{25}$ Se denomina "recursero" al mapeo y compendio de las distintas instituciones, organismos y dispositivos que tienen pertinencia en relación a una temática en determinado territorio. Dependiendo quien lo elabore se utilizan distintas metodologías para realizar ese relevamiento y sistematización de la información. Un desafío siempre presente es el de poder mantenerlos actualizados, tanto en relación a las organizaciones, organismos e instituciones que se mencionan como a sus datos (dirección, teléfono, correo electrónico y horario de atención).
} 
constante $^{26}$ que es utilizado por las trabajadoras de la línea 144 Nación y Provincia para asesorar y derivar a las mujeres que se comunican telefónicamente ${ }^{27}$.

Asimismo se analizaron documentos (artículos digitales y en formato papel, volantes, trípticos y cartillas de difusión pública, comunicados de prensa) producidos por numerosas organizaciones sociales y políticas con trabajo en la temática ${ }^{28}$.

\section{5.- A modo de advertencia}

Hasta aquí hemos presentado nuestro plan, nuestro mapa, la brújula a la cual recurrimos cuando, muy a menudo, nos desorientamos.

De aquí en más nos zambullimos para bucear, a veces disfrutando, otras pesadamente, en este desafío que hemos asumido y que encaramos con compromiso y mucho amor (que es en definitiva lo que nos impulsa en todas las acciones de la vida).

Writh Mills interpela a "sobre todo" no renunciar a la autonomía moral y política (1964: 236). No pretendemos que nuestra mirada y voz sean objetivas, imparciales ni impolutas. No nos acercamos asépticamente a un objeto de estudio.

Nos motivan, condicionan y enmarcan nuestra experiencia (individual y colectiva), historia e inquietudes. No nos esforzamos por alejarnos de ellas.

Al seleccionar a quienes entrevistar, al buscar y analizar bibliografía y artículos, hemos realizado una elección consiente y política, un recorte intencional (Yañez, 2016:64). Como una "heredera fragmentaria y selectiva de una tradición compleja y múltiple, incierta" (Ciriza, 2008 apud Yañez, 2016:64).

Writh Mills (1964) propone aprender a usar la experiencia en la vida en el trabajo intelectual, examinándola e interpretándola sin cesar (p. 207) y afirma: "los pensadores más admirables no separan su trabajo de sus vidas. Parecen tomar ambas

\footnotetext{
${ }^{26}$ La última actualización realizada, al momento de nuestro análisis, es del 19/10/2018.

${ }^{27}$ En este recursero se encuentran mencionadas todas las instituciones que el Estado ofrece como respuesta para abordar las situaciones de violencia doméstica hacia las mujeres.

${ }^{28}$ Entre ellas: Campaña Nacional contra las Violencias hacia las Mujeres, Marabunta, Poder Popular, CAUCE, Democracia Obrera, CTEP, Movimiento de los Pueblos, Venceremos, Plenario de Trabajadoras (Partido Obrero), Juntas y a la izquierda (Movimiento Socialista de los Trabajadores), Movimiento Teresa Rodríguez, Movimiento Popular La Dignidad, Isadora (Izquierda Socialista), Mala junta (Patria Grande), Corriente La Colectiva, Frente de Organizaciones en Lucha, Pañuelos en Rebeldía, Federación de Organizaciones de Base.
} 
cosas demasiado en serio para permitirse tal disociación" (p. 206). En las organizaciones en las que hemos participado siempre nos falta eso, muchas veces nos hemos propuesto avanzar con la sistematización de las experiencias y los debates, pocas veces lo hemos hecho. Nunca hay tiempo. Es una tarea pendiente, muy necesaria.

Curiel (2009) señala la descolonización como posición política para crear una especie de "'cimarronaje' intelectual, de prácticas sociales y de construcción de pensamiento propio de acuerdo a experiencias concretas" (p. 3). Es un gran desafío que nos interpela. Como también nos desafía e interpela el ejercicio cotidiano del feminismo, la deconstrucción de las relaciones y prácticas patriarcales y capitalistas, la construcción de un nuevo mundo...

Escribimos con todo este mar de fondo. Con muchos dolores a flor de piel, pero también con la esperanza que nos impulsa a seguir andando. Allí vamos... 


\section{II.- ¿DE QUÉ HABLAMOS CUANDO HABLAMOS DE...?}

Luego de haber realizado las presentaciones correspondientes (la nuestra, la de la problemática en cuestión y la del plan que nos orienta), en este capítulo delinearemos y le daremos precisión teórica a algunos de los conceptos centrales que utilizamos en nuestra tesis, en algunos casos explícitamente y en otros como parte del marco teórico desde el que abordamos nuestro trabajo.

\section{1.-...Violencia}

Los términos "violencia de género", "violencia hacia la mujer", "violencia contra la mujer", "violencias", "contra las mujeres", "violencia familiar" o "doméstica", muchas veces se utilizan como equivalentes. Sin embargo, cada uno de estos conceptos reviste particularidades que ameritan ser contempladas. Muchas veces la utilización de uno u otro implica un posicionamiento en relación a la problemática. Cada uno de ellos han sido objeto de críticas y se encuentra en debate la mayor o menor conveniencia en su utilización.

La ley 26.485 define, en su artículo 4, la violencia contra las mujeres como

toda conducta, acción u omisión, que de manera directa o indirecta, tanto en el ámbito público como en el privado, basada en una relación desigual de poder, afecte su vida, libertad, dignidad, integridad física, psicológica, sexual, económica o patrimonial, como así también su seguridad personal ${ }^{29}$.

En su artículo 6, al abordar las modalidades en las que se manifiestan los distintos tipos de violencias, define la violencia doméstica contra las mujeres como aquella ejercida:

por un integrante del grupo familiar, independientemente del espacio físico donde ésta ocurra, que dañe la dignidad, el bienestar, la integridad física, psicológica, sexual, económica o patrimonial, la libertad, comprendiendo la libertad reproductiva y el derecho al pleno desarrollo de las mujeres. Se entiende por grupo familiar el originado

\footnotetext{
${ }^{29}$ Y continúa: “Quedan comprendidas las perpetradas desde el Estado o por sus agentes. Se considera violencia indirecta, a los efectos de la presente ley, toda conducta, acción omisión, disposición, criterio o práctica discriminatoria que ponga a la mujer en desventaja con respecto al varón".
} 
en el parentesco sea por consanguinidad o por afinidad, el matrimonio, las uniones de hecho y las parejas o noviazgos. Incluye las relaciones vigentes o finalizadas, no siendo requisito la convivencia.

Rioseco (1999) define la violencia doméstica como toda conducta que por acción u omisión tenga por objeto causar daño o dolor a la pareja mujer, ya sea psicológico, físico o sexual (p. 577).

Al ser las mujeres las principales afectadas por la violencia doméstica (Teodori, 2015: 58) se suele utilizar el término como equivalente a "violencia hacia la mujer en el contexto doméstico".

La violencia familiar o intrafamiliar ha sido definida como los vínculos agresivos en el interior de una familia (Bengochea et al., 2017: 12). Este concepto invisibiliza el género de quien ejerce la violencia.

Se ha afirmado que la violencia contra las mujeres es un "subconjunto específico de la violencia de género" (Abdul Aziz y Moussa, 2016: 18).

Con el término violencia de género se hace alusión a la violencia basada en las desigualdades históricas de poder entre los géneros "revela la diferente distribución del poder, reforzando así la desigualdad y la subordinación social de las mujeres y favoreciendo que éstas se transformen en las destinatarias de diversas violencias estructurales y coyunturales" (Gamba, 2007).

Giberti (2015) critica la amplia difusión y utilización de dicha expresión ya que "no se sabe a cuál género se refiere. De ese modo queda en la penumbra la violencia patriarcal, la violencia machista" (contratapa) ${ }^{30}$.

Para evitar que los varones, autores de dicha violencia, queden fuera de la escena, la autora insta a utilizar la preposición "contra" (Bengochea et al., 2017: 12), como lo hace la Ley 26.485.

El Comité CEDAW en su Recomendación General nº 35 (2017) utiliza la expresión violencia por razón de género contra la mujer considerando que es un término más preciso:

\footnotetext{
${ }^{30} \mathrm{Y}$ agrega: "no sólo se mantiene oculta la expresión violencia contra las mujeres que inevitablemente compromete a los varones, también se los protege al impedir que la imagen masculina ilustre el imaginario social como sujeto al que es preciso educar superando los cánones del patriarcado destructor".
} 
que pone de manifiesto las causas y los efectos relacionados con el género de la violencia. La expresión refuerza aún más la noción de la violencia como problema social más que individual, que exige respuestas integrales, más allá de aquellas relativas a sucesos concretos, autores y víctimas y supervivientes. (pto. 9, pág. 4)

La expresión en plural "las mujeres" se utiliza para dar cuenta de la diversidad de experiencias vitales y de la gran heterogeneidad en los modos y formas de "ser mujer" (Campaña Nacional contra las Violencias hacia las Mujeres, 2013).

Con el término "las violencias" se pretende evidenciar la multiplicidad de tipos y modalidades de violencias que padecen las mujeres por el hecho de serlo así como también visibilizar tipos de violencias que suelen no detectarse, como la psicológica y la económica (CNVM, 2013).

La expresión "violencia doméstica contra las mujeres" o "mujeres en situación de violencia doméstica" es la que mejor da cuenta del fenómeno que abordamos en el presente trabajo.

\section{2.-...Perspectiva de género:}

Adoptar una perspectiva de género implica, en palabras de Alda Facio (1992), ponerse "bien puestos" los lentes de genero (p. 14).

Ser varón, mujer, trans, travesti, lesbiana, bi y otras identidades de género, constituye un hecho sociocultural e histórico. Las situaciones cotidianas impactan de manera diferente dependiendo de la identidad de género de la persona. Hoy en día no es lo mismo (para casi ninguna situación de la vida) ser hombre que mujer. Esta realidad debe ser tenida en cuenta en cada análisis que se realice.

Bengochea et al. afirman que la perspectiva de género como construcción teórica y política busca analizar las posibilidades vitales de mujeres y varones y las consecuencias que conlleva pertenecer a cada uno de los géneros (2017: 11).

Dicho impacto diferenciado debe tenerse presente en "todo análisis respecto de los diversos aspectos vinculados a los derechos humanos" (Subsecretaría de Promoción de Derechos Humanos, 2012: 1).

Facio (1992) sostiene que: 
Hacer un análisis de un texto o contexto desde la perspectiva de género significa, primero que nada tener conciencia de que las mujeres por su sexo, ocupan un lugar subordinado en nuestra sociedad y que el hombre/varón por su sexo ocupa un lugar privilegiado. (p.44)

En el "Protocolo para juzgar con perspectiva de género" (2013) de la Suprema Corte de Justicia de la Nación de México ${ }^{31}$, se afirma que dicha perspectiva

cuestiona el paradigma de único 'ser humano neutral y universal', basado en el hombre blanco, heterosexual, adulto sin discapacidad, no indígena, y en los roles que a dicho paradigma se atribuyen. Es por eso que no se trata de un método enfocado únicamente a las mujeres, sino de una estrategia que permite ver a las personas en su diversidad de contextos, necesidades y autonomía. (p. 66)

Partimos de que el género es una categoría socialmente relevante. La perspectiva de género es una de las herramientas con las que cuentan Ixs magistradxs y actorxs estatales para garantizar el derecho a la igualdad y no discriminación, "de no utilizarlas, además de revictimizar a las personas, estarán incurriendo en discriminación y comprometiendo la responsabilidad internacional del Estado" (SCJNM, 2013:69).

\section{3.-...Estereotipos}

A partir de la construcción cultural dicotómica de lo femenino y lo masculino, propia del sistema heteropatriarcal en el que vivimos, se construyen socialmente estereotipos sobre qué es ser mujer y qué es ser varón (SCJNM, 2013:49) y sobre cómo deben comportarse ambos géneros.

Los estereotipos no tienen en cuenta y desdibujan las pluralidades y múltiples identidades que existen en la realidad. Los estereotipos seleccionan al dominante de cada grupo y lo imponen como norma, desconociendo, invisibilizando y discriminando a quienes se aparten de la misma.

\footnotetext{
${ }^{31}$ El cual está elaborado en base al mismo marco jurídico que el nuestro (al haber ratificado la misma normativa internacional). Los organismos internacionales de Derechos Humanos han recomendado la adopción de protocolos destinados a que lxs magistradxs juzguen con perspectiva de género, en nuestro país aún no existe.
} 
El derecho internacional de los Derechos Humanos insiste en la necesidad de que el accionar del Estado se encuentre libre de estereotipos ${ }^{32}$.

A menudo las conductas de lxs actorxs estatales los refuerzan ${ }^{33}$.

La Comisión Interamericana de Derechos Humanos (en adelante CIDH) ha advertido en relación a la existencia y vigencia de patrones socioculturales discriminatorios los cuales influyen en la actuación de Ixs funcionarixs en todos los niveles de la rama judicial (CIDH, 2005).

La Corte IDH (2009) ha sostenido que el estereotipo de género "se refiere a una preconcepción de atributos o características poseídas o papeles que son o deberían ser ejecutados por hombres y mujeres respectivamente" y que "la creación y uso de estereotipos se convierte en una de las causas y consecuencias de la violencia de género en contra de la mujer" (párr. 401).

Se ha afirmado que "Cuando las leyes, políticas públicas y decisiones judiciales avalan, reproducen, consolidan y perpetúan estereotipos, generan discriminación y violentan el derecho a la igualdad" (SCJN, 2013:51).

El Comité de Expertas del Mecanismo de Seguimiento de la Convención para Prevenir, Sancionar y Erradicar la Violencia contra la Mujer (en adelante MESECVI) ${ }^{34}$ (2018) manifestó su preocupación ${ }^{35}$ ante los argumentos utilizados por los jueces del Tribunal Oral Criminal 1 de Mar del Plata en la sentencia en la que se absuelve a los tres imputados por el femicidio de la joven Lucía Pérez, se señala allí que:

Los criterios que han sido utilizados en esta sentencia construyen en la sociedad un mensaje de tolerancia hacia la violencia contra las mujeres y reflejan claros

\footnotetext{
${ }^{32}$ Tanto la Convención Belém Do Para, como la CEDAW, obligan al Estado a la modificación de los patrones culturales que sustentan los estereotipos. Ambos instrumentos internacionales han sido ratificados por Argentina generando obligaciones a todos los poderes, instituciones y personas que integran el aparato estatal.

${ }^{33}$ Así lo ha reconocido el Comité CEDAW (2009) en el caso "RKB vs. Turquía": " los estereotipos de género se perpetúan a través de varios medios e instituciones como son las leyes y los sistemas judiciales y pueden ser perpetuados por agentes estatales de todas las esferas y niveles de la administración" (párr. 8.8).

${ }^{34}$ Este Comité tiene como mandato realizar un seguimiento de la implementación por parte de los Estados de las obligaciones derivadas de la Convención de Belem Do Para, así como promover que garanticen la protección adecuada para las mujeres víctimas y sobrevivientes de violencia de acuerdo a los estándares internacionales. Asimismo realiza recomendaciones a los Estados (MESECVI, 2018: 1).

${ }^{35}$ En una nota enviada con fecha 29 de noviembre de 2018 al Presidente de la Corte Suprema de Justicia de la Nación Carlos Rosenkrantz.
} 
estereotipos de género utilizados para decidir el caso. Al respecto, casos ante la Corte Interamericana de Derechos Humanos (...) han ratificado pacíficamente que el uso de los estereotipos de género en la actuación de los operadores de justicia representan una clara violación a los derechos humanos de las mujeres, entre los que se encuentran el derecho a vivir libre de violencia y el derecho a la justicia y a los recursos judiciales. (p.3)

El accionar de Ixs funcionarios públicos, incluidxs Ixs actores judiciales, debe estar exento de estereotipos de género. Esto se constituye en una obligación jurídica, cuyo incumplimiento puede comprometer la responsabilidad internacional del Estado Argentino.

\section{4.-... Acceso a la justicia}

El acceso a la justicia es un derecho esencial para la realización de todos los derechos (Comité CEDAW, 2015: 3) y un elemento clave en la estrategia para erradicar la violencia contra las mujeres (Birgin y Gherardi, 2008:259).

La CIDH (2005) lo define como "el acceso de jure y de facto a instancias y recursos judiciales de protección frente a actos de violencia, de conformidad con los parámetros internacionales de derechos humanos" (p. 3).

Un acceso adecuado a la justicia y una respuesta judicial efectiva implican la obligación de hacer accesibles recursos judiciales sencillos, rápidos, idóneos e imparciales de manera no discriminatoria (CIDH, 2005: 3), y requieren una actuación intensa para vencer, eliminar o mitigar los obstáculos existentes (Reglas de Brasilia, 2008: 4).

El Comité CEDAW (2015) señala que para asegurar dicho acceso es necesario que se den seis componentes esenciales y relacionados entre sí: justiciabilidad, disponibilidad, accesibilidad, buena calidad, rendición de cuenta de los sistemas de justicia y suministro de recursos a las víctimas (p. 13).

Se sostiene que el acceso a la justicia involucra a los tres poderes del Estado y que puede ser considerado desde diferentes aspectos complementarios: la posibilidad de llegar al sistema judicial contando con patrocinio letrado (el acceso propiamente dicho); la disponibilidad de sostener el proceso completo y el conocimiento de los 
derechos y de los medios para poder ejercerlos (Birgin y Kohen, 2006: 19-20) ${ }^{36}$. También requiere que se logre un pronunciamiento judicial justo y en un tiempo prudencial (Birgin y Gherardi, 2008:259).

Partiendo de que dicho acceso no es igualitario (Begala y Lista, 2002 apud Gherardi, 2006: 131), cuando se habla de acceso a la justicia, por lo general, se hace referencia a su ausencia y a la desprotección jurídico-política que ello genera (Lista, 2011, apud Salanueva y González, 2012: 96). Es decir, se hace referencia a la

injusticia del no acceso por parte de diversas categorías de personas definidas de varias maneras: 'sectores vulnerables', 'desaventajados', 'excluídos', 'desafiliados sociales', o 'marginados', los que, de algún modo, detentan como rasgo común la pobreza y precariedad económica y a partir de ello la falta de poder y la debilidad política. (Lista, 2011, apud Salanueva y González, 2012: 96)

Las “Reglas de Brasilia sobre el acceso a la justicia" (2008) sostienen que la pobreza y el género podrán constituir causas de vulnerabilidad ${ }^{37}$ (artículo 3, p. 5) y que las personas en condición de vulnerabilidad encuentran obstáculos mayores para el ejercicio de sus derechos (p. 4).

Birgin y Gherardi (2008) afirman que "la dificultad para el acceso a la justicia constituye la mayor discriminación que enfrentan no solo las mujeres, sino los sectores más desfavorecidos de la sociedad que se ven imposibilitados de ejercer y exigir el cumplimiento de los derechos más básicos" (p. 262).

Al pretender acceder a la justicia, para solicitar la protección de un órgano judicial y obtener una respuesta que proteja sus derechos las mujeres pobres se encuentran con una gran cantidad de obstáculos, que muchas veces operan desalentándolas (Ballesteros, 2013). Los obstáculos que impiden la realización de este derecho

\footnotetext{
${ }^{36} \mathrm{El}$ acceso a la justicia para estas autoras tiene un doble significado: como garantía de igualdad de oportunidades para acceder a las instituciones, órganos y/o poderes del Estado, pero también como un conjunto de medidas que se adoptan para que las personas resuelvan sus conflictos y protejan sus derechos ante los tribunales de justicia (Ballesteros y Colanzi, 2015: 12).

${ }^{37}$ Con respecto a la pobreza, las Reglas sostienen que: "constituye una causa de exclusión social, tanto en el plano económico como en los planos social y cultural, y supone un serio obstáculo para el acceso a la justicia especialmente en aquellas personas en las que también concurre alguna otra causa de vulnerabilidad", y con respecto al género sostiene que "la discriminación que la mujer sufre en determinados ámbitos supone un obstáculo para el acceso a la justicia, que se ve agravado en aquellos casos en los que concurra alguna otra causa de vulnerabilidad".
} 
constituyen "violaciones persistentes de los derechos humanos de las mujeres" (Comité CEDAW, 2015: 3).

Las especiales dificultades que enfrentan las mujeres pobres es un problema en toda Latinoamérica (Salanueva y González, 2012: 96) ${ }^{38}$ y en Argentina el (no) acceso a la justicia para las mujeres víctimas de las distintas formas de violencia de género es materia de gran preocupación (ANDHES et al., 2016: 3).

\section{5.-...La (s) mujer(es)}

Simone De Beauvoir, en su obra "El segundo sexo" (2011) sienta una de las frases más paradigmáticas y elocuentes del movimiento feminista: “No se nace mujer: se llega a serlo" (p. 207). Y continúa, en esta obra precursora:

Ningún destino biológico, psíquico o económico define la figura que reviste en el seno de la sociedad la hembra humana; es el conjunto de la civilización el que elabora ese producto intermedio entre el macho y el castrado al que se califica de femenino. ( $p$. 207)

Más adelante agrega:

Es preciso volver a repetir una vez más que, en la colectividad humana, nada es natural, y que, entre otras cosas, la mujer es un producto elaborado por la civilización (...). La mujer no es definida ni por sus hormonas ni por sus misteriosos instintos, sino por el modo en que, a través de conciencias extrañas, recupera su cuerpo y sus relaciones con el mundo. (p. 718-719)

Entonces no existe una sola forma de ser mujer $^{39}$, las personas están atravesadas por múltiples identidades además de la de género, y sus comportamientos son producto de todas ellas.

En su libro "Identidad y Violencia", Amartya Sen (2007) previene sobre "los terribles efectos del empequeñecimiento de los individuos" y los riesgos de configurar a la persona a partir de un solo elemento de su identidad (p. 17) ${ }^{40}$.

\footnotetext{
${ }^{38} \mathrm{El}$ informe de la CIDH (2007) "Acceso a la justicia para mujeres víctimas de violencia en las Américas" da cuenta de la generalidad de esta problemática.

${ }^{39}$ Mujer en tanto identidad de género socioculturalmente construida.

${ }^{40} \mathrm{Se}$ ha advertido que "pretender la existencia de una sola identidad basada en el sexo desconoce la complejidad que caracteriza a las personas y deviene en la negación de derechos" (SCJNM, 2013).
} 
La expresión "mujeres" (utilizando el plural) pretende dar cuenta de esta heterogeneidad en las formas de "ser mujer" (CNCVM, 2013).

\section{6.-...Ruta crítica}

El concepto de "Ruta Crítica" se ha popularizado en el campo de las violencias en los últimos años (Teodori, 2015: 69). La misma "rara vez es un proceso lineal" (Bengochea et al., 2017: 9). Es un "proceso iterativo", "complejo", "que implica avances y retrocesos" (Sagot, 2000: 89). Y para comprenderla es "necesario analizar la violencia contra las mujeres como consecuencia de una manera histórica de construir relaciones entre varones y mujeres en las que el género femenino ocupa un lugar de inferioridad" (Bengochea et al., 2017: 9).

La misma ha sido definida como "un proceso que se construye a partir de la secuencia de decisiones tomadas y acciones ejecutadas por las mujeres afectadas por la violencia intrafamiliar y las respuestas encontradas en su búsqueda de soluciones" (Sagot, 2000: 89).

En otras palabras, la ruta crítica involucra tanto las decisiones y acciones de parte de las mujeres en situación de violencia doméstica, y que tiene por objetivo enfrentar esa situación, como las respuestas que estas reciben desde las instituciones y otrxs actorxs implicadxs (Sernam, 2009:19).

Dicho concepto "describe la secuencia de los posibles múltiples itinerarios de búsqueda de ayuda seguidos a lo largo de una o varias relaciones atravesadas por la violencia" (Bengochea et al., 2017: 9).

Se ha sostenido que, en el ámbito institucional, "los factores de respuesta están asociados al acceso, disponibilidad y calidad de los servicios, los cuales están determinados tanto por factores estructurales y normativos, como por las representaciones sociales, actitudes y comportamientos de los prestatarios y prestatarias" (Sagot, 2000: 89).

Teodori (2015) prefiere utilizar el término "trayectoria" (p. 69). Asimismo González y Barcaglioni (2018) utilizan la expresión "ruta crítica-trayectoria" (p. 7). 
En ambos trabajos se argumenta que estas expresiones aluden a los modos en que las personas buscan resolver sus problemas y permiten alcanzar una mirada más abarcativa del proceso recorrido por las mujeres (Teodori, 2015: 69; Gonzalez y Barcaglioni, 2018: 6) en relación al concepto de "ruta crítica", el cual, se afirma, es utilizado: "tanto por investigadores como por organizaciones sociales militantes, para denunciar falencias en las respuestas institucionales y ejercer reclamos en pos de garantizar el derecho de las mujeres a una vida libre de violencia" (Teodori, 2015: 69). En este trabajo preferimos utilizar la expresión "ruta crítica" ya que nos permite poner el foco de atención en las respuestas de parte de Ixs actorxs estatales involucradxs.

\section{7.-...Interseccionalidad:}

Cada persona participa de múltiples roles y relaciones sociales, diferentes entre sí: económicas, políticas, de género, étnicas, generacionales, entre otras. Se ha afirmado que las mismas "determinan posiciones subjetivas" (UNFPA, PNUD, UNICEF y ONU Mujeres, 2012: 28): "las personas forjan su yo a partir de las diversas posiciones de subordinación, dominación o de igualdad que ocupan en cada una de ellas" (UNFPA et al., 2012: 29) ${ }^{41}$.

En algunas personas o grupos sociales se da una compleja sumatoria de causales de vulnerabilidad. Esto ha sido estudiado y teorizado en profundidad, dando lugar a la categoría analítica de "interseccionalidad", la cual se detiene y visibiliza dicha complejidad (Bidaseca, Ballesteros, Katz y Jarque, 2014: 2-3).

El concepto de interseccionalidad fue acuñado por Williams Crenshaw (1995), y lo define como un "sistema complejo de estructuras de opresión que son múltiples y simultáneas" (Muñoz Cabrera, 2011 apud UNFPA et al., 2012: 27). Se ha utilizado la expresión "conexiones cruzadas" o "discriminación compuesta" como equivalentes a aquel y se lo ha definido como "la discriminación (...) doble o múltiple y referida a la

\footnotetext{
${ }^{41}$ Esto no implica que las personas solo sean receptoras pasivas de elementos externos que las determinan. Alcoff explica cómo la identidad de una mujer depende de su posición en la sociedad y es al mismo tiempo el producto de su propia reconstrucción. La mujer "es parte de un movimiento con su propia historia, fluido, y por lo tanto ella contribuye activamente al contexto en el cual su posición es delineada" afirma (Alcoff, 1988 apud Roberts, 2017: 16-17).
} 
interacción entre dos o más formas de discriminación, por ejemplo, la intersección de género, raza y etnia" (UNFPA et al., 2012: 28).

En esta conceptualización se entiende que además del sistema de opresión patriarcal se encuentran otros sistemas que promueven la exclusión e impiden el desarrollo de las personas $^{42}$ (UNFPA et al., 2012: 28).

Se trata de un modelo de análisis de las diferencias sociales que aborda el "desempoderamiento" que se produce cuando se cruzan, en una misma persona, diferentes modalidades y formas de discriminación (Hernández, 2011 apud UNFPA et al., 2012: 28).

Se ha afirmado que las causas de la discriminación interseccional o compuesta pueden incluir la etnia, la raza, la condición de minoría o indígena, el color, la situación socioeconómica, el idioma, la religión o las creencias, la opinión política, el origen nacional, el estado civil y/o maternal, la localización urbana o rural, el estado de salud, la discapacidad (Comité CEDAW, 2015: pto. 8), la condición de lesbiana, bisexual, transgénero o intersexual, la lejanía geográfica, la estigmatización de las mujeres que luchan por sus derechos (Comité CEDAW, 2017:12), la migración, la pobreza (Organización Naciones Unidas, 1996: 52), la condición de refugiada, las mujeres recluidas en instituciones o detenidas, las niñas, las ancianas y las mujeres en situaciones de conflicto armado (ONU, 1993:1).

Lugones (2008) plantea que la interseccionalidad muestra lo que se pierde (p. 82), "revela lo que no se ve cuando categorías como género y raza se conceptualizan como separadas unas de otras" (p. 81).

El feminismo de color ha puesto en tensión las categorías "mujer" o las categorías raciales "negro", "hispano" ya que homogeneizan y seleccionan al dominante en el grupo como su norma ${ }^{43}$ (Lugones, 2008: 81-82). El ejercicio de intersección da cuenta que entre "mujer" y "negro" existe un vacío que debería ocupar la "mujer negra", ya que ni "mujer" ni "negro" la incluyen (Lugones, 2008: 82).

\footnotetext{
${ }^{42}$ Así, se ha señalado, entre otros, al racismo y la xenofobia; el heterocentrismo, la homofobia y la transfobia y el adultocentrismo ( UNFPA et al., 2012: 28).

${ }^{43}$ De este modo "mujer" selecciona como norma a las hembras burguesas blancas heterosexuales; "negro" selecciona a los machos heterosexuales negros y, así, sucesivamente (Lugones, 2008: 81).
} 
El término "mujer" en sí, no tiene sentido o tiene un sentido racista ya que la lógica categorial ha seleccionado un grupo dominante: mujeres burguesas blancas heterosexuales, y por tanto "ha escondido la brutalización, el abuso, la deshumanización que la colonialidad del género implica" (Lugones, 2008: 82).

Virosta (2001) ha destacado la necesidad de reconfigurar la administración de justicia e incorporar las perspectivas interseccional e intercultural en el análisis jurídico (apud Ballesteros y Colanzi, 2015: 223).

La importancia del abordaje interseccional y de diseñar políticas públicas que tengan en cuenta las múltiples opresiones que sufren las personas ha sido reconocida por los organismos especializados ${ }^{44}$.

El Comité CEDAW ha afirmado que "las mujeres experimentan formas múltiples e interrelacionadas de discriminación, que tienen un agravante efecto negativo" (2017: 12), dado que la discriminación por el hecho de ser mujer "se ve agravada por factores interseccionales que afectan a algunas mujeres en diferente grado o de diferente forma que a los hombres y otras mujeres", y agrega que dichos factores "dificultan a las mujeres pertenecientes a esos grupos el acceso a la justicia" (2015: pto. 8). En este sentido reconoce que "la violencia por razón de género puede afectar a algunas mujeres en distinta medida, o en distintas formas, lo que significa que se requieren respuestas jurídicas y normativas adecuadas" (2017: 12).

En la IV Conferencia Mundial de las Mujeres los Estados se comprometieron a Intensificar los esfuerzos para garantizar el disfrute en condiciones de igualdad de todos los derechos humanos y libertades fundamentales a todas las mujeres y las niñas que enfrentan múltiples barreras (...) por factores como la raza, la edad, el idioma, el origen étnico, la cultura, la religión o la discapacidad, o por pertenecer a la población indígena. (ONU, 1995: punto 32)

\section{8.-...Maternidad (obligatoria):}

En su libro "Calibán y la bruja" (2010) Federici describe cómo durante la violenta transición del feudalismo al capitalismo en Europa se produjeron dos fenómenos

\footnotetext{
${ }^{44}$ Así, por ejemplo, la CIDH (2001) en el caso “Ana, Beatriz y Celia González Pérez vs. México", destaca que "el dolor y la humillación que sufrieron las mujeres se agrava por su condición indígena" (pto. 95).
} 
interrelacionados que requirieron una profundización y perfeccionamiento de los mecanismos de control sobre los cuerpos de las mujeres. Por un lado tuvo lugar una nueva división sexual del trabajo: se produjo una disociación entre producción de mercancías y reproducción de la fuerza de trabajo. Se recluyó a las mujeres en esta última a la par que se la despojaba de valor económico ${ }^{45}$ (Federici, 2010: 16). Por otro lado, ante las sucesivas crisis poblacionales que acontecieron en ese periodo, surge una preocupación estatal y científica por la cuestión demográfica, lo cual tiene como consecuencia una exacerbación en el control de la capacidad reproductiva de las mujeres, una "cruzada pro natalista" (Federici, 2010: 138). Se puso en marcha, entonces, un proceso de institucionalización de la maternidad es decir, de control por parte del Estado y los poderes religiosos de los significados y las actividades asignados al papel de las mujeres en la reproducción humana y social (Yañez, 2013:4) ${ }^{46}$.

Afirma Federici que el resultado "fue la esclavización de las mujeres a la procreación (...) sus úteros se transformaron en territorio político, controlados por los hombres y el Estado: la procreación fue directamente puesta al servicio de la acumulación capitalista" (2010: 138-139).

En este sentido se ha sostenido que la institución de la maternidad es un factor determinante de la posición social subordinada de las mujeres (Roberts, 1995 apud Hopp, 2017:1).

Las tareas de crianza y cuidado continúan asignadas socialmente a las mujeres, quienes deben realizarlas por amor, no por dinero. Se devalúa socialmente ese trabajo femenino (Hopp 2017:1). Roberts (1995) enfatiza la paradoja: La sociedad asigna a las mujeres enormes responsabilidades en la crianza de niños y niñas, sin embargo, no les paga por este trabajo y además las degrada (p. 2).

\footnotetext{
${ }^{45}$ Federici afirma que el capitalismo "no reconoce la producción y reproducción del trabajo como una actividad socio-económica y como una fuente de acumulación del capital y, en cambio, la mistifica como un recurso natural o un servicio personal, al tiempo que saca provecho de la condición no-asalariada del trabajo involucrado" (2010:16).

${ }^{46}$ Federici indica que "al negarle a las mujeres el control sobre sus cuerpos, el Estado las privó de la condición fundamental de su integridad física y psicológica, degradando la maternidad a la condición de trabajo forzado, además de confinar a las mujeres al trabajo reproductivo de una manera desconocida en sociedades anteriores" (Federici, 2010: 142).
} 
La maternidad es impuesta socialmente como destino obligado para las mujeres. Afirma Roberts (2017) que "ninguna mujer logra un reconocimiento total de su posición social hasta que no tiene un hijo (...) la sociedad ejerce presiones estructurales e ideológicas sobre las mujeres para que se conviertan en madres o madres en potencia" (p. 2). Señala Hopp (2017) que "aún las mujeres que no tenemos hijos somos vistas como madres en potencia y la ausencia de hijos es un fracaso para la mujer, que no ha llegado a ocupar su posición social designada" (p. 1).

Se ha calificado a la maternidad como "un concepto colonizado, un evento practicado y experimentado físicamente por las mujeres, pero ocupado y definido, cuyo contenido y valor es determinado, por los conceptos centrales de la ideología patriarcal" (Fineman 1991, apud Roberts, 2017: 2).

Desde la segunda mitad del siglo XX el feminismo ha cuestionado fuertemente la maternidad como "destino natural" de las mujeres (Yañez, 2013: 2).

Rich (1986), una de las pioneras en los estudios y reflexiones sobre la maternidad, distingue la maternidad como experiencia de la maternidad como institución ${ }^{47}$, cuyo objetivo es asegurar que todas las mujeres y su potencial reproductivo permanezcan bajo el control masculino (p. 47).

Señala que la institución de la maternidad ha ejercido "tremenda violencia sobre las mujeres" y les ha negado "el poder, sobre nuestras propias vidas, sobre los frutos de nuestro potencial reproductivo, sobre nuestros afectos “(p. 275). "Nos ha alienado a las mujeres de nuestros cuerpos al encarcelarnos en ellos" (p. 13).

Yañez (2013) afirma que con esta distinción entre experiencia e institución:

Rich realizó una dura crítica de la sujeción de las mujeres a la maternidad obligatoria, regida por mandatos y prácticas dictados por el heteropatriarcado y por los intereses económicos y políticos de cada momento histórico y a través de diferentes culturas. ( $p$. 2)

\footnotetext{
${ }^{47}$ En 1976 publicó "Nacemos de mujer. La maternidad como experiencia e institución", en donde realiza dicha distinción. En 1986 el material fue actualizado y revisado por la autora. Sostiene allí que "la institución de la maternidad no es idéntica a gestar, parir y cuidar niños/as, así como la institución de la heterosexualidad no es idéntica a la intimidad y el amor sexual. Ambas crean las prescripciones y las condiciones dentro de las cuales se toman o se bloquean las decisiones; no son la "realidad" pero han moldeado las circunstancias de nuestras vidas" y agrega que "cualquier institución que se exprese de manera tan universal termina afectando profundamente nuestra experiencia, incluso el lenguaje que usamos para describirla" (Rich, 1986, p. 42).
} 
La institución de la maternidad "se da en situaciones históricas específicas, en el marco de estructuras entrelazadas de raza, clase y género" (Hill Collins, 2007 apud Yañez, 2017:70).

Los aportes de las feministas afroamericanas imponen la necesidad de "pensar la maternidad desde múltiples perspectivas y posiciones dentro de los sistemas de poder y privilegio" (Yañez, 2017:72). En sus estudios han evidenciado que la idea de una maternidad intensiva, exclusiva, heterosexual, individualizada es un producto histórico que sólo ha sido posible para algunas mujeres: blancas, heterosexuales $y$ pertenecientes a las clases dominantes (Yañez, 2016: 70).

Siguiendo a Davis (2005) Yañez (2016) señala que "que en la misma época en que se glorificaba la maternidad de las mujeres blancas y se las encerraba en esa función, las mujeres esclavizadas no contaban con los más mínimos derechos sobre su descendencia y no se esperaba que mostraran apego por sus criaturas" ${ }^{\prime 8}$ (p. 70). Hopp, en el mismo sentido, destaca la importancia de las reflexiones sobre la interseccionalidad y alerta sobre la situación de aquellas mujeres cuyas características se alejan de las de quienes "las acusan, defienden y juzgan": "la empatía resulta más difícil aún, cuando las expectativas sobre las madres son atravesadas por estereotipos vinculados a las experiencias de los grupos sociales dominantes" afirma (2017:7).

No se trata de abolir la maternidad (Rich, 1986: 280) sino de ayudar a liberarla de "la institución que niega la individualidad de la mujer y usa a los niños y niñas como rehenes para exigir su obediencia" (Roberts, 2017: 22).

\section{9.-...Derechos humanos:}

Se ha sostenido que los derechos humanos son atributos inherentes a las personas por el mero hecho de serlo, cuyo disfrute resulta indispensable para vivir con dignidad (García Muñoz, 2009: 16).

NikKen afirma que "La noción de derechos humanos se corresponde con la afirmación de la dignidad de la persona frente al Estado" (s./f.: 1) y sostiene:

\footnotetext{
${ }^{48}$ Davis resalta el sufrimiento de muchas madres que, al no poder amamantar, llevaban los pechos hinchados, lo cual les dificultaba el trabajo y las hacía susceptibles de mayores castigos (Davis, 2005, apud Yañez, 2017:70).
} 
La sociedad contemporánea reconoce que todo ser humano, por el hecho de serlo, tiene derechos frente al Estado, derechos que este, o bien tiene el deber de respetar y garantizar o bien está llamado a organizar su acción a fin de satisfacer su plena realización. Estos derechos, atributos de toda persona e inherentes a su dignidad, que el Estado está en el deber de respetar, garantizar o satisfacer son los que hoy conocemos como derechos humanos. (s.f.: 1)

La Declaración Universal de Derechos Humanos (ONU, 1948) afirma "todos los seres humanos nacen libres e iguales en dignidad y derechos" (artículo 1) y "toda persona tiene los derechos y libertades proclamados en esta Declaración" (artículo 2).

A pesar de la amplitud de la definición fue necesario que se reconociera expresamente, en el marco de la Conferencia Mundial de Naciones Unidas sobre Derechos Humanos (Viena 1993), que "Los derechos humanos de la mujer y de la niña son parte inalienable, integrante e indivisible de los derechos humanos universales" ${ }^{49}$. Palacios Zuloaga refiere que

llama la atención que (...) cuarenta y cinco años después de la Declaración Universal de Derechos Humanos fuera necesario hacer esa aclaración, la que dado el tiempo transcurrido y el alarmante estado de los derechos humanos de las mujeres a nivel mundial, resultó más bien un mea culpa de parte de la comunidad global. (Palacios Zuloaga, 2011 apud Valle, 2018: 32)

El Derecho Internacional de los Derechos Humanos (en adelante DIDH) fue objeto de críticas desde el feminismo, las mismas, según Valle (2018), se centraron en:

la exclusión y/o subrepresentación de las mujeres en el temprano proceso de diseño y aplicación del DIDH; en el lenguaje androcéntrico a través del cual los tratados generales de derechos humanos usualmente se expresan; en la centralidad de la dicotomía público/privado en el reconocimiento de los derechos y en la determinación del alcance de las obligaciones estatales; y en la invisibilidad o minimización de ciertas problemáticas que impactan de manera diferencial y desproporcionada según el género (p. 32).

Se hizo necesario el reconocimiento especifico ${ }^{50}$ de los derechos dada "la especificidad de las violaciones de derechos humanos que sufren las mujeres en función de su

\footnotetext{
${ }^{49}$ Pto. 18 de la Declaración y Programa de acción de Viena.

${ }^{50} \mathrm{El}$ cual se inscribe en un proceso de especificación de los derechos humanos (García Muñoz, 2009:17).
} 
género, así como algunas necesidades que solamente las mujeres tienen (como las que rodean su función reproductiva y la experiencia de la maternidad)" (García Muñoz, 2009: 16).

Este reconocimiento así como la progresiva "genereización" ${ }^{51}$ del DIDH (García Muñoz, 2001: 2) fue en gran parte consecuencia de la intensa labor política que sostuvieron los movimientos de mujeres y feminista (Valle, 2018: 32).

García Muñoz (2009) afirma que el concepto de "derechos humanos de las mujeres" es un concepto dinámico, y sostiene que, en el momento actual, se pueden definir los Derechos Humanos de las Mujeres como:

El derecho universal de cada mujer del mundo a vivir una vida libre de discriminación y libre de violencia, con autonomía sexual y reproductiva, tanto en el ámbito público, como en el privado, tanto en tiempos de paz, como de guerra, para poder disfrutar efectivamente de la integralidad de los derechos humanos. (p.17)

En este capítulo hemos abordado una serie de conceptos que revisten particular importancia para nuestra tesis. En algunos casos porque se mencionan a menudo, como por ejemplo el de acceso a la justicia, y de allí la necesidad de definir el alcance y sentido con que lo utilizamos. En otros casos porque, si bien no son retomados con posterioridad, constituyen puntos de partida desde los cuales analizamos la información obtenida en el trabajo de campo, así ocurre por ejemplo con el concepto de maternidad obligatoria. La selección y definición de estos conceptos nos sirve asimismo para explicitar y enmarcar la posición que asumimos en el análisis de esta compleja problemática.

\footnotetext{
${ }^{51}$ Este concepto fue acuñado por García Muñoz y con el pretende "condensar en una sola palabra el fenómeno de transversalidad o impregnación de la protección internacional de los derechos humanos, por el género como concepto y perspectiva de análisis" (García Muñoz, 2000: 2).
} 
SEGUNDA PARTE

EL DERECHO DE LAS MUJERES A UNA VIDA LIBRE DE VIOLENCIA Y LAS OBLIGACIONES ESTATALES 
En los capítulos precedentes nos presentamos e introdujimos la problemática que abordaremos, también los objetivos que nos trazamos y la metodología que utilizamos. En esta segunda parte de nuestra tesis desarrollaremos el primer objetivo específico planteado: "analizar, desde una perspectiva de género y derechos humanos, las obligaciones asumidas internacionalmente por el Estado Argentino en relación a las prácticas de violencia contra las mujeres".

Para ello haremos un recorrido histórico del reconocimiento específico del derecho de las mujeres a una vida libre de violencia por el DIDH. También abordaremos las grandes herramientas internacionales: la CEDAW y la CBDP, así como los órganos y mecanismos de protección que establecen.

Luego analizaremos la norma de la debida diligencia. Dado que en esta tesis abordamos la violencia doméstica contra las mujeres, este principio reviste central importancia en dos aspectos íntimamente relacionados: por un lado es a la luz de este principio que se delinean y definen las obligaciones estatales ante hechos de violencia hacia las mujeres cometidos por particulares. Por el otro, y como contracara de una misma moneda, el Estado puede ser responsabilizado internacionalmente por actos de particulares si no cumplió con sus obligaciones con la debida diligencia requerida.

Para finalizar esta segunda parte abordaremos cada una de las obligaciones estatales en relación al derecho de las mujeres a una vida libre de violencias, delineándolas y llenándolas de contenido a la luz del DIDH. 


\section{III.- EL DERECHO DE LAS MUJERES A UNA VIDA LIBRE DE VIOLENCIA: SU RECONOCIMIENTO INTERNACIONAL}

\section{1.- Introducción}

Al repasar la historia del reconocimiento de los Derechos Humanos por parte de la comunidad internacional vemos que el de los derechos de las mujeres se inscribe en un periodo relativamente reciente, el cual se caracteriza por la "especificación" en el reconocimiento de derechos (García Muñoz, 2009:16- 17).

Este proceso de reconocimiento de los derechos de las mujeres se ha desarrollado en dos aspectos: por un lado elaborándose y creándose normativa y órganos de protección específicos. Por otro lado en la progresiva internalización de la perspectiva de género por parte de los órganos protectorios generales ${ }^{52}$ (García Muñoz, 2009; Fernández Valle, 2018: 32).

Se ha criticado la excesiva demora de la Corte IDH en abordar casos con perspectiva de género. Se han ensayado distintas hipótesis para explicar este suceso, por un lado se ha señalado la resistencia de la $\mathrm{CIDH}$ a remitir casos a la Corte IDH vinculados con violaciones de derechos humanos basadas en el género (Medina Quiroga, 2005: 10), por otro lado se ha hecho hincapié en la incapacidad de la propia Corte IDH para analizar con perspectiva de género alguno de los casos en los que efectivamente intervino (Palacios Zuloaga, 2011 apud Fernández Valle, 2018: 35).

Se ha sostenido asimismo que ambas hipótesis son complementarias para explicar la demora (Fernández Valle, 2018:35).

Como hitos en el mentado reconocimiento específico de derechos de las mujeres podemos señalar:

\footnotetext{
${ }^{52}$ Así por ejemplo, podemos citar la "Declaración y programa de acción de Viena" (1993) que, en su punto 42, insta a los órganos de vigilancia creados en virtud de tratados a incluir la cuestión de la condición de la mujer y los derechos humanos de la mujer en sus deliberaciones y conclusiones, utilizando datos concretos desglosados por sexo. Asimismo alienta a los Estados a que en sus informes a dichos órganos suministren información sobre la situación de jure y de facto de las mujeres.
} 
-En el año 1979, en el marco de la Organización de Naciones Unidas, se adopta la Convención para la Eliminación de Todas las formas de Discriminación contra la Mujer ${ }^{53}$.

-La Declaración y el Programa de acción de Viena, producto de la Conferencia Mundial sobre Derechos Humanos celebrada en Viena en $1993^{54}$, en su párrafo 18 (capítulo I), reconoce que los derechos humanos de la mujer y de la niña "son parte inalienable, integrante e indivisible de los derechos humanos universales", afirma que "la erradicación de todas las formas de discriminación basadas en el sexo son objetivos prioritarios de la comunidad internacional" y que la violencia y todas las formas de acoso y explotación sexuales deben ser eliminadas ya que "son incompatibles con la dignidad y la valía de la persona humana".

Insta a los gobiernos, a las instituciones intergubernamentales y a las organizaciones no gubernamentales a que intensifiquen sus esfuerzos en favor de la protección y promoción de los derechos humanos de la mujer y de la niña (párr. 18) y a la eliminación de todas las formas de discriminación contra la mujer, encubiertas o palmarias (párrafo 39, capítulo II).

La Conferencia pide a la Asamblea General de las Naciones Unidas que apruebe el proyecto de Declaración sobre la eliminación de la violencia contra la mujer (párrafo 38, capítulo II).

-Como consecuencia de dicha solicitud se adoptó la Declaración sobre la Eliminación de la Violencia contra la Mujer de Naciones Unidas (1993) ${ }^{55}$ (García Muñoz, 2009: 19). En ella se afirma que la aplicación efectiva de la CEDAW contribuiría a eliminar la violencia contra la mujer y que la Declaración viene a reforzar y complementar ese proceso; que la violencia contra la mujer constituye una violación de los derechos

\footnotetext{
${ }^{53}$ Este instrumento será analizado en profundidad más adelante junto con la Convención de Belém Do Para, el otro gran instrumento protectorio de los derechos de las mujeres a nivel regional.

${ }^{54}$ Ban Ki-moon, Secretario General de las Naciones Unidas, ha señalado la trascendencia de esta Conferencia y de la Declaración y el Programa en tanto se logró poner de relieve el carácter indivisible e interdependiente de los derechos económicos, sociales, culturales, civiles y políticos así como también se reforzaron los principios de universalidad de los derechos humanos, y se proclamaron inequívocamente los derechos de la mujer (Oficina del Alto Comisionado de las Naciones Unidas para los Derechos Humanos 2013: 5)

${ }^{55}$ Fue acogida en la 85a sesión plenaria por la Asamblea General el 20 de diciembre de 1993 mediante la Resolución 48/104.
} 
humanos y manifiesta la preocupación "por el descuido de larga data de la protección y fomento de esos derechos y libertades en casos de violencia contra la mujer" (p. 1). Reconoce la existencia de una "violencia continua y endémica" (p.2).

Insta a que se hagan todos los esfuerzos posibles para que la Declaración sea universalmente conocida y respetada. Avanza en una definición de violencia contra la mujer $^{56}$ (art. 1) y enuncia los actos que abarca, aunque afirma que sin limitarse a ellos (art. 2).

-En 1995 se realizó la IV Conferencia Mundial de las Mujeres adoptándose la

\section{Declaración y la Plataforma de Acción de Beijing.}

En dicha Declaración se reconoce la diversidad de las mujeres, sus funciones y circunstancias (punto 4), así como los derechos humanos de las mujeres y las niñas como parte inalienable, integral e indivisible de todos los derechos humanos y libertades fundamentales (punto 9). Se afirma expresamente que los derechos de la mujer son derechos humanos (punto 14); se reafirma la decisión de tomar medidas eficaces contra las violaciones de los derechos y libertades de las mujeres y niñas (pto. 23), de adoptar las medidas que sean necesarias para eliminar todas las formas de discriminación contra ellas y suprimir todos los obstáculos a la igualdad de género y al adelanto y potenciación del papel de la mujer (pto. 24); así como de prevenir y eliminar todas las formas de violencia contra las mujeres y las niñas (pto. 29). Reconoce asimismo la interseccionalidad de opresiones y afirma la decisión de intensificar los esfuerzos (pto. 32). En el punto 38 los gobiernos se comprometen a aplicar la Plataforma de Acción y a garantizar que todas las políticas y programas reflejen una perspectiva de género.

En la Plataforma de Acción se señala que la violencia contra la mujer viola y menoscaba o impide el disfrute de los derechos humanos y las libertades fundamentales y que es un problema que incumbe a todos los Estados y exige que se adopten medidas (pto. 112). Asimismo se afirma que:

La expresión 'violencia contra la mujer' se refiere a todo acto de violencia basado en el género que tiene como resultado posible o real un daño físico, sexual o psicológico,

\footnotetext{
${ }^{56}$ En el entendimiento de que se requiere una definición clara y completa de la violencia contra la mujer.
} 
incluidas las amenazas, la coerción o la privación arbitraria de la libertad, ya sea que ocurra en la vida pública o en la privada. (pto. 113)

-A nivel regional, en el año 1994, la Organización de Estados Americanos adoptó en la ciudad de Belem Do Para (Brasil) la Convención Interamericana para Prevenir, Sancionar y Erradicar la violencia contra la mujer. Este instrumento normativo será analizado en el apartado que sigue a continuación.

\section{2.- Las grandes herramientas internacionales: La CEDAW y la CBDP}

La Convención sobre la Eliminación de Todas las Formas de Discriminación contra la Mujer y la Convención Interamericana para Prevenir, Sancionar y Erradicar la violencia contra la mujer han sido ratificadas por $\operatorname{Argentina}^{57}$ y revisten gran importancia (Rodríguez, 2006: 581 y 583), generando obligaciones a todos los poderes, instituciones y personas que integran los aparatos estatales (García Muñoz, 2009: 28).

\section{1.- La CEDAW}

\section{La Convención sobre la Eliminación de Todas las Formas de Discriminación contra la} Mujer (CEDAW) fue adoptada el 18 diciembre de 1979 por la Asamblea General de las Naciones Unidas, mediante la Resolución 34/180. El 17 de julio, en una ceremonia especial realizada durante una Conferencia Mundial en Copenhague, fue suscrita por 64 Estados. La CEDAW entró en vigor el 3 de septiembre de 1981, después de la ratificación de 20 Estados (acorde lo establecido por el art. 27 de la Convención).

Es de trascendental importancia, "reúne en un único instrumento legal, internacional, de derechos humanos, las disposiciones de instrumentos anteriores de la ONU relativas a la discriminación contra la mujer" (Facio, 2002: 1). Incluso se ha sostenido que es la Carta Internacional de los Derechos Humanos de las Mujeres "porque es el primer instrumento internacional que incluye todos los derechos humanos de las

\footnotetext{
${ }^{57}$ La CEDAW, fue ratificada por Argentina por la ley 23.179 (B.O. 3/6/1985) y se halla incluida en la nómina de los instrumentos internacionales de derechos humanos a los cuales el art. 75 inc. 22 de la Constitución Nacional (desde 1994) les ha otorgado jerarquía constitucional. La CBDP fue ratificada por Argentina por ley $N^{\circ} 24.632$ (B.O. 9/4/1996). En el año 2011 el Congreso Nacional le otorgo jerarquía constitucional.
} 
mujeres explícita o implícitamente al prohibir todas las formas de discriminación por razones de sexo" (Facio, 2002: 1).

Contiene 30 artículos, los que tienen como objeto eliminar las distintas formas en que se manifiesta la discriminación en contra de las mujeres.

En su preámbulo sostiene que los Estados Parte están resueltos a adoptar las medidas necesarias a fin de suprimir esta discriminación en todas sus formas y manifestaciones. En su artículo 1 adopta un concepto amplio ${ }^{58}$ de "discriminación contra la mujer", definiéndola como:

toda distinción, exclusión a restricción basada en el sexo que tenga por objeto o por resultado menoscabar o anular el reconocimiento, goce o ejercicio por la mujer, independientemente de su estado civil, sobre la base de la igualdad del hombre y la mujer, de los derechos humanos y las libertades fundamentales en las esferas política, económica, social, cultural y civil o en cualquier otra esfera.

En su artículo 2 los Estados se comprometen a seguir "por todos los medios apropiados y sin dilaciones, una política encaminada a eliminar la discriminación contra la mujer" y se menciona explícitamente el compromiso de adaptar su legislación interna al objeto y fin del tratado (inc. b, c y g). Asimismo se comprometen a brindar protección efectiva a la mujer contra todo acto de discriminación (inc. c); a abstenerse de incurrir en todo acto o práctica de discriminación (inc. d); a tomar todas las medidas apropiadas para eliminar la discriminación practicada por cualesquiera personas, organizaciones o empresas (inc. e); a adoptar todos las medidas adecuadas para modificar usos y prácticas que constituyan discriminación contra la mujer (inc. f).

Como se puede observar los Estado Parte han asumido la responsabilidad por la discriminación que las mujeres soportan en todos los ámbitos de su existencia y con independencia de quien se la provoque, esto es, tanto si proviene de un agente del Estado, como de cualquier particular, organización o empresa (García Muñoz, 2009:30).

\footnotetext{
${ }^{58}$ Para mayor ilustración ver: Facio, Alda. La carta magna de todas las mujeres. 2002. San José, Costa Rica. La autora analiza en profundidad todos los aspectos relacionados con la definición contenida en el artículo 1 de la CEDAW.
} 
En su artículo 4 permite las medidas transitorias de "acción afirmativa", o "medidas correctivas" en palabras de Alda Facio (Facio, 2002: 3).

Obliga a los Estados a modificar los patrones socioculturales y eliminar los estereotipos en los roles de hombres y mujeres (art. 5). Lo cual retoma más adelante al referirse a la eliminación de la discriminación en la educación, estableciendo que se debe eliminar todo concepto estereotipado de los papeles masculino y femenino en todos los niveles y en todas las formas de enseñanza (art. 10 inc. c). García Muñoz (2009) afirma que "la CEDAW, es el primer tratado internacional de derechos humanos que, de manera explícita, establece la urgencia de actuar sobre los papeles tradicionales de mujeres y hombres, en la sociedad y en la familia" (p. 30).

En su artículo 6 dispone que los Estados tomarán todas las medidas para suprimir todas las formas de trata de mujeres y explotación de la prostitución de la mujer. Y el artículo 14 se refiere a la necesidad de eliminar la discriminación de la mujer rural, abordando distintos aspectos.

Contiene normas destinadas a suprimir la discriminación de las mujeres en diferentes ámbitos, y aborda distintos derechos, así se refiere a la vida política y pública, reconoce el derecho a votar y ser elegibles, a ocupar cargos públicos (art. 7); a representar a su gobierno en el plano internacional (art. 8); a la nacionalidad (art. 9). Aborda múltiples aspectos, refiriéndose a la educación (art. 10); al empleo (art. 11), donde hace particular hincapié en el embarazo de la trabajadora. El artículo 12 se ocupa de la atención médica de la mujer y el artículo 13 se refiere a la eliminación de la discriminación en otras esferas de la vida económica y social. Asimismo se reconoce la igualdad ante la ley, así como una capacidad jurídica idéntica a la del hombre (art. 15). Se aborda específicamente la discriminación contra la mujer en todos los asuntos relacionados con el matrimonio y las relaciones familiares y se establece que mujeres y hombres tienen mismos derechos y responsabilidades como progenitores (art. 16).

\section{1. a.- Mecanismos de protección: el Comité CEDAW}


La CEDAW crea el Comité para la Eliminación de la Discriminación contra la Mujer (en adelante "Comité CEDAW") $)^{59}$.

Es el órgano encargado de controlar el cumplimiento e interpretar las disposiciones de la CEDAW. Uno de sus objetivos es el examen de los progresos realizados por los Estados Parte en la aplicación de la Convención, para ello se establece la obligación de los mismos de confeccionar y presentar un informe sobre las medidas legislativas, judiciales, administrativas o de otra índole que hayan adoptado para hacer efectivas las disposiciones de la CEDAW y sobre los progresos realizados, el cual debe ser presentado por lo menos cada cuatro años (artículo 18).

Las organizaciones no gubernamentales pueden presentar al Comité informes alternativos, más conocidos como "informes sombra". A partir del análisis de toda esa información el Comité CEDAW confecciona un documento conocido como Observación Final, el cual contiene comentarios y recomendaciones.

El artículo 29 de la CEDAW dispone que las controversias que surjan entre Estados Partes con respecto a la interpretación o aplicación de la Convención se puede someter al arbitraje. Si no se llega a un acuerdo se puede someter a la Corte Internacional de Justicia.

\section{1. b.- Las Recomendaciones Generales}

El Comité CEDAW dicta Recomendaciones Generales (en adelante "RG"), las cuales se constituyen en una guía a la luz de la cual se debe leer la Convención.

Hasta noviembre de 2018 el Comité CEDAW había elaborado y publicado 35 Recomendaciones Generales.

Para la temática que abordamos revisten particular importancia las siguientes RG:

-RG N $\mathrm{N}^{\circ}$ 12: La violencia contra la mujer. Adoptada en 1989, en el 80 período de sesiones. El Comité CEDAW recomienda a los Estados que en los informes periódicos que están obligados a presentarle incluyan información sobre la violencia contra las mujeres, la legislación vigente, los servicios de apoyo existentes, y otras medidas

\footnotetext{
${ }^{59}$ Está compuesto por veintitrés personas expertas, de gran prestigio moral y competencia en la esfera abarcada por la Convención, que ejercen sus funciones a título personal, se tiene en cuenta una distribución geográfica equitativa y la representación de las diferentes formas de civilización, así como los principales sistemas jurídicos (art. 17).
} 
adoptadas para erradicar la violencia, así como también datos estadísticos sobre la frecuencia de cualquier tipo de violencia contra la mujer y sobre las mujeres víctimas de la violencia.

-RG $N^{\circ}$ 19: La violencia contra la mujer. Adoptada en 1992, en el 11 o período de sesiones. El Comité señala que la violencia contra la mujer es una forma de discriminación (en los términos del artículo 1 de la Convención) que impide gravemente el goce de derechos y libertades en pie de igualdad con el hombre (pto. 1 y 7); y que la aplicación cabal de la CEDAW exige que los Estados adopten medidas positivas para eliminar todas las formas de violencia contra la mujer (pto. 4).

Aborda el tema de la responsabilidad estatal por actos de particulares (pto. 9), el cual será tratado más adelante en el presente trabajo.

Entre las recomendaciones concretas del Comité a los Estados (pto. 24) se incluyen las siguientes: adoptar medidas apropiadas y eficaces para combatir los actos públicos o privados de violencia por razones de sexo; velar porque las leyes protejan de manera adecuada a todas las mujeres; proporcionar a las víctimas protección y apoyo apropiados; capacitación a Ixs funcionarixs judiciales, Ixs agentes del orden público y otrxs funcionarixs públicos para que apliquen la Convención; recopilación de estadísticas; adopción de medidas eficaces para que los medios de comunicación respeten a la mujer y para superar las actitudes y prácticas que perpetúan la violencia contra ella. También recomienda que se prevean procedimientos eficaces de denuncia y reparación, incluyendo la indemnización; que se establezcan servicios destinados a las víctimas de violencia: refugios, trabajadorxs sanitarios especialmente capacitadxs, rehabilitación y asesoramiento; que las medidas destinadas a proteger de la violencia incluyan las oportunidades de capacitación y empleo.

Específicamente en relación a la violencia en la familia señala las siguientes medidas a adoptar por los Estados: sanciones penales en los casos necesarios y recursos civiles en caso de violencia en el hogar; servicios, entre ellos, refugios, asesoramiento y programas de rehabilitación para los culpables (pto. 24 inc. r).

Señala que los Estados Partes deben adoptar todas las medidas jurídicas y de otra índole que sean necesarias para proteger eficazmente a las mujeres contra la violencia, 
entre ellas indica como medidas preventivas: programas de información y educación para modificar las actitudes relativas al papel y la condición del hombre y de la mujer; como medidas de protección: la creación de refugios, asesoramiento, rehabilitación y servicios de apoyo para las mujeres que son víctimas de violencia o que se encuentren en peligro de serlo (pto. 24 inc. t).

Aborda particularmente la situación de las mujeres en las zonas rurales afirmando que los Estados deben garantizar que en esas zonas los servicios sean asequibles (pto. 24 inc. o).

Esta RG reviste particular importancia porque ha sido invocada y utilizada por el Comité CEDAW al establecer la responsabilidad de los Estados en casos individuales de violencia doméstica. Este punto será abordado más adelante.

-RG N $N^{\circ} 33:$ Sobre el acceso de las mujeres a la justicia. Adoptada el 3 de agosto de 2015. El Comité afirma que el derecho de acceso de las mujeres a la justicia es esencial para la realización de todos los derechos protegidos en virtud de la CEDAW. Q el mismo es un derecho pluridimensional ya que abarca la justiciabilidad, la disponibilidad, el acceso, la buena calidad, el suministro de recursos jurídicos para las víctimas y la rendición de cuentas de los sistemas de justicia. (pto. 1).

El Comité CEDAW realiza recomendaciones a los Estados en relación a cada uno de estos aspectos (Capitulo II), así como también dirigidas a esferas específicas del derecho: penal, civil, de familia (Capitulo III).

Afirma que ha observado, en la práctica, una serie de obstáculos y restricciones que "impiden a la mujer realizar su derecho de acceso a la justicia en pie de igualdad". Esos obstáculos "constituyen violaciones persistentes de los derechos humanos de las mujeres" y se "producen en un contexto estructural de discriminación y desigualdad" ${ }^{60}$ (pto. 3).

En los puntos 8, 9 y 10 hace un análisis pormenorizado de las causas de la discriminación interseccional o compuesta.

\footnotetext{
${ }^{60}$ Señala, asimismo, que esto se debe a "factores como los estereotipos de género, las leyes discriminatorias, los procedimientos interseccionales o compuestos de discriminación y las prácticas y los requisitos en materia probatoria, y al hecho de que no ha asegurado sistemáticamente que los mecanismos judiciales son física, económica, social y culturalmente accesibles a todas las mujeres" (pto. 3).
} 
Señala como factores que impiden a la mujer el acceso a la justicia los siguientes: la concentración de los tribunales y los órganos cuasi judiciales en las principales ciudades; su falta de disponibilidad en regiones rurales y remotas; el tiempo y el dinero necesarios para acceder a ellos; la complejidad de los procedimientos; las barreras físicas para las mujeres con discapacidad; la falta de acceso a un asesoramiento letrado de calidad, competente en cuestiones de género, incluida la asistencia jurídica; las deficiencias en la calidad de los sistemas de justicia (por ejemplo, decisiones o sentencias que no tienen en cuenta el género debido a una falta de entrenamiento, demoras excesivas de los procedimientos, corrupción) (pto. 13).

-RG $N^{\circ}$ 35: Sobre la violencia por razón de género contra la mujer, por la que se actualiza la Recomendación General núm. 19. Adoptada el 26 de julio de 2017.

Esta RG, como su nombre lo indica, es una actualización de la RG 19. Se aprueba para conmemorar su 250 aniversario y ofrece a los Estados partes "orientación adicional para acelerar la eliminación de la violencia por razón de género contra la mujer" (pto. $3)$.

En esta RG el Comité utiliza la expresión "violencia por razón de género contra la mujer". En el punto 9 explica que ha adoptado esta expresión ya que la misma es más precisa "pone de manifiesto las causas y los efectos relacionados con el género de la violencia" y refuerza "la noción de la violencia como problema social más que individual, que exige respuestas integrales, más allá de aquellas relativas a sucesos concretos, autores y víctimas y supervivientes" ${ }^{61}$.

Es de destacar que en su punto 7 afirma que "la reducción significativa del gasto público, a menudo como parte de las denominadas 'medidas de austeridad' tras las crisis económicas y financieras, contribuyen a debilitar todavía más las respuestas de los Estados".

En su pto. 21 sostiene que los Estados están obligados a adoptar por todos los medios apropiados y sin dilaciones, una política encaminada a la eliminación de la discriminación contra la mujer, en especial la violencia por razón de género contra la

\footnotetext{
${ }^{61}$ En la RG n 19 utilizaba la expresión de "violencia contra la mujer".
} 
mujer, y que se trata de una obligación de carácter inmediato "las demoras no se pueden justificar por ningún motivo, ya sea económico, cultural o religioso".

Aborda en detalle la temática de la responsabilidad del Estado por la violencia por razón de género contra la mujer (pto. 22, 23 y 24), tema que será analizado más adelante en esta tesis.

Realiza recomendaciones dirigidas a los Estados para ser adoptadas en los distintos planos: legislativo, ejecutivo y judicial. $\mathrm{Y}$ en relación a las distintas obligaciones estatales: prevenir, proteger, enjuiciar, castigar y reparar, así como también las de producción, análisis y evaluación de datos y estadísticas.

\section{1. c.- El Protocolo facultativo y los casos individuales}

La Cedaw tenía la particularidad de no preveer ningún sistema de denuncias individuales. 20 años después de su aprobación, en el año 1999, se adoptó el Protocolo Facultativo a la CEDAW ${ }^{62}$ (en adelante "el Protocolo").

Facio (2002) ha afirmado que con la entrada en vigor del Protocolo "la CEDAW se convirtió realmente en nuestra CARTA MAGNA DE DERECHOS HUMANOS DE LAS MUJERES. Ahora nuestra carta no sólo reconoce y protege todos nuestros derechos, sino que también los garantiza" (p.12).

El Protocolo le otorga dos nuevas competencias al Comité CEDAW: la de examinar comunicaciones individuales y la de investigar violaciones graves o sistemáticas de derechos de las mujeres. Esto en relación a los Estados que lo ratifiquen.

El primero de estos mecanismos consiste en la competencia del Comité para conocer en casos concretos. Las denuncias deben ser presentadas por personas o grupos de ellas que aleguen ser víctimas de la violación denunciada o por sus representantes (art. 2).

Tras el examen de la queja, el Comité informará a las partes sobre sus opiniones y recomendaciones, en un documento en el cual establece los hechos y determina si los mismos constituyen una violación a alguna de las disposiciones de la CEDAW.

\footnotetext{
${ }^{62}$ Fue adoptado el 6 de octubre de 1999, por la Asamblea General de Naciones Unidas, mediante resolución $\mathrm{A} / 54 / 4$.
} 
Gracias a este mecanismo el Comité ha abordado múltiples casos de discriminación y violencias hacia las mujeres. Cabe destacar que lo ha hecho también en relación a situaciones de violencia doméstica, como lo veremos más adelante.

Por ultimo resta señalar que el mecanismo de investigación es el primer procedimiento específico de Naciones Unidas para la investigación sobre violaciones graves o sistemáticas de los derechos humanos de las mujeres (García Muñoz, 2009: 33).

Los Estados tienen la posibilidadde declarar la no aceptación de esta competencia del Comité CEDAW, al firmar o ratificar el Protocolo (art. 10).

\section{2- La Convención de Belem Do Pará}

En el marco del Sistema Interamericano, en 1994, la Organización de Estados Americanos (OEA) adoptó la Convención Interamericana para Prevenir, Sancionar y Erradicar la violencia contra la mujer ${ }^{63 .}$.

Es el primer instrumento internacional vinculante en el mundo que reconoce el derecho de las mujeres a vivir una vida libre de violencia (Camacho, 2003:71 y García Muñoz, 2009: 35). Afirma, en su artículo 3, que "Toda mujer tiene derecho a una vida libre de violencia, tanto en el ámbito público como en el privado".

Afirma Salvioli (20079 que en el texto de la convención "la violencia contra la mujer constituye de hecho y técnicamente una violación a los derechos humanos" (p. 149).

En el preámbulo se afirma que la violencia contra la mujer constituye una violación de los derechos humanos y que es una manifestación de las relaciones de poder históricamente desiguales entre mujeres y hombres.

Adopta una amplia definición de lo que entiende por violencia hacia las mujeres, al afirmar, en su artículo 1, que: "debe entenderse por violencia contra la mujer cualquier acción o conducta, basada en su género, que cause muerte, daño o sufrimiento físico, sexual o psicológico a la mujer, tanto en el ámbito público como en el privado".

En su artículo 6 reconoce que "El derecho de toda mujer a una vida libre de violencia incluye, entre otros: a. el derecho de la mujer a ser libre de toda forma de discriminación". Esta relación íntima e inescindible entre violencia y discriminación que

\footnotetext{
${ }^{63}$ Adoptada y abierta a la firma, ratificación y adhesión por la Asamblea General de la Organización de Estados Americanos, en su vigésimo cuarto periodo ordinario de sesiones, del 9 de junio de 1994, en Belem do Para, Brasil. Entrada en vigor: el 5 de marzo de 1995 de conformidad con el Artículo 21.
} 
explicita la CBDP va en idéntico sentido de lo que el Comité CEDAW expresara en su RG $\mathrm{n}^{\circ} 19$ referida con anterioridad.

El capítulo III consigna los deberes de los Estados. Allí, en su artículo 7, se contienen las medidas que los Estados partes deben adoptar sin dilaciones y por todos los medios apropiados. Este artículo contiene obligaciones de respeto (inc. a) y de debida diligencia en la prevención, investigación y sanción (inc. b); así como también la obligación de adaptar la legislación interna y las medidas administrativas con el objeto y fin de la convención (inc. c y h); y de adoptar la medidas jurídicas pertinentes para conminar al agresor a abstenerse de violentar a la mujer (inc. d). El punto e. nos resulta particularmente trascendente al obligar a los Estados a "tomar todas las medidas apropiadas (...) para modificar prácticas jurídicas o consuetudinarias que respalden la persistencia o la tolerancia de la violencia contra la mujer"; asimismo dispone que se deben establecer procedimientos legales justos y eficaces para la mujer (inc. f); así como también los mecanismos para asegurarle el acceso efectivo a resarcimiento, reparación del daño u otros (inc. g).

Como veremos más adelante, es en base a la violación de lo dispuesto por este artículo 7 que la Corte IDH y la CIDH han abordado la mayoría de los casos más paradigmáticos de derechos de las mujeres.

El artículo 8 se refiere a las medidas que los Estados convienen en adoptar en forma progresiva $^{64}$. Sostiene García Muñoz (2009) que la progresividad no puede ser utilizada por los Estados para excusar incumplimientos indefinidos y que la explicación del carácter progresivo de estas obligaciones está dada porque requieren acciones sobre áreas de alta complejidad (patrones socio culturales, conciencia pública), cuyos resultados se visualizan a medio y largo plazo (p. 37).

\footnotetext{
${ }^{64}$ Para fomentar el conocimiento del derecho de la mujer a una vida libre de violencia; modificar los patrones socioculturales de conducta de hombres y mujeres, incluyendo el diseño de programas de educación; fomentar la educación y capacitación del personal en la administración de justicia, policial y demás funcionarios encargados de la aplicación de la ley; suministrar los servicios especializados apropiados para la atención necesaria a la mujer; fomentar y apoyar programas destinados a concientizar al público; ofrecer a la mujer acceso a programas eficaces de rehabilitación y capacitación; alentar a los medios de comunicación para que contribuyan a erradicar la violencia contra la mujer; garantizar la investigación y recopilación de estadísticas y promover la cooperación internacional.
} 
En su artículo 9, la CBDP, hace referencia a que los Estados deben prestar especial atención a las situaciones de mujeres en las que se intersectan causales de vulnerabilidad.

\section{2. a- Mecanismos de protección}

En los artículos 10, 11 y 12 de la CBDP se establecen los mecanismos de protección. Se dispone que en los informes nacionales a la Comisión Interamericana de Mujeres ${ }^{65}$ (CIM), los Estados Partes deberán incluir información sobre las medidas adoptadas así como sobre las dificultades y los factores que contribuyan a la violencia contra la mujer.

Los Estados y la Comisión Interamericana de Mujeres, podrán requerir a la Corte IDH opinión consultiva sobre la interpretación de la CBDP.

Asimismo establece la posibilidad de presentar peticiones a la $\mathrm{CIDH}$ con denuncias o quejas de violación del artículo $7^{66}$.

Ha sido particularmente destacado el trabajo de la CIDH en el examen de casos y elaboración de informes temáticos o por países (García Muñoz, 2009: 35; Fernández Valle, 2018: 34). La misma cuenta en su seno con una Relatoría Especial sobre Derechos de las Mujeres. Particular importancia reviste para el presente trabajo el informe titulado "Acceso a la Justicia para las mujeres víctimas de violencia en las Américas" (2007), el cual será abordado y utilizado como insumo en los capítulos siguientes.

La Corte IDH ha abordado la cuestión de su competencia para entender en violaciones al art. 7 de la CBDP en el caso "Gonzales y otras c. México" (en adelante caso "Campo Algodonero") que abordaremos a continuación.

Los Estados Parte de la CBDP han creado un Mecanismo de Seguimiento a la Convención (MESECVI), integrado por un Comité de Expertas Independientes

\footnotetext{
${ }^{65}$ Es un organismo especializado de la OEA, que nació en 1928 (antes de la fundación de la Organización), "es el primer precedente mundial de institución intergubernamental con el mandato de velar por los derechos civiles y políticos de las mujeres" (García Muñoz, 2009: 38). Está integrada por una delegada de cada Estado miembro de la OEA. Ha emitido numerosos informes y documentos.

${ }^{66}$ Estas peticiones pueden ser presentadas por cualquier persona, grupo de personas, o entidad no gubernamental legalmente reconocida.
} 
encargadas del examen de los informes de los Estados ${ }^{67}$. Ha producido tres informe Hemisféricos (2008, 2012 y 2017) en los cuales reúne la información sobre el estado de cumplimiento de la Convención en todos los Estados Parte y realiza recomendaciones para fortalecer la implementación de la CBDP.

\section{2. b.- La Corte IDH y la CBDP: el caso "Campo Algodonero"}

La sentencia en el caso "Campo Algodonero" se ha constituido en un precedente de suma importancia en la jurisprudencia de la Corte Interamericana. Esto debido a diversos aspectos, entre ellos la perspectiva de género adoptada por la Corte, el hecho de que es la primera vez que la misma analiza una situación de violencia estructural hacia las mujeres, así como por las medidas de no repetición que dispone. Fernández Valle (2018) sostiene que, en general, se afirma que el verdadero cambio de paradigma en la labor de la Corte IDH vino de la mano de su intervención en este caso (p. 35) $)^{68}$.

Es una sentencia que se constituye en referencia obligada para analizar las obligaciones de los Estados en relación a la violencia hacia las mujeres, y otorga importantes herramientas para avanzar en la exigencia a los mismos para que cumplan con los compromisos que han asumido internacionalmente.

La sentencia es paradigmática, como paradigmáticos fueron los hechos que la motivaron $^{69}$. Las irregularidades, desidia y negligencia tanto en la búsqueda de las mujeres desaparecidas, como en la investigación de los hechos después de encontrados los cuerpos quedaron evidenciadas a lo largo del proceso y reflejadas en la sentencia de la Corte IDH. Este proceder de las autoridades estatales tenía una motivación: los estereotipos de género existentes en Ciudad Juárez, y la fuerte discriminación hacia las mujeres, todo lo cual provocaba un contexto generalizado de

\footnotetext{
${ }^{67}$ En la página web de la OEA se lo define como "una metodología de evaluación multilateral sistemática y permanente, fundamentada en un foro de intercambio y cooperación técnica entre los Estados Parte de la Convención y un Comité de Expertas/os" (http://www.oas.org/es/mesecvi/nosotros.asp, fecha de última consulta 23/2/2018).

${ }^{68}$ Esto en relación a las críticas, que hemos señalado, al desempeño de la Corte en cuanto a la perspectiva de género y derechos de las mujeres.

${ }^{69}$ Esmeralda, Laura Berenice y Claudia Ivette eran dos niñas y una joven mujer, desaparecidas en Ciudad Juárez, México, torturadas (aunque la Corte utiliza la expresión de vejadas o maltratadas), y asesinadas, hallándose sus cadáveres en un campo algodonero.Las tres eran trabajadoras, mujeres pobres. La situación de vulnerabilidad en la que se encontraban por ser mujeres en una sociedad misógina, se ve agravada por su pertenencia de clase.
} 
violencia hacia las mismas, en el marco del cual los hechos de los que fueron víctimas Esmeralda, Laura y Claudia, fueron expresiones extremas y brutales, pero no excepcionales, de una extendida misoginia.

Esta sentencia brinda material para detenernos en distintos aspectos jurídicos, e incluso para realizar análisis desde diferentes enfoques: metodológicos, procedimentales, sociológicos.

Nos detendremos aquí y abordaremos a continuación dos aspectos que caracterizamos como particularmente relevantes ${ }^{70}$.

\section{2. b.1.-La competencia de la Corte IDH para entender en violaciones al artículo 7 de la Convención Belém do Pará}

El Estado Mexicano al contestar la demanda interpuesta en su contra por la CIDH afirmó que la Corte IDH no tenía competencia contenciosa para entender sobre violaciones a la CBDP. Sostuvo que esta Convención solo le otorgaba expresamente competencia a la Comisión Interamericana.

La Corte luego de realizar una interpretación literal de la CBDP se considera competente $^{71}$ (pto. 41), no obstante se propone analizar la cuestión aplicando todos los elementos interpretativos que se refieren en el art. 31 de la Convención de Viena sobre el Derechos de los Tratados (pto. 42) y así lo hace (p. 12 a 19).

Luego de este análisis sostiene que tiene competencia contenciosa para conocer en las violaciones al art. 7 de la CBDP. Pero entiende que no la tiene en relación a las violaciones de los artículos 8 y 9, ya que refiere que las interpretaciones sistemática y teleológica son insuficientes ante la claridad literal del art. $12^{72}$. Por esto acepta parcialmente la excepción preliminar del Estado (p. 19).

Este análisis pormenorizado que realiza la Corte sobre su competencia para entender en violaciones a la CBDP se constituye en uno de los aspectos más relevantes de la

\footnotetext{
${ }^{70}$ Otros aspectos transcendentes serán abordados más adelante al referirnos a la obligación estatal de la debida diligencia y a la responsabilidad del Estado por actos de particulares.

${ }^{71}$ Basándose en que el artículo 12 de la CBDP remite a las "normas y requisitos de procedimiento para la presentación y consideración de peticiones estipuladas en la Convención Americana de Derechos Humanos y en el Estatuto y el reglamento de la Comisión interamericana de derechos humanos", sin exceptuar ninguna de las normas ni requisitos, por lo que aquellas que se refieren al sometimiento de casos ante la Corte también son aplicables (pto. 40).

${ }^{72}$ Que solo otorga competencia para casos individuales en relación al art. 7.
} 
sentencia. Es la primera vez que lo hace y lo realiza en profundidad, tomando distintos elementos interpretativos ${ }^{73}$. El tratamiento expreso y detallado de dicha competencia implica un avance, ya que la Corte no ha dejado dudas en relación a que ella es competente para aplicar la CBDP, declarar violaciones autónomas a la misma, y condenar a los Estado por ello.

\section{2. b. 2.- Las obligaciones reforzadas. La relación entre la Convención Americana y la}

\section{Convención de Belém do Pará}

Otro aspecto de la sentencia de la Corte particularmente relevante es el desarrollo que la misma realiza sobre el deber de prevención, y la afirmación que hace de que "en caso de violencia contra la mujer, los Estados tienen, además de las obligaciones genéricas contenidas en la Convención Americana, una obligación reforzada a partir de la Convención Belém do Pará" (pto. 258 de la sentencia).

La CBDP establece la obligación de debida diligencia en la prevención, la Corte entiende que esto es un plus en relación a los deberes de garantía de los derechos humanos que los Estados tienen a raíz de la Convención Americana de Derechos humanos (en adelante CADH). Es decir, la CBDP refuerza las obligaciones emanadas de la CADH. Habría un piso de obligaciones que tienen los Estados para cumplir con debida diligencia su deber de prevención, que proviene de la $\mathrm{CADH}$, el cual en casos de violencia hacia la mujer se vería reforzado en virtud de la $\mathrm{CBDP}^{74}$.

La articulación entre ambos instrumentos y el refuerzo que la CBDP implica sobre lo establecido por la CADH demuestra la riqueza del análisis realizado por la Corte. Así se materializa lo que se denomina "perspectiva de género". La CBDP establece un plus, algo extra en relación a la $\mathrm{CADH}, \mathrm{y}$ esto es así por la situación de discriminación histórica y particular vulnerabilidad en la que se encuentran las mujeres en nuestras sociedades, lo cual justifica un tratamiento y una protección diferenciada.

\footnotetext{
${ }^{73}$ La Corte en otras ocasiones había aplicado la CBDP, así en el "Caso del Penal Miguel Castro Castro" (Sentencia de 25 de noviembre de 2006) se pronunció sobre la violación del Pacto de San José de Costa Rica en relación a la Convención Belém Do Pará. Pero es en "Campo Algodonero" donde la Corte por primera vez analiza expresamente su competencia contenciosa para entender en violaciones al art. 7 de la CBDP, y explicita en qué se basa para entenderse competente, de este modo la Corte despeja todas las dudas o incertidumbres que, en relación a este punto, podían existir.

${ }^{74}$ Sin embargo la Corte no explicita cuáles son esas obligaciones genéricas, ni en qué consistiría su refuerzo.
} 
La Corte aplica el estándar de debida diligencia reforzado y analiza si el Estado mexicano cumplió con sus obligaciones de protección y garantía de los derechos humanos ante acciones de particulares. Siguiendo a Abramovich (2010) podemos decir que el deber de debida diligencia reforzado redefine los requisitos que deben cumplirse para que se le pueda atribuir responsabilidad al Estado por actos de particulares, los cuales tendrán especiales características a la luz de lo establecido por el art. 7으 de la CBDP.

Hemos visto en este capítulo que la "genereización" del DIDH, así como la adopción de normativa específica de reconocimiento de los derechos de las mujeres, son recientes. Igualmente podemos afirmar que el derecho a una vida libre de violencias ha sido ampliamente reconocido y que se han creado órganos y mecanismos destinados a su protección, así como al análisis y seguimiento de la situación de las mujeres a lo largo y ancho del mundo. 


\section{IV.- LA DEBIDA DILIGENCIA Y LA RESPONSABILIDAD ESTATAL EN PREVENIR, INVESTIGAR, SANCIONAR Y REPARAR LA VIOLENCIA DE GÉNERO CONTRA LAS MUJERES}

Hemos visto en el capítulo anterior que el derecho de las mujeres a una vida libre de violencias se encuentra ampliamente reconocido. La CEDAW y la CBDP son dos instrumentos de suma importancia en este reconocimiento, y los órganos y mecanismos establecidos en consecuencia lo son en su protección. Los Estados tienen obligaciones en relación a estos derechos de las mujeres, deben respetarlos y garantizarlos. Cuando son los particulares quienes vulneran a las mujeres en sus derechos las obligaciones estatales deben ser analizadas a la luz del principio de la debida diligencia. En este capítulo analizaremos dicho principio el cual reviste central importancia para nuestra tesis.

\section{1.- La debida diligencia para prevenir, investigar, sancionar y reparar la violencia de género contra las mujeres}

La norma de la debida diligencia tiene una larga historia en el derecho internacional (Ertrk, 2006: párr. 19; Abdul Aziz y Moussa, 2016; CIDH, 2011: párr. 122).

Es un principio ampliamente reconocido (CIDH, 2011: párr. 114) y utilizado en el campo del Derecho Internacional de los Derechos Humanos tanto en la normativa, como por los órganos y mecanismos de protección generales y específicos.

En lo que a violencia contra las mujeres se refiere, este principio es de central importancia, por un lado por la estrecha relación existente entre la discriminación, la violencia y la debida diligencia ${ }^{75}$, de la cual han dado cuenta tanto el sistema interamericano de DDHH como el sistema universal ${ }^{76}$.

\footnotetext{
${ }^{75}$ Se ha enfatizado que "la falla del Estado de actuar con debida diligencia para proteger a las mujeres de la violencia constituye una forma de discriminación, y una negación de su derecho a la igual protección de la ley" (CIDH, 2011: párr. 111).

${ }^{76}$ En este sentido ver: $\mathrm{CIDH}, 2011$ : párr. 111, donde remite, entre otros, a: Comité CEDAW, Comunicación 2/2003, Sra. A.T. c. Hungría, 26 de enero de 2005; Corte Europea de Derechos Humanos, Caso de Opuz c. Turquía, Petición No. 33401/02, 9 de junio de 2009; CIDH, Informe № 28/07, Casos 12.496-12.498, Claudia Ivette González y Otros, Informe sobre el Fondo (México), 9 de marzo de 2007;
} 
Por otro lado porque, como veremos más adelante, es a partir de este principio que se delinean y definen las obligaciones estatales, así como la responsabilidad estatal ante hechos de violencia hacia las mujeres cometidos por particulares.

La normativa específica, protectoria de los derechos de las mujeres, utiliza este concepto (CIDH, 2005: pto. 32) ${ }^{77}$.

Recordemos aquí que en el caso de violencias hacia las mujeres el deber de la debida diligencia tiene connotaciones especiales y se ve reforzado "debido a la discriminación histórica que han sufrido como grupo" (CIDH, 2011: párr. 128). Esto ha sido reconocido expresamente la Corte IDH, como lo hemos desarrollado anteriormente.

\section{1.- El abordaje del principio de la debida diligencia por los órganos de protección y los especializados}

Los órganos y mecanismos de protección y los especializados han utilizado el estándar de la debida diligencia para interpretar el contenido y delinear, en la práctica, las obligaciones de los Estados en relación a las violencias contra las mujeres (CIDH, 2011: parr. 123 y 125; Ertrk, 2006: pto. 14). Así como también para responsabilizar a los Estados por actos de violencia doméstica cometidos por particulares, cuestión que abordaremos en el próximo apartado.

Las sucesivas Relatoras Especiales "sobre la violencia contra la mujer, sus causas y consecuencias" (en adelante "La Relatora Especial") ${ }^{78}$ han abordado en varias

Corte Interamericana de Derechos Humanos, Caso de González et al. (“Campo Algodonero”) c. México, Sentencia de 16 de noviembre de 2009.

${ }^{77}$ Así la Convención de Belem Do Pará en su artículo 7 inc. b establece entre los deberes de los Estados el de "actuar con la debida diligencia para prevenir, investigar y sancionar la violencia contra la mujer". La Declaración sobre la Violencia contra la Mujer (ONU) en su artículo 4 inc. C estableció la obligación de los Estados de "proceder con la debida diligencia a fin de prevenir, investigar y, conforme, a la legislación nacional, castigar todo acto de violencia contra la mujer, ya se trate de actos perpetrados por el Estado o por particulares". Esta disposición también se incluyó en el apartado b) del párrafo 125 de la Plataforma de Acción de Beijing.

${ }^{78}$ En 1994, en el marco de Naciones Unidas, se estableció el mandato de la "Relatora Especial sobre la violencia contra las mujeres, sus causas y consecuencias", en la resolución se enfatiza "la obligación de los Gobiernos (...) a ejercer la debida diligencia para prevenir, juzgar y (...) sancionar los actos de violencia contra las mujeres y tomar acción apropiada y efectiva (...) ya sean actos perpetrados por el Estado o por actores privados, así como proveer acceso (...) a servicios de asistencia especializada para víctimas" (Comisión de Derechos Humanos-ONU, 1994). 
oportunidades esta cuestión, incluso han producido informes temáticos sobre este principio en particular ${ }^{79}$.

La Relatora Especial Radhika Coomaraswamy destacó, en su informe de 2000, que la debida diligencia exige más que "la promulgación de prohibiciones formales" y que los Estados deben actuar de buena fé para impedir eficazmente la violencia contra la mujer (apud Ertürk, 2006: 12). La Relatora Especial Yakin Ertürk (2006) afirmó que la obligación de la debida diligencia debe aplicarse de buena fé con miras a prevenir y responder a la violencia contra la mujer y que es necesario que los Estados adopten medidas positivas para asegurarse que los derechos humanos de la mujer se protegen, respetan, promueven y ejercen (pto. 36).

Ertürk (2006) ha señalado a 1988 como el año en que dicho principio se incorporó en el sistema interamericano de derechos humanos, por ser el año en que la Corte IDH dictaminó en la causa Velásquez Rodríguez c. Honduras (pto.20).

La Relatora Especial Coomaraswamy (1995: parr. 72) ha afirmado asimismo que "el Estado que no toma medidas para reprimir los actos de violencia contra la mujer es tan culpable como sus autores" (apud Merino Sancho, 2007:402).

La CIDH presentó en numerosas oportunidades casos ante la Corte IDH donde se demandaba a los Estados por la falta de debida diligencia en proteger y garantizar el ejercicio y goce de los derechos de las mujeres.

En el mentado caso Velázquez Rodríguez la Corte IDH (1988) entendió que el Estado no había cumplido sus obligaciones con arreglo al párrafo 1 del artículo 1 de la CADH, concluyendo que un acto ilegal "puede dar lugar a la responsabilidad internacional del Estado, no por el acto en sí, sino por la falta de la debida diligencia para impedir la violación o reaccionar a ella tal como lo exige la Convención" (párr. 172).

\footnotetext{
${ }^{79}$ Entre ellos los siguientes: Ertürk. Informe de la Relatora Especial sobre la violencia contra la mujer, sus causas y consecuencia. La Norma de la debida diligencia como instrumento para la Eliminación de la Violencia contra la Mujer. Comisión de Derechos Humanos, E/CN.4/2006/61, 20 enero 2006, Naciones Unidas, Nueva York/ Rashida Manjoo. Informe de la Relatora Especial sobre la violencia contra la mujer, sus causas y consecuencias, Consejo de Derechos Humanos, A/HRC/23/49, 14 de mayo de 2013, párr. 11-77.
} 
En el caso Masacre de las Dos Erres vs. Guatemala la demanda se relacionaba con la falta de debida diligencia en la investigación, juzgamiento y sanción de los responsables de la masacre ${ }^{80}$.

En el caso Rosendo Cantú y otra vs. México la demanda se refiere a la supuesta responsabilidad internacional del Estado por la falta de debida diligencia en la investigación y sanción de los responsables de la violación sexual y tortura de una niña indígena $^{81}$.

Señala aquí la Corte IDH (2010) que en casos de violencia contra la mujer las obligaciones genéricas establecidas en la CADH se complementan y refuerzan con las obligaciones derivadas del tratado específico: la CBDP. Y recuerda que artículo 7.b de esta Convención obliga de manera específica a los Estados a utilizar la debida diligencia para prevenir, sancionar y erradicar la violencia contra la mujer ${ }^{82}$ (pto. 177).

La Corte IDH concluye que las autoridades estatales mexicanas no actuaron con la debida diligencia en la investigación ${ }^{83}$.

En su informe de fondo sobre el caso María da Penha Maia Fernandes c. Brasil (2001) la CIDH aplicó por primera vez la Convención de Belém do Pará y decidió que el Estado había menoscabado su obligación de ejercer la debida diligencia para prevenir,

\footnotetext{
${ }^{80}$ En su sentencia del 24 de noviembre de 2009 la Corte IDH entendió que la falta de investigación de hechos graves constituyen un incumplimiento de las obligaciones del Estado frente a graves violaciones a derechos humanos, las cuales generan obligaciones para los Estados como la de investigar y sancionar dichas prácticas. Entiende la Corte que el Estado debió iniciar ex officio y sin dilación una investigación seria, imparcial y efectiva de todos los hechos de la masacre relacionados con la vulneración de la vida, así como respecto a otras afectaciones específicas contra la integridad personal, tales como las torturas y actos de violencia contra la mujer con una perspectiva de género (ya que muchas de las víctimas eran mujeres y niñas), de conformidad con la $\mathrm{CADH}$, y las obligaciones específicas dispuestas en la Convención Interamericana contra la Tortura y en la CBDP (párr. 141).

${ }^{81}$ En su sentencia del 31 de agosto de 2010 la Corte IDH entendió que desde el momento en que el Estado tuvo conocimiento de la existencia de una violación sexual cometida contra quien pertenece a un grupo en situación de especial vulnerabilidad por su condición de indígena y de niña, tiene la obligación de realizar una investigación seria y efectiva.

${ }^{82}$ Por lo tanto sostiene la Corte que "resulta particularmente importante que las autoridades a cargo de la investigación la lleven adelante con determinación y eficacia, teniendo en cuenta el deber de la sociedad de rechazar la violencia contra las mujeres y las obligaciones del Estado de erradicarla y de brindar confianza a las víctimas en las instituciones estatales para su protección" (pto. 177).

${ }^{83}$ Entendiendo que el Estado violó los derechos a las garantías judiciales y a la protección judicial previstos en los artículos 8.1 y 25.1 de la CADH, en relación con el artículo 1.1 de la misma, e incumplió el deber establecido en el artículo 7.b de la CBDP (párr. 182)
} 
sancionar y erradicar la violencia doméstica, al no condenar y sancionar al victimario durante 15 años $^{84}$.

Señaló que la obligación de los Estados de actuar con la debida diligencia necesaria para investigar y sancionar violaciones de los derechos humanos se aplica a casos de violencia doméstica e interpretó que el alcance del deber de actuar con la debida diligencia frente a la violencia doméstica en un sentido amplio, comprende no sólo la pronta investigación, procesamiento y sanción de dichos actos, sino también la obligación de "prevenir estas prácticas degradantes" (párr. 56) ${ }^{85}$.

La CIDH llegó a la conclusión de que Brasil no había actuado con la debida diligencia para impedir un caso de violencia doméstica y responder a él a pesar de las pruebas evidentes que existían contra el acusado y la gravedad de los cargos. Por ultimo emitió una serie de recomendaciones, algunas de ellas destinadas a "profundizar el proceso de reformas que eviten la tolerancia estatal y el tratamiento discriminatorio respecto a la violencia doméstica contra las mujeres en Brasil" (párr. 61) ${ }^{86}$.

La ley contra la violencia doméstica de Brasil (2006) fue llamada "Ley María da Penha". En el informe de fondo en el caso Jessica Lenahan vs. Estados Unidos (2011) la CIDH dedica un capítulo especial a analizar el principio de la debida diligencia y la violencia contra las mujeres, repasando los instrumentos que lo consagran, la aplicación del mismo por los órganos y mecanismos protectorios, y sus alcances.

\footnotetext{
${ }^{84}$ En este caso María da Penha Maia Fernandes, víctima de violencia doméstica, sufrió graves consecuencias en su salud, quedando parapléjica producto de las agresiones físicas y las tentativas de homicidio de parte de su esposo. Maria da Penha había presentado varias denuncias ante el Estado. La $\mathrm{CIDH}$ encontró que el Estado había violado los derechos de la víctima a garantías y protecciones judiciales efectivas garantizados bajo los artículos 8 y 25 de la CADH, en concordancia con la obligación general de respetar y garantizar estos derechos bajo el artículo 1.1, y el artículo 7 de la CBDP (párr. 60). ${ }^{85} \mathrm{La} \mathrm{CIDH}$ entendió que las decisiones judiciales en este caso presentaron una ineficacia, negligencia $\mathrm{u}$ omisión por parte de las autoridades judiciales brasileñas y una demora injustificada en el juzgamiento, y afirma que "demuestran que el Estado no ha sido capaz de organizar su estructura para garantizar esos derechos" (párr. 44). Asimismo verificó la existencia de un patrón general de tolerancia estatal hacia casos de violencia doméstica, lo que promovió su repetición, y reafirmó el vínculo estrecho entre el problema de la violencia contra las mujeres y la discriminación en el contexto doméstico (párr. 55).

${ }^{86}$ Así señalo la necesidad de adoptar medidas de capacitación y sensibilización destinadas a funcionarios judiciales y policiales especializados para que comprendan la importancia de no tolerar la violencia contra las mujeres y programas educativos para la población en general; la necesidad de simplificar los procedimientos judiciales penales para poder reducir los tiempos procesales sin afectar los derechos y garantías de debido proceso; así como también de multiplicar el número de delegaciones especiales de policía para los derechos de la mujer y dotarlas con los recursos especiales necesarios (párr. 61).
} 
Destaca cuatro principios en relación al estándar de la debida diligencia en casos de violencia contra la mujer: -El Estado puede incurrir en responsabilidad internacional por no actuar con la debida diligencia para prevenir, investigar, sancionar y reparar los actos de violencia contra la mujer, un deber aplicable a los actos cometidos por particulares en ciertas circunstancias. -El deber de los Estados de enfrentar y responder a la violencia contra la mujer también implica medidas para prevenir la discriminación que perpetúa este grave problema (dado el vínculo entre la discriminación, la violencia contra la mujer y la debida diligencia) ${ }^{87}$. -Destaca el vínculo entre el deber de actuar con la debida diligencia y la obligación de los Estados de garantizar el acceso a recursos judiciales adecuados y efectivos para las víctimas y sus familiares, cuando son objeto de actos de violencia. Como cuarto punto señala que los sistemas de derechos humanos han identificado grupos de mujeres expuestos a un riesgo particular de sufrir actos de violencia, debido a formas de discriminación que sufren por más de un factor, lo que debe ser considerado por los Estados en la adopción de medidas para prevenir todas las formas de violencia (párr. 126 y 127).

Como vemos el principio de la debida diligencia es ampliamente reconocido y utilizado por los órganos internacionales y reviste particular importancia en los casos de violencias hacia las mujeres. A continuación analizaremos otra de sus facetas más trascendentes en lo que hace a nuestro interés: su utilización para analizar la responsabilidad estatal ante hechos de violencia hacia las mujeres cometidos por particulares.

\section{2.- La debida diligencia y la responsabilidad estatal por actos de particulares}

La responsabilidad del Estado con respecto a las violencias contra las mujeres, puede generarse a raíz de actos $u$ omisiones de agentes estatales o de particulares en determinadas circunstancias.

Se ha sostenido que tradicionalmente los Estados solo han sido responsables de sus propias acciones o de las acciones de sus funcionarixs (Abdul Aziz y Moussa, 2016:1) y

\footnotetext{
${ }^{87} \mathrm{La}$ CIDH señala la obligación estatal de adoptar las medidas necesarias para modificar los patrones socioculturales de comportamiento, eliminar los prejuicios y los roles estereotipados que se imponen.
} 
se ha caracterizado la definición de un campo de responsabilidad jurídica estatal por crímenes de particulares como un tema espinoso (Abramovich, 2010: 168).

Abordaremos aquí este aspecto, a la luz de la normativa pertinente y de las producciones de los mecanismos y órganos de protección y los especializados en la temática.

Como hemos visto el Estado tiene la obligación de respetar los derechos de las mujeres, por lo que será responsable de los actos u omisiones de los órganos y agentes estatales que constituyan violencia contra la mujer. También debe implementar medidas para prevenir que ello suceda (Comité Cedaw, 1992: pto. 8; 2017: pto. 22 y $23)^{88}$.

Asimismo, los Estados son responsables por los actos $u$ omisiones de agentes privados facultados por el derecho de ese Estado para ejercer atribuciones del poder público ${ }^{89}$. Por otro lado los Estados también son responsables ante los actos u omisiones de particulares en relación a sus obligaciones (las del Estado) de la debida diligencia.

Como hemos dicho en el apartado anterior el principio de la debida diligencia cobra trascendental relevancia por ser a partir de las obligaciones que de él se desprenden que se avanza en responsabilizar a los Estados por actos de particulares.

La Relatora Especial (1995) ha afirmado que el principio de la debida diligencia es la norma "que se ha aceptado como medida para evaluar la responsabilidad del Estado en las violaciones de los derechos humanos cometidas por sujetos de derecho privado" (párr. 103, apud Merino Sancho, 2007: 401).

En relación a los derechos de las mujeres esto reviste especial relevancia ya que comúnmente son particulares quienes violan sus derechos a una vida libre de violencias, en este sentido se ha afirmado que la forma más común de violencia

\footnotetext{
${ }^{88}$ El Comité CEDAW aborda expresamente esta aspecto en su RG 19 (punto 8) y en la reciente RG 35, en esta última afirma: "incluye los actos u omisiones de los funcionarios de los poderes ejecutivo, legislativo y judicial (...) Además de garantizar que las leyes, políticas, programas y procedimientos no discriminan a la mujer (...) los Estados partes deben contar con un marco jurídico y de servicios jurídicos efectivo y accesible para hacer frente a todas las formas de violencia por razón de género contra la mujer cometidas por agentes estatales" (punto 22).

${ }^{89}$ Entre ellos los organismos privados que prestan servicios públicos "como la atención de la salud o la educación, o gestionan el funcionamiento de lugares de detención, se consideran actos atribuibles al propio Estado, al igual que los actos $\mathrm{u}$ omisiones de agentes privados que actúan siguiendo instrucciones o bajo la dirección o el control de ese Estado, en particular al operar en el extranjero" (Comité CEDAW, 2017: pto. 24).
} 
experimentada por las mujeres en todo el mundo es la violencia dentro de la pareja (Secretario General ONU, 2006: párr. 112). La debida diligencia rompe con la división artificial de la 'esfera pública/privada' y la dicotomía entre actores estatales y no estatales (Ertürk, 2006) ya que los Estados tienen el permiso y la obligación de involucrarse en el llamado ámbito privado donde tienen lugar la mayoría de los casos de violencia contra las mujeres y del que los Estados han estado tradicionalmente excluidos (Abdul Aziz y Moussa, 2016:1).

La Recomendación General n 19 del Comité CEDAW (1992) aborda esta cuestión:

de conformidad con la Convención, la discriminación no se limita a los actos cometidos por los gobiernos o en su nombre (...) en virtud del inciso e) del artículo 2 de la Convención, los Estados Partes se comprometen a adoptar todas las medidas adecuadas para eliminar la discriminación contra la mujer practicada por cualesquiera personas, organizaciones o empresas. En virtud del derecho internacional y de pactos específicos de derechos humanos, los Estados también pueden ser responsables de actos privados si no adoptan medidas con la diligencia debida para impedir la violación de los derechos o para investigar y castigar los actos de violencia y proporcionar indemnización. (pto. 9)

Esta RG fue utilizada por el Comité Cedaw en casos de violencia doméstica para responsabilizar a los Estados, así en el caso Şahide Goekce vs. Austria (2007), en el cual concluyó que: "Ios actos que tiene ante sí revelan una violación de los derechos de la difunta Şahide Goekce a la vida y la integridad física y mental con arreglo al apartado a) y los apartados c) a f) del artículo 2 y el artículo 3 de la Convención considerados en conjunción con el artículo 1 de la Convención y la Recomendación general № 19 del Comité" (pto. 12.3); en el caso Fatma Yildirim vs. Austria (2007) llegó a la misma conclusión en términos idénticos a los enunciados (pto. 12.1.6) ${ }^{90}$.

\footnotetext{
${ }^{90} \mathrm{En}$ el caso A. T. vs. Hungría (2005) también de violencia doméstica contra la mujer, el Comité concluyó que "las obligaciones del Estado parte que se establecen en los apartados a), b) y e) del artículo 2 de la Convención se extienden a la prevención y la protección de la violencia contra la mujer, obligaciones que, en el presente caso, no se han cumplido, lo cual constituye una infracción de los derechos humanos y las libertades fundamentales de la autora, especialmente del derecho a la seguridad de su persona" (pto. 9.2.), el Comité considera que el Estado parte no ha cumplido sus obligaciones y así ha infringido los derechos de la autora reconocidos en los apartados a), b) y e) del artículo 2 y en el apartado a) del artículo 5 junto con el artículo 16 de la Convención (párr. 9.3 y 9.6).
} 
En su Recomendación General n 35 (2017) el Comité retoma aquella (la RG 19) y avanza en relación a los actos $u$ omisiones de agentes privados que pueden generar responsabilidad internacional del Estado (pto. 24) y afirma:

los Estados partes serán considerados responsables en caso de que no adopten todas las medidas apropiadas para prevenir, investigar, enjuiciar, castigar y ofrecer reparación por los actos u omisiones de agentes no estatales que den lugar a la violencia por razón de género contra la mujer (...) El hecho de que un Estado parte no adopte todas las medidas adecuadas (...) en los casos en que sus autoridades tengan conocimiento o deban ser conscientes del riesgo de dicha violencia, o el hecho de que no investigue, enjuicie y castigue a los autores ni ofrezca reparación a las víctimas y supervivientes de esos actos, constituye un permiso tácito o una incitación a cometer actos de violencia por razón de género contra la mujer. Tales fallos u omisiones constituyen violaciones de los derechos humanos. (p. 10) ${ }^{91}$

En el sistema regional de protección de los DDHH también se ha afirmado que la responsabilidad de los Estados de actuar con la debida diligencia frente a actos violentos "se extiende a las acciones de actores no estatales, terceros y particulares" (CIDH, 2007: pto. 29).

Tanto la CIDH como la Corte IDH han utilizado el concepto de la debida diligencia para abordar y pronunciarse sobre casos y situaciones de violencias contra las mujeres ejercida por particulares. Son numerosos los precedentes en ese sentido ${ }^{92}(\mathrm{CIDH}, 2011$ : párr. 125).

\footnotetext{
${ }^{91}$ Puntualiza que: “En virtud de la obligación de diligencia debida, los Estados partes deben adoptar y aplicar diversas medidas para hacer frente a la violencia por razón de género contra la mujer cometida por agentes no estatales, lo que comprende contar con leyes, instituciones y un sistema para abordar dicha violencia y garantizar que funcionan de manera eficaz en la práctica y que cuentan con el apoyo de todos los agentes y órganos del Estado que hacen cumplir las leyes con diligencia" (p. 10).

${ }^{92}$ Para nosotrxs son particularmente relevantes el caso Jessica Lenahan c. Estados Unidos (2011) y el caso María Da Penha Maia Fernandes c. Brasil (2001) (ambos abordados por la CIDH), por tratarse de casos de violencia doméstica hacia las mujeres. Vale resaltar que es prolifera la producción de los órganos interamericanos en el aspecto abordado, así podemos mencionar: $\mathrm{CIDH}$, caso Claudia Ivette Gonzalez y Otros (México), 9 de marzo de 2007, párrs. 160-255; CIDH, Situación de los Derechos Humanos de la Mujer en Ciudad Juárez, México: El Derecho a No Ser Objeto de Violencia y Discriminación, 2003, párr. 104; CIDH, Las mujeres frente a la violencia y la discriminación derivadas del conflicto armado en Colombia, 2006, párr. 24; CIDH, Informe sobre los derechos de las mujeres en Chile: la igualdad en la familia, el trabajo y la política, 2009, párr. 44; CIDH, El derecho de las mujeres a una
} 
La CIDH (2011) ha señalado que el principio de la debida diligencia "ha sido crucial" para definir las circunstancias en que el Estado puede estar obligado a prevenir actos $u$ omisiones de particulares y a responder a ellos. Los casos de violencia contra las mujeres cometidos por particulares requieren un análisis integral de las obligaciones jurídicas de los Estados de actuar con la debida diligencia requerida para prevenir, investigar, sancionar y reparar (párr. 130). Los deberes estatales en estos casos comprenden "la organización de toda la estructura estatal -incluyendo el marco legislativo, las políticas públicas, los órganos encargados de implementar la ley como la policía, y el sistema judicial- para prevenir y responder de forma adecuada y efectiva a estos problemas" (párr. 125).

En el caso Velázquez Rodríguez (1988) la Corte Interamericana sostuvo que un hecho ilícito violatorio de los derechos humanos obra de un particular puede acarrear la responsabilidad internacional del Estado "no por ese hecho en sí mismo, sino por falta de la debida diligencia para prevenir la violación o para tratarla en los términos requeridos por la Convención" ${ }^{\prime 93}$ (párr. 172). Los Estados tiene la obligación positiva de adoptar las medidas necesarias para asegurar la efectiva protección de los derechos humanos en las relaciones inter-individuales (Corte IDH, 2005: párr. 111).

Sin embargo la Corte IDH (2006) ha afirmado que la obligación estatal de garantía "no implica una responsabilidad ilimitada de los Estados frente a cualquier acto o hecho de particulares", debe atenderse a las circunstancias particulares del caso y a la concreción de dichas obligaciones. Los deberes de adoptar medidas de prevención y protección de los particulares en sus relaciones entre sí se encuentran condicionados al conocimiento de una situación de riesgo real e inmediato para un individuo o grupo de individuos determinado y a las posibilidades razonables de prevenir o evitar ese riesgo (párr. 123) ${ }^{94}$.

vida libre de violencia y discriminación en Haití, 2009, párr. 80. Corte IDH. Caso González y otras (“Campo Algodonero") Vs. México. Sentencia de 16 de noviembre de 2009 (CIDH, 2011: párr. 125).

${ }^{93}$ Se refiere a la Convención Americana de Derechos Humanos.

${ }^{94} \mathrm{La} \mathrm{CIDH}$ sostiene que para establecer dicha imputabilidad internacional de actos de terceros como violaciones atribuibles al Estado, la Corte IDH se ha basado en la doctrina de la Corte Europea. Dicha doctrina sugiere que puede aplicarse la responsabilidad estatal de violaciones cometidas por terceros cuando se demuestra que el Estado tenía conocimiento (o debían haberlo tenido) de una situación de riesgo real e inmediato y no adoptó medidas razonables para evitarlo (CIDH, 2005: parr.31). 
Repasando: Los Estados tienen obligación de tomar medidas para garantizar y proteger efectivamente, con la debida diligencia, los derechos en las relaciones entre Ixs particulares. Cuando el Estado incumple esta función de protección y garantía puede ser responsabilizado por actos de particulares, en determinadas circunstancias.

La Corte IDH en la paradigmática sentencia en el caso "Campo algodonero", referido anteriormente, ha abordado nuevamente los requisitos que deben reunirse para que pueda realizarse esa atribución de responsabilidad: conocimiento de una situación de riesgo real e inmediato para un individuo o grupo de individuos determinado y posibilidades razonables de prevenir o evitar ese riesgo (pto. 280). Pero, como hemos dicho, en virtud del deber de debida diligencia reforzado que establece el art. 7 de la CBDP (al que la Corte vuelve a referirse en el punto 284 de su sentencia), algunos de los requisitos se ven redefinidos, es decir: dicho deber reforzado debe tenerse en cuenta para analizar también los requisitos que deben cumplirse para la atribución de responsabilidad al Estado por actos de particulares. Así en este caso la Corte tiene en cuenta el contexto para analizar el requisito del conocimiento del riesgo real e inminente, y también al analizar las medidas razonables que se debían haber tomado para encontrar a las mujeres con vida.

Abramovich (2010) entiende que la Corte adhiere en este caso a la doctrina del riesgo previsible y evitable ${ }^{95}$ (aunque la propia Corte cita precedentes que expresan otros criterios de atribución de responsabilidad) (p. 168). Pero, como hemos dicho, lo hace con las particularidades que la obligación reforzada del art. 7 de la CBDP introduce en el análisis de sus requisitos ${ }^{96}$.

La Corte analiza la actuación estatal en relación al contexto y concluye que el Estado no actuó con la debida diligencia requerida. Finalmente considera que hay atribución

\footnotetext{
${ }^{95}$ Sostiene este autor que habría 3 doctrinas de atribución de responsabilidad a los Estados por acciones de particulares: la doctrina de la complicidad, la del riesgo previsible y evitable, y una intermedia: la del riesgo creado (p. 168).

${ }^{96} \mathrm{Al}$ repasar los requisitos la Corte deja en claro que no se puede responsabilizar al Estado si este no tuvo conocimiento del riesgo real e inminente que corrían las victimas, en particular antes de su desaparición, es decir no basta con el riesgo general que existe, con el contexto de violencia existente, sino que se exige un riesgo particularizado. Es a partir de que el Estado tomó conocimiento de este riesgo (luego de la desaparición) que la Corte entiende que está en condiciones de responsabilizarlo por los hechos de los particulares al no haber actuado con la debida diligencia estricta que el contexto del caso ameritaba y las obligaciones reforzadas del art. 7 de la CBDP imponían.
} 
de responsabilidad al Estado, por actos de particulares, y que el mismo violó los derechos a la vida, integridad personal y libertad personal en relación con la obligación general de garantía (pto. 602, parr. 4).

Reviste particular interés la trascendencia que la Corte IDH le atribuye al contexto de violencia hacia las mujeres existente en Ciudad Juárez (el cual había sido acreditado a lo largo del proceso, así como también el conocimiento del mismo por las autoridades estatales) para analizar el deber de debida diligencia del Estado. Allí se evidencia la perspectiva de género que ha adoptado la Corte para abordar los hechos de este caso. En otro orden de cosas queremos señalar la relevancia de la sentencia cuando le recrimina al Estado mexicano no haber demostrado la adopción de medidas efectivas de prevención (pto. 279), acercándose de este modo el deber de prevención, reconocido expresamente por la Corte como un deber de medio, a uno de resultado. Vázquez Camacho (2011) afirma que esta exigencia es una implicancia (entre otras) del estándar más estricto construido por la Corte al aplicar el art. 7 de la CBDP (p. 540) ${ }^{97}$. Esta exigencia reviste gran potencialidad sobre todo teniendo en cuenta la realidad de muchos países latinoamericanos donde se adoptan leyes y medidas formales en relación a la violencia hacia las mujeres, pero no hay políticas públicas adecuadas y pertinentes.

\footnotetext{
${ }^{97}$ Sostiene que: "cuando se trata de un caso de discriminación histórica por razón de género hacia un grupo determinado o determinable y vulnerable, la obligación de prevención razonable será considerada cumplida si el Estado prueba la efectividad de las medidas adoptadas para evitar el riesgo, de forma que la obligación de prevención deja de ser meramente una obligación de medio y se acerca más a una de resultado" (p. 540). Abramovich (2010) afirma que "el deber de debida diligencia reforzado parece operar también sobre la evitabilidad del riesgo, esto es, sobre los factores que contribuyen a prevenir la materialización del riesgo y que están según la Corte en la órbita del propio Estado (...) En Campo Algodonero resulta clara la vinculación entre el incumplimiento de los deberes de adopción de políticas públicas, de mecanismos idóneos y efectivos de protección judicial y de adecuación normativa, con las circunstancias que contribuyen a que las agencias públicas no logren prever ni evitar crímenes" (p. 178).
} 
Hasta aquí hemos descripto el marco general y los principios desde los que se debe abordar la cuestión de las obligaciones estatales en relación al derecho de las mujeres a una vida libre de violencias.

Nos proponemos ahora adentrarnos en el análisis del contenido de las distintas obligaciones que los Estados deben cumplir siempre bajo el estándar de la debida diligencia $^{98}$.

\section{1.- Introducción: Respetar y Garantizar}

Los Estados tienen distintas obligaciones en relación al derecho de las mujeres a una vida libre de violencias reconocido en el artículo 3 de la Convención de Belem Do Pará. En primer lugar podemos señalar la obligación de respetar este derecho. Así lo establece el artículo 1.1 de la $C A D H$, el artículo 7 inc. a de la $\operatorname{CBDP}^{99}$ y el artículo 2 d) de la CEDAW ${ }^{100}$.

La Corte IDH (1988) se ha referido a la obligación de respetar los derechos y libertades como la primer obligación asumida por los Estados (párr. 165) ${ }^{101}$ y ha sostenido que "en toda circunstancia en la cual un órgano o funcionario del Estado o de una

\footnotetext{
${ }^{98}$ La Relatora Especial Radhika Coomaraswamy (1999) afirma que en sus visitas a los territorios ha tratado de evaluar el cumplimiento por los Estados de la norma de la debida diligencia en relación a la violencia contra la mujer ejercida por particulares, para lo cual envió preguntas a los Estados y luego evaluó la información recibida (pto. 25). Yakin Ertürk, la Relatora Especial siguiente, menciona en su informe del 2006 dicha lista y afirma que en la misma se enumeran una serie de consideraciones para determinar si los Estados cumplen las obligaciones de la debida diligencia (pto. 32). Aquellas preguntas y estas consideraciones son insumos por demás valiosos para el análisis que aquí realizamos.

${ }^{99}$ “Los Estados Partes condenan todas las formas de violencia contra la mujer y convienen en adoptar, por todos los medios apropiados y sin dilaciones, políticas orientadas a prevenir, sancionar y erradicar dicha violencia y en llevar a cabo lo siguiente:

a. abstenerse de cualquier acción o práctica de violencia contra la mujer y velar por que las autoridades, sus funcionarios, personal y agentes e instituciones se comporten de conformidad con esta obligación".

${ }^{100}$ “los Estados partes, sus órganos y agentes deben abstenerse de incurrir en todo acto o práctica de discriminación directa o indirecta contra la mujer y velar por que las autoridades e instituciones públicas actúen de conformidad con esa obligación".

${ }^{101}$ En su sentencia del 29 de julio de 1988 en el caso Velázquez Rodríguez Vs. Honduras señaló que: "Conforme al artículo 1.1 es ilícita toda forma de ejercicio del poder público que viole los derechos reconocidos por la Convención" (párr. 169).
} 
institución de carácter público lesione indebidamente uno de tales derechos, se está ante un supuesto de inobservancia del deber de respeto" (párr. 169).

Asimismo el Comité Cedaw (2010) puntualiza ${ }^{102}$, en lo que aquí nos interesa, que dicha obligación requiere que los Estados "se abstengan de elaborar leyes, políticas, normas, programas, procedimientos administrativos y estructuras institucionales que directa 0 indirectamente priven a la mujer del goce de sus derechos civiles, políticos, económicos, sociales y culturales en pie de igualdad con el hombre" (párr. 9).

Los Estados también tienen la obligación de garantizar el libre y pleno ejercicio de los derechos reconocidos a toda persona sujeta a su jurisdicción (Corte IDH, 1988: párr. 166). Esta obligación "puede ser cumplida de diferentes maneras, en función del derecho específico que el Estado deba garantizar y de las particulares necesidades de protección" (Corte IDH, 2009: párr. 236).

La Corte IDH (1988) ha señalado que esta es la segunda obligación de los Estados (párr. 166). La cual no se agota con la existencia de un orden normativo sino que requiere una conducta gubernamental "que asegure la existencia, en la realidad, de una eficaz garantía del libre y pleno ejercicio de los derechos humanos" (párr. 167). En este sentido ha señalado que:

implica el deber de organizar todo el aparato gubernamental y, en general, todas las estructuras a través de las cuales se manifiesta el ejercicio del poder público, de manera tal que sean capaces de asegurar jurídicamente el libre y pleno ejercicio de los derechos humanos. (párr. 166)

Como consecuencia de esta obligación los Estados deben prevenir, investigar y sancionar toda violación de los derechos reconocidos y procurar, además, el restablecimiento, si es posible, del derecho conculcado y, en su caso, la reparación de los daños producidos por la violación de los derechos humanos (Corte IDH, 1988: párr. 166 y 2009: párr. 236). A continuación abordaremos cada uno de los aspectos mencionados.

\footnotetext{
102 en su Recomendación General n² 28.
} 


\section{2.- Prevenir}

La prevención incluye medidas gubernamentales para evitar que la violencia contra la mujer ocurra (Abdul Aziz y Moussa, 2016: 15). Estas pueden ser sumamente variadas.

La CIDH (2007) ha sostenido que entre los deberes del Estado de actuar con debida diligencia para prevenir o transformar situaciones estructurales o extendidas de violencia contra las mujeres, deben considerarse comprendidas las medidas especiales de promoción de la igualdad y la erradicación de patrones sociales y culturales que favorecen la discriminación de las mujeres en la sociedad (pto. 101).

En el "Marco y directrices de debida diligencia sobre la responsabilidad del Estado para la eliminación de la violencia contra las mujeres", trabajo coordinado por Abdul Aziz y Moussa $(2016)^{103}$, se afirma que:

Los programas de prevención efectivos sensibilizan sobre la [violencia contra las mujeres] y proporcionan información acerca de los servicios y la protección legal disponible después del incidente. Estos programas también abordan los factores de riesgo subyacentes y las causas de la [violencia contra las mujeres] y, a menudo, incluyen capacitación y campañas de educación. (p.15)

Asimismo se detallan las características y alcances que deben revestir las medidas estatales destinadas a la prevención de la violencia contra las mujeres para cumplir con la obligación de la debida diligencia. Como síntesis de todo el desarrollo realizado en dicho estudio podemos señalar: Las estrategias preventivas deben abordar las causas subyacentes de las violencias contra las mujeres, buscando eliminar su tolerancia y aceptación; deben tener como objetivo transformar las percepciones sociales, las actitudes y los comportamientos que la causan, apoyan y toleran. Se afirma que los programas preventivos deben propender a la eliminación de los factores de riesgo fortaleciendo los derechos económicos y legales de las mujeres, eliminando las desigualdades de género en el acceso al empleo formal asalariado y la

\footnotetext{
${ }^{103}$ Este documento es producto del trabajo realizado en el marco del Proyecto de la debida diligencia (dirigido por Zarizana Abdul Aziz y Janine Moussa) donde se analizan los componentes de cada una de las obligaciones de la debida diligencia, y se abordan las medidas tomadas por los Estados de distintos puntos del mundo (alrededor de 30-40 países), información recabada a partir de encuestas realizadas.
} 
educación secundaria. Se destaca la trascendencia de programas participativos que pueden acabar con el aislamiento y el estigma que sufren las mujeres víctimas/sobrevivientes. Así como también la importancia de ampliar el alcance y que los programas de prevención aborden las diferentes formas de violencia hacia las mujeres y se dirijan a todxs Ixs actorxs y a todas las beneficiarias (Abdul Aziz y Moussa, 2016: 15 a 26).

Se hace hincapié en la importancia de la promulgación de una legislación integral, y se afirma que su "implementación adecuada y su cumplimiento es una estrategia de prevención efectiva, sobre todo si los perpetradores están seguros de que sus actos no quedarán impunes" (p.27).

Se señala que debe incorporarse el concepto de interseccionalidad y prestarse especial atención y diseñar políticas públicas específicas para los grupos de riesgo (p. 31 a 33). Así como la importancia de mantener estrategias sostenidas (con acciones en distintos ámbitos) y no solo respuestas temporales. Afirma que los planes nacionales de acción y los mecanismos institucionales son estrategias "buenas y sostenibles" (p. 33 y 34).

Enfatiza la importancia de que desde el Estado se colabore con las organizaciones feministas/de mujeres, ya que desde allí se han impulsado las investigaciones y estrategias de vanguardia sobre el punto (p. 35). Y resalta la relevancia de la producción y análisis de datos (sobre la prevalencia, las causas y las consecuencias de la violencia), ya que son fundamentales para el diseño de los programas de prevención así como para su evaluación (p. 29 a 31).

La importancia de la producción de información estadística ${ }^{104}$ para prevenir la violencia contra las mujeres también ha sido destacada por la CIDH (2007) reconociendo en ella un insumo fundamental para "vigilar la situación social", diseñar y evaluar políticas públicas (pto. 42).

La Relatora Especial Yakin Ertürk (2006), al analizar la situación a nivel mundial, concluye que se ha hecho relativamente poco en lo que se refiere a la obligación de

\footnotetext{
${ }^{104}$ Contemplada en el artículo 8 inciso $\mathrm{H}$ de la CBDP que establece la obligación de"garantizar la investigación y recopilación de estadísticas y demás información pertinente sobre las causas, consecuencias y frecuencia de la violencia contra las mujeres, con el fin de evaluar la eficacia de las medidas para prevenir, sancionar y eliminar la violencia contra las mujeres y de formular e introducir los cambios necesarios".
} 
prevención ${ }^{105}$, en particular en relación a la obligación de transformar las estructuras y los valores patriarcales que perpetúan y consolidan la violencia sexista ${ }^{106}$ (pto. 15).

\section{3.- Proteger}

La obligación de proteger con la debida diligencia (también denominada prevención secundaria) se centra en evitar que ocurran nuevos actos de violencia y en asegurar que las mujeres que la han padecido o están en riesgo concreto de sufrirla tengan acceso a la justicia y a servicios adecuados y oportunos.

La obligación de proteger con la debida diligencia exige que los Estados garanticen (a las mujeres que sufrieron violencia o corren el riesgo concreto de sufrirla): disponibilidad y accesibilidad a líneas de ayuda directas, a servicios de atención a la salud (física y psicológica) y apoyo, que respondan a sus necesidades inmediatas, las protejan contra otros daños y se ocupen de las consecuencias; disponibilidad y accesibilidad a procedimientos judiciales adecuados y oportunos, a las órdenes de protección (restricción o expulsión del agresor), para lo cual es importante que exista un marco normativo idóneo; asistencia jurídica de calidad, asistencia material inmediata (centros de acogida, ropa, manutención de Ixs hijxs, empleo, educación) (Ertürk, 2006: ptos. 82 y 83; Abdul Aziz y Moussa, 2016: 36), servicios especializados apropiados para la atención, refugios, servicios de orientación para toda la familia, servicios de custodia y cuidado de Ixs niñxs y adolescentes afectadxs (artículo 8 inc. d de la (BDP), así como recursos judiciales para conminar al agresor a cesar en sus acciones y proteger la integridad física, la libertad, la vida y la propiedad de las mujeres $^{107}$ (artículo 7 inc. d de la CBDP; CIDH, 2007: pto. 56). Asimismo la policía, el

\footnotetext{
${ }^{105}$ Refiere que en relación a esta obligación los Estados han tratado de cumplir mediante la adopción de leyes específicas, la realización de campañas de sensibilización y de capacitaciones para grupos profesionales específicos (pto. 38). Sin embargo afirma que hay pocos datos que demuestren que los Estados están participando activamente para generar transformaciones en la sociedad (pto. 46).

${ }^{106}$ Y señala que: "la aplicación de la norma de la debida diligencia ha tendido a limitarse a responder a la violencia contra la mujer una vez que se ha producido, y en este contexto se ha concentrado en las reformas legislativas, el acceso a la justicia y la provisión de servicios".

${ }^{107} \mathrm{Se}$ ha sostenido que esta obligación debe ser interpretada "como un aspecto particular de la obligación de garantizar el acceso a mecanismos idóneos y efectivos de protección judicial conforme lo dispone el artículo 25 de la Convención Americana. En tal sentido, una dimensión particular del derecho a la protección judicial, consiste en el derecho a acceder a una tutela cautelar efectiva" (CIDH, 2007: pto. 56).
} 
personal médico y otros servicios de emergencia deben actuar rápida e inmediatamente; los equipos de emergencia deben estar capacitados para intervenir con eficacia, se debe garantizar la capacitación continuada. También es muy importante la coordinación entre los distintos servicios intervinientes (Abdul Aziz y Moussa, 2016: 36 y 48).

En situaciones en las que es evidente que determinadas mujeres y niñas pueden ser víctimas de violencia, los órganos encargados de aplicar la ley tienen la obligación de establecer mecanismos de protección efectivos y apropiados para impedir que se produzcan otros daños (Ertürk, 2006: 82).

La Relatora Especial Ertürk (2006) al analizar las conductas de los Estados en relación al cumplimiento de su obligación de debida diligencia en cuanto a la protección afirma que los mismos adoptan como principales medidas la provisión de servicios para la mujer, por ejemplo líneas telefónicas directas, atención de salud, centros de asesoramiento, asistencia letrada, centros de acogida, órdenes de interdicción y ayuda financiera para las víctimas (pto. 47).

\section{4.- Investigar, juzgar y sancionar}

Los Estados también tienen la obligación de investigar, juzgar y castigar con la debida diligencia los actos de violencias contra las mujeres.

Se ha señalado que para que sean efectivas las medidas adoptadas en relación a las violencias contra las mujeres se debe responder a ella en tanto violación de derechos humanos (Abdul Aziz y Moussa, 2016:98).

Señala la Relatora Especial Ertürk (2006) que esta obligación "ha sido considerada generalmente por los Estados como la obligación de aprobar o modificar leyes y reforzar la capacidad y las competencias de la policía, los fiscales y los magistrados" (pto.50).

La investigación se refiere a la obligación de llevar a cabo una acción eficaz para establecer los hechos y se debe ejercer de manera efectiva, pronta, imparcial y exhaustiva (Abdul Aziz y Moussa, 2016: 98). Se ha señalado que es una obligación de 
medios y no de resultado (Cejil y MPF, 2013) y que es una etapa crucial en casos de violencia contra las mujeres (CIDH, 2007: pto. 38).

Debe ser llevada adelante con debida diligencia, los alcances e implicancias de la misma estarán dados por las características de la situación a abordar.

Las investigaciones deben ser oportunas, y deben cumplir con requisitos y estándares que la Corte IDH y la $\mathrm{CIDH}$ han ido elaborando al abordar casos concretos ${ }^{108}$, así como también con las elaboraciones y recomendaciones de otros organismos ${ }^{109}$.

En este sentido, en relación a los estándares sobre la obligación de investigar con debida diligencia, podemos mencionar que: la investigación debe llevarse a cabo de manera inmediata, exhaustiva, seria e imparcial; por autoridades competentes e imparciales, con perspectiva de género y que articulen entre $s^{110}$.Debe realizarse con seriedad y no como una simple formalidad, debe tener un sentido y ser asumida por el Estado como un deber jurídico propio y no como una simple gestión de intereses particulares, que dependa de la iniciativa procesal de la víctima o de sus familiares o del aporte privado de elementos probatorios, sin que la autoridad pública busque efectivamente la verdad. En cuanto a las evidencias se deben recopilar y analizar todas las pruebas materiales y documentales y las declaraciones de Ixs testigxs. El Estado puede ser responsable por no "ordenar, practicar o valorar pruebas" que pueden ser fundamentales para el debido esclarecimiento de los hechos (CIDH, 2007: párr. 40, 41, 46 y 47$)$.

Basándose en instrumentos internacionales producidos y aprobados en el marco de la Organización de Naciones unidas, la CIDH (2007) ha destacado otros elementos a ser tenidos en cuenta, entre ellos: las autopsias deben ser adecuadas y se deben preservar evidencias específicas en caso de sospecha de violencia sexual; Ixs fiscales deben evadir cualquier tipo de discriminación en su trabajo en base a consideraciones

\footnotetext{
${ }^{108}$ Así lo han hecho en los casos "Ríos y otros", "Rosendo Cantú y otra”, "Villagrán Morales" y "Campo Algodonero" en relación a muertes violentas.

${ }^{109} \mathrm{Vgr}$. ONU (1998): "Estrategias y medidas prácticas, modelos para la eliminación de la violencia contra la mujer en el campo de la prevención del delito y la justicia penal". A/RES/52/86.

${ }^{110} \mathrm{La} \mathrm{CIDH} \mathrm{(2007)} \mathrm{ha} \mathrm{referido} \mathrm{que:} \mathrm{"cuando} \mathrm{tales} \mathrm{investigaciones} \mathrm{no} \mathrm{son} \mathrm{llevadas} \mathrm{a} \mathrm{cabo} \mathrm{por} \mathrm{autoridades}$ apropiadas y sensibilizadas en materia de género o estas autoridades no colaboran entre sí, se registran retrasos y vacíos clave en las investigaciones, que afectan negativamente el futuro procesal del caso" (pto. 46).
} 
políticas, sociales, religiosas, raciales, culturales y sexuales; los gobiernos deben poner a disposición abogadxs y servicios legales destinados a personas en situación de desventaja económica y social; la policía debe tener como consideración prioritaria la seguridad de la víctima y sus familiares en las decisiones relacionadas con el arresto y detención del agresor; el Estado debe determinar responsabilidades y sancionar cuando la policía no actúa en concordancia con el marco normativo. Se destaca la importancia de proteger la salud mental y física de las víctimas durante la duración del proceso penal, incluyendo la etapa de investigación a fin de evitar la revictimización; así como también de la adopción de medidas para proteger la seguridad, la privacidad y la intimidad de las víctimas; se debe proporcionar a las víctimas información sobre sus derechos en todas las fases del proceso (CIDH, 2007: párr. 47, 53 y 54).

El juzgamiento se refiere a la obligación de ejercer jurisdicción penal contra los responsables de los abusos contra los derechos humanos (Abdul Aziz y Moussa, 2016: 98).

En este sentido los Estados deben tomar medidas para, entre otras cosas: garantizar que los procedimientos penales no sean traumático para las víctimas; hacer frente a los factores que influyen en que las mujeres no realicen la denuncia o luego no continúen con el proceso; asegurar que la policía facilite el involucramiento positivo temprano de la víctima; asegurar que los recursos y los procedimientos legales sean accesibles a las víctimas y que las autoridades actúen dentro de un marco legal donde las garantías del debido proceso sean respetadas; proteger la privacidad de las mujeres de la divulgación pública o el trato excesivamente duro durante la investigación y los procesos judiciales; proporcionar asistencia jurídica gratuita; reducir el retraso en todas las etapas del proceso; establecer unidades especializadas policiales, fiscalías y tribunales (o jueces) para trabajar de forma exclusiva (o principalmente) en situaciones de violencia contra las mujeres, integradas por personal capacitado y adecuadamente financiadas. Lxs investigadorxs y Ixs fiscales deben ser capaces de tener en cuenta las percepciones, necesidades y deseos de las víctimas así como las obligaciones internacionales del Estado. La velocidad y la calidad de la intervención de la policía son 
cruciales. Asimismo se debe asegurar una justa carga de la prueba y de estándares probatorios $^{111}$ (Abdul Aziz y Moussa, 2016: 98 a 100).

Cabe destacarse aquí, nuevamente, la importancia de que todxs Ixs actorxs institucionales intervinientes coordinen y colaboren estrechamente entre sí.

Los Estados también tienen la obligación de aplicar sanciones, es decir de imponer un castigo a los perpetradores, como consecuencia de haber ejercido violencia contra una mujer. Las mismas pueden ser civiles, penales, administrativas o de "otro tipo" (por ejemplo, sanciones comunitarias o sociales) "siempre que garanticen consecuencias negativas para el agresor" (Abdul Aziz y Moussa, 2016: 100) ${ }^{112 .}$.

Para cumplir con esta obligación los Estados deben: asegurar la responsabilidad de los perpetradores; que exista una certeza de castigo. Se ha afirmado que se debe garantizar que la sanción sea proporcional al delito y que cumpla con los objetivos de la sanción: la prevención de la reincidencia, la rehabilitación de los perpetradores y la disuasión de otros individuos ${ }^{113}$; así como también la necesidad de ampliar el régimen de condena disponible más allá del encarcelamiento, cuando sea apropiado y de asegurar que la condena esté basada en el principio de que la violencia contra las mujeres no es justificable (Abdul Aziz y Moussa, 2016: 100 y 101).

En su informe de fondo sobre el caso María da Penha Maia Fernandes c. Brasil (2001) la $\mathrm{CIDH}$ sostuvo que la inefectividad judicial antes casos de violencia contra las mujeres crea un ambiente de impunidad que facilita la violencia "al no existir evidencias socialmente percibidas de la voluntad y efectividad del Estado como representante de la sociedad, para sancionar esos actos" (párr. 56). Asimismo ha definido a la impunidad como

\footnotetext{
${ }^{111}$ Se señala también que si bien en muchos sistemas jurídicos el fiscal tiene el derecho de decidir sobre la conveniencia de proceder con el juzgamiento de un delito "menor" esta discrecionalidad es problemática en los casosde violencia doméstica, ya que la misma muchas veces consiste en ofensas repetitivas que de forma aislada pueden considerarse 'menores' (Abdul Aziz y Moussa, 2016:99).

${ }^{112}$ Se ha afirmado que el encarcelamiento es la forma más común de condena para todas las formas de violencia, aunque muchas veces no es lo que las mujeres prefieren (Abdul Aziz y Moussa, 2016: 100 y 101).

${ }^{113}$ Se ha sostenido que "Las sentencias que no cumplan con estos objetivos fomentan la reincidencia, una sensación de impunidad y la normalización de la [violencia contra las mujeres] en el imaginario colectivo, lo que resulta en su repetición en nuestra vida cotidiana" (Abdul Aziz y Moussa, 2016: 100).
} 
una infracción de las obligaciones que tienen los Estados de investigar las violaciones, adoptar las medidas apropiadas respecto de sus autores, especialmente en la esfera de la justicia, para que sean procesados, Juzgados y condenados a penas apropiadas, de garantizar a las víctimas recursos eficaces y la reparación del perjuicio sufrido y de tomar todas las medidas necesarias para evitar la repetición de dichas violaciones. (CIDH, 2001: párr. 86)

En el mismo sentido, dicho órgano de protección, citando precedentes de la Corte IDH, ha afirmado que "la ausencia de una investigación y sanción se constituye en un incumplimiento de la obligación del Estado de garantizar el libre y pleno ejercicio de los derechos humanos de las víctimas y de sus familiares, y respecto de la sociedad para conocer lo ocurrido" (CIDH, 2007: pto. 40).

Coincidentemente la Corte IDH (1998) ha sostenido que el Estado tiene la obligación de combatir la impunidad"114 "por todos los medios legales disponibles ya que (...) propicia la repetición crónica de las violaciones de derechos humanos y la total indefensión de las víctimas y sus familiares" (párr. 176).

\section{5.- Reparar}

Las mujeres que han padecido situaciones de violencia de género tienen derecho a una reparación integral. Se ha definido a la reparación como "cualquier forma de remedio o indemnización puesto a disposición de las víctimas/sobrevivientes para hacer frente a los daños o pérdidas sufridas" (Abdul Aziz y Moussa, 2016: 101).

Las medidas de reparación adecuadas dependerán de las circunstancias de cada situación: del daño padecido y las necesidades de la mujer, por ejemplo, y tienen como objetivo eliminar o mitigar los efectos de la violencia, deben ser apropiadas y proporcionales a la violación sufrida (Abdul Aziz y Moussa, 2016: 101; CIDH, 2007: pto. 58).

La CIDH (2007) sostiene que este derecho ha sido afirmado internacionalmente y que la misma debe ser "adecuada, efectiva y rápida". Asimismo, debe ser integral e incluir

\footnotetext{
${ }^{114}$ La cual fue definida por la Corte como una "falta en su conjunto de investigación, persecución, captura, enjuiciamiento y condena de los responsables de las violaciones de los derechos protegidos por la Convención Americana" (Corte IDH, 1998: párr. 176).
} 
las garantías de restitución, indemnización, rehabilitación, satisfacción y no repetición (pto. 58).

EI MESECVI, en su Tercer informe Hemisférico (2017), ha recomendado a los Estados que avancen en la reparación integral del daño provocado por la violencia "incluyendo la adecuada reparación económica a las víctimas y sus familiares, con perspectiva de género de forma que tome en cuenta las necesidades y prioridades específicas de las mujeres víctimas con un enfoque de derechos humanos"115 (p. 211).

Se ha señalado que la obligación de proporcionar reparaciones adecuadas implica: garantizar a la mujer el acceso a remedios penales y civiles; la creación y acceso a servicios efectivos y apropiados de protección, apoyo y rehabilitación; la compensación, la cual puede consistir en una indemnización económica por las lesiones físicas y psicológicas sufridas, por la pérdida del empleo y de oportunidades educativas, por la pérdida de prestaciones sociales, por daños a la reputación y a la dignidad así como por los gastos legales, médicos o sociales incurridos como consecuencia de la violencia (Ertürk, 2006: pto. 84); también incluye las disculpas, la divulgación de la verdad y la verificación de los hechos; los tributos simbólicos; las sanciones a los responsables y el cese de la violencia (Abdul Aziz y Moussa, 2016: 101). El efecto de la reparación no sólo debe ser la restitución, sino también la rectificación de los factores causales subyacentes de las violencias contra las mujeres y la discriminación (Abdul Aziz y Moussa, 2016: 101). Se evidencia aquí, una vez más, la íntima relación existente entre todas las obligaciones estatales.

La Relatora Especial sostiene que este "aspecto de la debida diligencia sigue estando muy poco desarrollado" y que se dispone de pocos datos acerca de la obligación de reparar adecuadamente (Ertürk, 2006: pto. 55).

En el "Marco de la Debida Diligencia" Abdul Aziz y Moussa (2016), luego de analizar la información recabada, concluyen que las mujeres rara vez logran obtener órdenes de indemnización y que, cuando las consiguen, la falta de mecanismos para exigirlas hace que los agresores no paguen. Por esto sostienen que los Estados deben garantizar que las víctimas/sobrevivientes sean indemnizadas. También señalan que los Estados

\footnotetext{
${ }^{115}$ Punto 31 de las "Recomendaciones".
} 
limitan su enfoque a la indemnización monetaria y la sanción de los agresores, pero que deberían ampliar esta mirada y ofrecer diversas formas de reparación (p. 101).

Hemos visto, en este capítulo, que a la luz del principio de la debida diligencia los Estados están obligados a tomar medidas razonables para prevenir las violencias hacia las mujeres, para protegerlas cuando la misma ocurrió o ante el riesgo concreto de padecerla, para investigar, juzgar y sancionar de manera oportuna y adecuada y para reparar a las mujeres afectadas. Estas obligaciones recaen en cabeza del Estado aunque, como hemos dicho, la mayoría de los casos de violencias contra las mujeres son cometidos por particulares. El incumplimiento de las mismas puede acarrear la responsabilidad internacional de los Estados. 
TERCER PARTE

LAS RESPUESTAS DEL ESTADO EN EL PARTIDO DE LA PLATA 
Luego de haber definido, en la sección anterior, las obligaciones que ha asumido el Estado Argentino en relación al derecho de las mujeres a una vida libre de violencias, en esta tercer parte de la tesis desarrollaremos los objetivos específicos II y III de nuestro plan ${ }^{116}$, guiándonos por las preguntas que en el mismo hemos formulado: “¿Cuál es el proceso de la 'ruta crítica' seguido por las mujeres en situación de violencia doméstica? ¿Cuáles son las respuestas estatales que obtienen en el Partido de La Plata?".

Como paso previo a adentrarnos en dicho abordaje nos detendremos en el análisis de la ley de Protección integral $n^{\circ}$ 26485, ya que con su sanción el Estado Argentino dio cumplimiento a uno de los aspectos de los compromisos asumidos internacionalmente y es de plena aplicación en el Partido de La Plata.

Luego procederemos a abordar la respuesta estatal existente en el Partido de La Plata para las mujeres en situación de violencia doméstica: comenzaremos por analizar las políticas públicas implementadas por las gestiones gubernamentales de la Provincia de Buenos Aires y del Municipio de La Plata; un capítulo aparte le dedicaremos a las Comisarías y otro a las instituciones judiciales. En todos ellos analizaremos las características de los dispositivos y de las repuestas que las mujeres obtienen. Así iremos delineando los pasos que las mujeres deben seguir para acceder al mecanismo de protección estatal.

Para finalizar esta tercer parte de nuestra tesis ahondaremos en el análisis de los obstáculos detectados en los capítulos anteriores, profundizando el diálogo entre la información recolectada en nuestra tarea de campo y las producciones teóricas que hemos seleccionado. Asimismo, realizaremos un primer acercamiento entre los obstáculos detectados en las respuestas existentes en el Partido de La Plata y los requisitos y recomendaciones realizados por los órganos y mecanismos especializados y los de protección. Esto con la intención de ir acercándonos a posibles respuestas para la tercer pregunta que nos hemos formulado en nuestro plan: “¿Cumple el Estado con

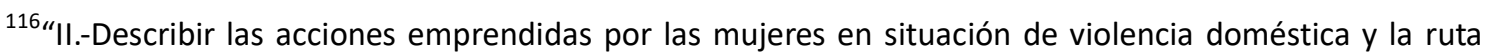
seguida por ellas para encontrar atención y solución a sus problemas de violencia. III.- Indagar las respuestas estatales obtenidas por estas mujeres".
} 
las obligaciones asumidas internacionalmente en relación a la violencia doméstica, en tanto respeto y protección de los Derechos Humanos de las mujeres en este aspecto?". 
Una de las obligaciones que el Estado Argentino ha contraído internacionalmente es la sanción de legislación que proteja y prevenga a las mujeres de actos que las violenten.

En cumplimiento de esta obligación, y también debido al destacable rol que ha tenido en nuestro país el movimiento de mujeres y feminista a la hora de colocar en la agenda estatal la problemática de las violencias hacia las mujeres (Berto, González, Sarmiento, Veiga: 2017), en el año 2009 se sancionó la "Ley de protección integral para prevenir, sancionar y erradicar la violencia contra las mujeres en los ámbitos en que desarrollen sus relaciones interpersonales" ${ }^{117}$ (en adelante: Ley de Protección Integral).

Esta ley tiene como uno de sus objetivos el acceso a la justicia de las mujeres que padecen violencia y su asistencia integral ${ }^{118}$. La ley se reglamentó un año más tarde con el Decreto 1011/2010.

Durante algunos años se debatió si dicha ley era de aplicación en la Provincia de Buenos Aires (Raffo, 2011 y Frías, 2010 apud Ballesteros, 2012) o si por el contrario no lo era (Grau, 2010 apud Ballesteros, 2012). Hemos sostenido que dicha norma siempre fue de aplicación en la Provincia (Ballesteros y De La Vega, 2012: 45) ${ }^{119}$. Este debate quedó saldado por la promulgación, en el año 2012 , de la ley $14.407^{120}$ a través de la cual la Provincia de Buenos Aires adhiere expresamente a la Ley de Protección Integral.

En Argentina la Ley de Protección Integral es la primera que nomina la violencia hacia las mujeres, y lo hace de forma amplia, así en su artículo 5 habla de los tipos de violencia, entre los que incluye: física, sexual, psicológica, económica y patrimonial y simbólica, en su artículo 6 menciona las modalidades: violencia doméstica, violencia

\footnotetext{
${ }^{117}$ Ley $n^{\circ} 26.485$. Sancionada el 11 de marzo de 2009 y promulgada de hecho el 1 de abril de 2009.

${ }^{118}$ Artículo 2, inc. f y g respectivamente.

${ }^{119}$ Téngase presente que la Ley de Protección Integral, en su artículo 1o, establece que sus disposiciones son de orden público y de aplicación en todo el territorio de la República, excepto las disposiciones de carácter procesal del Capítulo II del Título III, que dependen de cada jurisdicción. Las leyes de orden público se conocen también como "leyes imperativas", se caracterizan por prevalecer sobre cualquier acuerdo de la voluntad de las personas sujetas a ellas.

${ }^{120}$ Publicada en el Boletín Oficial de la Provincia de Buenos Aires, 12 de diciembre de 2012.
} 
institucional, violencia laboral, violencia contra la libertad reproductiva, violencia obstétrica, violencia mediática, siempre hacia las mujeres.

Con anterioridad a esta ley las leyes aplicables a las situaciones de violencia contra las mujeres en el marco familiar eran, en la Provincia de Buenos Aires, la Ley provincial 12.569 denominada "Ley de Violencia Familiar" ${ }^{121}$ y en Ciudad de Buenos Aires la ley 24.417 de "Protección contra la violencia familiar", como puede observarse ninguna de ellas nominaba la violencia contra las mujeres.

De este modo las afectaciones diferenciadas que las mujeres padecen (Facio, 1999:8; Ballesteros, 2010:8) y el sufrimiento de las mujeres en situación de violencia doméstica ${ }^{122}$, quedaban invisibilizados (Segato, 2011) tras la institución familiar, la cual históricamente ha ocultado los intereses y derechos de las mujeres (Ferreira, 1992; Viano, 1987).

Las otras violencias contra las mujeres quedaban fuera del discurso jurídico (de la legislación interna), en lo concreto eran subsumidas en las leyes generales. Se invisibilizaba así el sufrimiento de las mujeres y las circunstancias diferenciadas que, en la mayor parte de los aspectos de la vidas, viven las mujeres con respecto a los hombres.

Durante el proceso de elaboración de la Ley de Protección Integral muchas eran las resistencias a que la misma se focalizara exclusivamente en las mujeres. Entendemos que este proceso de disputas, anterior a la sanción de la ley, es un claro ejemplo de la lucha por nominar el sufrimiento de las mismas, se trataba de la lucha por el acceso e inscripción en la narrativa jurídica de las mujeres (Segato, 2011: 3).

El discurso jurídico tiene un lugar privilegiado en relación a la temática en cuestión, ya que se constituye en condición necesaria, aunque no suficiente, para la equidad de sexo-género (Femenías, 2010). En este campo, se ha avanzado en la visibilización (González y Salanueva, 2012: 104), la nominación y el reconocimiento del sufrimiento de las mujeres en situación de violencia, pero falta mucho por andar en relación al despliegue de la función discursiva, performativa, de la ley (Segato, 2011: 1).

\footnotetext{
${ }^{121}$ Publicada en el Boletín Oficial de la Provincia de Buenos Aires el 2 de enero de 2001.

${ }^{122}$ Muy extendido cuantitativamente y muy intenso por lo sostenido en el tiempo y lo dañino para la salud.
} 
La sanción de esta ley no ha implicado un cambio inmediato en la vida de las mujeres en situación de violencia, así como tampoco en el tratamiento de las mismas por parte de Ixs operadorxs judiciales y agentes policiales. Siguiendo a Segato (2011) podemos afirmar que se evidencia aquí lo errado de esa extendida concepción que entiende que basta con que se sancionen leyes para que así se comiencen a resolver determinadas problemáticas, planteando una relación de causa-efecto entre leyes y practicas (causalidad propiamente normativa de la ley) (p. 2).

Este fenómeno se da en toda la región, no solo en Argentina. Así América Latina es una de las regiones del planeta dotadas de una de las legislaciones más avanzadas en relación a violencias contra las mujeres. Son muchos los Estados de ese territorio que han ratificado la CBDP y en la mayoría de los países se han sancionado leyes que abordan la violencia contra la mujer, o tienen por objetivo su sanción (Birgin y Gherardi, 2008: 243). Sin embargo, esto no se traduce en una disminución de los casos de violencia, así como tampoco en una mejora en el tratamiento de las mujeres que emprenden acciones para salir de la situación de violencia en el que se hallan inmersas. Esto ha sido revelado por múltiples estudios como hemos mencionado en el capítulo I de esta tesis.

Para pensar esta realidad es que entendemos más que pertinentes las palabras de Segato. Se impone la necesidad de que la dimensión discursiva de la ley integre parte de nuestro análisis: "su capacidad de impactar y modelar, con las categorías que consagra legislativa y jurídicamente, la sensibilidad ética de las personas" (Segato, 2011: 2).

Pero claro está que, para que esta función pueda desarrollarse, no alcanza con que una ley sea sancionada y conocida por Ixs especialistas en la materia, sino que toman importancia, en este marco, las campañas publicitarias y de difusión de la misma (Segato, 2011: 6).

Podemos decir que aquí radica uno de los puntos débiles en relación a la Ley de Protección Integral: la misma, aún hoy a 9 años de su sanción, es ampliamente desconocida. Es desconocida por la sociedad en general pero también por Ixs 
operadorxs judiciales y agentes policiales que tendrían que aplicarla. De este modo la función discursiva se ve imposibilitada.

Ahora bien, aunque muchas veces el comportamiento de Ixs operadorxs judiciales puede deberse a la falta de formación y al desconocimiento de la normativa específica, muchas otras se debe a las resistencias patriarcales que ellxs expresan. De este modo se oponen y se resisten a convalidar el reconocimiento que oficialmente se ha realizado del sufrimiento de las mujeres. Segato (2011) afirma: "una ley (...) que no consiga representar, interpelar y controlar la ética de las personas y las ideas corrientes sobre lo que es decente o indecente, bueno o malo, no tendrá vigencia real, y será, necesariamente una ley sin eficacia normativa..." (p. 2).

En los últimos años el movimiento feminista y de mujeres se ha dado la tarea de estudiar y entender la ley. Hasta hace poco el reclamo era por legislación protectoria, mientras que la misma ya existía, una vez más: hasta los sectores más interesados y activos en la problemática la desconocían. Muchas organizaciones que abordan la problemática de la violencia hacia las mujeres se han dado la tarea de difundir y publicitar la ley, sin embargo las posibilidades de alcance de estas campañas y actividades sigue siendo marginal.

En el ámbito de la Provincia de Buenos Aires resultan aplicables la Ley provincial 12.569 de "Violencia Familiar", que hemos mencionado más arriba, acotada a las situaciones de violencia en el ámbito del grupo familiar, relaciones de noviazgo y ex parejas (artículos 1 y 2), su decreto reglamentario $2.875^{123}$, y la Ley Nacional 26.485.

La interpretación armónica de la normativa vigente establece un alto estándar de protección y prevención contra las violencias hacia las mujeres.

De dicha normativa surge un régimen de protección para las mujeres en situación de violencia doméstica que comprende: medidas urgentes a dictarse en un término que no puede exceder las 48 horas, incluyéndose entre ellas la exclusión del hogar, la prohibición del acceso al mismo al agresor, el perímetro de exclusión del agresor de los lugares de habitual concurrencia de la mujer, reintegro al hogar si la persona que

${ }^{123}$ Actualizado por los Decretos $436 / 15,686 / 16$ y $165 / 18$. 
padeció la violencia tuvo que salir de él; la fijación de una cuota alimentaria y un régimen de comunicación provisorio, o la suspensión del mismo; la provisión de asistencia legal, médica y psicológica; la prohibición al agresor de tener armas; la creación de un programa de asistencia económica para las mujeres y programas de promoción familiar para sostener de forma temporaria a quien quede a cargo de Ixs hijxs a consecuencia de la violencia; casas de hospedajes que brinden albergue temporario; no exigencia de patrocinio letrado para solicitar las medidas urgentes; gratuidad de las actuaciones, derecho a ser oída por el juez, resolución oportuna, protección judicial urgente y mecanismos para denunciar a Ixs funcionarixs ante el incumplimiento de los plazos y otras irregularidades (arts. 10, 16 y 26 de la Ley 26.485 y arts. 7,7 bis y 20 de la Ley 12.569 ). 


\section{VII.- LAS POLÍTICAS PÚBLICAS EN EL PARTIDO DE LA PLATA}

Hemos visto en el capítulo anterior que en la Provincia de Buenos Aires la interpretación armónica de la normativa vigente establece un alto estándar de protección contra la violencia hacia las mujeres. Sin embargo, los avances legislativos no representan un cambio en la vida de las mujeres maltratadas (Hollweck y Urbancic Baxter, 2006; Sagot, 2000), si no se diseñan e implementan políticas públicas integrales, adecuadas y efectivas, tendientes a sostener a la mujer en el proceso emprendido (Birgin y Gherardi, 2008:242). Esto constituye una necesidad apremiante (Urtazun y Delmas, 2012; Gonzalez y Galletti, 2012) y una obligación del Estado Argentino (Corte IDH, 2009: párr. 258; Ballesteros, Cisneros y Barcaglioni, 2012:11). La Corte IDH ha señalado, en el Caso Campo Algodonero (2009), la exigencia de que los Estados demuestren la efectividad de las medidas tomadas ${ }^{124}$.

La política pública implica cursos de acción y flujos de información relacionados con un objetivo público (Lahera Parada, 2002) y siempre comprende al Estado (Raffin, 2010). Las mismas deben ser diseñadas e implementadas desde una perspectiva de género (Valle Rodríguez y Bueno Sánchez, 2006; Subsecretaría de Promoción de Derechos Humanos, 2012; Facio, 1999:44).

En el Partido de La Plata la oferta estatal para mujeres en situación de violencia consiste en la línea telefónica 144 Provincia y la Comisaría de la Mujer y la Familia, en el marco del poder ejecutivo provincial; la oficina de atención de la Dirección General de Género y Diversidad de la Municipalidad y los Centros de Salud barriales, en el marco del ejecutivo municipal. Ubicamos a estos dispositivos en el primer tramo de la ruta crítica. Se caracterizan principalmente por ser instancias a donde las mujeres concurren inicialmente, al comenzar a dar los primeros pasos para alejarse de la situación de violencia en la que se encuentran. Por lo general la respuesta que brindan consiste en el asesoramiento y derivación, en algunos casos ofrecen también un acompañamiento sostenido en el tiempo.

\footnotetext{
${ }^{124}$ Se ha afirmado que esta exigencia es una implicancia (entre otras) del estándar más estricto construido por la Corte al aplicar el art. 7 de la CBDP (Vázquez Camacho, 2011).
} 
Las dependencias policiales, enmarcadas en el poder ejecutivo provincial, constituyen una boca de entrada para las solicitudes de protección judicial.

En el presente capítulo nos detendremos en el análisis de los dispositivos mencionados con excepción de las Comisarías las cuales por revestir características particularmente diferenciales en relación a los otros serán analizadas en el próximo capítulo.

Siguiendo a González y Galletti (2016) utilizamos el concepto de dispositivo en el sentido de "un aparato o mecanismo que desarrolla determinadas acciones. (...) dicho artificio está dispuesto para cumplir con su objetivo" (p. 47). Estas autoras siguiendo a Foucault (1984) afirman:

pensamos al dispositivo como un conjunto heterogéneo, formado por: discursos, instituciones, instalaciones arquitectónicas, decisiones reglamentarias, leyes, medidas administrativas, enunciados científicos, proposiciones filosóficas y morales entre otros elementos. (p. 48)

\section{1.- La línea 144 de la Provincia de Buenos Aires}

Muchas veces lo único que escuchas del otro lado del teléfono es me mata, me mata, me mata (S. abogada, ex trabajadora de la línea 144 Provincia).

La línea 144 Nación comenzó a funcionar en abril de 2013 como correlato de la ley de Protección Integral que, en su artículo 9 inciso 0 , establece como facultad del Consejo Nacional de las Mujeres la creación de una línea de atención telefónica gratuita destinada a la contención, información y asesoramiento a mujeres que se encuentran en situación de violencia, como así también a familiares y allegadxs a las mismas ${ }^{125}$.

En el 2016 se conforma la línea 144 Provincia en reemplazo de la línea telefónica de atención gratuita del Programa de Atención a Mujeres Víctimas de Violencia (en adelante AVM) de la Secretaría de Derechos Humanos bonaerense.

La línea 144 Provincia (en adelante también “la 144" o la "línea 144") es la política pública estrella del gobierno provincial en materia de asistencia, contención y asesoramiento para mujeres en situación de violencia (Gago, 2017 y D Amico, 2018). “La ultra promocionada línea 144" es la prioridad de los anuncios gubernamentales en

\footnotetext{
${ }^{125}$ Casi la mitad de los llamados que recibía la línea 144 Nación provenían de la Provincia de Buenos Aires (D' Amico, 2018).
} 
esta temática (Gago, 2017:2). La gobernadora María Eugenia Vidal visitó las instalaciones del centro de atención telefónica de la línea 144 Provincia en enero del 2017 acompañada por la entonces subsecretaria de Género y Diversidad Sexual, Daniela Reich, y por el intendente Julio Garro (Diario El Popular, 2017 y El correo gráfico, 2017).

Consiste en una línea telefónica gratuita que atiende las 24 hs. los 365 días del año. Depende de la Subsecretaría de Género y Diversidad Sexual de la Secretaría de Derechos Humanos de la Provincia De Buenos Aires. La línea consta de un "call

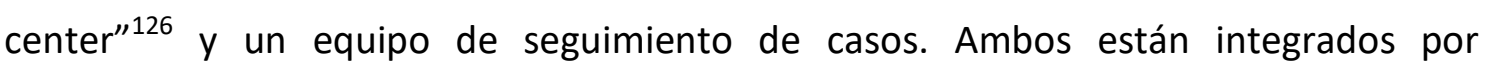
abogadas, psicólogas y trabajadoras sociales.

\section{1.- La atención de las llamadas telefónicas: "el call"}

En el "call center" las profesionales atienden llamadas las 24 hs del día. Se reparten en turnos de 6 horas, compuestos cada uno por alrededor de 10 trabajadoras y una coordinadora de turno.

En el 2016 se recibieron 12 mil llamados, en el 2017 se pasó a 28 mil por mes (D Amico, 2018:7), de los cuales solo pudieron ser atendidos alrededor de 15.000 .

Las Ilamadas que se reciben son heterogéneas, del total de llamados atendidos sólo el $30 \%$ corresponde a casos de violencia de género (D Amico, 2018:7), el resto consiste en llamadas equivocadas, acosadores, personas con padecimiento mental, los propios agresores para amenazar e insultar a las trabajadoras (Gago, 2017:2). También muchas veces se comunican directivxs de escuelas preocupadxs por alguna situación de violencia hacia niñxs o adolescentes y familiares de mujeres en situación de violencia. Qué hacer en relación a estas situaciones ha sido objeto de reflexión, análisis y debate de parte de las trabajadoras del "call"127.

\footnotetext{
${ }^{126}$ Utilizaremos esta expresión ya que es la que utilizan las trabajadoras, las personas entrevistadas y el material de análisis y periodístico que hemos consultado.

${ }^{127}$ Las trabajadoras plantearon y realizaron una presentación fundamentando que no estaban capacitadas para abordar situación de violencia hacia niñxs. Finalmente se decidió que cuando quien llama informa sobre una situación de niñxs o adolescentes violentadxs las trabajadoras les toman los datos, generas una expectativa (en palabras de S.), y se remite a modo de informe a su Directora, quien debería transmitir la información al organismo competente pertinente, sin embargo $S$. refiere que nunca se hace nada con eso, que han podido ver como esos informes quedan ahí sin dársele ningún tipo de trámite. Esto "evidencia el mal funcionamiento de otras líneas. Todo lo que nos llega de Niñez, por
} 
La línea de intervención, en general, es que llame la mujer, afirma S. que se entiende que ese ya es un primer paso, el decidir hablar por teléfono acerca de la situación de violencia. Las trabajadoras de la Línea 144 Provincia no tienen información acerca de qué pasa con las mujeres que llaman al "call" una vez que cortan el llamado. Con excepción de las que vuelven a comunicarse.

A los varones no se los asesora por una política de cuidado (afirma S.) ya que podría tratarse de "posibles agresores que recaban información en relación a la ruta crítica o a mujeres concernidas en situación de violencia" (Buenos Aires Provincia, s./f., Protocolo de atención telefónica de casos-Línea 144: 10) ${ }^{128}$.

El Protocolo de atención telefónica de casos-Línea 144 establece que las Ilamadas, en líneas generales, se clasifican en "de emergencia" y "asesoramiento" y requieren un abordaje diferenciado de partes de las trabajadoras que las atienden (Buenos Aires Provincia, s./f.: 4-5).

La llamada de emergencia es aquella referida a situaciones de violencia que se precipitan en el momento del contacto telefónico o en el inmediato momento anterior (Buenos Aires Provincia, s./f., Protocolo de atención telefónica de casos-Línea 144: 4). Suele ingresar a la línea 144 por una derivación del 911, previo a lo cual, por lo general, le toman los datos a la mujer y envían un patrullero ${ }^{129}$. Luego de finalizar el llamado con la mujer la coordinadora de turno de la 144 tiene una nueva comunicación con el encargado del 911 para que este les informe si el patrullero llegó al domicilio en cuestión, y el resultado.

En estas comunicaciones lo primero que intentan hacer las trabajadoras que atienden es, en palabras de S., ordenar a la mujer, tratar de que se tranquilice y pueda ver qué alternativas tiene mientras llega el patrullero. S. cita a modo de ejemplos algunas indicaciones que ha dado: ¿tenés un sillón? Ponelo atrás de la puerta para trabar,

ejemplo, es porque hay otra política pública en la que no se está invirtiendo y a la que no se le está dando importancia" afirma una de las coordinadoras del "call" entrevistada por D' Amico (2018: 11).

${ }^{128}$ En esta tercer parte de nuestra tesis utilizamos cartillas elaboradas por "Buenos Aires Provincia", las cuales carecen de fecha. Con el objeto de otorgar precisión a las citas utilizadas las acompañaremos, en estos casos, del nombre de cada cartilla.

${ }^{129}$ Las trabajadoras de la línea 144 han solicitado en numerosas oportunidades que ese sea el esquema de articulación pero muchas veces lxs operadorxs del 911 no solicitan el patrullero. 
¿podes salir a lo de tu vecina?, muchas nos han llamado en situación de encierro, le preguntamos si puede gritarle a alguien por la ventana, que es lo que ve, etc. ${ }^{130}$.

Es habitual que los patrulleros no acudan ante estos llamados, con el argumento de que no hay móvil disponible, o sin explicitar que no irán. También lo es que el personal policial llegue al lugar y no sepa qué hacer o que maltrate a la mujer y se dirija amablemente al agresor. En estas situaciones lo que se hace muchas veces es decirle a la señora que le pase el teléfono al policía y hablamos nosotras y a veces nos va bien, y a veces no, afirma S..

En los llamados de asesoramiento el propósito es brindar información, contención y derivación (Buenos Aires Provincia, s./f., Protocolo de atención telefónica de casosLínea 144: 5).

Cuando atienden estas llamadas, las trabajadoras de la línea tienen como definición que el primer punto de derivación sea la dirección de género, mujer o atención ante violencias que exista en el municipio donde vive la mujer. Señala S. que: la intención es referenciarla territorialmente a esa mujer, para que se arme, para q se ordene, para que la contengan, para que a partir de ahí pueda construir red si es que no la tiene o reforzarla si la tiene, y eso es lo que permite accionar en todo lo demás. Y además porque caracterizan que de derivarla sólo a la Comisaría o al Juzgado probablemente no reciba una respuesta adecuada y se vaya desalentada.

Cuando la mujer que llama es del Partido de La Plata la derivan a la oficina de atención de la Dirección General de Género y Diversidad de la Municipalidad de La Plata (ex DPG).

Las trabajadoras del "call" deben explicar detalladamente que tipo de respuesta van a encontrar las mujeres en el dispositivo al que se las deriva, así como también los alcances de la denuncia y de las medidas de protección (Buenos Aires Provincia, s./f.,

\footnotetext{
${ }^{130}$ También refiere un caso en el que asesoró a una joven mujer de La Plata que llamó a la línea 144 mientras viajaba en el colectivo un sábado a las 7 hs. y su ex pareja había subido al mismo transporte hostigándola de manera constante, en el camino se fueron construyendo respuestas: $\mathrm{S}$. le dijo que se ponga cerca del chofer y que le explicara la situación, acordaron que la joven bajaría en una parada donde había una remisería que conocía, le avisó a la madre para que la espere; Ixs pasajerxs intervinieron increpando al hombre para que no maltrate a la joven. Luego de que ella bajó, cuando el hombre se disponía a seguirla, el chofer del colectivo le cerró la puerta. De este desenlace S. se enteró porque la joven volvió a llamar para agradecer.
} 
Protocolo de atención telefónica de casos-Línea 144: 4), asimismo deben recabar información para dimensionar las característica de la situación en la que se encuentra la mujer y pensar en conjunto alternativas viables.

Este aspecto es particularmente difícil: brindar de forma clara gran cantidad de información, sobre aspectos desconocidos por las mujeres, y que ello no redunde en un desanimo de la persona que está comunicándose, afirma S. que esto es un gran desafío sino la envenenas de un montón de información que se re pierden.

\section{2.- Las tensiones entre la cantidad y la calidad}

La duración de la comunicación depende de muchos factores: si la persona que se comunica es la primera vez que llama, en que situación está, cual es el nivel de complejidad de la misma, en que territorio se encuentra, las redes con las que cuenta, las característica de las instancias a las que se la derive y el nivel de conocimiento previo de la mujer en relación a ellas. Es frecuente que las mismas se extiendan por alrededor de una hora.

En marzo de 2018 asumió Agustina Ayllón al frente de la Subsecretaría de Género y Diversidad Sexual de la Provincia ${ }^{131}$ y Débora Schwartzberg fue nombrada directora de la línea 144. A partir de ese momento se exigió a las operadoras que las llamadas duraran un máximo de 20 minutos. En múltiples oportunidades las trabajadoras explicitaron lo indadecuada que era esta directiva en relación a la particularidad de la temática que se aborda, sin embargo Schwartzberg siguió exigiendo esto ${ }^{132}$.Se llegó a controlar incluso el tiempo que las trabajadoras demoraban en el baño.

El objetivo era que se atienda mayor cantidad de llamadas aunque eso repercutiera directamente en desmedro de la calidad de la atención, sostiene S..

Se ha sostenido que se pretendía aplicar la lógica de los "call center" de atención al cliente de las empresas donde hay un guión y un tiempo de llamada estandarizada. La directiva era exclusivamente cuantitativa, el éxito de la política pública se evaluaba en relación a la cantidad de llamadas atendidas (D Amico, 2018: 8). “Nosotras somos las que sabemos cuándo podés y cuándo no podes cortar una llamada. (...) No podemos

\footnotetext{
${ }^{131}$ En reemplazo de Daniela Reich.

${ }^{132}$ S. relata que incluso dicha funcionaria llegó al punto de ingresar al sector del "call center" y exigirle a una operadora que corte una llamada en curso porque se había excedido de los 20 minutos dispuestos.
} 
aplicar un criterio de eficacia tecnocrática frente a situaciones de tal vulnerabilidad", sostiene una de las trabajadoras entrevistadas por Gago (2017:3). Tenés que entrar en tema, contextualizar, ver cuál es la historia de esa mujer y construir respuestas complejas y creativas, afirma S.

Otro de los cambios que implementó la nueva gestión fue eliminar las reuniones de equipo que servían como espacios de intercambio y capacitación, así como también de fortalecimiento y contención entre las trabajadoras.

\section{3.- El equipo de seguimiento}

El "equipo de seguimiento de casos" (en adelante EdS) funciona en dos turnos diarios, de 8 a 17 hs. y tienen la particularidad de que son las trabajadoras que lo integran quienes se recontactan con la mujer, algún familiar, psicologx, o referente afectivo de la misma.

Refiere S. que los motivos por los que desde el "call" derivan una situación al EdS están protocolizados: intento de femicidio, si el agresor es de las fuerzas de seguridad, por gravedad, por alto riesgo cuando la operadora entiende que la mujer no lo está dimensionando, por padecimiento mental, cuando la mujer no tiene red, cuando está en situación de calle y por violencia institucional. Salvo estas excepciones las llamadas son resueltas por el "call".

Las profesionales del EdS realizan una continuidad del acompañamiento telefónico de la situación, y muchas veces se comunican y articulan con otras instituciones $u$ organismos pertinentes.

También intervienen en la confección de los informes ambientales para tramitar la única posibilidad de recursos económicos para la mujeres que los necesiten y se comuniquen con la Línea: el Programa Nacional "Hacemos futuro" (antes era el "Ellas hacen") $)^{133}$. Sin embargo son muy pocos los resultados positivos que se obtienen ${ }^{134}$.

\footnotetext{
${ }^{133}$ EI EdS hace los informes ambientales para que se incorpore a la mujer al Programa, luego se remiten al 144 Nación para que las profesionales de esa línea los firmen ya que tienen que ser confeccionados por trabajadoras sociales y en el EdS no hay. Desde allí los remiten al Ministerio de Desarrollo social de Nación.

${ }^{134}$ S. relata que ella trabajó alrededor de 10 solicitudes por mes y al mes de mayo de 2018 solo una mujer había empezado a cobrar.
} 


\section{4.- Las condiciones de trabajo y de vida de las trabajadoras de "la 144"}

La inestabilidad y la incertidumbre acerca de la continuidad laboral, el ritmo sumamente intenso de trabajo, la presión y ausencia de contención y acompañamiento institucional, las amenazas que reciben cotidianamente de parte de agresores, las malas condiciones estructurales de trabajo y los bajos salarios son las principales preocupaciones y puntos de reclamo de las trabajadoras de la Línea 144 Provincia.

Las modalidades de contratación han sido objeto de reclamo y movilización de parte de las trabajadoras de la Línea (D Amico, 2018; Gago, 2017; Trabajadoras de la Línea 144 Nacional y Provincial, Cuerpo de delegdxs ATE DDHH, Delegadas INAM y ATE Capital, 2018). Los tipos de relaciones laborales son múltiples. "Existen cuatro tipos de contratación de los cuales tres son precarias y no garantizan condiciones laborales dignas" afirma uno de los volantes de difusión pública redactados por las trabajadoras (Trabajadoras de la Línea 144 Nacional y Provincial, Cuerpo de delegdxs ATE DDHH, Delegadas INAM, y ATE Capital, 2018).

Se ha señalado que de las 100 personas que integran la línea 144 Provincia aproximadamente 90 están precarizadas (D Amico, 2018: 7). De estas, alrededor de 70 están contratadas a través de un convenio con la empresa Provincia Net (empresa de recursos tecnológicos del Banco Provincia), sus condiciones de trabajo están regidas por el Convenio Colectivo de Empleados de Comercio, y carecen de estabilidad ya que sus contratos se renuevan cada 3 meses.

La mayoría de las restantes fueron contratadas como monotributistas, en el marco de la ley de emergencia provincial. Hay trabajadoras que son "pase en comisión" de otro organismo público de la Provincia o trabajadoras de Nación.

Unas pocas son trabajadoras estatales con estabilidad laboral y todos los derechos propios del empleo público, y son aquellas que se desempeñaban anteriormente en el Programa AVM.

El salario ha sido objeto de reclamo por parte de las trabajadoras ya que el monto que perciben es bajo. Las operadoras que trabajan los fines de semana y feriados son las 
peor pagadas ${ }^{135}$. Se les paga la hora con el mismo valor que a las que trabajan durante la semana sin tener en cuenta principios del derecho laboral que establecen que el trabajo realizado en horario nocturno, fin de semana y feriados deben ser pagado el doble ${ }^{136}$.

Las afectaciones a la salud física y psíquica también reviste gran preocupación para las trabajadoras de la Línea. Los elementos mencionados anteriormente así como el contacto constante con casos de violencia y emergencias, la responsabilidad ante las llamadas que reciben y la presión cotidiana, genera en las trabajadoras diversas patologías (Gago, 2017): tendinitis, contracturas, estrés, laringitis, manchas en la piel, problemas gástricos, insomnio, ansiedad, disfonía, problemas en el oído.

En la Línea hay mucho recambio de trabajadoras, S. sostiene que la gente se quema y se va... hay compañeras super recontra valiosas que le ponen un montón de garra y las re queman. "Estas mujeres trabajan con la angustia ajena mientras hacen malabares con la propia. Una suerte de violencia redoblada" afirma Gago (2017:2).

Las trabajadoras de la línea se organizaron sindicalmente para exigir mejores condiciones de trabajo. Hicieron intervenciones callejeras, participaron en movilizaciones ${ }^{137}$, dieron notas periodísticas y conferencias de prensa.

En abril de 2018 todas las trabajadoras de la línea 144 Provincia hicieron un paro para reclamar por mejoras en las condiciones de trabajo ${ }^{138}$. Luego de esto, en el mes de mayo de 2018, 4 trabajadoras sociales y 1 abogada fueron despedidas, la explicación que les dieron fue, en palabras de S. que su trabajo no iba en la misma línea que la línea de la gestión ya que se habían adherido al paro.

\footnotetext{
${ }^{135}$ En el 2017 luego de hacer pública su situación se logró que a estas trabajadoras les aumenten el salario de $\$ 6000$ a $\$ 12.000$. El salario del resto de las operadoras rondaba los $\$ 15.000$.

${ }^{136}$ Por consideraciones que tienen en cuenta aspectos biosociales con impacto en la salud de las personas.

${ }^{137}$ El 8 de marzo del 2018 y el 3 de junio en la marcha por Ni una menos, se expresaron con múltiples carteles alusivos a su situación laboral: "Vidal precariza manteniendo la sonrisa", "mujeres violentadas a ambos lados del teléfono/sueldos dignos y trabajos estables iya!", "La precarización es violencia".

${ }^{138}$ Algunas trabajadoras hacía tres meses que no cobraban. Asimismo en el "call" había habido un brote de otitis y herpes que se contagiaron varias trabajadoras, por utilizar las mismas "binchas" telefónicas sin desinfectar ni limpiar.
} 


\section{2.- Los Centros de atención primaria de Salud de la Municipalidad de La Plata}

Podés tener toda la perspectiva y hacer un laburo zarpado de acompañamiento con la mujer, pero si no tenés nada para proponerle es muy difícil

(P. trabajadora social de Centros de Salud del barrio Altos de San Lorenzo, La Plata). Se ha caracterizado el área de salud como un aliado relevante en el abordaje de las situaciones de violencias hacia las mujeres y se ha sostenido que allí existe la posibilidad de detectar diversas situaciones de violencia en etapas tempranas (Equipo Latinoamericano de Justicia y Género-ELA, 2014:28).

Los Centros de atención primaria de Salud (en adelante Centros de Salud) en el Partido de La Plata están repartidos y anclados territorialmente en todo el Municipio. Es habitual que desde otras instituciones, como las escuelas, deriven a los Centros de Salud a las mujeres en situación de violencia. También es habitual que en dicho espacio esto emerja, relacionado a otras demandas, y sea abordado por Ixs profesionales.

Los Centros de Salud dependen de la Secretaría de Salud municipal, la cual tiene un programa llamado ProFavi (Programa de Fortalecimiento de la Atención de la Violencia Intrafamiliar en Atención Primaria de Salud) ${ }^{139}$. El mismo está compuesto por duplas integradas por una psicóloga y una trabajadora social que tienen a cargo un área (cada área está integrada por unos diez a doce Centros de Salud). En el municipio se han creado cuatro áreas en función de una disposición geográfica (Luzzi, Haudemand, Fernández, 2011: 6).

Estas duplas trabajan a demanda de los equipos de salud. La modalidad de esa articulación depende de las características de los equipos del Centro de Salud y de la dupla correspondiente ${ }^{140}$. Afirma P. que por las limitaciones que tiene el programa más

\footnotetext{
${ }^{139}$ Se ha sostenido que "su propósito consiste en acercarse a los Centros de Salud (CS) de los diferentes barrios para contribuir en la resolución de situaciones de violencia familiar a partir del acompañamiento institucional, tanto para el seguimiento de casos y derivaciones a otras instituciones como para la asistencia en la atención primaria de personas en situación de violencia" (Luzzi, Haudemand, Fernández, 2011: 6).

${ }^{140}$ En algunos Centros de Salud las profesionales del Profavi acuden días y horarios fijos por lo que ante una situación de violencia se le informa a la mujer que acuda esos días y horarios. Otras veces se le piden un teléfono a la mujer y el Profavi se contacta, y le ofrecen un espacio de entrevista. En algunos Centros de Salud la dupla correspondiente trabaja la situación y el centro de salud sigue con su dinámica (en palabras de P.), y en otros las trabaja en conjunto con Ixs profesionales del Centro.
} 
que un asesoramiento sobre lo que es la denuncia y medidas protectorias, no se puede hacer.

En algunos Centros de Salud la dupla que les corresponde está vacante por lo que no cuentan con ese recurso, en estos casos la situación es abordada exclusivamente por Ixs profesionales de ese Centro. Afirma P. que es un programa que se viene vaciando porque son muy pocas las profesionales que hay para la cantidad de Centros de Salud, implica muchos viajes, pero no les cubren los viáticos, existe porque quedó de la gestión anterior, así debilitado como estaba.

Cuando la mujer quiere realizar la denuncia, o emprender medidas en relación a la situación que está atravesando, habitualmente se la deriva a la Dirección General de Género y Diversidad de la Municipalidad, tanto si la situación es abordada por Ixs profesionales del Centro de Salud como si lo es por el Profavi. Muchas veces este último deriva directamente al Área de Procesos Urgentes (en adelante APUR).

La intervención se limita a asesorar y derivar. Algunos profesionales ofrecen también un acompañamiento sostenido en el tiempo, les proponemos que vuelvan al Centro de Salud para ver cómo continuar acompañando en base a lo que haya charlado en la $D P G^{141}$, afirma P., pero esto depende de Ixs profesionales que intervienen.

\section{3.- La Dirección General de Género y Diversidad de la Municipalidad de La Plata (ex $\left.D P G^{142}\right)$.}

Lo que nos salva es el compañerismo (...) La sororidad, a pleno (E. psicóloga del equipo de atención de la Dirección General de Género y Diversidad).

El equipo de atención de la Dirección General de Género y Diversidad de la Municipalidad de La Plata (en adelante DGGyD) funciona en una oficina (la 115) del

\footnotetext{
${ }^{141}$ En referencia a la actual Dirección General de Género y Diversidad de la Municipalidad de La Plata, la cual antes se llamaba Dirección de Políticas de Genero.

${ }^{142}$ Todas las personas entrevistadas se siguen refiriendo a ella como "la DPG" a pesar de que hubo un cambio en el organigrama y un cambio en el nombre (antes se llamaba Dirección de Políticas de género). Esto no se tradujo en más presupuesto, ni en una mejora de las condiciones laborales y de atención, afirma $\mathrm{E}$.
} 
Pasaje Dardo Rocha, el cual se encuentra ubicado en calle 50 entre 6 y 7 , en pleno centro de la ciudad de La Plata. La oficina no es fácil de encontrar.

El equipo de trabajo está compuesto por 10 (a veces 8 ) trabajadoras, la mayoría son psicólogas, también hay trabajadoras sociales y una abogada.

Hasta el 2017 atendían de 9 a 14 hs. En el 2018 se extendió el horario de atención hasta las 17 hs., sin embargo no se sumaron más trabajadoras al equipo sino que hubo una reorganización de horarios quedando 2 de ellas en la franja horaria de la tarde.

Atienden por sistema de turnos asignados previamente. Las mujeres esperan en un angosto pasillo, y se les entrega una encuesta para que completen.

El primer paso es una entrevista, la cual se realiza en duplas, afirma E. que en estas instancias se ofrece la posibilidad de una escucha que no culpabilice.

Si bien la entrevista no está estandarizada las profesionales cuentan con una guía, para recabar datos y para establecer el riesgo y los grados de visibilización o no de ese riesgo por parte de la mujer.

Luego de esa primer entrevista se establece una nueva fecha para verse. El equipo realiza un acompañamiento y asesoramiento, no se patrocina ni se realizan terapias individuales.

Cuando se decide que la mejor estrategia es solicitar las medidas de protección al Juzgado, las profesionales de la DGGyD derivan a las mujeres al APUR (más adelante será analizado con detenimiento), implementando distintas estrategias para que las mujeres puedan seguir utilizando ese dispositivo de patrocinio jurídico gratuito sin ser expuestas a situaciones hostiles: se elaboran informes, donde las profesionales vuelcan por escrito el relato de los hechos, para que las mujeres concurran con ese informe y eviten tener que relatar nuevamente todo allí, donde pueden verse sometidas a comentarios negativos.

Otras veces, excepcionales, las trabajadoras de la DGGyD acompañan a las mujeres a APUR, porque está en riesgo o para que no sea revictimizada, afirma $\mathrm{E}$.

E. señala distintos aspectos en los que tanto las mujeres que van a solicitar el patrocinio como ellas mismas, como profesionales, han sufrido tratos inadecuados y revictimizantes de parte de los funcionarios de APUR. 
Otras veces desde el equipo de atención de DGGyD derivan a las mujeres a la fiscalía, en estos casos se les indica que concurran en primer lugar al Centro de Atención a la Victima de la Fiscalía General. No derivan a las comisarías, debido a las malas experiencias previas.

No se realizan terapias individuales sino que se hace un acompañamiento del proceso que la mujer está llevando adelante. Cuando se detecta la necesidad de un espacio de terapia individual se articula con otras instituciones para intentar conseguirlo, lo cual no siempre se logra.

Se propone a las mujeres que asistan periódicamente a la Dirección para realizar un seguimiento de la situación, en el esquema de constituir ese espacio como el lugar de referencia de la mujer.

Por otro lado también es incumbencia de las trabajadoras del equipo de la DGGyD el realizar las entrevistas de admisión a la casa refugio que funciona en La Plata, así como también acompañar luego del egreso de la misma.

\section{1.-Las tensiones entre la cantidad y la calidad}

La extensión horaria referida fue una decisión de la directora, afirma E. que insistían con que había que tener más horas de atención y agrega: para nosotras es importante que no sea solamente cuántas mujeres atendemos sino el proceso, la calidad de la entrevista, qué le decís, si vuelve o no vuelve. No tanta estadística, sino una estrategia más real, más concreta de salida.

El equipo de atención se reúne una vez por semana. En esta instancia se abordan interdisciplinariamente cuestiones pendientes o complejas que hayan surgido en las entrevistas. Dicha instancia de reunión se constituye en un espacio de contención y reflexión para las profesionales. Sin embargo las autoridades no propician estos espacios, señala E.: es muy paradójico pero es una lucha constante con las autoridades la reunión de equipo.

\section{2.-Las condiciones de vida y de trabajo de las trabajadoras de la DGGyD}

La relación laboral de las trabajadoras del equipo de atención de la DGGyD es precaria, están "contratadas" y cada 3 meses se renuevan los contratos municipales. Muchas de ellas trabajan desde hace 6 años pero el Municipio no reconoce antigüedad. Las 
trabajadoras que ingresaron recientemente fueron ubicadas en categorías más altas, con salarios mayores, que las que están desde hace más tiempo. Por lo cual uno de los reclamos de las trabajadoras es que por la misma tarea se pague el mismo salario.

El salario básico de estas trabajadoras es de $\$ 13.000$, "de bolsillo" son 2 o 3 mil mas. Sostienen E. que todas tienen otros trabajos para poder sostenerse ellas y sus familias, y que muchas profesionales comprometidas y capacitadas en la temática renuncian: No lo sostenes (...) la mayoría o termina renunciando o ocupa su tiempo en otro trabajo, entonces no puede ir y demás.

\section{4.- La debilidad y la protección}

Las condiciones de trabajo en que las trabajadoras de los dispositivos analizados recientemente se desempeñan distan de ser las óptimas. Estas trabajadoras abordan situaciones complejas y muchas veces dramáticas: hemos escuchado violaciones, afirma S.. Diseñan distintas estrategias usando su creatividad, sensibilidad y compromiso con la temática. S. afirma que el vacío institucional es muy grande, sentís que no tenés respaldo: institucionalmente no tenés respuesta de nadie. Te las tenés que arreglar como podes. Así también los estresazos de las trabajadoras.

E. sostiene: En todos estos espacios de laburo lo que nos salva es el compañerismo, la cuestión de equipo y complicidad, tanto profesional para intervenir, como trabajadora. La sororidad, a pleno.

Las trabajadoras de los tres dispositivos analizados coinciden en que la directiva clara que tienen en sus espacios de trabajo es la derivación hacia otros dispositivos siendo el ámbito judicial el punto de llegada. La mayor respuesta que tienen indicada institucionalmente para ofrecer a las mujeres en situación de violencias es la realización de la denuncia y la solicitud de las medidas judiciales de protección.

Hay múltiples situaciones que les plantean las mujeres, cuya resolución y abordaje escapan de las posibilidades de incidencia de las medidas judiciales, aquí no hay claridad institucional en relación a los recursos con los que se cuenta y las posibilidades de diseñar estrategias adecuadas dependen de múltiples factores. Refiere P. que no hay una política direccionada y ordenada en relación a cómo se trabajan estas 
situaciones y que recursos hay, no hay un circuito en el que yo tengo una situación de violencia y sé que puedo tener esto, esto y esto, y ofrecerle a la mujer esto, afirma.

Esto sucede en relación a una serie de problemáticas que adquieren un matiz dramático al enmarcarse en el contexto de una situación de violencia: la escases de recursos económicos y/o la dependencia económica del agresor, las dificultades de acceso a la vivienda, a tratamientos psicológicos, y al trabajo, así como la ausencia de alternativas para el cuidado de Ixs hijxs. No podemos ofrecer ni siquiera la carga de una SUBE como para sostener un espacio en un mes afirma E.

Las profesionales intervinientes se encuentran ante la incertidumbre de no saber si los recursos que formalmente existen estarán disponibles o no ante una situación particular. En este sentido refiere E.: A veces en una entrevista no sabés por dónde encararla, porque no les decimos cosas a las mujeres que no podemos sostener.

P. afirma: podés tener toda la perspectiva y hacer un laburo zarpado de acompañamiento con la mujer, pero si no tenés nada para proponerle es muy difícil, se cae en la voluntad individual de esa mujer que tiene que ser una leona y llevarse puesto todo... hay mujeres que eso no lo pueden hacer. La mayoría no lo puede hacer....Yo creo que si a la mayoría de las mujeres en la primer entrevista vos le decís 'Mirá bueno, podemos ingresarte a una lista de trabajo, hay posibilidades de contar por varios meses con un subsidio para que vos alquiles'. Si vos le tirás 2 o 3 puntas la mujer arranca.

En el modelo implementado en el Partido de La Plata la casi única respuesta estatal ${ }^{143}$ para proteger a una mujer que ha emprendido acciones para salir de la situación de violencia doméstica en la que se encuentra o para evitar sufrirla ante la inminencia de la misma, son las medidas protectorias resueltas por la judicatura. El rol de los dispositivos analizados en este capítulo consiste principalmente en asesorar y derivar, en algunos casos también en contener y acompañar a las mujeres para que, cuando estén en condiciones de hacerlo, encare un nuevo tramo en su recorrido: el solicitar las medidas de protección a los organismos judiciales pertinentes. Para accionar este mecanismo las mujeres deben realizar una presentación judicial. La denuncia en sede

\footnotetext{
${ }^{143}$ Con excepción del ingreso al Refugio y la implementación del botón anti pánico, las cuales son medidas de protección que pueden ser tomada por las trabajadoras de la DGGyD.
} 
policial también constituye una boca de entrada al dispositivo judicial como veremos a continuación. 


\section{VIII.- LAS COMISARIAS}

Los dispositivos estatales referidos anteriormente tienen roles de asesoramiento y/o contención, la denuncia en la dependencia policial implica el inicio del proceso judicial. El modelo de gestión estatal actual exige que las mujeres realicen una denuncia en sede policial o una presentación judicial ante un juzgado para poder obtener protección estatal ante una situación de violencia y que se dispongan las medidas protectorias pertinentes.

La Dependencia Policial es el lugar donde mayormente acuden las mujeres a realizar la denuncia ante una situación de violencia (Malacalza 2018:241 y ELA, 2012). En un Informe alternativo al Comité CEDAW se informa que, en el Departamento Judicial de La Plata, de 10 causas iniciadas ante la Receptoría General de Expedientes 8 provienen de Comisarías (ANDHES et al., 2016:3).

Las comisarías son el dispositivo, con pertinencia en la temática, más extendido (en términos cuantitativos) en el territorio de la Provincia de Buenos Aires. El Equipo Latinoamericano de Justicia y Género-ELA (2014) afirma que las comisarías representan la mayor cantidad de servicios disponibles para las mujeres en situación de violencia, constituyéndose en el principal recurso con que ellas cuentan (p. 28).

En el partido de La Plata otros factores también contribuyen a que las Comisarías sean la boca de entrada mayormente utilizada: mientras que las fiscalías, Juzgados y Defensorías se concentran en el centro comercial y administrativo de la ciudad, las Comisarías se distribuyen en todo el territorio de la misma. Por otro lado muchas instituciones derivan a las mujeres a las Comisarías ${ }^{144}$.

En dicho Partido hay sólo una Comisaría de la Mujer y la Familia ${ }^{145}$, la cual se encuentra ubicada en calle 1 entre 42 y 43. Por otro lado hay Oficinas de Atención a las

\footnotetext{
${ }^{144}$ Así por ejemplo en la Página web de la Suprema Corte de Justicia de la Provincia de Buenos Aires el primer y segundo lugar que se señala para efectuar una denuncia por violencia familiar son la Comisaría de la Mujer y la Familia y "cualquier otra Comisaría" respectivamente (http://www.scba.gov.ar/servicios/registroviolencia1.asp.). Desde la línea 144 Provincia y desde la DGGyD no se deriva a las mujeres a las Comisarías (ni a la de la Mujer y la Familia ni a las comunes), por entenderse que allí las respuestas son inadecuadas.

${ }^{145}$ En la Provincia de Buenos Aires existe un total de 125 Comisarías de la Mujer y la Familia (OVG, 2016: 24).
} 
Víctimas de Violencia dependientes del Ministerio de Seguridad de la Provincia que funcionan dentro de las dependencias policiales en el Destacamento Policial de Barrio Aeropuerto y en la Comisaría $3^{\circ}$ de Los Hornos.

A raíz de un convenio entre la Suprema Corte de Justicia de Buenos Aires y el Ministerio de Justicia y Seguridad de la Provincia, en el año 2012, se implementó el “Formulario para denuncia de violencia familiar ley $12.5699^{146}$. El mismo debe ser utilizado por el personal policial cuando una mujer concurre a denunciar una situación de violencia ${ }^{147}$.

En el trabajo de campo realizado hemos detectado que las mujeres que acuden a las comisarías a realizar la denuncia para activar el mecanismo judicial de protección de sus derechos antes situaciones de violencia doméstica, se encuentran con respuestas inadecuadas de parte del personal policial. Algunas de ellas serán analizadas a continuación. Otras actitudes negativas del personal policial serán abordadas en el capítulo $\mathrm{X}$ ya que, por tener puntos en común con actitudes y prácticas del personal judicial, hemos decidido analizarlas conjuntamente.

\section{1.- Las idas y vueltas}

Sucede con frecuencia que el personal policial de las Comisarías comunes se niegue a recibir la denuncia y derive a la mujer a la Comisaría de la Mujer y la Familia. Esto es contrario a lo establecido por la normativa vigente que dispone que la denuncia sea recepcionada en forma obligatoria en cualquier dependencia policial ${ }^{148}$.

Frecuentemente en la Comisaría de la Mujer y la Familia se niegan a recibir las denuncias de las mujeres que tienen domicilio en, por ejemplo, Altos de San Lorenzo y las derivan al Destacamento de Barrio Aeropuerto con el argumento de que esa es la jurisdicción que les corresponde. Sin embargo, si bien geográficamente este barrio es más cercano a aquel, no hay transporte público que los conecte por lo que las mujeres deben tomar un micro hasta el centro de la ciudad de La Plata y de allí otro hasta

\footnotetext{
${ }^{146}$ Aprobado el 12 de diciembre de 2012.

${ }^{147}$ Sin embargo es habitual que el personal policial utilice los formularios de denuncia de delitos comunes, esto sucede incluso en la Comisaría de la Mujer y la Familia.

${ }^{148}$ Así lo establece el artículo 6 del Decreto 2875/05 (modificado por el decreto 436/15) reglamentario de la Ley 12569.
} 
Barrio Aeropuerto, mientras que a la Comisaría de la Mujer y la Familia de calle 1 llegan con solo tomarse un medio de transporte. Ha sucedido también que en el Destacamento de Barrio Aeropuerto no tomen la denuncia por no estar presente el personal de la Oficina de Atención a las Víctimas de Violencia, por lo que se le indica a la mujer que vuelva a conducirse a la Comisaría de la Mujer y la Familia.

Muchas veces las mujeres, que a menudo van acompañadas de sus hijxs, no cuentan con los recursos económicos para afrontar los gastos derivados de esos traslados. Otras veces no cuentan con el tiempo necesario para continuar con esas gestiones y regresan a sus hogares sin haber podido comenzar el trámite, se nos fue toda la mañana yendo y viniendo, y había que volver porque llegaba el marido, refiere D.

\section{2.- Cuando la respuesta es un no}

El personal policial tiene la obligación de tomar la denuncia, aunque no se trate de delito, si se trata de violencia hacia la mujer ${ }^{149}$.

Es una práctica habitual de parte de la agencia policial el negarse a hacerlo. A veces expresamente, minimizando la situación relatada por la mujer, por ejemplo EG. refiere una situación en la que en la Comisaría común se negaban a tomarle la denuncia porque no tenía ningún golpe visible. Otras veces exigen requisitos que no están en ninguna norma (que la mujer vaya acompañada de testigos por ejemplo). En otras oportunidades el justificativo es formal: S. relata un caso en el cual la mujer se comunicó con la línea 144 y refirió que había sufrido un abuso sexual de parte de un amigo. Como el mismo no era su pareja en la Comisaría de la Mujer y la Familia de La Plata se negaron a tomarle la denuncia, basándose en la ley de provincia que habla de vínculo familiar y noviazgos (y en el referido formulario que así se titula). La mujer se retiró de la dependencia policial sin concretar la denuncia.

Otras veces la negativa tiene como argumento impedimentos materiales: no le tomaron la denuncia porque no tenían papel, afirma EG.

Es habitual que en las Comisarías comunes, cuando el personal policial conoce al agresor y, muchas veces, a la mujer, las desalienten de hacer la denuncia, así afirma $\mathrm{E}$ :

149 Idem. 
hay muchísimas limitaciones, mucho 'qué es lo que querés denunciar?' No se da el espacio, tiene que ir la mujer muy segura 'Vengo a relatar esto, esto y esto y no me importa que opines'; hay mucho maltrato, el poner en duda: '¿Pero te parece?' Eso que hace que la mujer termine no denunciando.

Muchas veces va el agresor en el mismo momento y a la misma dependencia policial y se le toma la denuncia a él, o no se le toma a ninguno de Ixs dos.

Cuando el agresor es personal policial las resistencias a tomar la denuncia se incrementan, y la situación reviste mayor complejidad.

\section{3.- Hagamos como si...}

Muchas veces el personal policial desalienta a la mujer de realizar la denuncia ofreciéndole efectuar una exposición civil, a la que no se le da ningún trámite posterior ni se notifica a ninguna instancia judicial. De este modo la mujer se queda a la espera de una respuesta que nunca llegará, lo cual la desalienta de volver a solicitar intervención estatal. E. afirma que hay una mezcla de maltrato y destrato que la mujer termina haciendo una exposición pero porque no entendió, y queda todo ahí cuando ella quiere que vaya al Juzgado.

Si bien esta práctica policial aún subsiste muchas mujeres no se quedan con esa negativa sino que intentan con otros espacios. E. señala que algo cambió socialmente, hay algo que interpela, que la mujer vuelve a hablar con nosotras, diciendo 'Mirá dos veces fui a la comisaría, no sé qué pasa pero no terminé haciendo la denuncia, o hice una exposición' algo socialmente pasa porque continúa insistiendo en que alguien la escuche y la proteja.

\section{4.- Ante la violencia... más violencia}

Habitualmente las mujeres, tanto al ir a la dependencia policial a radicar la denuncia, como al llamar a la policía para que intervenga en caso de nuevas agresiones o de incumplimiento por parte del agresor de la medida judicial dictada, se encuentran con respuestas de parte del personal policial (tanto femenino como masculino) que tienden a desalentarlas, a naturalizar la violencia hacia las mujeres, y a reproducir el 
discurso y las prácticas patriarcales que colocan a la mujer en una situación de subordinación al varón, y que justifican el accionar del varón violento.

Del trabajo de campo realizado surgen relatos sobre pretendidos consejos de parte del personal policial para que se reconcilien, o para que ella no se complique la vida, o expresiones como no es para tanto. En este sentido refiere $S$. que es habitual que te llama la mujer diciendo que esta la policía conversando con el marido y a ella la mandaron para adentro sin escucharla, lo que se hace muchas veces es decirle a la señora que le pase el teléfono al policía y hablamos nosotras y a veces nos va bien, y a veces no.

Por ser las comisarías un dispositivo ampliamente utilizado por las mujeres que emprenden acciones en busca de protección estatal en relación a la situación de violencia doméstica en la que se encuentran, la calidad y características de la respuesta que allí se obtiene reviste particular relevancia ya que la misma podría ser determinante para que la mujer mantenga su decisión o desista de ella.

Es habitual que las mujeres se encuentren allí con los obstáculos y dificultades que hemos señalado, los cuales pueden operar desalentándolas y desanimándolas en su decisión de solicitar intervención estatal para salir de la situación de violencia en la que se encuentran. Muchas veces las mujeres se quedan en el camino (en palabras de P.) otra veces siguen adelante a pesar de esos obstáculos, en estos casos luego de la Comisaría deberán comenzar a transitar las instancias judiciales, las cuales serán abordadas a continuación. 


\section{IX.-LAS INSTANCIAS JUDICIALES}

En general, no se sienten seguras con la medida...Porque muchas han pasado por eso. Son cosas que también se instalan, el saber popular es muchas veces el más certero (P., trabajadora social de Centros de Salud del Barrio Altos de San Lorenzo, La Plata).

Como hemos dicho en el capítulo anterior, la denuncia en la Comisaría implica el inicio del proceso judicial. Sin embargo, no es un requisito esencial y tampoco suficiente para que se dispongan las medidas protectorias. Las mujeres que mantengan su decisión de emprender acciones para obtener protección estatal, deberán desplegar una serie de actividades ante los actorxs judiciales pertinentes.

Estamos acá en un segundo momento de la ruta crítica, en el cual las mujeres realizan acciones para solicitar y obtener la disposición de medidas protectorias de parte de la judicatura.

En el Partido de La Plata como actores judiciales sobresalientes, en relación a la problemática de la violencia doméstica contra las mujeres, podemos señalar los siguientes: Juzgados de Protección contra la Violencia Familiar, Niñez y Salud Mental (conocidos como "Juzgados Protectorios") ${ }^{150}$, Área de Procesos Urgentes (APUR), fiscalías penales. Cada uno de estos dispositivos serán analizados en detalle a continuación. También serán abordados los obstáculos con los que las mujeres se encuentran, a menudo, al transitar este nuevo tramo de su ruta crítica. Otros aspectos, que también se pueden constituir en obstáculos, y que son comunes al dispositivo policial y al judicial serán abordados en el Capítulo X.

\footnotetext{
${ }^{150}$ En el mes de diciembre de 2018 llegó a su fin esta llamada "experiencia piloto". El 31 de octubre de 2018 la Suprema Corte de Justicia de la Provincia de Buenos estableció, a través de la Resolución 2149/18 que antes de que se ponga en funcionamiento el nuevo juzgado de familia 7 las causas se redistribuirían entre los Juzgados de familia sin diferencias, con lo cual queda anulada la competencia especial asignada a los Juzgados 4 y 5 en virtud de la Resolución 3488 del 2010.
} 


\section{1.-Juzgados de Protección contra la Violencia Familiar, Niñez y Salud Mental}

En el Departamento Judicial de La Plata se implementaron, como experiencia piloto, los Ilamados "Juzgados Protectorios": Juzgados de familia unipersonales especializados en Violencia Familiar, Niñez y Salud Mental.

En el año 2010 la Suprema Corte de Justicia de la Provincia de Buenos Aires ${ }^{151}$ dispuso que las causas referidas a las temáticas mencionadas fueran atendidas por dos de los seis Juzgados Unipersonales que se pondrían en marcha (el juzgado 4 y el 5 ) ${ }^{152}$, esto "con carácter de prueba piloto y a los fines de proyectar una reforma legislativa" (considerando VII).

Se señala, en el considerando II de dicha Resolución, que en el Departamento Judicial de La Plata más del 30\% del total de las causas iniciadas corresponden a "violencia familiar" y que la dedicación que estos trámites insumen va en desmedro del resto de la competencia asignada a ese fuero.

Asimismo refiere que ante la creciente cantidad de causas por violencia familiar y la importancia de esta problemática se hace "imperiosa la necesidad de un tratamiento especializado" ${ }^{153}$ (p. 1).

Se sostiene, en el considerando VIII, que la mayor especialización del Órgano, tendría como fin la atención más eficaz de las causas por medio del incremento del trabajo en conjunto con otros organismos pertinentes (del Poder Ejecutivo, Departamentos Ejecutivos Municipales, Instituciones de Salud) (p. 3).

Estos Juzgados comenzaron a funcionar a partir del mes de noviembre del año 2011, culminando esta experiencia piloto en el mes de diciembre de 2018.

Cada uno de estos Juzgados recibía más de 45 causas diarias por violencia familiar y desde el año 2010 al 2015, el número de causas iniciadas se había cuadruplicado en cada uno de ellos (OVG, 2016).

El desempeño de estos órganos especializados en violencia familiar ha sido particularmente analizado por el Observatorio de Violencia de Género (en adelante

\footnotetext{
${ }^{151}$ A través de la Resolución 3488.

${ }^{152}$ Artículo 1.

${ }^{153}$ Considerando II de la Resolución.
} 
OVG) de la Defensoría del Pueblo de la Provincia de Buenos Aires (2016), el cual ha advertido en sus informes sobre las dificultades estructurales y de funcionamiento (OVG, 2016:3).

Estos Juzgados Protectorios, quedan ubicados en calle 58 entre 11 y 12 . Al igual que el resto de las instancias judiciales del Municipio de La Plata, están en el centro geográfico y administrativo de la ciudad. Por lo cual el acceso a ellos puede verse dificultado para muchas mujeres que viven por fuera del casco urbano de la misma. Este aspecto será analizado en el próximo capítulo.

\section{1.- ¿Yo señor (a)? No señor (a)}

En la página web de la Suprema Corte de Justicia de la Provincia de Buenos Aires ${ }^{154}$, se consigna a los Juzgados de Paz y a los de Familia como lugares pertinentes para recibir denuncias. Sin embargo, en los Juzgados Protectorios no toman denuncias ni presentaciones/peticiones verbales, por lo que cuando una mujer se hace presente en la mesa de entradas del mismo, generalmente luego de haber realizado una larga fila con espera, se le dice que tiene que conseguir unx abogadx que la patrocine $y$ confeccione la presentación. Con frecuencia son asesoradas en relación a la existencia de APUR para que se hagan presentes allí (González y Galletti, 2016:52), esto depende de la voluntad de la persona que atienda a la mujer.

González y Galletti (2016) al analizar las fuentes de entrada de denuncias a estos Juzgados afirman "No incluimos la opción, que establece la normativa, acerca de la presentación espontánea de la víctima por considerar que esta situación se torna inviable debido a las dificultades institucionales y personales de llevarla adelante" (p. 52).

A pesar de estar en un lugar pertinente para solicitar protección ante una situación de violencia la mujer obtiene como respuesta una nueva derivación ${ }^{155}$, a otro lugar, ubicado en otro punto geográfico y donde tendrá que someterse a una nueva espera. Esto constituye un elemento que obstaculiza el camino de la mujer. Reiteremos aquí que habitualmente las mujeres disponen de poco tiempo para realizar estos trámites

\footnotetext{
${ }^{154}$ En un apartado titulado "información para victimas/denunciantes", consultado el 15/11/2018.

${ }^{155}$ Con frecuencia las mujeres llegan al Juzgado luego de haber sido derivadas hacia allí desde otro dispositivo estatal: Comisaría, hospital, centro de salud, escuela.
} 
por lo cual cada instancia de espera y demora favorece que se frustren las posibilidades de completar las gestiones necesarias para la solicitud de las medidas protectorias.

\section{2.- Una vuelta más...}

En algunas oportunidades la persona que atiende a la mujer no la informa acerca de la existencia de APUR y solo le refiere que necesita unx abogadx que la patrocine. Se establece de este modo, en la práctica, un requisito arbitrario que opera como un importante obstáculo por la falta de acceso y contacto cotidiano de las mujeres pobres a Ixs abogadxs, y el desconocimiento de a dónde acudir para conseguir patrocinio jurídico gratuito. Se coloca a la mujer en una situación difícil de resolver si no cuentan con recursos económicos para pagar los honorarios de abogadxs particulares. Las mujeres muchas veces desisten o pierden tiempo y dinero deambulando por distintas instituciones sin obtener respuestas satisfactorias.

El decreto 2875/05 reglamentario de la ley provincial de violencia familiar ${ }^{156}$ establece que "una vez instada la acción y de modo inmediato se garantizará a los pretensos accionantes, la debida asistencia jurídica de modo gratuito" ${ }^{157}$. Se trata de un derecho de las mujeres en situación de violencias que se les proporcione asistencia jurídica gratuita, pero en la práctica es utilizado como un requisito que obstaculiza su acceso a medidas de protección.

\section{3.- Poniendo el cuerpo}

Una vez que la mujer consigue patrocinio letrado por sus propios medios ${ }^{158}$ son estos profesionales quienes confeccionan el escrito solicitando las medidas protectorias. Luego de lo cual la mujer debe hacerse presente en el Juzgado Protectorio (previo paso por la Receptoría General de Expedientes), hacer la fila de espera correspondiente y presentar el escrito en la mesa de entrada donde le colocan un sello de recibido, sin aportarle más información al respecto. Las mujeres se retiran sin haber

\footnotetext{
${ }^{156}$ Ley $\mathrm{N}^{\circ} 12.569$.

${ }^{157}$ Artículo 5.

${ }^{158}$ La oferta gratuita consiste en APUR y en los consultorios jurídicos de la Facultad de Derecho de la UNLP.
} 
obtenido respuestas concretas y muchas veces con la falsa expectativa de tener las medidas, cuando aún esto no es así.

Cuando la mujer realiza la denuncia en la Comisaría, la misma es remitida al Juzgado Protectorio. Sin embargo, no alcanza con esto. Los Juzgados tienen como práctica habitual dictar una primera resolución estableciendo que, a los fines de dictaminar, deberá aguardarse a la presentación de la víctima con patrocinio letrado. Según el OVG (2016) esta resolución a veces es notificada a la mujer y otras veces no lo es. Esta instancia constituye un nuevo obstáculo para las mujeres por las razones de tiempos y recursos económicos que hemos mencionado anteriormente. Asimismo, se constituye en un paso revictimizante: la mujer ya ha relatado la situación de violencia en la que se encuentra ante el personal policial, por lo que no habría razones para que tenga que volver a expresarla ante el personal judicial.

En el "Formulario para denuncia de violencia familiar ley 12.569 " se consignan las distintas medidas judiciales que se podrían disponer, el personal policial debería preguntar a la mujer y marcar en el formulario las que quiere solicitar, con lo cual tendría que alcanzar.

Refiere EG. que: si la mujer no se acerca no se dictan las medidas...Si la persona no se acerca en general la citan, un mes después, porque nos ha pasado, un mes después le llega la citación del Juzgado para que diga qué quiere hacer con eso. Si quiere impulsar las medidas o no.

Como hemos mencionado anteriormente muchas veces las mujeres entienden que con hacer la denuncia en sede policial ya se ha accionado el mecanismo pertinente para obtener las medidas, en el peor de los casos entienden que ya las tienen. Y desconocen que deben hacerse presentes en el Juzgado Protectorio para continuar con el trámite. De este modo quedan en una situación de desprotección total, ya que no continúan emprendiendo acciones en el entendimiento de que cuentan con medidas de protección que aún no existen.

La exigencia de hacerse presente personalmente ante Ixs operadorxs judiciales también se repite en casos de desobediencias de parte de los agresores en relación a 
las medidas de protección: la mujer debe ir personalmente a denunciar la situación. Este aspecto lo abordaremos con mayor detalle más adelante.

\section{4.- ¿Cuándo? ¿Cómo? i¿Cuándo?!}

La normativa establece los plazos: el juzgado debe resolver las medidas urgentes en 48 horas desde que se anotició ${ }^{159}$, aunque no sea competente. Estos plazos la mayoría de las veces no se cumplen, demorándose semanas en dictar las "medidas urgentes". Sostiene EG. que en un principio empezó a funcionar bien, había respuestas relativamente rápidas...Pero hoy en día hay un letargo enorme, está funcionando muy lento. Asimismo señala que tienen prácticas nefastas como por ejemplo antedatarte los despachos, las resoluciones. Vos vas día por medio y te encontrás que el día que fuiste, la resolución está firmada y tiene fecha de la semana pasada, afirma. Es decir: se le pone a las resoluciones una fecha anterior a la fecha en la que efectivamente la firmó el/la magistradx.

El OVG sostiene que esto "aumenta la desprotección y refuerza la idea de impunidad, al dilatar en el tiempo el resguardo de la víctima y el establecimiento de los mecanismos destinados a poner freno a la acción del agresor" (OVG, 2016:5).

\section{5.- Poniendo el cuerpo otra vez más...}

Para tener conocimiento de que se dispuso la medida judicial protectoria y que hay que notificarla las mujeres tienen que acudir al juzgado la cantidad de veces necesaria hasta que le informen que la misma ya está. Refiere EG. que ahora en soporte en papel en el expediente no hay más nada. Por esta digitalización. Pero bueno, ahí tenemos también otro obstáculo: que no está actualizada la mesa virtual. Relata que al ir al Juzgado Ixs empleadxs lo muestran en sus computadoras.

Una vez dictada la resolución judicial disponiendo las medidas de protección son las propias mujeres las que la tienen que diligenciar: deben retirar el oficio judicial que dispone las medidas y llevarlo a la comisaría más cercana al domicilio del agresor. $\mathrm{S}$. relata que desde la línea 144 las asesoran para que lleven siempre consigo una copia de las mismas, y que dejen otras copias en los lugares que frecuentan: la escuela o el jardín de Ixs niñxs, casas de familiares o amigxs.

\footnotetext{
${ }^{159}$ Art. 7 inc. $n$ de la Ley 12. 569.
} 
Cuando las mujeres tienen patrocinio particular la confección del oficio para ser notificado al agresor queda en cabeza de lxs abogadxs, no lo realiza el juzgado, refiere EG. que esto implica perder 2 días más. Porque vos te venís al estudio, lo tipeas, armas el oficio, luego lo tenés que llevar al juzgado y lo dejás a confronte y luego lo retiras y lo llevas a la Comisaría.

\section{6.- Y otra vuelta más, seguro que nos vamos a marear}

Para que las medidas entren en vigencia es importante que el agresor sea notificado personalmente, esto representa una nueva dificultad: muchas veces las mujeres desconocen el domicilio actual del mismo. Son escurridizos refiere EG.

En muchas dependencias policiales Ixs encargadxs de las notificaciones tienen horarios laborales reducidos (de 8 a 12 hs. por ejemplo) y no logran notificar a los agresores en dicha franja horaria. Es decir: la notificación de las medidas protectorias queda sujeta a los tiempos y disponibilidad de recursos de las dependencias policiales.

S. relata que en varias ocasiones asesoró a mujeres para que le indiquen al personal policial que notifiquen al agresor al tiempo que concurre el patrullero por el llamado ante un hostigamiento: hemos tenido varios problemas porque no se notifican las medidas (...) hemos trabajado casos en que los que no se podía notificar a los hombres y que van a agredirlas y va la policía, entonces le decimos a la mujer que le de la notificación a al personal policial para que lo notifiquen ahí, y eso sucede.

Es la propia mujer la que debe acudir a la dependencia policial a corroborar si la notificación se efectúo o no. Los Juzgados Protectorios se desentienden y no realizan ningún tipo de seguimientos en relación a este punto.

\section{7.- $Y$ después ¿Qué?}

Una vez dispuesta la medida por el/la magistradx interviniente no hay un seguimiento de parte de Ixs actorxs judiciales de su cumplimiento.

Muchas veces los agresores las incumplen y esto no genera ninguna consecuencia. Señala P.: la mayoría de las mujeres, al menos en el último tiempo, no llegan a la parte de la denuncia y del pedido de las medidas protectorias. Esto porque tienen varias denuncias previas, muchas, esa es la situación, que ya han realizado denuncias 
anteriormente, que ya han tenido medidas protectorias y la situación sigue entonces ya no les interesa laburar el tema de la denuncia, ni las medidas judiciales.

En el momento en que se está incumpliendo la medida la mujer puede llamar a la policía para que se haga presente y garantice el cumplimiento de la manda judicial, este mecanismo tiene dificultades: en algunos barrios de La Plata los patrulleros se niegan a ingresar. Asimismo, en muchos de ellos la policía tiene una compleja relación con Ixs habitantes, por lo que su presencia tampoco representa un reaseguro para la mujer, quien muchas veces queda expuesta a ser juzgada por sus vecinos por haber convocado a la fuerza policial. Asimismo muchas veces el personal policial violenta nuevamente a la mujer con prácticas y expresiones que desvalorizan su sufrimiento, su palabra, sus derechos.

Afirma P. que la respuesta es pobre: se está un poquito mejor en lo que es lo tiempos de la justicia, como más aceitado, que la mujer no se muera esperando que le salga la medida. El tema es que la mujer se sigue muriendo igual, teniendo la medida.

Luego de ocurrido el incumplimiento la mujer debe hacerse presente en sede penal para denunciarlo. Se exige que lo haga personalmente. La denuncia la debe realizar en la sede de las fiscalías: calle 7 entre 56 y 57. Para llegar allí, nuevamente la mujer debe recorrer un largo camino: generalmente concurren a los Juzgados Protectorios, o a APUR, desde donde son derivadas al fuero penal. Una y otra vez las mujeres deben relatar sus padecimientos ante distintxs actorxs estatales.

Las medidas protectorias judiciales con frecuencia tienen un tiempo preestablecido de vigencia, el personal policial siempre se fija en si están vigentes o no al momento de intervenir.

Cumplido el plazo y en caso de continuar la situación que las motivó la mujer debe hacerse presente nuevamente en el juzgado protectorio y solicitar la prórroga de las mismas, a través de un escrito jurídico, con patrocinio letrado.

\section{8.- La prohibición de mediación}

La ley provincial de Mediación Penal ${ }^{160}$ establece que "las causas vinculadas con hechos suscitados por motivos de familia, convivencia (...)" son "especialmente

\footnotetext{
${ }^{160} \mathrm{~N}^{\circ} 13.433$, art. 6 inc. a).
} 
susceptibles de sometimiento" a mediación. En virtud de esta norma era frecuente que Ixs actorxs judiciales citen a mediar en situaciones de violencia doméstica hacia las mujeres. Sin embargo la normativa específica la prohíbe expresamente, así la ley provincial 12.569 en su artículo 11 y la ley Nacional 26.485 en su art. 28.

En trabajos anteriores hemos hecho referencia a la extendida utilización de la citación judicial a audiencias de conciliación o mediación con el agresor ${ }^{161}$, lo cual sucedía tanto en el fuero de familia como en sede penal (Ballesteros y De La Vega, 2012:16). El caso "Mariana Condori"162 visibilizó la utilización de este instituto de parte de Ixs operadorxs judiciales y las consecuencias que puede provocar en la vida de las mujeres (Carbajal, 2016).

Del trabajo de campo realizado para la elaboración de esta tesis no surge que Ixs actores judiciales del Partido de La Plata continúen realizando citaciones a conciliar o mediar las situaciones de violencia ${ }^{163}$.

Sin embargo Ixs operadorxs judiciales aún generan situaciones que pueden exponer a las mujeres a nuevas violencias. El OVG (2016) en su informe señala que el Juzgado Protectorio № 4 del Departamento Judicial de La Plata dispone en sus resoluciones: 'En relación a la prohibición de acercamiento dispuesta supra, se exceptúan su aplicación respecto a las convocatorias que las distintas Judicaturas pudieran disponer por considerarlas ineludibles con la finalidad del abordaje del conflicto entre las partes de autos, debiéndose en dicho caso adoptarse los recaudos correspondientes'. (p. 7)

Señala EG. que luego de que se disponen las medidas protectorias el cuerpo técnico del Juzgado cita a las partes, tanto al agresor como a la víctima, para tener una entrevista, la cual debe ser, según la ley, en horarios separados y días separados. Eso

\footnotetext{
${ }^{161}$ Podríamos señalar dos razones, entre muchas otras, que podrían explicar este proceder de parte de Ixs operadores judiciales: la falta de capacitación de Ixs funcionarixs en relación a las características de las relaciones donde hay violencia hacia la mujer, siendo una de ellas la situación asimétrica de poder existente, y a la concepción de que los casos de violencia tienen escasa relevancia.

${ }^{162}$ La joven de 20 años, fue hallada ahorcada el 14 de marzo de 2012 en La Plata. Ella vivía con su novio y sufría violencia por parte de él de manera constante. Mariana lo había denunciado en reiteradas oportunidades, sin obtener respuesta alguna. La violencia se recrudeció luego de las denuncias. 10 días antes de su muerte Mariana había sido citada por el fiscal Romero para "conciliar" con el agresor. El fiscal no dispuso ni solicitó ninguna medida de protección para Mariana.

${ }^{163}$ Esto a la fecha de realización de las entrevistas, es decir entre los meses de septiembre y diciembre de 2018.
} 
no se cumple, el Juzgado sigue citando con media hora de diferencia. Con lo cual se corre el riesgo de que la mujer y su agresor se encuentren en la sede del juzgado.

\section{9.- Pedazos para armar}

Los Juzgado Protectorios solo intervienen en relación a la situación de violencia y al dictado de las medidas, todas las cuestiones que excedan esto deben ser tramitadas ante los Juzgados de Familia ordinarios que son quienes las abordan (divorcio, régimen de comunicación, alimentos y cuidado parental de Ixs hijxs).

Esta fragmentación de los conflictos redunda en una mayor dificultad para las mujeres que deben llevar adelante dos procesos judiciales distintos, con dinámicas e instancias independientes uno del otro con todas las complejidades que ellos implica.

Lo cual también puede dar lugar a resoluciones judiciales contradictorias o que no contemplen la existencia de otro proceso judicial simultáneo o anterior.

\section{2.- Área de Procesos Urgentes (APUR)}

A partir de la creación de los "Juzgados Protectorios", analizados en el apartado anterior, en el Departamento Judicial de La Plata, se puso en funcionamiento el Área de Procesos Urgentes (APUR), en el marco de la Defensoría Pública, con competencia en violencia familiar, salud mental y protección de niñxs. El APUR comenzó a funcionar en octubre de 2012 y patrocina gratuitamente a las mujeres que tramitan sus causas por violencia doméstica ante dichos Juzgados.

La mujer suele concurrir a APUR derivada desde la dependencia policial, en cuyo caso, algunas veces, se presenta con una copia de la denuncia efectuada. En otras oportunidades va directamente a APUR, habiendo sido derivada allí por la DGGyD, por el personal de la mesa de entrada del Juzgado Protectorio o por alguna otra institución donde fue asesorada.

La sede de APUR queda ubicada en calle 14 № 824, 2 o Piso, entre 48 y 49 . Allí se confecciona el escrito solicitando las medidas de protección. Luego de esto la mujer debe dirigirse a la Receptoría General de expedientes de la Suprema Corte de Justicia de la Provincia de Buenos Aires (ubicada en calle 13 entre 47 y 48), para que se ingrese 
el trámite. Luego debe concurrir personalmente al Juzgado asignado a realizar la presentación, los Juzgados Protectorios quedan ubicados en calle 58 entre 11 y 12.

Desde APUR no se realiza un seguimiento de las actuaciones del expediente, salvo la representación de la denunciante en alguna cuestión puntual que se pueda suscitar (una audiencia, por ejemplo).

Se ha afirmado que desde APUR se realiza una utilización estandarizada de las medidas de protección que contempla la Ley $12.569^{164}$, que sólo se brinda asistencia en casos de violencia familiar y no por otras situaciones de violencia contra las mujeres, que las mujeres siguen realizando gran cantidad de actos procesales sin acompañamiento jurídico (por ejemplo el diligenciamiento de los oficios), y que hay contacto insuficiente entre las mujeres y sus defensores. También se sostuvo que hay una invisibilización de otras modalidades de violencia, como la violencia psicológica y la violencia económicapatrimonial (OVG, 2016: 11-12).

No hay una articulación con las Defensorías Civiles ordinarias desde donde se representa a las partes en relación a las cuestiones de fondo, en las cuales suelen propiciarse, por ejemplo, instancias de mediación. Así como tampoco hay coordinación con ámbitos del Ministerio Público del fuero penal.

Se han presentado quejas ante el OVG de parte de mujeres que refieren haber sido entrevistadas por varias personas en lugares diferentes del Área, teniendo que relatar los hechos en reiteradas oportunidades.

Los tiempos de espera para ser atendidas por Ixs abogadxs son prolongados, hay que esperar y hacer una fila en la recepción, y luego, cuando se encuentran en el piso correspondiente, otra espera, D. afirma que en 14 es infinito lo que hay que esperar.

No permiten que las mujeres suban al piso donde se encuentran las oficinas de APUR con personas que las acompañen. Así como tampoco les permiten que ingresen con ellas cuando entran a entrevistarse con el abogado. Esta práctica es contraria a lo que establece la normativa que expresamente dispone que "en cualquier instancia del proceso se admitirá la presencia de un/a acompañante como ayuda protectora"165.

\footnotetext{
${ }^{164}$ Frente a una heterogeneidad de situaciones particulares que ameritarían la posibilidad y necesidad de solicitar medidas variadas.

${ }^{165}$ Artículo 6 ter. de la Ley 12569 y articulo 25 de la Ley 26485.
} 


\section{1.- ¿Y por casa cómo andamos?}

Un desastre. Un horror. Terrible. Son algunas de las respuestas que obtuvimos de las personas entrevistadas al ser preguntadas por el trato que reciben las mujeres de parte de los abogados de APUR.

La falta de perspectiva de género de los abogados también fue un aspecto destacado. El cual será abordado en detalle más adelante.

A menudo las mujeres no entienden lo que les es informado por los abogados. Señala E.: no hay voluntad de darse a entender, de intentar que la otra persona entienda lo que están diciendo y refiere que es algo que también les ha ocurrido a ellas en tanto profesionales.

Muchas veces Ixs integrante de APUR hacen ir a las mujeres en reiteradas oportunidades a su sede sin darle ninguna respuesta ni información. E. ejemplifica esta situación parafraseando un diálogo con una mujer que asesoraba: 'Bueno, volvé la próxima'. Y ¿Fuiste? 'Si, pero no me dijo nada. O no le entendí nada'.

Son frecuentes las situaciones en que las mujeres renuncian al patrocinio de APUR y consiguen el de los Consultorios Jurídicos Gratuitos de la Facultad de Ciencias Jurídicas y Sociales de la UNLP ${ }^{166}$.

\section{3.- Fuero Penal. Las Fiscalías Especializadas ${ }^{167}$.}

En el año 2014 la entonces Procuradora General del Ministerio Público de la Provincia de Buenos Aires, la Dra. Carmen Falbo, a través de la Resolución $346^{168}$, instruyó a Ixs

\footnotetext{
${ }^{166}$ Estos Consultorios tienen su oficina en el edificio principal de dicha casa de estudios, situado en la calle 48 e/ 6 y 7, que atiende de lunes a viernes de 14 a $17 \mathrm{hs.} \mathrm{El} \mathrm{programa} \mathrm{se} \mathrm{inició} \mathrm{en} \mathrm{el} \mathrm{año} 1993$ y posibilitó la apertura de consultorios en distintos barrios periféricos del Gran La Plata, llegando a 17 lugares de atención. "El proyecto busca facilitar el acceso a la justicia de los sectores sociales más desprotegidos, a la vez que se propone suplir la ausencia de práctica efectiva en el ejercicio profesional que tienen los estudiantes avanzados y los profesionales recién recibidos" (Cristeche y Vertiz, 2013: 104).

${ }^{167} \mathrm{El}$ OVG (2016) ha sostenido, entre otras cuestiones, en relación a este punto que: las dependencias abocadas a la temática de violencia familiar y de género se han conformado en 7 Departamentos Judiciales, sobre un total de 19, que Estas Unidades fiscales tienen competencias dispares y contradictorias entre sí. Las mismas no cuentan con un Cuerpo de Profesionales Interdisciplinario y/o un cuerpo de peritos especializados para el abordaje integral de la violencia de género. Los cargos de los responsables de dichas dependencias no han sido designado teniendo en cuenta la formación específica en violencia de género.
} 
Fiscales Generales a conformar fiscalías temáticas, unidades o secretarías especializadas en la investigación de delitos de "violencia familiar" dejando a criterio de cada unx de ellxs la forma de instrumentación (art. 8).

Un año después y a raíz del cuestionado desempeño de la fiscal Carolina Carballido Calatayud $^{169}$, así como del Fiscal Emiliano Buscaglia ${ }^{170}$, un grupo de organizaciones ${ }^{171}$, presentaron un pedido de informe ante la Procuradora General Falbo, para que dé cuenta de cuáles son los procedimientos y/o mecanismos destinados a garantizar la idoneidad y probada experiencia en la lucha contra la violencia de género de las personas designadas al frente de las Fiscalías Especializadas en Violencia de Género en los Departamentos Judiciales de la Provincia ${ }^{172}$.

La Sala de Relatoría de Menores e Incapaces de la Procuración General de la Provincia de Buenos Aires (área encargada institucionalmente de las cuestiones relacionadas con género y derechos de las mujeres) es la que elaboró el informe en respuesta a la solicitud realizada. En dicho informe se consigna:

\footnotetext{
${ }^{168}$ Esta resolución también establece reglas de conexidad con el objeto de que las distintas causas originadas por situaciones de violencia familiar tramiten ante un mismo agente fiscal.

${ }^{169}$ Titular la Unidad Fiscal Descentralizada Especializada en Violencia de Género del Departamento Judicial de San Isidro quien ante la muerte de una beba tras una golpiza propinada por Alejandro Fernández, procedió a imputar a Yanina González, madre de la pequeña y pareja de Fernández, por "abandono de persona". La joven de 23 años padecía un retraso madurativo, y era víctima de violencia de género. El comunicado público difundido en mayo de 2015 señala "Pese a estar al frente de una Unidad Especializada en Violencia de Género, la funcionaria se privó de contemplar esa perspectiva durante el juicio (...): cargó contra la mujer sentada injustamente en el banquillo, responsabilizándola por la muerte de la niña sin investigar al presunto femicida" (Comisión Provincial por la Memoria et. al.). ${ }^{170}$ Titular de la Unidad Funcional e Instrucción $N^{\circ} 5$ Especializada en Violencia de Género de Moreno quien se encontraba a cargo de la Fiscalía que intervenía en la causa por las agresiones constantes que la familia de Alejandra Hertler padecía desde 2011 de parte de su ex pareja, Diego Alejandro Solís, el agresor Ixs hostigaba continuamente desde hacía 4 años y desde la fiscalía no se ha había tomado ninguna medida (Comisión Provincial por la Memoria et. al., 2015).

${ }^{171}$ Comisión Provincial por la Memoria (CPM), Red por los Derechos de las Personas con Discapacidad (REDI), Equipo Latinoamericano de Justicia y Género (ELA), Asociación por los Derechos Civiles (ADC), Asociación Civil por la Igualdad y la Justicia(ACIJ) y la Red Internacional de Periodistas con Visión de Género (RIPVG) en Argentina.

${ }^{172}$ En el marco de este proceso, y anteriormente a la presentación de dicho pedido de informe, se realizaron comunicaciones telefónicas con la Procuración General para obtener información en relación al mecanismo y requisitos de selección de las personas a cargo de las Fiscalías Especializadas, luego de un largo derrotero se estableció comunicación con la Sala de Relatoría en temas de Menores e Incapaces, coordinada por dra. Marcela Piccioni, quien informó que la Dra. Falbo instruyó a Ixs Fiscales Generales de cada Departamento Judicial, estos deben informar al Área de Piccioni quien es la persona encargada de la temática. Es preocupante que las cuestiones relacionadas con género y derechos de las mujeres estén enmarcadas institucionalmente en un área denominada "temas de menores e incapaces".
} 
se generó la implementación y designación en los distintos departamentos judiciales por parte de cada uno de los fiscales generales, de fiscalías referentes en la temática, quienes con el mismo presupuesto, los recursos existentes y el esfuerzo de los operadores judiciales, organizaron en sus respectivos departamentos, la labor en el ámbito del ministerio público fiscal provincial. (p.3)

En el Departamento Judicial La Plata la Fiscalía Especializada en Violencia de Género comenzó a funcionar en noviembre de 2015, a cargo de la fiscal Mariana Ruffino. Durante el primer semestre del 2018 se radicaron allí 1.430 denuncias. Según fuentes periodísticas $^{173}$ (que citan a funcionarias judiciales) las mismas fueron tipificadas como lesiones leves o graves, amenazas, desobediencia, daños, abusos sexuales y homicidios. Alrededor del 70 por ciento correspondería a amenazas y lesiones leves. Asimismo se refiere que alrededor del 70 por ciento de las mujeres denunciantes quiere que se archive la causa.

Con respecto al último aspecto señalado PM. ha referido que es habitual que las mujeres concurran ante Ixs actorxs judiciales del fuero penal a solicitar que no continúe el proceso penal, más aún cuando se dispone la detención del agresor, efecto no deseado por la mayoría de las mujeres (Abdul Aziz y Moussa, 2016: 101) , muchas veces con el argumento de que es un buen padre, que aporta el cuidado de Ixs hijxs y/o a la manutención económica, ante lo cual su encarcelamiento repercute negativamente en la vida del grupo familiar.

Las denuncias ingresan en la Fiscalía Especializada desde las Comisaría o la Oficina de Denuncias de la Fiscalía General de La Plata. Esta fiscalía puede disponer medidas cautelares como restricciones de acercamiento, exclusión del hogar o aprehensiones. Las mujeres concurren a la sede penal principalmente cuando son asesoradas a hacerlo por parte de las trabajadoras de la línea 144 o de la DGGyD, ante situaciones de alto riesgo y donde hay lesiones o violencia sexual. También en caso de

\footnotetext{
${ }^{173}$ Infocielo. En la fiscalía de violencia de género de La Plata se iniciaron ocho causas diarias. 31 de julio de2018.https://infocielo.com/nota/94190/en_la_fiscalia_de violencia de genero de_la_plata_se inici aron ocho causas diarias/
} 
incumplimiento de las medidas de protección dispuestas por Ixs magistradxs (de acuerdo a lo establecido por el art. 239 del C.P.).

Refiere E. que, por lo general, asesoran a la mujer para que se haga presente en "Atención a la víctima" (dependientes de la Fiscalía General Departamental), para que allí las orienten y asesoren. El edificio de calle 7 entre 56 y 57, donde funcionan las fiscalías, es un verdadero laberinto donde no es sencillo encontrar las oficinas de Ixs distintxs acotorxs judiciales.

Todas las denuncias de delitos relacionados a la violencia familiar y a la desobediencia tramitan ante la UFIJ 13. EG. sostiene que la misma tiene una mirada restrictiva en relación al punto. Relata que sus experiencias no han sido buenas: hemos tenido expedientes con 8 desobediencias sistemáticas, y las han archivado. Las archivan por falta de acreditación de los hechos, pero no tenemos forma, no suele haber testigos, tenemos solo una causa que fue elevada a juicio porque él la golpeo en plena calle, y había vecinos.

Este aspecto ha sido reconocido por quien fuera la Procuradora General de la Suprema Corte de Justicia en la mentada Resolución 346/14. Allí afirma:

Se ha verificado que las conductas reiteradas que reflejan un cuadro de permanencia contextual de violencia como consecuencia de la relación o convivencia entre el agresor y la víctima, se traduce en el plano jurídico en una cantidad de denuncias, las cuales, algunas de ellas -atento la imposibilidad de tener por acreditado el hecho de agresión denunciado- son archivadas por el Ministerio Público Fiscal hasta tanto aparezcan nuevos elementos probatorios que permitan variar el criterio adoptado. (p. 3)

Señala EG. las dificultades en relación a que no se aborda la situación en toda su complejidad sino sólo los hechos de manera aislada. Relata un caso en el que la ex pareja había amenazado en reiteradas oportunidades a la mujer y también la había golpeado, ante lo cual se realizó la denuncia penal ante la UFIJ 13, luego de esto, y en ese marco de continuos hostigamientos, el agresor amenaza con violar a la hija de la pareja actual de la mujer, y no nos querían tomar la denuncia, nos decían 'No, esto no corresponde aca'. Nosotras insistimos porque era un hecho más en el marco de la violencia sistemática. 


\section{4.- Acerca de la coordinación}

Siguiendo a Repetto (2005) entendemos por coordinación aquel

proceso mediante el cual se va generando sinergia entre las acciones y los recursos de los diversos involucrados en un campo concreto de gestión pública, al mismo tiempo que en dicho proceso se va construyendo un sistema de reglas de juego formales e informales a través de los cuales los actores participantes encuentran fuertes incentivos a cooperar. (apud Repetto, 2010: 23)

Este autor considera a la coordinación como una función estatal "que requiere ser cumplida para avanzar en la integralidad más allá del tipo de diseño institucional que la operacionalice y actor o conjunto de actores que la lideren" (Acuña y Repetto, 2006 apud Repetto, 2010: 23).

En el Municipio de La Plata una mujer puede estar tramitando un proceso ante un Juzgado de Familia, como un divorcio por ejemplo, con un defensor civil, y además otro proceso por violencia ante un Juzgado Protectorio, con el patrocinio de APUR, y además haber realizado una denuncia penal por desobediencia ante la UFIJ 13 . Todos estos procesos tienen como partes al mismo hombre y a la misma mujer y el mismo contexto de violencia, sin embargo Ixs actorxs judiciales intervinientes los abordan de manera fragmentada e independiente. Asimismo si bien actualmente en el fuero de familia las actuaciones han sido digitalizadas Ixs operadorxs judiciales no habitúan realizar una búsqueda contextualizante.

Esta práctica es revictimizante y también pone en riesgo a la mujer. Así, por ejemplo, EG. ha relatado que a veces en el marco de un proceso de divorcio se cita a ambas partes a una audiencia desconociendo que existe un resolución judicial que dispone un perímetro de no acercamiento.

Además dicha fragmentación en el abordaje de los conflictos puede dar lugar a resoluciones judiciales contradictorias.

Como vemos existe una ausencia problemática de coordinación entre los distintos fueros y entre Ixs múltiples actorxs judiciales intervinientes. 
Afirma el OVG (2016) que de este modo se genera un desconocimiento de antecedentes previos que pudieran contribuir a merituar la situación de riesgo, así como también una falta de integralidad en el abordaje del conflicto (p.9).

La referida Resolución 346/14 tiene presente esta problemática y refiere que:

el agente fiscal que se encuentra a cargo de la investigación de un delito cometido dentro de un contexto de violencia familiar, no debería omitir poner en conocimiento dicha situación y requerir los informes de antecedentes respectivos a los Juzgados Tribunales de Familia o al Juzgado de Paz del domicilio de la víctima, según correspondiere. (Procuradora General de la Suprema Corte de Justicia, 2014: 4) 174 $^{174}$

Esta problemática fue uno de los aspectos referidos en el informe alternativo ante el Comité CEDAW, suscripto por un gran número de organizaciones ${ }^{175}$, en el marco de la presentación del cuarto informe periódico del Estado Argentino (ANDHES et. al, 2016:3).

En este capítulo hemos visto que en el Partido de La Plata (y en la Provincia de Buenos Aires en general) se ha establecido un procedimiento de gestión centrado en la denuncia como mecanismo privilegiado para el acceso a la justicia de las mujeres en situación de violencia doméstica (OVG, 2016: 9). Las medidas de protección, que se presentan como la principal y casi exclusiva respuesta estatal protectoria, solo pueden tomarse por la judicatura, por lo que, cuando son necesarias, desde los otros dispositivos existentes se deriva a las mujeres a la Comisaría y/o a las instancias judiciales.

\footnotetext{
${ }^{174}$ Asimismo esta norma establece reglas de conexión para que las distintas causas por violencia familiar contra un mismo agresor tramiten ante el mismo fiscal.

${ }^{175}$ Abogados y abogadas del NOA en Derechos Humanos y Estudios Sociales (ANDHES), Asociación Católicas por el Derecho a Decidir- Argentina (CDD), Asociación Lola Mora, Centro de Estudios de Estado y Sociedad (CEDES), Centro de Estudios Legales y Sociales (CELS), Centro de la Mujer (CEDEM), Colectivo de Investigación y Acción Jurídica de La Plata (CIAJ), Centro de Intercambios y Servicios para el Cono Sur (CISCSA-AFM), Comisión Argentina para los Refugiados y Migrantes (CAREF), Comité de América Latina y el Caribe para la Defensa de los Derechos de las Mujeres (CLADEM), Equipo Latinoamericano de Justicia y Género (ELA), Feministas en acción, Fundación Interamericana del Corazón (FIC), Fundación para Estudio e Investigación de la Mujer (FEIM), Fundación Siglo 21, Instituto de Genero, Derecho y Desarrollo (INSGENAR), Mujeres en Igualdad (MEI), Mujeres Trabajando, Observatorio de Violencia de Género de la Defensoría del Pueblo de la Provincia de Buenos Aires.
} 
En dicha Provincia (y en todo el país) el modelo de gestión estatal de la violencia contra las mujeres se basa en las premisas de "responsabilización" y "activación" (OVG, 2016:11), y en una "noción privatista del riesgo" (Malacalza, 2018:239) ${ }^{176}$. En este sentido hemos visto que el mecanismo de denuncia/solicitud de medidas judiciales, existente en el Partido de La Plata exige un gran despliegue de actividad, así como de recursos logísticos y económicos de parte de las mujeres. Las mujeres pobres al recorrer las instancias que se exigen para solicitar y obtener las medidas judiciales de protección se encuentran con una gran cantidad de obstáculos, los cuales deberán ir sorteando como puedan, y con las estrategias que cada una de ellas esté en condiciones de implementar, si continúan con la decisión de mantenerse en la ruta crítica. Las mujeres que no cumplan con todas las exigencias descriptas se verán privadas de la protección estatal.

\footnotetext{
${ }^{176}$ Se ha sostenido, en este sentido, que el Estado espera la activación del individuo el cual "ya no es un sujeto de derechos, sino un individuo que tiene responsabilidades frente a un Estado que puede incluso, en caso de no cumplir con lo dispuesto, privarlo/a de la ayuda establecida" (OVG, 2016:11). Malacalza (2018) afirma que "Cada sujeto tiene que garantizar su responsabilidad en la autorregulación y autogobierno frente al contexto de creciente precariedad social, económica y laboral (...) lo que antes eran tareas de prevención y regulación de las instituciones, ahora es responsabilidad de las víctimas “( $p$. 239).
} 


\section{X.- LOS OBSTACULOS}

Los obstáculos o las mayores dificultades tienen que ver con todas las instituciones o todas las lógicas que reproducen a esas mujeres en esos roles: pasivos, de madres, esposas, responsables. Un montón de mecanismos quizás más cotidianos, que hacen que esa mujer no se imagine proyectando por fuera de esa situación (P. trabajadora social de Centros de Salud del Barrio Altos de San Lorenzo, La Plata).

En los capítulos VII, VIII y IX de esta tercer parte de nuestra tesis hemos descripto las características de la respuesta ofrecida estatalmente para mujeres en situación de violencia doméstica en el Partido de La Plata. También hemos abordado allí ${ }^{177}$ el análisis de aquellos factores que operan negativamente sobre la decisión de la mujer de iniciar o continuar con la ruta crítica (Sagot, 2000: 97) y que surgían a medida que avanzábamos en la escritura.

En el capítulo que aquí comenzamos repasaremos los obstáculos detectados en los capítulos anteriores para luego adentrarnos en el análisis de otros, algunos de los cuales son comunes a dos o más instancias abordadas anteriormente y por eso decidimos tratarlos aquí. Otros exceden la dinámica de lo existente, y dan cuenta de los vacíos, lo que no existe y hace falta.

Pero antes de ello queremos retroceder unos pasos para reflexionar acerca de los términos "obstáculos" y "factores inhibidores", íntimamente relacionados con la categoría de "ruta crítica" que utilizamos a lo largo de esta tercer parte de nuestra tesis. El concepto de "ruta crítica" parte del supuesto de que existen una serie de factores que impulsan o inhiben a una mujer a buscar ayuda (Sagot, 2000: 88).

Los factores impulsores que propician esa decisión son múltiples y dependen de cada mujer y cada situación particular (Sagot, 2000: 88). Sagot los clasifica en internos ${ }^{178}$ y externos $^{179}$ y afirma que en la vida concreta de las mujeres "están íntimamente relacionados" (Sagot, 2000: 91).

\footnotetext{
${ }^{177}$ Con la intención de no fragmentar el análisis y la escritura así como también de no caer en reiteraciones innecesarias.

${ }^{178}$ Los cuales "están asociados a procesos personales, sentimientos, representaciones sociales y razonamientos de las mujeres" (Sagot, 2000: 91).

${ }^{179}$ Estos "se relacionan con las influencias que reciben las mujeres de su medio exterior, tales como apoyos, recursos materiales, información, existencia y calidad de los servicios, aumento de la violencia o efectos de la violencia en otras personas de la familia" (Sagot, 2000: 91).
} 
Hay hechos que pueden funcionar como precipitadores de la decisión, la "gota que derrama el vaso". Afirma Sagot (2000) que si bien no existe un único factor precipitante "generalmente el punto de saturación está asociado a momentos particulares de agresión" (p. 102) y señala entre ellos el aumento de la violencia, la violencia sexual, las agresiones contra Ixs hijxs y las amenazas de muerte, entre otros (p. 103).

También hay factores que contribuyen a que la mujer desista de la decisión, o que el proceso sea más dificultoso. Sagot los llama "factores inhibidores" ${ }^{180}$ y los clasifica en internos $^{181}$ y externos $^{182}$ (2000: 97).

El Comité CEDAW (2015) los denomina "obstáculos y restricciones" y afirma que "se producen en un contexto estructural de discriminación y desigualdad" (p. 3).

Como hemos dicho en los párrafos iniciales de esta sección, analizaremos aquí los factores inhibidores externos, ya que es donde se visualiza el rol del Estado, que obstaculizan o restringen las posibilidades de las mujeres que viven en situación de pobreza.

Lo haremos desde una perspectiva interseccional en el entendimiento de que al sufrir varias formas de discriminación combinadas (por ser mujeres y por su condición socioeconómica) los obstáculos que enfrentan pueden ser particularmente críticos (CIDH, 2007: pto. 195), lo que las coloca en situación de mayor vulnerabilidad (González y Galletti, 2013: 70).

\section{1.- A modo de repaso}

En las dependencias policiales hemos detectado como prácticas habituales, que operan como obstáculos ${ }^{183}$, y pueden desalentar a las mujeres en su decisión de

\footnotetext{
${ }^{180}$ Los factores inhibidores "son todos aquellos elementos que actúan negativamente sobre la decisión de iniciar o continuar una ruta crítica" (Sagot, 2000: 97).

${ }^{181} \mathrm{La}$ autora señala los siguientes factores como inhibidores internos: el miedo al agresor, los mandatos de madre y esposa, los roles tradicionales de género (p. 97), la concepción de que lo que ocurre en la familia es privado (p. 98), el desconocimiento de los derechos y la falta de información (p. 99). Los cuales "se interrelacionan estrechamente con los elementos contextuales y las presiones del medio (...) se configuran y adquieren sentido como tales en una determinada realidad social y cultural" (Sagot, 2000: 99).

${ }^{182}$ Entre estos Sagot señala: presiones familiares, limitaciones materiales e Ineficacia Institucional ( $p$. 99), la inseguridad económica y la falta de recursos materiales (p. 100), actitudes negativas de Ixs prestatarixs y las inadecuadas respuestas institucionales (p. 100-102).
} 
transitar la ruta crítica las siguientes: la derivación indebida de parte del personal de las Comisarías comunes a la Comisaría de la Mujer y la familia o de esta a las Oficinas de Atención a la víctima del Destacamento Policial de Barrio Aeropuerto y de la Comisaría $3^{\circ}$ de Los Hornos. Así como la negativa del personal policial a tomar la denuncia, a veces expresamente, otras exigiendo requisitos arbitrarios o alegando imposibilidades materiales y la confección de exposiciones civil en lugar de las denuncias correspondientes.

Hemos visto también ${ }^{184}$ como el mecanismo de denuncia/solicitud de medidas judiciales exige un gran despliegue de actividad de parte de las mujeres, así como de recursos logísticos y económicos. Lo cual se constituye en obstáculos para aquellas mujeres que, por distintas circunstancias ${ }^{185}$, no se encuentran en condiciones óptimas de afrontarlos ${ }^{186}$. La exigencia judicial de que, a pesar de haber realizado una denuncia policial, la mujer se presente ante el Juzgado, es una sobre carga, y puede ser revictimizante ${ }^{187}$; que tenga que hacerlo con patrocinio letrado puede constituirse en un obstáculo insalvable para las mujeres pobres ${ }^{188}$. El incumplimiento judicial de los plazos legales para el dictado de las medidas urgentes coloca a la mujer en un estado de desprotección.

Otros factores inhibidores externos frecuentes son: la imposibilidad o dificultad para notificar al agresor ${ }^{189}$; la falta de actividad judicial para realizar un seguimiento en relación al cumplimiento de la medida judicial; la ausencia de consecuencias ante el incumplimiento de las mismas por parte del agresor; la negativa del personal policial a entrar a determinados barrios cuando las mujeres llaman requiriendo asistencia ante

\footnotetext{
183 Las cuales han sido abordadas en el capítulo VIII.

${ }^{184}$ En los capítulos VIII y IX.

${ }^{185}$ Entre ellas podemos mencionar: carencia de tiempo, de recursos económicos o logísticos, dificultades con la lectoescritura, dificultades físicas para trasladarse, problemas de salud, compañía constante de hijxs pequeñxs, dificultades en la comunicación con lxs operadorxs lo que redunda en una incomprensión de las indicaciones recibidas.

${ }^{186}$ Recordemos aquí las palabras de $\mathrm{P}$. cuando afirma que se exige que la mujer sea una leona y se lleve puesto todo.

${ }^{187}$ Ya que la mujer, a menudo, debe volver a relatar en sede judicial lo que ya relató en sede policial.

${ }^{188}$ Cuando no se les informa en relación a la existencia de APUR u otras opciones de patrocinio gratuito.

${ }^{189}$ Los Juzgados Protectorios se desentienden y no realizan ningún tipo de seguimientos en relación a este punto, es la propia mujer la que debe acudir a la Dependencia Policial a instar la notificación y luego a corroborar si se efectúo o no.
} 
una nueva agresión en incumplimiento de una orden judicial; que la única respuesta ante el incumplimiento sea el inicio de una causa penal y la eventual detención del agresor.

\section{2.- Desde lejos no se ve}

Falta de sensibilidad (CIDH, 2007: párr. 141) y empatía, actitudes hostiles (Gonzalez y Galletti, 2013: 40) y discriminatorias $(\mathrm{CIDH}, 2007: 88)^{190}$ de parte de Ixs actorxs estatales para con las mujeres que transitan la ruta crítica es una escena frecuente. Muchas veces las mujeres llegan a ser revictimizadas (CIDH, 2007: párr. 141).

A menudo la distancia y hostilidad que se establece tiene su fundamento en la pertenencia a distintas clases sociales. A Ixs operadorx judiciales les resulta imposible empatizar con el sufrimiento de la persona pobre, así como visibilizar las dificultades extra con las que se enfrenta una persona que carece de recursos económicos. Coincide aquí una doble discriminación: de género y clase.

Hopp (2017) refiere que las reflexiones sobre la interseccionalidad brindan un marco "para pensar la situación de las mujeres cuya clase social, etnia, nacionalidad, edad, etc. se alejen de las características de los y las juezas que están a cargo de juzgarlas” ${ }^{191}$ (p. 7). La "lejanía en las experiencias" entre las mujeres pobres en situación de violencia y Ixs funcionarixs judiciales "suele dificultar la comprensión de quienes acusan, defienden y juzgan la situación de una mujer cuyas vivencias les resultan completamente ajenas" (Hopp, 2017: 7). Esto en el entendimiento de que Ixs funcionarixs del poder judicial "en su abrumadora mayoría, no han experimentado la pobreza y desconocen los efectos de la violencia habitual" (Hopp, 2017: 7).

Frecuentemente Ixs operadorxs judiciales exteriorizan su malestar ante la forma de hablar de las mujeres pobres. A menudo lo hacen cuando estas no responden adecuadamente ante las preguntas que, con el lenguaje críptico del derecho, se les formulan (Cristeche y Vertiz, 2013: 121).

\footnotetext{
${ }^{190}$ Citando: $\mathrm{CIDH}$, Comunicado de Prensa, № 20/04, La Relatoría Especial de la CIDH evalúa la vigencia del derecho de la mujer guatemalteca a vivir libre de violencia y discriminación, Washington D.C., 18 de septiembre de 2004, párr. 26.

${ }^{191}$ Según esta autora Ixs jueces, fiscales y defensorxs son mayoritariamente hombres, de mediana edad, alto nivel educativo y de clase social privilegiada (Hopp, 2017: 7).
} 
Es habitual que de forma directa o indirecta trasmitan lo intrascendente que consideran las situaciones de violencia cuyo relato están escuchando. E. señala: Lamentablemente sigue habiendo expresiones como 'Bueno, no te veo golpeada', ‘¿hace cuánto que pasó? ¿Por qué no dijiste antes?', y también en relación a la violencia psicológica, se duda de la palabra de la mujer.

También es frecuente que Ixs operadorxs judiciales manifiesten expresamente el descreimiento en el relato de las mujeres.

EG. afirma: la justicia es patriarcal y en general tiene una tendencia a descreer de los relatos. Nos ha pasado que el propio cuerpo técnico [del juzgado protectorio] le ha dicho a algunas mujeres que son exageradas, que son básicamente casi quilomberas, que todo ese relato es exagerado, muchas veces culpabilizan a las mujeres.

El Comité CEDAW (2015) ha señalado que es debido a los estereotipos existentes que se ve afectada la credibilidad "de las declaraciones, los argumentos y los testimonios de las mujeres" (pto. 27).

La CIDH (2007) ha sostenido que la desconfianza en lo alegado por las víctimas de violencia es una de las razones ${ }^{192}$ que explican la inacción de las autoridades estatales (pto. 166).

E. sostiene que cuando esto sucede a las mujeres las afecta mucho porque es escuchar, a la par de su agresor digamos, es mucha la violencia a sostener. Porque no se le está creyendo. Y agrega: hay que resguardar un poco el cuerpo de esa mujer.

En relación a empleadxs judiciales que trabajan en atención al público agrega EG.: el trato hacia las mujeres es malo. No tienen paciencia. Les hablan como si fuera un lugar a donde vas a buscar un correo postal, no hay una perspectiva de escuchar, de ser más amable. Sino que es una respuesta muy seca, incluso a veces me ha pasado que son las 2 menos 10, y le dicen 'Andá, andá allá' y yo después les digo, 'No mirá, está cerrado', esas cosas básicas.

Lxs operadorxs judiciales y policiales a menudo tratan de manera irrespetuosa a las mujeres, las prejuzguen, justifican al violento, descreen en su palabra y/o minimizan la

\footnotetext{
${ }^{192}$ Otras de ellas son la percepción del tema como un asunto privado y de baja prioridad (CIDH, 2005: 84: 166).
} 
situación ${ }^{193}$. Este maltrato puede constituirse en un obstáculo que opere desalentando a la mujer en su decisión de continuar recorriendo la ruta crítica.

\section{3.- Hecha la ley}

Muchas veces Ixs operadorxs se comportan con un excesivo formalismo, justificándose en que la ley no les posibilita actuar de determinada forma (Salanueva y González, 2011). En otros casos sin embargo cuando la ley es protectoria de los derechos de las mujeres, se resisten a aplicarla, así por ejemplo el poco abordaje y recepción de la violencia económica, expresamente contemplada en la ley 26.485 (OVG, 2016:12).

El Comité Cedaw (2015) afirma que la interpretación errónea de las leyes o su aplicación defectuosa puede deberse a las concepciones estereotipadas de Ixs magistradxs y señala que "los estereotipos comprometen la imparcialidad y la integridad del sistema de justicia, que a su vez puede dar lugar a la denegación de justicia, incluida la revictimización de las denunciantes" (pto. 27).

Se ha afirmado que en la región de América Latina y el Caribe "la gran mayoría de los problemas en la aplicación de las leyes de violencia doméstica y los más graves provienen de las creencias y valores patriarcales de las autoridades", los cuales algunas veces son reconocidos y conscientes y otras no ${ }^{194}$ (Rioseco Ortega, 2005: 28).

La CIDH (2007) afirma que en la aplicación de las leyes "aún persiste la influencia de patrones discriminatorios" que determinan un tratamiento inferior hacia las mujeres (pto. 225). Y sostiene que existe en América una

tendencia judicial a tomar decisiones sustentadas en sistemas morales y religiosos en los que se privilegia lo formal sobre lo sustancial y los derechos se interpretan de manera restrictiva, reproduciendo las raíces de la discriminación y de la inequidad en la región. (p. 77)

De parte de los funcionarixs judiciales y agentes policiales, se continúa percibiendo el problema de la violencia contra las mujeres como un asunto no prioritario (CIDH, 2007:

\footnotetext{
${ }^{193}$ De esta forma reproducen estereotipos discriminatorios, y evidencian la cosmovisión patriarcal presente en la mayoría de Ixs operadorxs.

${ }^{194}$ Entre ellos la autora señala la creencia de que la violencia doméstica es un problema privado, que la familia debe mantenerse siempre unida y que quien recibe maltrato es porque lo provoca.
} 
pto. 151), que pertenece al ámbito privado (CIDH, 2007: pto. 166), y que debe ser resueltos sin la intervención del Estado (CIDH, 2007: pto. 147).

La lógica y las prácticas patriarcales se expresan de distintas formas: minimizando la situación, justificando al agresor, naturalizando la violencia. Refiere Rioseco Ortega (2005) que la creencia de que quien recibe maltrato es porque lo provoca es una de las creencias patriarcales vigentes (p. 28).

En este sentido P. refiere relatos de mujeres sobre entrevistas mantenidas con los abogados de APUR: 'me dijo el abogado, que yo no me ponga en pareja ahora con otra persona, 'porque sino lo iba a hacer enojar más a él', 'si vos te ponés de novio, así no estás colaborando'.

La CIDH (2007) ha afirmado que ha verificado que "la violencia y la discriminación contra las mujeres todavía son hechos aceptados en las sociedades americanas", lo cual se ve reflejado en la respuesta de Ixs funcionarios y en el tratamiento de los casos (pto. 147).

E. (trabajadora de la DGGyD) señala que es muy excepcional que ellas salgan de la oficina para acompañar a una mujer a realizar algún trámite, y que una de esas excepciones suele ser acompañarla a APUR por las malas intervenciones de dicha Defensoría: hay maltrato hacia las mujeres, pero además hay intervenciones en contraposición a lo que la mujer está diciendo que le está pasando. Entonces revierten de hecho intervenciones que hemos hecho nosotras, por ejemplo, o desconocen el proceso que se viene realizando e intervienen de forma tal que implica dar marcha atrás terriblemente. Y ejemplifica con situaciones en las que, a modo de consejo, desde APUR se les ha dicho a las mujeres: 'No, ¿para qué una medida? Hablale, decile que te vas a ir de joda con tus amigas, ponete una pollera...' las mujeres nos los cuentan diciendo 'No lo podía creer'.

También señala que funcionarios de APUR les han referido a ellas (a las profesionales de la Dirección Municipal): Bueno, ahora todo es violencia de género. Toda una moda. Por otro lado agrega que, muchas veces, no se entiende lo que te dicen y te desacreditan por no entender, porque nos pasa a nosotras, capaz que a mí se me 
mezcla una palabra que no es la propiamente adecuada, y ya, olvidate, tengo que remar 15 minutos para volver a hablar de igual a igual o aunque sea que te escuchen.

La CIDH (2007) ha constatado la influencia de patrones socioculturales discriminatorios que influyen en la percepción del problema y afectan las actuaciones de Ixs abogadxs, fiscales, magistradxs y funcionarixs de la administración de la justicia en general, así como de la policía (pto. 151).

Las actitudes negativas de Ixs agentes estatales referidas anteriormente "son parte integral de este mundo que promueve la impunidad" (Sagot, 2000: 100-101). Además de constituir, muchas veces, violencia institucional, y de dejar desprotegida a la mujer, pueden generar también que las mismas desistan de continuar con el camino emprendido en la búsqueda de protección estatal ante una situación de violencia doméstica.

\section{4.- ¿Los lentes violetas?}

En las actitudes, abordajes y respuestas referidos en el apartado anterior se evidencia la falta de perspectiva de género de parte de Ixs actorxs estatales intervinientes.

Afirma EG. que no tienen perspectiva de género, para nada. En absoluto. Es evidente todo el tiempo, en como abordan la situación ${ }^{195}$.

A menudo se evidencia el desconocimiento de las obligaciones jurídicas contraídas por el Estado en el ámbito internacional y de las leyes que resultan aplicables para situaciones de violencias hacia las mujeres. Así como también la falta de capacitación para poder comprender los distintos tipos de violencia hacia la mujer: sexual, física, psicológica, económica, institucional (OVG, 2016: 12), y la relación entre ellos (CIDH, 2007: pto. 194).

Refiere EG.: hay una decisión también de no formarse en esas cuestiones, la Corte de Provincia acá hace muchas capacitaciones y siempre somos las mismas personas, yo no veo a ningún operador. No veo a los operadores en las capacitaciones, nos conocemos todes.

\footnotetext{
${ }^{195}$ En relación a los abogados de APUR.
} 
La CIDH ha señalado la falta de implementación y la incorrecta aplicación del marco jurídico existente por parte de los funcionarixs judiciales como uno de los obstáculos que afectan el procesamiento efectivo de casos de violencia contra las mujeres. (2007: pto. 217). También señaló la resistencia y el desconocimiento de algunxs magistradxs sobre la "aplicación e interpretación de tratados internacionales de derechos humanos en el derecho interno, particularmente los aplicables en los casos de mujeres" (2007: pto. 227).

Como hemos visto frecuentemente se continúa percibiendo a la violencia doméstica hacia las mujeres como un problema del ámbito privado, y no se lo aprehende en su dimensión de violación a los derechos humanos de las mujeres.

El OVG (2016) ha referido que "a pesar de la conformación de áreas específicas como APUR hemos observado que continúan careciendo de personal especializado" (p. 12 ). Afirman González y Galletti (2013) que las prácticas de Ixs profesionales siguen "atadas en algunos casos a estereotipos clásicos de género" y destacan el rol de la formación universitaria en la transmisión de concepciones estereotipadas (p. 72).

La falta de perspectiva de género y de Derechos Humanos, así como de capacitación y formación en el personal estatal que interviene en el abordaje de las situaciones de violencias hacia las mujeres repercute directamente en la inadecuada respuesta que se les brinda a las mismas ${ }^{196}$.

\section{5.- Todos los caminos conducen a...}

Los dispositivos estatales ${ }^{197}$ de abordaje de la problemática de la violencia doméstica hacia las mujeres se encuentran ubicados en el casco urbano, la mayoría en el centro geográfico, comercial y administrativo de la ciudad de La Plata.

Los sectores sociales en situación de pobreza, viven fuera del casco urbano de la ciudad (Cristeche y Vertiz, 2013: 119), por lo cual cuando quieren acceder a estas instancias deben desplazarse distancias que implican la inversión de tiempo y dinero.

\footnotetext{
${ }^{196}$ Como hemos visto en los puntos 2 y 3 del presente capítulo.

${ }^{197}$ Con excepción de los Centros de Salud y las Oficinas de Atención a la Victima del Ministerio de Seguridad ubicadas en la Comisaría 30 de Los Hornos y en el Destacamento Policial de Barrio Aeropuerto.
} 
Las mujeres pobres en situación de violencia tienen que emplear significativos recursos económicos y logísticos propios para poder acceder a los dispositivos pertinentes, interponer una denuncia y participar en el procedimiento judicial (CIDH, 2007: pto. 182). Por esto, S. sostiene que, es muy difícil que las mujeres puedan acercarse.

Esta distancia opera como un obstáculo. En ocasiones las mujeres no pueden ausentarse mucho tiempo de sus viviendas o están supeditadas estrictamente a otros horarios, como por ejemplo los de entrada y salida de Ixs hijxs de la escuela.

A menudo no cuentan con el tiempo necesario para trasladarse hacia el centro de la ciudad. Cualquier demora podría alertar al agresor y provocar su represalia ${ }^{198}$. El inicio de la ruta crítica implica riesgos para las mujeres (Sagot, 2000: 88), se ha afirmado que cuando intentan abandonar al violento, a menudo, la violencia escala y se convierte en letal (Roberts, 1990:11).

En muchos casos, la lejanía implica resignar el día de trabajo (Cristeche y Vertiz, 2013: 111). En ocasiones las mujeres tienen trabajos precarios a los que no pueden faltar, ya que corren el riesgo de perderlos. Se ha señalado que "es probable que muchas personas decidan no acudir a un organismo por las obligaciones laborales" (Cristeche y Vertiz, 2013: 111).

Otras veces las mujeres no cuentan con los recursos económicos para erogar el costo del transporte. No tienen plata ni para cargar la SUBE, afirma E.

Las dificultades señaladas en relación al tiempo y los recursos económicos se ven acentuadas cuando la mujer debe trasladar junto a ella a sus hijxs. Es habitual que se encuentren de forma casi permanente con Ixs niñxs, y que no tengan alternativas de cuidado, lo cual complica aún más sus posibilidades de desplazarse hacia el centro de la ciudad.

El Comité CEDAW (2015) ha afirmado que "la concentración de los tribunales y los órganos cuasi judiciales en las principales ciudades, su falta de disponibilidad en regiones rurales y remotas, el tiempo y el dinero necesarios para acceder a ellos" son factores que impiden a la mujer el acceso a la justicia (p. 13).

\footnotetext{
${ }^{198}$ Generalmente las mujeres procuran que el agresor no se entere de que ellas han emprendido acciones para salir de la situación de violencia hasta que han sido dispuestas las medidas judiciales y hay que notificarlo.
} 
Señala asimismo que para asegurar dicho acceso es necesario que se den seis componentes esenciales y relacionados entre sí: justiciabilidad, disponibilidad, accesibilidad, buena calidad, rendición de cuenta de los sistemas de justicia y suministro de recursos a las víctimas (Comité CEDAW, 2015: 13) ${ }^{199}$. La situación descripta evidencia el incumplimiento de los mismos.

La CIDH (2007) también ha manifestado su preocupación por "la ubicación geográfica de las instancias judiciales receptoras de denuncias" (pto. 172).

\section{6.- Se hace camino al andar}

Son varios los momentos de la ruta crítica en que las mujeres desconocen cómo deben continuar así como también los alcances y consecuencias de los trámites realizados.

Esto provoca muchas veces el despliegue de actividad infructuosa, con el consecuente desánimo, pérdida de tiempo y recursos económicos.

La falta de información (CIDH, 2007: pto. 142), la información imprecisa y la mala orientación se convierten en poderosos factores inhibidores para las afectadas (Sagot, 2000:101).

Así, por ejemplo, en ocasiones las mujeres entienden que con la realización de la denuncia en sede policial alcanza para la obtención de las medidas protectorias, y concurren a la Defensoría (porque así se lo indicaron en la Comisaría) pero sin tener información de cuál es el objeto de ese nuevo paso.

P. señala que Muchas mujeres que llegaron a una instancia de la denuncia y después no la pudieron continuar. Por tiempos, porque no entendieron, por la dinámica más del circuito de la justicia, que se quedaron en el camino. Entonces te dicen 'No, pero yo ya lo denuncié y no pasó nada'. Y bueno, quizás llegó a la instancia de la comisaría y llegó al Juzgado, pero no llegó a tramitar todas las medidas. O no volvió entonces esa medida se cayó, o lo que sea. Es tan engorroso el proceso judicial.

\footnotetext{
${ }^{199}$ En su RG n 33 el Comité (2015) realiza recomendaciones para que los Estados cumplan con dichos componentes y garanticen el acceso a la justicia de las mujeres en situación de violencia. En relación al punto que aquí estamos abordando proponen, entre otros: establecer tribunales móviles (p. 8), sufragar el costo del transporte (p. 9), crear centros de atención integral, reducir el número de pasos para obtener acceso a la justicia (p. 9).
} 
EG. refiere que en varias oportunidades pudo observar mujeres que se apersonaban en los Juzgados Protectorios y luego de la espera correspondiente obtenían como única respuesta la entrega de un papel donde figura la dirección de APUR ${ }^{200}$.

Hay poco interés de parte de los dispositivos pertinentes, en particular de las instituciones judiciales, por brindar información sustantiva que oriente a las mujeres, las cuales "se mueven a tientas" (Sagot, 2000: 106).

Afirma el OVG (2016) que "el modelo de gestión de las causas obstaculiza el acceso a información completa y veraz (...) sobre el proceso judicial” (p.3).

El desconocimiento y desorientación de parte de las mujeres sobre el trayecto institucional que deben transitar se constituye en un obstáculo en su recorrido de la ruta crítica.

\section{7.- El rompecabezas}

Al emprender acciones para solicitar protección estatal por la situación de violencia doméstica que padecen, las mujeres se encuentran con múltiples actorxs, ningunx de Ixs cuales puede dar una respuesta integral. Deben recorrer gran cantidad de instancias, que muchas veces quedan distanciadas entre sí, lo cual insume mucho tiempo y recursos.

Sagot (2000) califica estas trayectorias como "largas y tortuosas", con "gestiones que parecen interminables" (p. 106) y donde las mujeres se pierden en "un mundo de complicados, y a veces antojadizos, trámites y procedimientos" afirma (pp. 100-101). En el mejor de los casos, es decir una mujer que ha sido asesorada adecuadamente y acude a todos los organismos pertinentes, tendrá que ir a la Comisaría de la Mujer y la Familia (ubicada en calle 1 entre 42 y 43) y/o a la DGGyD ${ }^{201}$ (calle 50 entre 6 y 7), luego a otra dependencia municipal a que le activen el botón antipánico, a APUR (calle 14 entre 47 y 48) a que le confeccionen el escrito solicitando medidas, a la receptoría

\footnotetext{
${ }^{200}$ Señala la entrevistada que en una oportunidad la mujer no sabía leer, estaba evidentemente angustiada y con dos niños pequeños por lo que ella le informó en relación a lo que implicaba ir a la Defensoría, y la orientó geográficamente. En otra oportunidad en una situación similar EG. le informó a la mujer que APUR cerraba a las 14 hs. ya que también estaba con niñxs pequeñxs y el personal del juzgado solo se había limitado a indicarle que se dirija a allí y darle el papel referido, a pesar de que eran las 13,50 hs. y que por la distancia existente y la situación de la mujer no llegaría a tiempo.

${ }^{201} \mathrm{Si}$ acude sin turno, y ya tienen todos los del día dados, le darán turno para que concurra otro día.
} 
General de Expedientes (13 entre 47 y 48 ) a que le den entrada al trámite y le informen que juzgado intervendrá, al Juzgado Protectorio que le tocó (58 entre 11 y 12) a realizar la presentación. Luego deberá volver allí las veces necesarias hasta que "salga" el oficio disponiendo las medidas, el cual deberá llevar a la comisaría más cercana al domicilio del agresor. Luego si hay incumplimiento, concurrirá a la DGGyD, al Juzgado Protectorio o a APUR a denunciarlo desde donde se la derivará a la fiscalía (calle 7 entre 56 y 57). Mientras tanto por las cuestiones relativas al ingreso al Programa "Hacemos futuro" o al trámite de chapas para vivienda deberá concurrir a la DGGyD, desde donde se propone mantener el contacto y continuar acompañando a la mujer al principio una vez cada 15 días y luego una vez por mes.

Muchas veces se suma el paso por las comisarías comunes, desde donde suelen ser derivadas a la Comisaría de la Mujer y la Familia.

Las mujeres deben "compartimentalizar" y "encuadrar" (Sagot, 2000: 106) sus preocupaciones, sentires y experiencias en diferentes ramas del ejercicio profesional y de las incumbencias institucionales de los organismos intervinientes.

Es sumamente complejo comprender el recorte de competencias de cada una de esas instancias, asimismo, como hemos visto, la información muchas veces no es proporcionada de forma completa y adecuada.

A lo dificultoso que se presenta ese camino institucional en sí mismo, "pared" y "laberinto" en el que las mujeres andan "a tientas" (Sagot, 2000: 101 y 106), debemos señalar la complejidad que añade la carencia de recursos económicos para solventar los traslados y los alimentos necesarios durante el tiempo que insume recorrerlo. Más aun cuando las mujeres van acompañadas de sus hijxs pequeñxs, que se cansan, tienen hambre, calor o frío.

Esta circunstancia constituye una dificultad extra que requiere un gran esfuerzo físico y mental, el cual se le exige a la mujer si pretende las medidas de protección. A cambio se le ofrecen escasas respuestas.

Afirma P. que: Todo lo que tiene que ver con lo que implica llevarla como a la instancia más pública o de pedir alguna respuesta del Estado, es muy engorroso, lleva mucho 
tiempo, es imposible para las mujeres que además no pueden no hacerse cargo de sus hijos, o no pueden salir de sus casas.

Esas distintas instancias pertinentes no tienen ninguna colaboración ni coordinación entre sí, y muchas veces ofrecen respuestas disimiles y hasta contradictorias.

La conexión la hacen las mujeres que llevan y traen papeles de un punto a otro, muchas veces sin conocer ni entender el sentido de esos actos. El derecho de las mujeres a tomar una decisión informada es sustituido por las prácticas cotidianas ya establecidas (Sagot, 2000: 106).

Esa sobrecarga de actos "conllevan instancias de revictimización para las mujeres e incluso la imposibilidad real de afrontar tales tramitaciones" (OVG, 2016:11).

La CIDH (2007) afirma que la fragmentación de instituciones con competencia en la temática y la ausencia de coordinación y colaboración entre ellas crea confusión y onerosidad en el seguimiento de los procesos (pts. 183 y 236).

Dicha fragmentación y dispersión de las instituciones pertinentes, se constituyen en obstáculos para las mujeres que transitan la ruta crítica en busca de respuestas para la situación de violencia en la que se encuentran.

\section{8.- ¿Pero entonces quien lo tiene?}

La incertidumbre de las trabajadoras acerca de los recursos con los que se puede contar en determinada situación, referida en el punto 4 del capítulo 7, se traduce en incertidumbre para la mujer.

En caso en que la situación de la mujer lo amerite, se les informa ${ }^{202}$ sobre las posibilidades de ser inscriptas en el Programa "Hacemos futuro", de conseguir chapas para vivienda o ser ingresadas al refugio municipal. Pero también se les aclaran las dificultades, demoras e inconvenientes. No les decimos cosas a las mujeres que no podemos sostener, afirma $\mathrm{E}$.

Esto muchas veces opera desalentando a la mujer. Yo creo que si a la mayoría de las mujeres en la primer entrevista vos le decís 'Mirá bueno, podemos ingresarte a una lista

\footnotetext{
${ }^{202}$ Desde la línea 144 Provincia, los Centros de Salud o la DGGyD. Esta información no es brindada por las instancias judiciales.
} 
de trabajo, hay posibilidades de contar por varios meses con un subsidio para que vos alquiles...' Si vos le tirás 2 o 3 puntas la mujer arranca, refiere P.

La incertidumbre acerca de las características, alcances y posibilidades de los recursos con los que pueden contar se convierten en factores inhibidores y obstaculizadores del camino emprendido por las mujeres.

\section{9.- Un techo para vivir}

Frecuentemente son las mujeres las que deben irse de la vivienda familiar para alejarse de la situación de violencia doméstica. Las mujeres pobres generalmente no tienen otro lugar a donde ir.

La mayoría no quiere dejar la vivienda sin sus hijxs (Roberts, 2017: 13-14), lo cual dificulta las posibilidades de encontrar un lugar adecuado para vivir.

La casa "es el punto de partida para organizar y reorganizar la vida" (Sagot, 2000: 100). La perspectiva de no tener un techo o recursos básicos para la supervivencia (Sagot, 2000: 100) y la consecuente agudización en la precariedad de las condiciones de vida propias y de sus hijxs hace que muchas mujeres decidan continuar en la vivienda junto al agresor.

Es decir, el tener hijxs a cargo, cuyo cuidado y bienestar depende de las mujeres (Hopp, 2017), y la imposibilidad de ofrecerles un vivienda alternativa se constituye en un importante factor inhibidor. Afirma Roberts (2017) que la mujer "de alguna manera debe balancear su propia seguridad contra el daño a sus hijos proveniente de la vivienda inadecuada, la pérdida de seguridad económica, y la ausencia de la compañía de su padre" (pp. 13-14).

En los casos en que se haya solicitado la medida judicial de exclusión del hogar, hasta tanto la misma sea dictada, la mujer necesita de un lugar para habitar, mas aun si el agresor se anotició de que ella realizó la denuncia. Este es un momento sumamente riesgoso, ya que a menudo desencadena una escalada en la violencia de parte del agresor (Roberts, 2017:11). 
Frecuentemente las mujeres no solicitan esa medida ya que son muy difíciles de sostener y suele ser más seguro que sea la mujer la que se vaya del hogar, sostiene $\mathrm{E}$. más aun cuando sus vecinxs son familiares y/o amigxs del agresor.

No hay ninguna política pública adecuada tendiente a ofrecer una alternativa habitacional para estas mujeres y sus hijxs.

Lo único que existe es la posibilidad de conseguir chapas en el marco del Ministerio de Desarrollo Social de la Provincia de Buenos Aires, pero el requisito es que la mujer provea el terreno donde se construirá la vivienda, y la documentación correspondiente. El tramite demora alrededor de 1 año.

Esta situación coloca a la mujer en una disyuntiva dramática: o se queda en la casa con el agresor, o se va con sus hijxs a la calle. La preocupación por sus hijxs "conduce a las mujeres a tolerar instituciones sociales que de otro modo rechazarían" (Roberts, 2017: 12).

P. refiere que la preocupación siempre es '¿A dónde voy? No tengo plata, no tengo casa, no tengo trabajo'... Todo con los chicos.

El caso de B. ilustra lo que decimos: B. tenía una casilla en un terreno del barrio "El retiro" de La Plata, vendió todo y con el dinero y los materiales construyeron en un terreno de su pareja en el barrio platense de Los Hornos, el cual estaba ubicado junto al de la hermana de él. Tras años de padecer múltiples violencias, y al enterarse que su pareja había intentado abusar de una de sus hijas (que no es hija de él) B. decidió separarse. El problema era a dónde ir con sus hijxs (con ella vivían una niña de 11 años, otra de 7, y su nietito de 3), en la DGGyD le dijeron que si conseguía un terreno se podría iniciar un trámite para que le provean chapas. B. buscó distintas posibilidades pero no obtuvo ningún resultado positivo, mientras tanto seguía conviviendo con el agresor quien aún no se había enterado de nada. B. realizó la denuncia penal por el intento de abuso y solicitó las medidas de protección. Le explicaron que él se iba a enterar, $y$, ante el temor a su reacción, $B$. se fue junto a sus hijxs y su nieto, a lo de su madre, donde vivían además dos de sus hermanas con sus parejas y sus hijxs. A B. y lxs pequeñxs le armaron un lugarcito en el patio con chapas prestadas, era invierno y fue 
muy duro afirma B.. Esta mujer perdió todo lo que con esfuerzo había comprado ${ }^{203}$, se entristece al contarlo: todo lo que tenía perdí, el lavarropas todavía lo estoy pagando, la heladera, los colchones todo quedó en la casa.

En ciudad de La Plata existe un Refugio Municipal, es un dispositivo pensado para alto riesgo de vida, de las mujeres y sus hijxs, refiere E., está pensado para el riesgo concreto, el agresor tiene arma, la está buscando, hay algo que es insostenible, entonces se resguarda físicamente a la mujer y se la saca de ese lugar de peligro, ejemplifica. Por cuestiones de seguridad no se difunde su ubicación ni los nombres de las personas que trabajan allí.

El informe de gestión de 2017 de la Secretaría de Derechos Humanos de la Provincia sostiene, en referencia a la Red de Hogares de Protección Integral creada en 2016, que el objetivo es "lograr una mejor respuesta estatal para brindar seguridad, protección y atención especializada a las mujeres y sus hijxs que viven en situación de riesgo por violencia de género" (p. 20).

Pero la casa refugio ${ }^{204}$ también se utiliza como respuesta al no haber otra salida habitacional. Sostiene E. que intentan que no sea así pero es lo que sucede. Afirma que siempre se trata que la última opción sea la casa refugio... pero cuando empieza a quedar el camino cada vez más chiquito, empezamos a pensar la casa refugio como salida. Pero antes pensamos otras opciones, porque no es lo ideal. Y agrega: es un dispositivo a debatir a veces, porque es la mujer la que sale de su lugar, queda como encerrada si se quiere en otro espacio.

P. refiere en el mismo sentido: en los casos que consideramos necesario tratamos de que la mujer ingrese a la casa, pero si lo podemos evitar lo evitamos.

Una coordinadora de la Línea 144 Provincia afirma: “Una vez que la mujer entra, ahí se terminó la política pública. No saben qué hacer para sacarla de ahí. No hay articulaciones en territorio con políticas de vivienda, de empleo, se queda ahí" (D Amico, 2018).

\footnotetext{
${ }^{203}$ Trabaja para una empresa de limpieza y de a poco había ido comprando las cosas para su casa.

${ }^{204}$ Afirma E. que las autoridades hablan de "Hogares" pero las trabajadoras de la DGGyD prefieren utilizar el término de "Refugios", como lo hace la bibliografía especializada.
} 
No puede ser que un hogar o casa refugio sea un depósito de mujeres afirma E. Y señala como limitantes el bajo presupuesto con el que cuenta (hay problemas con la comida incluso, refiere), el poco personal, y que no hay recursos para las mujeres ${ }^{205}$. Cuando una mujer ingresa al refugio durante el primer tiempo no puede salir del mismo ${ }^{206}$, sus hijxs tendrían que sostener la escolaridad, lo cual se va resolviendo de acuerdo a la voluntad e ingenio de las personas que trabajan en el refugio, no hay nada aceitado afirma $\mathrm{E}$.

No se cuenta con ningún recurso adecuado para preparar el egreso de la mujer, lo único que se puede tramitar es el ingreso al Programa "Hacemos futuro" del Ministerio de Desarrollo Social de Nación, y las chapas mencionadas con anterioridad. Todo esto representa un obstáculo para las mujeres pobres que buscan respuestas estatales.

La ausencia de políticas públicas tendiente a ofrecer alternativas habitacionales adecuadas para las mujeres y sus hijxs, representa un obstáculo muchas veces insalvable para las mujeres en situación de violencia.

\section{0.- El dinero sí importa}

El factor económico es una de las preocupaciones más recurrentes. Al concretarse la separación, sea por las medidas judiciales o sin ellas, las mujeres, en la gran mayoría de los casos, quedan a cargo de Ixs hijxs, con todo lo que ello implica en relación a los recursos económicos que insume. Asimismo se suelen quedar sin el aporte económico que el hombre agresor realizaba al hogar.

A ello se suma la inexistencia de un sostenimiento económico de parte del Estado para las mujeres en esta situación.

Sagot (2000) afirma que la inseguridad económica y la falta de recursos materiales han jugado un papel importante en detener las decisiones y acciones de las mujeres ( $p$. 100).

\footnotetext{
${ }^{205}$ La entrevista de admisión a la casa refugio es realizada por las trabajadoras de la DGGyD, sin embargo señala $E$. que muchas mujeres ingresan sin pasar por esta entrevista y sin que el equipo de atención tenga conocimiento.

${ }^{206}$ Si bien este es el criterio general actualmente se está analizando cada situación en particular.
} 
Sostiene P. que la mayoría de las mujeres en situación de violencia que acompaña le plantean la necesidad de un trabajo y la imposibilidad de conseguirlo, y agrega: En general también son situaciones de violencia económica porque la mayoría de las mujeres no tienen un trabajo, o si lo tienen es un trabajo precario, informal. Algunas por ejemplo trabajan con cooperativas, municipal o de alguna organización y también tienen dificultades para mantener la regularidad en el trabajo, de hecho ha pasado que han perdido puestos de trabajo por las situaciones de violencia.

E. relata que las mujeres que concurren a la DGGyD muchas veces no tienen dinero ni siquiera para cargar la tarjeta SUBE para volver a sus hogares, que los trámites para solicitar las medidas de protección pueden durar muchas horas y que las mujeres y sus hijxs no comen nada durante ese tiempo por falta de dinero, y agrega: se puede trabajar en el fortalecimiento subjetivo de la mujer pero si después en la materialidad eso no se traduce en recursos materiales o económicos, la posibilidad de construcción de una vivienda etc. algo que permita solventar esa salida, es muy difícil. Y agrega: Es una limitante muy concreta porque... 'todo muy lindo lo que vos me decís, pero ¿yo cómo hago? Si de hecho a gatas puedo venir acá'.

La única posibilidad de un subsidio económico para las mujeres en situación de violencia que están emprendiendo acciones para salir de ella, actualmente, es el Programa "Hacemos futuro" (que reemplazo el "Ellas hacen") del Ministerio de Desarrollo Social de Nación. El trámite es engorroso, demora mucho tiempo y son pocos los casos en los que el resultado es positivo ${ }^{207}$. Además $\mathrm{E}$. afirma que no existe la cuestión del trabajo, en términos de cooperativa o de encuentro entre mujeres que se planteaba en el anterior (...) salen muy pocos y tarda mucho y lleva mucha burocracia encima.

En trabajos anteriores hemos consignado la existencia del Fondo de Emergencia, el cual consistía en $\$ 1000$ por mujer para las primeras 72 hs. (Ballesteros, 2013). Antes funcionaba, era lo único que había, sostiene E. y agrega que se trataba de una suma fija por mujer que permitía por ejemplo 2 meses de alquiler de una pensión, tal vez en un mes salía uno.

\footnotetext{
${ }^{207}$ S. relata que presentó alrededor de 10 solicitudes de incorporación al Programa de las cuales solo una tuvo una respuesta satisfactoria.
} 
Desde el equipo de atención de la $\mathrm{DGGyD}^{208}$ no saben cuándo estará disponible y cuando no. Refiere E. que, al momento de la entrevista ${ }^{209}$, el mismo consiste en alrededor de \$7500 por fondo, no por mujer. Cuando cuentan con él lo utilizan para cargar tarjetas SUBE, para comprar pañales, o comida para que la mujer y sus hijxs almuercen. Afirma E. que con este "fondo" han contado en alrededor de 3 oportunidades en los 10 primeros meses del año $2018^{210}$. Ni siquiera una caja chica hay, para hacer frente a las necesidades más apremiantes. Ese fondo de emergencia nos servía a cuentagotas pero servía. No hay nada. Ni siquiera les podemos ofrecer carga para la SUBE para que puedan venir, refiere E. y agrega que les ha sucedido que mujeres les pidan plata prestada.

Actualmente cuentan con unas bolsitas con cuatro productos (fideos, lenteja, un aceite, y algo más que varía) que los provee el Ministerio de Desarrollo Social de la Provincia de Buenos Aires, y las tienen en la sede de la DGGyD para entregar a las mujeres que más lo necesiten, hay que pensar a qué mujer darle porque no hay demasiado, sostiene $\mathrm{E}$.

La carencia de recursos propios y la inexistencia de un sostenimiento económico de parte del Estado para las mujeres en esta situación suelen constituirse en una circunstancia que opera como disuasoria de su decisión de separarse del agresor.

\section{1.- ¿Y con Ixs pibxs que?}

Las tareas de crianza y cuidado de Ixs hijxs son socialmente asignadas a las mujeres (Hopp, 2017:1), y toda la responsabilidad por su bienestar también. Las mujeres al analizar las posibilidades de salir de la situación de violencia en la que se encuentran ponen especial énfasis en la situación de sus hijxs.

"Las madres tratan de resistir usualmente por el bien de sus hijos" afirma Roberts (2017: 15). Y refiere que "Hoy en día los hijos hacen difícil que las madres se escapen" (p. 13-14). Sostiene esta autora que el patriarcado toma a Ixs niñxs como rehenes,

\footnotetext{
${ }^{208}$ Que es desde donde se tramita la solicitud del fondo de emergencia.

${ }^{209}$ noviembre de 2018.

${ }^{210}$ Refiere E. que cuando las trabajadoras lo solicitan las autoridades argumentan que hay un problema de definición de titularidad de a quién corresponde, si a la Provincia o al Municipio, en el Municipio a su vez hay internas entre ellas, entonces se pelean por quién tendría esa titularidad, agrega.
} 
tanto literal como simbólicamente, para asegurar la obediencia de las mujeres ( $p$. $12)^{211}$.

Como hemos dicho en el punto 9, la mayoría de las mujeres no quieren dejar la vivienda sin sus hijxs (Roberts, 2017: 13-14) y están decididas a llevarlxs con ellas. Incluso en las ocasiones en que caracterizan al agresor como un buen padre, ya que existe la creencia que abandonar la vivienda sin llevarse a sus hijxs implicará "perderlxs": él le decía que la denunciaba por abandono de hogar y no iba a poder ver más a los nenes, afirma $\mathrm{D}^{212}$.

Tener que resolver las condiciones de vida propias y las de Ixs hijxs, en un contexto de pobreza y violencia, en el marco de un sistema patriarcal, es sumamente complejo.

Las guarderías gratuitas son prácticamente inexistentes. No hay ninguna oferta pública y gratuita de cuidado de Ixs niñxs menores de 2 años.

A los obstáculos mencionados de falta de alternativas habitacionales y sostén económico se suma la dificultad de tener que transcurrir la mayor parte del tiempo (a veces la totalidad) con Ixs niñxs. Este aspecto reduce las posibilidades de emprender acciones para procurar mejorar las condiciones de vida.

Detectamos aquí otro gran obstáculo, tanto para acudir a las sedes de las instituciones para avanzar en el proceso contra el agresor, como para generar mejores condiciones de vida luego de la separación (como por ejemplo conseguir y mantener un trabajo y una vivienda).

\section{2.- La cuestión del tiempo}

Muchos de los dispositivos de atención y asesoramiento tienen horarios acotados. APUR, los Juzgados y Fiscalías, atienden de 8 a 14 hs.

Esto sumado a las largas esperas y demoras que se suceden en esas instituciones hacen casi imposible que en un día se pueda terminar el trámite de la solicitud de medidas judiciales. Estuve 5 horas en la comisaría hasta que me tomaron la denuncia,

\footnotetext{
${ }^{211}$ Sostiene Hopp, al analizar el artículo de Robert: "La autora entiende que, en estas situaciones, los hijos rehenes de las estructuras que sostienen al patriarcado, son las cadenas que mantienen a sus madres en su posición socialmente subordinada" (Hopp, 2017: 9).

212 Sostiene Hopp que dejar a lxs niños con el agresor "será motivo en su contra al momento de decidir una disputa por la tenencia" (2017: 9).
} 
dice A.. Es todo un trámite de ir y estar veinte horas ahí, afirma D, y agrega: en $14^{213}$ es infinito .

Se requieren varias horas de dos o tres días hábiles para poder completar el trámite de solicitud de las medidas. A esto hay que sumarle los pasos posteriores: obtener el papel que dispone las medidas, llevarlo a la Comisaría.

Por lo general es hacer la denuncia un día y al otro día tener toda la mañana para hacer todo lo de las medidas. Arrancar, 8:30 por ejemplo en 14, entrar, hablar con el abogado, y a las 12:30/13 hs. estás llegando a 58, relata SL.

Esto se constituye en un obstáculo tanto para las mujeres que tienen trabajos en relación de dependencia como para aquellas que dependen de los horarios en los que sus parejas se ausenten de la vivienda o de los de ingreso y egreso de Ixs niñxs a los establecimientos educativos.

B. nos relata lo difícil que fue acercarse a la DGGyD: ella trabajaba todos los días de 8 a 15 hs. luego de lo cual cuidaba de sus hijas y su pequeño nieto en su casa, sus horarios de llegada eran vigilados por su cuñada que vivía en la casa contigua a la suya. S., la mujer que la ayudaba ${ }^{214}$ Ilamó a la DGGyD para pedir turno, allí le dieron uno a las 12 hs el cual coincidía con el horario laboral de B. ante la insistencia de su acompañante B. habló con su patrón para pedirle el día, él le dijo que se lo daba pero se lo descontaba, finalmente el nieto de B. (que vive con ella) se enfermó por lo que B. no pudo ir a la Dirección Municipal. Pidieron un nuevo turno, se lo dieron a las 13.30 hs. B. habló nuevamente con su patrón quien le dijo que no se podría tomar más días. S. habló con las autoridades de la institución en la que trabajaban y les comentó la situación, le dijeron que podría retirarse antes de su horario habitual pero si ingresaba más temprano y garantizaba terminar con su trabajo antes de partir.

B pudo ir a la primer entrevista a la DGGyD, sin embargo estaba muy nerviosa y preocupada, ya que a la angustia y temor por el hecho de tomar medidas para terminar con las violencias que padecía cotidianamente de parte de su pareja se le sumaba la preocupación por estar "descuidando" su trabajo. Después de esa primera entrevista vinieron más situaciones en las que B. debía acudir a realizar trámites antes

\footnotetext{
${ }^{213}$ En alusión a la calle 14 donde queda APUR.

${ }^{214}$ Una abogada que trabajaba en una de las oficinas que B. limpiaba, en una institución pública.
} 
de las 14 hs. (otra vez la Dirección Municipal, APUR, Juzgado Protectorio). Si bien B. pudo conservar su trabajo fue gracias a la intervención de las personas que la acompañaban que intercedieron ante las autoridades de la institución donde ella limpiaba. Igualmente les fueron descontados los días en que no se presentó a trabajar.

Hemos visto que en el Partido de La Plata son numerosos los factores que obstaculizan el camino de las mujeres pobres para acceder a medidas de protección, también que las mismas son insuficientes e inadecuadas debido a la complejidad de la problemática. A las mujeres se les exige un gran despliegue de actividad, para lo cual tendrían que contar con un nivel de recursos económicos y logísticos a menudo inaccesibles para las mujeres pobres. A cambio se les ofrece una respuesta parcial, inadecuada y muchas veces demorada. El modelo de gestión estatal de la violencia contra las mujeres esta permeado por la lógica securitaria y punitivista que ocupa un lugar central en las estrategias estatales de resolución de los conflictos sociales (Malacalza, 2018: 238).

Las palabras de P. ilustran lo que decimos: Hay un montón de situaciones que no se tienen en cuenta, que son en general típicas de una situación de violencia, y que los programas, las políticas, las instituciones no se amoldan a eso, sino que la mujer tiene que, como sea, amoldarse a las lógicas institucionales para poder llegar a un papel, que además después, en el fondo, sabe que mucho no le va a servir. Entonces se genera como una situación de no ver alternativa, de frustración y de decir "No, ya está, que voy a hacer. Me la banco". Pero por otro lado también hay mucho, y cada vez más, mujeres que sí han salido de situaciones de violencia que son las que logran que otras mujeres accionen. Te dicen "Dale sí, se puede hacer, hacelo, como sea, como te salga. Si te tenés que quedar en la calle, quedate en la calle".

Como hemos visto ${ }^{215}$ el Estado Argentino ha asumido obligaciones concretas en relación al derecho de las mujeres a una vida libre de violencias. Para cumplir con dichas obligaciones se deben tomar medidas positivas con la debida diligencia. Estas obligaciones alcanzan a todos las áreas estatales de todos los niveles (Nación,

\footnotetext{
${ }^{215}$ En la segunda parte de esta tesis.
} 
Provincia, Municipio). Las características de la respuesta estatal existente en el Partido de La Plata, que hemos descripto en esta tercer parte, no reúne los requisitos definidos por los órganos y mecanismos internacionales para poder considerarse una respuesta adecuada, oportuna y efectiva. Ahondaremos en este aspecto en el capítulo siguiente. 
CUARTA PARTE

CIERRE Y DESPEDIDA 


\section{XI.- REFLEXIONES Y PALABRAS FINALES}

A lo largo de nuestro trabajo hemos visto que el derecho de las mujeres a una vida libre de violencia es un Derecho Humano. Asimismo abordamos las obligaciones que el Estado Argentino ha asumido internacionalmente al ratificar normativa protectoria de los Derechos Humanos de las mujeres.

Ahondamos en el principio de la debida diligencia y a la luz del mismo le hemos dado contenido a las obligaciones estatales de prevenir, proteger, investigar, juzgar, sancionar y reparar en relación a las violencias hacia las mujeres. Para esto hemos puesto en dialogo producciones de distintos órganos de protección y actorxs especializadxs, tanto del Sistema Interamericano como del Sistema Universal de Derechos Humanos.

Más adelante hemos descripto cuales son las políticas públicas ofrecidas estatalmente en el Partido de La Plata, así como el rol de las Comisarías y de las instituciones judiciales pertinentes. Delineamos los caminos institucionales que las mujeres en situación de violencia doméstica deben recorrer en dicho Partido cuando buscan protección estatal. Detectamos los obstáculos con los que se encuentran y los analizamos.

En este capítulo final de nuestra tesis haremos un repaso de lo trabajado anteriormente para poder reflexionar acerca de la última pregunta orientadora que incluimos en nuestro plan de trabajo: “¿Cumple el Estado con las obligaciones asumidas internacionalmente en relación a la violencia doméstica, en tanto respeto y protección de los Derechos Humanos de las mujeres en este aspecto?".

Hemos visto que el Estado Argentino ha ratificado los dos grandes instrumentos internacionales específicos de protección de los DDHH de las mujeres: la CEDAW y la CBDP. De este modo se ha comprometido internacionalmente y ha asumido obligaciones ${ }^{216}$ en relación al derecho de las mujeres a una vida libre de violencia.

\footnotetext{
${ }^{216}$ Abordadas en los capítulos IV y V de la segunda parte de esta tesis.
} 
En cumplimiento de dichas obligaciones el Estado Argentino ha sancionado la "Ley de protección integral a las mujeres" ${ }^{217}$ la cual tiene como uno de sus objetivos el acceso a la justicia de las mujeres que padecen violencia y su asistencia integral ${ }^{218}$. En Argentina esta ley es la primera que nomina la violencia hacia las mujeres, y lo hace de forma amplia. En este campo, se ha avanzado en la visibilización (González y Salanueva, 2012: 104), la nominación y el reconocimiento del sufrimiento de las mujeres en situación de violencia, pero es solo el comienzo ${ }^{219}$, falta mucho por andar en relación al despliegue de la función discursiva, performativa, de la ley (Segato, 2011: 1). Sostiene la Relatora Especial Ertürk que "el desafío actual para combatir la violencia contra la mujer consiste en aplicar las normas existentes de derechos humanos" (2006: 2).

El abordaje de una problemática tan compleja como la violencia doméstica hacia las mujeres debe ser integral (Dohmen, 2006: 229; Birgin y Gherardi, 2008: 242), esta necesidad ha sido reconocida por la normativa vigente y se constituye en una obligación para el Estado Argentino (Ballesteros, Cisneros y Barcaglioni, 2012:11). En este sentido la Corte IDH (2009) ha resuelto que los Estados deben adoptar una estrategia de prevención y protección integral para cumplir con la obligación de debida diligencia en casos de violencia contra las mujeres (pto. 258).

Actualmente en la Provincia de Buenos Aires la interpretación armónica de la normativa vigente establece un alto estándar de protección y prevención contra la violencia hacia las mujeres.

Sin embrago se ha sostenido que en dicha provincia se han concentrado los recursos presupuestarios y profesionales en la creación de dispositivos institucionales que atiendan las denuncias en sede policial y judicial, para el acompañamiento en el inicio de esa etapa del proceso, pero no se contemplan mecanismos integrales para el

\footnotetext{
${ }^{217}$ Ley no 26.485 de protección integral para prevenir, sancionar y erradicar la violencia contra las mujeres en los ámbitos en que desarrollen sus relaciones interpersonales.

${ }^{218}$ Artículo 2, inc. f y g respectivamente.

${ }^{219}$ En las preguntas orientativas elaboradas por la Relatora Especial Coomaraswamy (1999: pto. 25) para analizar si los Estados cumplen con sus obligaciones de debida diligencia, la mitad de ellas se refieren a la legislación interna de los países, y la otra mitad a las medidas adoptadas en otros aspectos.
} 
seguimiento y la atención de las mujeres que han sufrido situaciones de violencia (ANDHES et al., 2016: 9 y 10).

Se confirma de este modo la brecha existente entre leyes y prácticas que ha sido advertida por el Comité CEDAW (2010) en sus observaciones al Estado Argentino y que muchos estudios han señalado (Segato, 2011: 2; Sagot, 2000; CIDH, 2007; Hollweck y Urbancic Baxter, 2006; Sernam, 2009; Barcaglioni, s/f) ${ }^{220}$.

Cuando una mujer decide emprender acciones para salir de la situación de violencia doméstica en la que se encuentra, y solicita la intervención del Estado para poder lograrlo, el modelo de gestión estatal actual plantea que las medidas para proteger sus derechos ${ }^{221}$ serán tomadas por Ixs magistradxs, para lo cual la mujer debe realizar una denuncia policial, y/o una presentación judicial.

En otras palabras: Las medidas de protección judiciales se presentan como la principal y casi exclusiva respuesta estatal, solo pueden tomarse por la judicatura por lo que, cuando son necesarias, desde los otros dispositivos pertinentes se deriva a la mujer a la Comisaría de la Mujer y la Familia y/o a las instancias judiciales. La denuncia ante estos implica el inicio del proceso judicial.

En el Partido de La Plata, además de las instancias judiciales y policiales, la oferta estatal para mujeres en situación de violencia doméstica consiste en la línea telefónica 144 Provincia, la oficina de atención de la Dirección General de Género y Diversidad de la Municipalidad y los Centros de Salud municipales. Ubicamos a estos dispositivos en el primer tramo de la ruta crítica. Se caracterizan principalmente por ser instancias a donde las mujeres concurren inicialmente, al comenzar a dar los primeros pasos para alejarse de la situación de violencia en la que se encuentran. Por lo general asesoran y derivan, en algunos casos ofrecen también un acompañamiento sostenido en el tiempo.

\footnotetext{
${ }^{220}$ Aspecto que hemos abordado en el capítulo 1 de la primera parte de esta tesis.

${ }^{221}$ Medidas de exclusión del hogar, perímetro de no acercamiento, fijación de alimentos provisorios, entre otras.
} 
Las mujeres que quieran acceder al mecanismo de protección estatal existente en el Partido de La Plata recorrerán, en el mejor de los $\operatorname{casos}^{222}$, el siguiente camino: irán a la Comisaría de la Mujer y la Familia (ubicada en calle 1 entre 42 y 43) y/o a la DGGyD 223 (calle 50 entre 6 y 7); luego a otra dependencia municipal a que le activen el botón antipánico; a APUR (calle 14 entre 47 y 48 ) a que le confeccionen el escrito solicitando medidas; a la Receptoría General de Expedientes (calle 13 entre 47 y 48 ) a que le den entrada al trámite y le informen qué juzgado intervendrá; al Juzgado Protectorio correspondiente (calle 58 entre 11 y 12) a realizar la presentación. Luego deberá volver allí las veces necesarias hasta que "salga" el oficio disponiendo las medidas protectorias, el cual deberá llevar a la comisaría más cercana al domicilio del agresor $^{224}$. Luego, si hay incumplimiento, concurrirá al Juzgado Protectorio, a la DGGyD, o a APUR a denunciarlo desde donde se la derivará a la Fiscalía (calle 7 entre 56 y 57$)^{225}$. Mientras tanto por las cuestiones relativas al ingreso al Programa "Hacemos futuro" o al trámite de chapas para vivienda deberá concurrir a la DGGyD, desde donde se propone mantener el contacto y continuar acompañando a la mujer al principio una vez cada 15 días y luego una vez por mes.

Muchas veces se suma el paso por las comisarías comunes, desde donde suelen ser derivadas a la Comisaría de la Mujer y la Familia.

Al transitar la ruta crítica las mujeres se encuentran con distintos factores externos (Sagot, 2000: 97) que obstaculizan su camino, que contribuyen a que la mujer desista de la decisión, o que el proceso sea más dificultoso. Entre ellos han sido señalados la inseguridad económica, la falta de recursos materiales, las actitudes negativas de los prestatarixs y las inadecuadas respuestas institucionales (Sagot, 2000: 100-102).

\footnotetext{
${ }^{222}$ Es decir una mujer que ha sido asesorada adecuadamente y acude a todos los organismos pertinentes.

${ }^{223}$ Si acude sin turno, y ya tienen todos los del día dados, le darán turno para que concurra otro día.

${ }^{224}$ También será la mujer la encargada de realizar el seguimiento acerca de si la notificación se pudo concretar o no.

${ }^{225}$ Allí, en el mejor de los casos, obtendrá como respuesta el inicio de una causa penal por desobediencia, lesiones, amenazas.
} 
Desde una perspectiva interseccional hemos analizado ${ }^{226}$ los factores inhibidores externos que obstaculizan o restringen las posibilidades de las mujeres que viven en situación de pobreza ${ }^{227}$, en el Partido de La Plata, para mantenerse en la ruta crítica y/o salir de la situación de violencia en la que se encuentran.

Vimos que al pretender acceder a la justicia, para solicitar la protección de un órgano judicial y obtener una respuesta que proteja sus derechos, las mujeres pobres se encuentran con gran cantidad de obstáculos, que muchas veces operan desalentándolas en su decisión.

En las dependencias policiales hemos detectado como prácticas habituales que operan como obstáculos las siguientes: la derivación indebida de parte del personal de las comisarías comunes a la Comisaría de la Mujer y la Familia o de esta a las Oficinas de Atención a la víctima del Destacamento Policial de Barrio Aeropuerto y de la Comisaría $3^{\circ}$ de Los Hornos; la negativa del personal policial a tomar la denuncia, a veces expresamente, otras exigiendo requisitos arbitrarios o alegando imposibilidades materiales; la confección de exposiciones civil de parte del personal policial en lugar de las denuncias correspondientes.

El mecanismo de denuncia/solicitud de medidas judiciales ${ }^{228}$ exige un gran despliegue de actividad de parte de las mujeres, así como de recursos logísticos y económicos. Las mujeres que no estén en condiciones de realizar toda la actividad requerida no podrán acceder al mecanismo previsto. Cada derivación, cada nuevo paso, nuevo requerimiento, nuevo trámite, nuevo papel, se constituyen en obstáculos para muchas mujeres que, por distintas circunstancias ${ }^{229}$, no se encuentran en condiciones óptimas de afrontarlos ${ }^{230}$. Cada instancia de espera y demora favorece que se frustren las posibilidades de completar las gestiones necesarias para la solicitud de las medidas

\footnotetext{
${ }^{226}$ En la tercer parte de esta tesis.

${ }^{227}$ Al sufrir varias formas de discriminación combinadas (por ser mujeres y por su condición socioeconómica) los obstáculos que enfrentan pueden ser particularmente críticos (CIDH, 2005:96-97: 195), lo que las coloca en situación de mayor vulnerabilidad (González y Galletti, 2013: 70).

${ }^{228}$ Descripto en los capítulos VIII y IX.

${ }^{229}$ Entre ellas podemos mencionar: carencia de tiempo, de recursos económicos o logísticos, dificultades con la lectoescritura, dificultades físicas para trasladarse, problemas de salud, compañía constante de hijxs pequeñxs, dificultades en la comunicación con lxs operadorxs lo que redunda en una incomprensión de las indicaciones recibidas.

${ }^{230}$ Recordemos aquí las palabras de $\mathrm{P}$. cuando afirma que se exige que la mujer sea una leona y se lleve puesto todo.
} 
protectorias. La exigencia judicial de que la mujer debe hacerse presente en el Juzgado con patrocinio letrado ${ }^{231}$, representa una doble dificultad. Por un lado la exigencia de patrocinio letrado, cuando no va acompañada de la información pertinente en relación a la existencia de APUR u otras opciones de patrocinio gratuito, puede constituirse en un obstáculo insalvable para las mujeres pobres. Por otro, el requerimiento de que la mujer se presente ante el Juzgado, exponiendo su situación nuevamente, es una sobre carga, y puede ser revictimizante ${ }^{232}$. El incumplimiento judicial de los plazos legales para el dictado de las medidas urgentes coloca a la mujer en un estado de desprotección.

Otro obstáculo frecuente consiste en la imposibilidad o dificultad para notificar al agresor. Los Juzgados Protectorios se desentienden y no realizan ningún tipo de seguimientos en relación a este punto ${ }^{233}$. Tampoco hay actividad judicial para realizar un seguimiento en relación al cumplimiento de la medida judicial. Muchas veces los agresores las incumplen y esto no genera ninguna consecuencia ${ }^{234}$. En el momento en que se está incumpliendo la medida la única opción para la mujer es llamar a la policía, sin embargo en algunos barrios de La Plata los patrulleros se niegan a ingresar, lo cual deja a la mujer absolutamente desprotegida ante la nueva agresión. A posteriori la única respuesta ante el incumplimiento es el inicio de una causa penal (a instancias de la mujer) y la eventual detención del agresor, lo cual muchas veces no es deseado por las mujeres. La inadecuación, potencial o concreta, de la respuesta estatal también puede operar como un factor inhibitorio para las mujeres que transitan la ruta crítica. Como hemos señalado en el capítulo $\mathrm{X}$, la ubicación geográfica de los dispositivos pertinentes también se constituye en un obstáculo. Las mujeres pobres tienen que emplear significativos recursos económicos y logísticos propios para poder acceder a los mismos, cuando no cuentan con ellos se ven privadas de poder solicitar protección

\footnotetext{
${ }^{231}$ Como paso previo a que se dictamine sobre las medidas solicitadas en sede policial.

${ }^{232}$ Ya que la mujer a menudo debe volver a relatar ante el personal judicial lo que ya relató en sede policial.

${ }^{233}$ Es la propia mujer la que debe acudir a la Dependencia Policial a llevar el oficio judicial y luego a corroborar si la notificación se efectúo o no.

${ }^{234}$ Lo cual refuerza la sensación de impunidad, y la de desprotección de la mujer.
} 
estatal ante la situación de violencia en la que se encuentran ${ }^{235}$. Si tienen hijxs pequeñxs a su cargo las dificultades se acentúan.

También constituyen factores inhibidores externos la inexistencia de políticas públicas adecuadas tendientes a ofrecer una alternativa habitacional para las mujeres y sus hijxs, así como también las características del Refugio existente.

La ausencia de políticas públicas tendientes a sostener económicamente a las mujeres ${ }^{236}$ así como la falta de certidumbre acerca de los recursos estatales con los que se puede contar, son un fuerte obstáculo para las mujeres pobres. Así como también lo es la ausencia de alternativas de cuidado para Ixs hijxs que sean públicas, gratuitas y accesibles.

Hay otra serie de circunstancias, producto de la inadecuada respuesta institucional implementada en el Partido de La Plata, que también operan como factores inhibidores de las mujeres que transitan la ruta crítica. Entre ellas señalamos las siguientes ${ }^{237}$ : falta de información, información imprecisa y/o inadecuada; mala orientación, en relación al trayecto institucional que hay que recorrer así como a los alcances de los trámites requeridos, lo cual puede provocar el despliegue de actividad infructuosa, con el consecuente desánimo, pérdida de tiempo y recursos económicos; existencia de múltiples instancias que deben ser recorridas por las mujeres, muchas veces distanciadas entre sí, lo cual insume mucho tiempo y recursos ${ }^{238}$, sin que ninguna de ellas pueda dar una respuesta integral. La ausencia de coordinación entre los múltiples actorxs pertinentes también se constituye en un obstáculo, puede ser revictimizante, repercute en el desconcierto y puede poner en riesgo a la mujer, además de devaluar la calidad de la respuesta institucional que se ofrece.

Los horarios de atención reducidos, así como las largas demoras y esperas a las que se ven sometidas las mujeres en los distintos dispositivos estatales a los que acuden en el

\footnotetext{
${ }^{235}$ El Comité CEDAW (2015) ha señalado que el tiempo y el dinero necesarios para acceder a los tribunales son factores que impiden a la mujer el acceso a la justicia (pto. 13).

${ }^{236}$ Las cuales, como hemos visto, en caso de prosperar las medidas y concretarse una separación, suelen quedar a cargo de Ixs hijxs, sin el aporte económico que el hombre agresor realizaba al hogar, y muchas veces sin vivienda

${ }^{237}$ Las cuales fueron abordadas en el capítulo $X$.

${ }^{238}$ Una vez más destacamos que quien no cuenta con ellos se verá privada de la posibilidad de acceder a los dispositivos existentes. También recordamos aquí que las dificultades mencionadas se ven acentuadas cuando las mujeres deben desplazarse junto con sus hijxs.
} 
tránsito de la ruta crítica, constituyen fuertes factores inhibitorios ya que es casi imposible que en un día se pueda terminar el trámite de la solicitud de medidas judiciales ${ }^{239}$.

Las palabras de P. resultan pertinente para resumir lo descripto: la mujer tiene que, como sea, amoldarse a las lógicas institucionales para poder llegar a un papel, que además después, en el fondo, sabe que mucho no le va a servir. Entonces se genera como una situación de no ver alternativa, de frustración y de decir "No, ya está, que voy a hacer. Me la banco".

Ahora bien, hemos visto que, a la luz del principio de la debida diligencia ${ }^{240}$, los Estados están obligados a tomar medidas razonables para prevenir las violencias hacia las mujeres, para protegerlas cuando la misma ocurrió o ante el riesgo concreto de padecerla, para investigar, juzgar y sancionar de manera oportuna y adecuada y para reparar a las mujeres afectadas.

En consonancia con los objetivos que nos hemos propuesto al inicio de esta tesis, hemos centrado nuestro análisis de la ruta crítica en las respuestas del Estado para las mujeres que la transitan, esto nos ubican centralmente en un aspecto de las obligaciones estatales analizadas: el de la protección.

En el punto 3 del capítulo $V$ hemos detallado el contenido de esta obligación y hemos afirmado que la obligación de proteger con la debida diligencia exige que los Estados garanticen múltiples aspectos. A la luz de lo descripto en la tercer parte de esta tesis se evidencia que en el Partido de La Plata no se cumple con los siguientes aspectos de la obligación de proteger: disponibilidad y accesibilidad $^{241}$ a servicios especializados

\footnotetext{
${ }^{239}$ Esto se constituye en un obstáculo tanto para las mujeres que tienen trabajos en relación de dependencia como para aquellas que dependen de los horarios en los que sus parejas se ausenten de la vivienda o de los de ingreso y egreso de Ixs niñxs a los establecimientos educativos.

${ }^{240}$ Abordado en el capítulo IV de esta tesis.

${ }^{241}$ El Comité Cedaw (2015) realiza recomendaciones a los Estados para que estos cumplan con sus obligaciones, en relación a los distintos elementos que deben asegurarse para garantizar el derecho de acceso a la justicia. En lo atinente al requisito de la "disponibilidad" recomienda, entre otras cosas, que los Estados aseguren el acceso a los centros de crisis, la asistencia financiera, los refugios, las líneas de emergencia y los servicios médicos, psicosociales y de orientación (pto. 16). En cuanto al requisito de la "accesibilidad" recomienda que los Estados establezcan centros de acceso a la justicia, como "centros de atención integral", que incluyan una gama de servicios jurídicos y sociales, a fin de reducir el número de pasos que deben realizar las mujeres para obtener acceso a la justicia. Esos centros deben proporcionar
} 
apropiados de atención y apoyo, que respondan a las necesidades inmediatas de las mujeres, las protejan contra otros daños y se ocupen de las consecuencias; disponibilidad y accesibilidad ${ }^{242}$ a procedimientos judiciales adecuados y oportunos; asistencia jurídica de calidad $^{243}$; asistencia material inmediata: centros de acogida, ropa, manutención de Ixs hijxs, empleo, educación (artículo 7 inc. D y 8 inc. D de la CBDP; Ertürk, 2006: pts. 82 y 83; Abdul Aziz y Moussa, 2016: 36; CIDH, 2007: pto. 56); servicios de orientación para toda la familia, servicios de custodia y cuidado de Ixs niñxs y adolescentes afectadxs (artículo 8 inc. D de la CBDP).

Asimismo, como hemos visto, en el Partido de La Plata tampoco se cumple con la obligación estatal de proporcionar reparaciones adecuadas, la cual implica, entre otros aspectos, los siguientes: la creación y acceso a servicios efectivos y apropiados de protección, apoyo y rehabilitación y la compensación ${ }^{244}$ (Ertürk, 2006: pto. 84); también incluye las disculpas, la verificación de los hechos, los tributos simbólicos, las sanciones a los responsables y el cese de la violencia (Abdul Aziz y Moussa, 2016: $101)^{245}$.

asesoramiento jurídico y asistencia, iniciar el procedimiento judicial y coordinar los servicios de apoyo para las mujeres en todas las esferas, como las cuestiones de familia, la salud, la seguridad social, el empleo, la propiedad y la inmigración. Esos centros deben ser accesibles para todas las mujeres, incluidas las que viven en la pobreza y/o en zonas rurales y remotas, asimismo indica el Comité que se debe prestar especial atención a las mujeres con discapacidad (pto. 17).

${ }^{242}$ Entre las recomendaciones realizadas por el Comité CEDAW (2015) señala que los Estados deben mejorar el acceso irrestricto de la mujer a los sistemas de justicia (pto. 15), este aspecto hace al requisito de la justiciabilidad. Asimismo recomienda, que los Estados aseguren la creación y el mantenimiento de tribunales que garanticen el derecho de la mujer de acceder a la justicia sin discriminación en todo el territorio del Estado parte (pto. 16), esto hace al requisito de la "disponibilidad" de los sistemas de justicia. Asimismo recomienda, en relación a la "accesibilidad", que aseguren que el entorno físico y la localización de las instituciones judiciales y cuasi judiciales y otros servicios sean acogedores, seguros y accesibles a todas las mujeres, y que se preste especial atención a sufragar el costo del transporte hasta las instituciones judiciales y hasta otros servicios a las mujeres que no cuentan con medios suficientes (pto 17).

${ }^{243}$ El Comité Cedaw (2015) recomienda que los Estados partes aseguren que los proveedores de asistencia jurídica y defensa pública sean competentes, sensibles a las cuestiones de género, respetuosos de la confidencialidad y que tengan el tiempo suficiente para defender a sus clientes (pto. 37).

${ }^{244}$ La cual puede consistir en la concesión de una indemnización económica por las lesiones físicas y psicológicas sufridas, por la pérdida del empleo y de oportunidades educativas, por la pérdida de prestaciones sociales, por daños a la reputación y a la dignidad así como por los gastos legales, médicos o sociales incurridos como consecuencia de la violencia (Ertürk, 2006: pto. 84).

${ }^{245}$ EI MESECVI (2017), en su Tercer Informe Hemisférico ha recomendado a los Estados que avancen en la reparación integral del daño provocado por la violencia "incluyendo la adecuada reparación económica a las víctimas y sus familiares, con perspectiva de género de forma que tome en cuenta las 
Entonces: la obligación de proteger con la debida diligencia se centra en evitar que ocurran nuevos actos de violencia y en asegurar que las mujeres que la han padecido o están en riesgo concreto de sufrirla, tengan acceso a servicios pertinentes y a recursos judiciales, los cuales deben ser adecuados y oportunos (CIDH, 2009: párr. 126 y 127$)^{246}$. La repuesta estatal en el Partido de La Plata es contraria a la exigencia de la adecuación mencionada, ya que no cumple con los aspectos referidos en los párrafos precedentes, ni con el estándar que se desprende del "Sistema de las cuatro A" 247 (asequibilidad $^{248}$, adaptabilidad ${ }^{249}$, accesibilidad ${ }^{250}$, aceptabilidad ${ }^{251}$ ). Tampoco puede considerarse oportuna: la demora en la resolución judicial que dispone las medidas, así como el tiempo que le lleva a una mujer poder realizar todos los trámites necesarios para solicitar las medidas judiciales, pueden dar lugar a que, en el transcurso, las mujeres padezcan nuevos hechos de violencia. Dicho mecanismo tampoco consiste en una respuesta integral.

necesidades y prioridades específicas de las mujeres víctimas con un enfoque de derechos humanos" ( $p$. 213, pto. 31).

${ }^{246}$ Recordemos que en este sentido la CIDH (2011) ha sostenido, en relación a los deberes estatales en casos de violencia contra las mujeres cometidos por particulares, que comprenden: "la organización de toda la estructura estatal -incluyendo el marco legislativo, las políticas públicas, los órganos encargados de implementar la ley como la policía, y el sistema judicial- para prevenir y responder de forma adecuada y efectiva a estos problemas" (párr. 125).

${ }^{247}$ El Mesecvi (2013) señala que los servicios destinados a las mujeres víctimas de violencia deben ser adecuados y responder a los estándares en materia de derechos humanos, que se traducen en dicho sistema. Este sistema fue desarrollado originariamente por Katarina Tomaševski (2001) en relación al derecho a la educación y luego fue adoptado para el conjunto de derechos humanos (p.10).

${ }^{248}$ La obligación de "asequibilidad" o "disponibilidad" implica el deber de satisfacer cada uno de los derechos incluidos en la CBDP, para lo que cada Estado debe asumir la doble obligación de: a) establecer los medios, servicios o instituciones aptas para el conjunto de deberes que se establece en el art. 7 de la CBDP; y b) abstenerse de "cualquier acción o práctica de violencia contra la mujer y velar por que las autoridades, sus funcionarios, personal y agentes e instituciones se comporten de conformidad con esta obligación" (art. 7 inc. A de la CBDP) (Mesecvi, 2013: 10).

${ }^{249}$ La obligación de "adaptabilidad" compromete al Estado a desarrollar políticas e instituciones y brindar todos aquellos servicios que mejor se adapten a las distintas necesidades de las mujeres, considerando especialmente los grupos en condiciones de vulnerabilidad (art. 9 CBDP) (Mesecvi, 2013: 10).

${ }^{250}$ La obligación de "accesibilidad" compromete al Estado a garantizar que todos los medios, acciones y servicios estén disponibles sin discriminación alguna (art. 6 C CBDP) (Mesecvi, 2013: 10)

${ }^{251}$ Esta obligación implica que es el Estado el que debe asegurar la adecuada calidad de las políticas, acciones y servicios que se brindan para garantizar el derecho de las mujeres a una vida libre de violencia (art. 7 y 8 CBDP) (Mesecvi, 2013: 10). 
Por otro lado, al analizar ${ }^{252}$ los obstáculos con los que se encuentran las mujeres, observamos que las actitudes negativas de parte de Ixs actorxs estatales involucradxs también operan como factores inhibidores externos. La falta de personal capacitado en la temática propicia que tales actitudes tengan lugar. Entre ellas podemos señalar: actitudes hostiles, discriminatorias y maltrato ${ }^{253}$ hacia las mujeres de parte del personal judicial y policial; descreimiento en su relato; actitudes que refuerzan los estereotipos discriminatorios y/o desprotegen a la mujer; ausencia de perspectiva de género; excesivo formalismo; negativa a aplicar las leyes protectorias; falta de visibilización y comprensión de la violencia hacia las mujeres como una violación de derechos humanos ${ }^{254}$.

Hemos visto ${ }^{255}$ que Ixs actorxs estatales están obligadxs a adoptar una perspectiva de género $^{256}$. Las prácticas y actitudes mencionadas en el párrafo anterior contravienen dicha obligación. En esos casos, las mujeres vuelven a sufrir violencia, ahora son Ixs propixs agentes estatales quienes ejercen violencia institucional ${ }^{257}$ hacia ellas.

Como hemos visto el Estado tiene la obligación de respetar los derechos de las mujeres, por lo que será responsable de los actos u omisiones de los órganos y agentes estatales que constituyan violencia contra la mujer.

\footnotetext{
${ }^{252}$ En la tercer parte de esta tesis.

${ }^{253}$ Son tratadas de manera irrespetuosa, prejuzgadas, se justifica al violento y/o se minimiza la situación.

${ }^{254}$ Así como también la percepción de la problemática como un asunto no prioritario, que pertenece al ámbito privado y que debe ser resueltos sin la intervención del Estado, y la creencia de que quien recibe maltrato es porque lo provoca.

${ }^{255}$ En el punto 2 del capítulo Il y en el punto 4 del capítulo $X$.

${ }^{256}$ Como hemos dicho el Estado Argentino, al ratificar la CBDP y la CEDAW, ha asumido compromisos jurídicos en relación a no reforzar los estereotipos de género. Todos los agentes estatales, incluidos Ixs magistradxs, fiscales y defensorxs están obligados a que sus análisis y abordajes no sean producto de concepciones estereotipadas. El Comité Cedaw (2015) en sus recomendaciones ha incluido, en relación al punto que aquí abordamos, las siguientes: que aseguren que los profesionales de los sistemas de justicia tramiten los casos teniendo en cuenta las cuestiones de género (pto. 15); apliquen mecanismos que garanticen que las normas probatorias, investigaciones y otros procedimientos probatorios jurídicos y cuasi judiciales sean imparciales y no estén influenciados por prejuicios o estereotipos de género (pto. 18). Señala que este aspecto hace a la buena calidad de los sistemas de justicia. Asimismo recomienda que los Estados tomen medidas, incluidas las de concienciación y fomento de la capacidad de todos los agentes de los sistemas de justicia y de los estudiantes de derecho, para eliminar los estereotipos de género e incorporar una perspectiva de género en todos los aspectos del sistema de justicia (pto. 29).

${ }^{257}$ La violencia institucional contra las mujeres ha sido definida por la ley 26.485 (art. 6 inc. D) como "aquella realizada por las/los funcionarias/os, profesionales, personal y agentes pertenecientes a cualquier órgano, ente o institución pública, que tenga como fin retardar, obstaculizar o impedir que las mujeres tengan acceso a las políticas públicas y ejerzan los derechos previstos en esta ley".
} 
A modo de repaso podemos decir que la responsabilidad del Estado con respecto a la violencia contra las mujeres, puede generarse a raíz de actos u omisiones de agentes estatales (Comité Cedaw, 1992: pto. 8 y 2017: pto. 22 y 23), o de particulares, en relación a sus obligaciones (las del Estado) de debida diligencia (Comité Cedaw, 1992: pto. 9 y 2017: pto. 10). Actualmente en el Partido de La Plata las características de la respuesta estatal existente podría generar la responsabilidad internacional del Estado en ambos sentidos: por la violencia generada por Ixs propixs actorxs estatales involucradxs, así como por la falta de debida diligencia en la protección de las mujeres pobres en situación de violencia doméstica que recorren la ruta crítica en busca de respuestas.

Por otro lado, hemos visto que las mujeres pobres son consideradas un grupo en condiciones de vulnerabilidad, expuesto a un riesgo particular de sufrir vulneraciones a sus derechos $^{258}$. El Estado tiene la obligación de contemplar esta situación y adoptar medidas específicas de prevención y protección (CIDH, 2009: párr. 127; MESECVI, 2017: pto. 27) $)^{259}$. En el Partido de La Plata no hay ningún tipo de medidas en ese sentido, es decir: no hay políticas públicas específicas para los grupos de riesgo. La respuesta y el abordaje existente es único y no se contemplan las diferentes necesidades que tienen las mujeres.

Al analizar el concepto de acceso a la justicia señalamos que, en relación a él, la obligación de los Estados no es sólo negativa ${ }^{260}$, sino fundamentalmente positiva: de organizar el aparato institucional de modo que todas las personas puedan $\operatorname{acceder}^{261} \mathrm{a}$

\footnotetext{
${ }^{258}$ Ya que en ellas se intersectan dos causales de opresión y discriminación: ser mujer y pobre.

${ }^{259}$ Teniendo en cuenta esta situación la Relatora Especial destaca la necesidad de adoptar estrategias polifacéticas (Ertürk, 2006:2). EI MESECVI (2017) ha señalado a los Estados la necesidad de que se adecue el aparato estatal teniéndose en cuenta las "necesidades especiales y obstáculos que enfrentan grupos de mujeres y niñas con mayor vulnerabilidad a la violencia para acceder a la justicia, como las situaciones de pobreza y exclusión, (...) las necesidades de las personas con discapacidad, entre otras" (pto. 27). El Comité Cedaw (2015) también ha realizado recomendaciones en ese sentido (pto. 17), estas medidas hacen al requisito de la "accesibilidad".

260 De no impedir el acceso a esos recursos.

${ }^{261}$ Acceso en el sentido amplio de poder llegar, mantenerse y obtener respuestas adecuadas. En este
} 
la justicia, para lo cual los Estados deben remover los obstáculos normativos, sociales o económicos que impiden o limitan la posibilidad de acceso a la justicia por parte de las mujeres (CIDH, 2007 apud Mesecvi, 2013: 14). En el Partido de La Plata los obstáculos sociales y económicos no han sido removidos, ni se observa una línea de acción clara destinada a ello.

La respuesta estatal tampoco cumple con los componente que el comité CEDAW (2015) ha señalado que es necesario que se den para asegurar el acceso a la justicia de las mujeres: justiciabilidad, disponibilidad, accesibilidad, buena calidad y suministro de recursos a las víctimas (p. 13) 262 .

En la tercer parte de esta tesis hemos visto que a las mujeres se les exige un gran despliegue de actividades y un enorme esfuerzo físico y mental, sin embargo, como contrapartida, las respuestas que se les ofrecen son pobres, fragmentadas e insuficientes $^{263}$.

Las palabras de P. nos sirven a modo de repaso y nos permiten visibilizar la situación de desprotección en que se encuentran las mujeres: Solicitar las medidas judiciales para mí, muchas veces, sirve por una cuestión de llevarlo como a una instancia más pública, (...) pero no para que la mujer en sí que se sienta segura con el papel. En general, no se sienten seguras con la medida...Porque muchas han pasado por eso. Son cosas que también se instalan, el saber popular es muchas veces el más certero... De que vos podés tener el papel y no pasa nada, porque vas a llamar a la policía y no va a venir, o porque va a venir la policía y va a decir "Bueno andate", se va a ir y el tipo va a volver... o porque hay tipos que se envalentonan más cuando la mujer hace la denuncia; o porque las mujeres no tienen posibilidad de irse a otro lado, entonces tienen a la familia del chabón al lado, al chabón que se fue a vivir a lo de la hermana enfrente ...

sentido se ha señalado la necesidad de políticas sociales activas tales como subsidios, preferencias para vivienda, capacitación laboral y servicios de cuidado para Ixs hijxs, las cuales son "condición necesaria de toda política pública de prevención y erradicación de la violencia familiar" (Birgin y Gherardi, 2008:262).

${ }^{262}$ En las notas al pie de este capítulo hemos abordado algunas de las recomendaciones que el Comité CEDAW (2015), en su RG $n^{\circ} 33$, realiza a los Estados para orientarlos en el cumplimiento de dichos componentes y para que garanticen el acceso a la justicia de las mujeres en situación de violencia.

${ }^{263}$ E. dio cuenta de esta situación en la entrevista, habló de las exigencias y las trabas, y sostuvo: Tanto se le exige a la mujer, de su fortalecimiento, pero si tenés todo el tiempo trabas es muy difícil. 
está bastante instalado eso de que la medida en sí no tiene mucho peso en términos de esa mujer sentirse protegida por el Estado, por algún organismo, por alguien que la acompañe. En otro tramo de la entrevista afirma: se cae en la voluntad individual de esa mujer que tiene que ser una leona y llevarse puesto todo... hay mujeres que eso no lo pueden hacer. La mayoría no lo puede hacer....Yo creo que si a la mayoría de las mujeres en la primer entrevista vos le decís 'Mirá bueno, podemos ingresarte a una lista de trabajo, hay posibilidades de contar por varios meses con un subsidio para que vos alquiles'. Si vos le tirás 2 o 3 puntas la mujer arranca.

Como vemos la respuesta estatal para las mujeres en situación de violencia doméstica implementada en el Partido de La Plata no reviste las características de adecuación, integralidad, calidad, asequibilidad, accesibilidad, aceptabilidad, adaptabilidad, requeridas por los órganos especializados. Esto constituye una violación a sus derechos a una vida libre de violencias y un incumplimiento del deber estatal de la debida diligencia ${ }^{264}$.

Por todo lo dicho podemos afirmar que en Argentina se ha avanzado en el reconocimiento normativo del derecho de las mujeres a una vida libre de violencia así como del derecho de las que se encuentran en situación de violencia de acceder a medidas integrales de asistencia, protección y seguridad. De este modo el Estado Argentino cumple un aspecto de las obligaciones contraídas internacionalmente. Sin embargo, la respuesta estatal para las mujeres en situación de violencia que transitan la ruta crítica en el Partido de La Plata es parcial, insuficiente e inadecuada. El sistema implementado, en los casos concretos, no otorga la protección y contención necesarias, no existiendo recursos idóneos para el abordaje de esta compleja

\footnotetext{
${ }^{264}$ El Comité CEDAW (2015) al detectar una serie de obstáculos y restricciones similares a los abordados en los párrafos precedentes ha afirmado que los mismos "constituyen violaciones persistentes de los derechos humanos de las mujeres" (pto. 3). También ha afirmado que el hecho de que un Estado parte no adopte todas las medidas adecuadas "constituye un permiso tácito o una incitación a cometer actos de violencia por razón de género contra la mujer" (p. 10). En el mismo sentido la CIDH, en su informe de fondo sobre el caso María da Penha Maia Fernandes c. Brasil (2001), sostuvo que la inefectividad judicial antes casos de violencia contra mujeres crea un ambiente de impunidad que facilita la violencia "al no existir evidencias socialmente percibidas de la voluntad y efectividad del Estado como representante de la sociedad, para sancionar esos actos" (párr. 56).
} 
problemática. De este modo el Estado incumple con las obligaciones asumidas internacionalmente en relación al abordaje integral, y la construcción de respuestas idóneas y apropiadas ante situaciones de violencia doméstica hacia las mujeres, a la luz de la obligación de la debida diligencia.

Llegando al final de nuestra tesis queremos reflexionar sobra nuevas inquietudes que nos han surgido a lo largo de estos meses de intenso trabajo.

A raíz de las entrevistas que hemos realizado nos ha impactado profundamente las condiciones en que las mujeres que trabajan en los dispositivos estatales, descriptos en el capítulo VII, desempeñan su tarea. La angustia, indignación, impotencia que nos transmitieron, así como su intenso compromiso y sensibilidad con la temática nos conmovieron. Las entrevistadas, o sus compañeras, han padecido situaciones de violencia laboral ${ }^{265}$. Siendo Ixs propixs funcionarixs estatales quienes la generan. Paradoja habitual. Asimismo no deja de sorprender la tensión que existe entre la alta calificación profesional y la intensa dedicación que se requiere para ingresar a esos puestos laborales, con los bajos salarios y malas condiciones que se ofrecen. "Mujeres violentadas a ambos lados de la línea" dice Virosta ${ }^{266}$. Nos preguntamos sobre las razones de esta situación, en el hecho de que es una tarea femeneizada ${ }^{267}$ vislumbramos una posible respuesta, pero esto es tema para otra tesis.

También nos sorprende e interpela el rol de las organizaciones sociales y del movimiento feminista. En múltiples sentidos. Por un lado al exigir al Estado que se avance en el reconocimiento y protección de los derechos de las mujeres y personas

\footnotetext{
${ }^{265}$ La cual también está contemplada en la ley 26485, y el Estado también se ha comprometido a prevenirla, sancionarla y erradicarla.

${ }^{266}$ En relación a las condiciones de trabajo de las profesionales del call de la Línea 144 Provincia.

${ }^{267}$ Como continuidad y herencia de la expulsión que sufrieron las mujeres del mercado de producción de mercancías y su confinamiento al de reproducción de la fuerza de trabajo descripto por Federici (2010). Cuando las mujeres pudieron acceder al mercado de trabajo formal lo hicieron en peores condiciones que los hombres, Amorós afirma que "las diferencias se darán en el grado de explotación, en el terreno de lo cuantitativo" (2013: 88). Las llamadas "tareas femeneizadas" suelen estar desprestigiadas socialmente y ser muy desgastantes, sin embargo cuentan con bajas remuneraciones, se las suele relacionar con el cariño, amor, bondad de las mujeres-madres. Como ejemplos de ellas podemos citar a las maestras jardineras, maestras de escuela, enfermeras. Afirma Amorós que se trata aquí de "proyecciones a escala de la sociedad de los roles que le son asignados a la mujer en el hogar" (2013, 89).
} 
LGTTBIQ $^{268}$. Por otro lado al construir aquí y ahora las respuestas que el Estado no está dando. P. señala en este sentido que las mujeres en general se sienten más protegidas por las redes del barrio, por el Centro de Salud o por algunos profesionales o por alguna organización. Pero esto también es para otro trabajo...

Nuestras entrevistadas nos han dejado un sabor amargo, una especie de desazón por lo enorme de la tarea por delante y por lo atrasado del punto de partida. Sin embargo también nos ha maravillado su mirada crítica, su espíritu de lucha, su compromiso con la temática, su "feminismo compañero" ${ }^{269 "}$ y el amor, el amor que las impulsa a continuar.

Ese amor, del que hablamos al comienzo de esta tesis, que no es individual ni romántico, sino que es colectivo, sororo, que se construye desde abajo, día a día, al calor de las luchas, del caminar juntas, hermanadas, hacia un mismo lugar... un mundo nuevo sin opresorxs ni oprimidxs. Porque vivas, diversas, deseantes, nos queremos iarriba las que luchan!

\footnotetext{
${ }^{268}$ Como ejemplo podemos señalar las movilizaciones convocadas por el colectivo "Ni una menos", los paros y movilizaciones del 8 de marzo de los últimos 3 años, las actividades y movilizaciones para el 25 de noviembre (Día de la no violencia hacia las mujeres), para el 28 de septiembre (día internacional por el derecho al aborto seguro), así como las acciones, múltiples, creativas, diversas, y la multitudinaria concentración que tuvo lugar frente al Congreso los días 13 y 14 de junio y 7 y 8 de agosto de 2018 en oportunidad de debatirse la Ley de Interrupción Voluntaria del Embarazo.

${ }^{269}$ "Se trata de las feministas compañeras que no hacen del individualismo posmoderno una moda, sino que se buscan y nos buscamos para sabernos cerca (...) Las feministas compañeras que andamos los barrios, los Juzgados, las plazas, las casas, los comedores populares, los piquetes, las huertas, los campos, las cárceles, las comisarías, las radios, los periódicos. Somos las que decimos y gritamos que no estamos solas. Que si tocan a una nos tocan a todas. Somos el cuerpo del Ni una menos que se vino gestando en esta larga historia de más de un siglo. Feministas compañeras. Las que nos llamamos cuando no sabemos cómo seguir andando con las heridas abiertas. Las que nos acompañamos cuando no sabemos cómo hacer la denuncia en comisarías donde lxs canas se ríen de nosotras, en Juzgados indiferentes, en medios de comunicación que nos invisibilizan o estigmatizan. Feministas compañeras. (...) Audaces, valientes, tiernas, rabiosas, lúdicas, las feministas compañeras nos ayudaron alguna vez a salir del lugar de víctimas, para volvernos sujetas en la historia. Sujetas no sujetadas. Mujeres que recreamos la solidaridad, haciéndonos fuertes en el camino compartido. Feministas compañeras, activistas, luchadoras populares. Mujeres siempre pero siempre al pie del cañón. Tendiendo la mano a todas y a todos quienes sufrimos distintas opresiones. Feministas libertarias, de abajo y a la izquierda. Cuerpos disidentes del héteropatriarcado, que se reinventan a sí mismos, en el amor, en la lucha, en el placer, en la libertad. Cuerpos territorios de la dignidad y de la rebeldía" (Korol, 2015 apud Pensaré cartoneras, 2018: 31).
} 


\section{XII- BIBLIOGRAFÍA}

-Abramovich, V. (2010). Responsabilidad estatal por violencia de género: comentarios sobre el caso "Campo Algodonero" en la Corte Interamericana de Derechos Humanos. En S. Millaleo (Ed.), Anuario de Derechos Humanos № 6, pp. 167-182. doi:10.5354/0718-2279.2011.11491

-Abdul Aziz Z. y Moussa J. (2016). Proyecto de la Debida Diligencia. Marco de la Debida Diligencia. Marco sobre la responsabilidad estatal para la eliminación de la violencia contra las mujeres. Iniciativa Internacional de Derechos Humanos, Inc. (IHRI).

-Amnistía Internacional (2008). Muy tarde, muy poco, mujeres desprotegidas ante la violencia de género en Argentina; prioridades de acción para el Estado Argentino. Buenos Aires, Argentina.

-Amorós, C. (2013). Sobre la ideología de la división sexual del trabajo. En Organización Política La Caldera, Feminismos y antipatriarcado, pp. 65-91. La Plata, Argentina: La Caldera Ediciones.

-ANDHES; CDD; Asociación Lola Mora; CEDES; CELS; CEDEM; ... Observatorio de Violencia de Género de la Defensoría del Pueblo de la Provincia de Buenos Aires, (2016). Evaluación sobre el cumplimiento de la convención para la eliminación de todas las formas de discriminación contra las mujeres (cedaw) en el marco de la presentación del cuarto informe periódico ante el comité cedaw $65^{\circ}$ período de sesiones. Argentina.

-Ballesteros, S. (2010). Los jueces y juezas ante las ocupaciones de tierra. Un análisis desde una perspectiva de género. Ponencia presentada en las VI Jornadas de Sociología, La Plata, Argentina.

-(2012). Informe parcial de la beca para el perfeccionamiento en la investigación [Mimeo]. Universidad Nacional de La Plata.

-(2013). Informe final de la beca para el perfeccionamiento en la investigación [Mimeo]. Universidad Nacional de La Plata.

-Ballesteros, S.; Cisneros S. y Barcaglioni G. (2012). Las violencias contra las mujeres: los discursos en juego y el acceso a la justicia. Ponencia presentada en el XIII Congreso 
Nacional y III Latinoamericano de Sociología Jurídica: Debates socio-jurídicos en torno a los cambio sociales en Latinoamérica. Viedma, Argentina.

-Ballesteros, S.; Colanzi, I.; Hasicic, C. y Urtazún, C. (2014). Las organizaciones sociales y colectivos frente a las tramas de la violencia. Ponencia presentada en el XV Congreso Nacional y V Latinoamericano de Sociología Jurídica. Rosario, Argentina.

-Ballesteros, S. y Colanzi, I. (2015). Las luchas colectivas de las mujeres en el abordaje de la violencia familiar y de género. En Derecho Y Ciencias Sociales, (12), pp. 217-235. Recuperado de https://revistas.unlp.edu.ar/dcs/article/view/2154

-Ballesteros S. y De la Vega L. (2012). No estamos solas, estamos organizadas: Las dificultades de las mujeres en situación de violencia frente a la inacción de los actores estatales y la organización social como espacio de contención y acompañamiento. En Revista Derecho y Ciencias Sociales, (7), pp. 39-52. La Plata, Argentina: FCJyS-UNLP.

-(2012). El acceso a la justicia de mujeres pobres en situación de violencia. Ponencia presentada en las 20 Jornadas de Investigadores en Formación: Reflexiones en torno al proceso de investigación. Buenos Aires, Argentina.

-Barcaglioni, G. (s/f). Acceso a la justicia de las mujeres víctimas de violencia. Recuperado

de

http://www.mujeresaloeste.org.ar/justicia/Barcaglioni,\%20Gabriela\%20Mar\%C3\%ADa. doc.

-Bartlett, K. (1990). Métodos legales feministas. Recuperado el 5 de febrero 2019 de https://es.scribd.com/document/334225745/Bartlett-Katharine-Metodos-Feministasen-El-Derecho.

-Defensoría del pueblo de la Provincia de santa Fé (2017). Ruta Crítica: trayectorias que siguen las mujeres en situación de violencia. Santa Fe, Argentina: De l'aire.

-Bengochea, A.; Juen, C.; Parola, G.; Reges, C.; Suzal, A. y Tufró, F. (2017). Mujeres que rompen el silencio. La Ruta Crítica en la Ciudad Autónoma de Buenos Aires. Ciudad Autónoma de Buenos Aires, Argentina: Dirección general de la mujer- Ministerio de Desarrollo Humano y Hábitat.

-Bergallo, P. (2007). Igualdad de género: Experiencias y perspectivas para su exigibilidad judicial. En V. Abramovich, A. Bovino y C. Courtis (comp). La aplicación de 
los tratados sobre derechos humanos en el ámbito local. La experiencia de una década, p.p.629-683.Buenos Aires, Argentina: Editores del Puerto.

-Bidaseca, K. (2010). Perturbando el texto colonial. Los Estudios (Pos) coloniales en América Latina. Buenos Aires, Argentina: Editorial SB.

-Bidaseca, K. (2015). Una herramienta de lucha para desarmar la violencia del amo. En Varias Autoras, Ni una menos. Vivxs nos queremos. Buenos Aires, Argentina: Milena Caserola.

-Bidaseca, K.; Ballesteros, S.; Katz, M. y Jarque, M. (2014). Cuerpos racializados, opresiones múltiples. Ser mujer, indígena y migrante ante la justicia. Ponencia presentada en las Terceras Jornadas de Debate y Actualización en Temas de Antropología Jurídica. San Martín, Argentina.

-Birgin, H. y Kohen, B. (2006). Introducción. El acceso a la justicia como derecho. En H. Birgin y B. Kohen (comp.), Acceso a la justicia como garantía de igualdad. Instituciones, actores y experiencias comparadas. Buenos Aires, Argentina: Ed. Biblos.

-Birgin, H. y Gherardi, N. (2008). Violencia familiar: acceso a La justicia y obstáculos para denunciar. En E. Sánchez y M. L. Femeninas (comp.), Articulaciones sobre violencia contra las mujeres, pp. 239 a 263. La Plata, Argentina: Edulp.

-Buenos Aires Provincia (s/f). Protocolo de atención telefónica de casos. Línea 144.

-(s/f). Sistema integrado provincial para el abordaje de la violencia familiar y de género.

-(s/f). Acompañantes en red.

-Camacho, R. (2003). Acercándonos a los instrumentos internacionales de protección de los derechos humanos de las mujeres. San José de Costa Rica, Costa Rica: Instituto Interamericano de Derechos Humanos.

-Campaña Nacional contra las Violencias hacia las Mujeres (2013). Comunicado de prensa: Saquemos los trapitos al sol. Buenos Aires, Argentina.

-Carbajal, M. (31 de octubre de 2016). A examen por los retrocesos en cuestiones de género. En Página 12. Recuperado el 18/3/2019 de https://www.pagina12.com.ar/diario/sociedad/3-313067-2016-10-31.html 
-CEJIL y Ministerio Público Fiscal (2013). La debida diligencia en la actuación del Ministerio Público Fiscal en casos de violencia de género. Ciudad Autónoma de Buenos Aires, Argentina: Eudeba.

-Ciriza, A. (2008). Genealogías feministas y memoria: a propósito de la cuestión de la ciudadanía de mujeres. En A. Ciriza (comp.), Intervenciones sobre ciudadanía de mujeres, política y memoria. Perspectivas subalternas, pp. 25-57. Buenos Aires, Argentina: Feminaria Editora.

-COHRE (2010). Un lugar en el mundo. El derecho a una vivienda adecuada como elemento esencial de una vida libre de violencia doméstica. Ginebra, Suiza: COHRE. -Colectivo de abogadxs populares La Ciega (2015). Hecha la Ley. Legis/aciones kirchneristas. Apuntes críticos para la reflexión. La Plata, Argentina: Pixel editora. -Comisión de Derechos Humanos de la Organización de Naciones Unidas (1994). La cuestión de la integración de los derechos de la mujer en los mecanismos de derechos humanos de las Naciones Unidas y la eliminación de la violencia contra la mujer. E/CN.4/1994/45.

-Comisión Interamericana de Derechos Humanos, OEA (2001). María Eugenia Morales de Sierra vs. Guatemala, caso № 11.625. Informe № 4/01. 19 de enero de 2001.

-(2001). Ana, Beatriz y Celia González Pérez vs. México. Caso № 11.565. Informe № 53/01. 4 de abril de 2001.

-(2001). María da Penha Maia Fernandes vs. Brasil. Caso № 12.051. Informe № 54/01. 16 de abril de 2001.

-(2007). Acceso a la justicia para mujeres víctimas de violencia en las Américas. Washington, Estados Unidos.

-(2011). Jessica Lenahan (Gonzales) y otros vs. Estados Unidos. Caso № 12.626. Informe № 80/11. 21 de julio de 2011.

-Comité para la Eliminación de la Discriminación contra la Mujer:

-(1989). Recomendación general 12: La violencia contra la mujer.

-(1992). Recomendación general N 19: La violencia contra la mujer. 
-(2005). Caso A. T. vs. Hungría. Comunicación № 2/2003. Decisión del 26 de enero del 2005.

-(2007). Caso Şahide Goekce (fallecida) vs. Austria. Comunicación № 5/2005. Decisión del 6 de agosto del 2007.

-(2007). Caso Fatma Yildirim (fallecida) vs. Austria. Comunicación № 6/2005. Decisión del 6 de agosto del 2007.

-(2009). Caso RKB vs. Turquía. Comunicación N²28/2010. Decisión del 14 de julio de 2009.

-(2010). Recomendación general № 28 relativa al artículo 2 de la Convención sobre la eliminación de todas las formas de discriminación contra la mujer. CEDAW/C/GC/28. 16 de diciembre de 2010.

-(2015). Recomendación general $N^{\circ}$ 33: sobre el acceso de las mujeres a la justicia. 3 de agosto de 2015.

- (2017). Recomendación general № 35 sobre la violencia por razón de género contra la mujer, por la que se actualiza la recomendación general núm. 19. 26 de julio de 2017.

-Corriente de Organizaciones de Base La Brecha (2015). A seguir poniendo el cuerpo. En Varias Autoras, Ni una menos. Vivxs nos queremos. Buenos Aires, Argentina: Edición Milena Caserola.

-Corte Interamericana de Derechos Humanos, OEA (1988). Caso Velázquez Rodríguez Vs. Honduras. Fondo. Sentencia del 29 de julio de 1988.

-(2005). Caso de la Masacre de Mapiripán vs. Colombia. Sentencia del 15 de septiembre de 2005.

-(2006). Caso de la Masacre de Pueblo Bello vs. Colombia. Sentencia de 31 de enero de 2006.

-(2009). Caso Masacre de las Dos Erres vs. Guatemala. Sentencia del 24 de noviembre de 2009.

-Caso González y otras ("Campo Algodonero") vs. México. Sentencia de 16 de noviembre de 2009.

-(2010). Rosendo Cantú y otra vs. México. Sentencia del 31 de agosto de 2010. 
-Comisión Provincial por la Memoria; Red por los Derechos de las Personas con Discapacidad; Equipo Latinoamericano de Justicia y Género; Asociación por los Derechos Civiles; Asociación Civil por la Igualdad y la Justicia y Red Internacional de Periodistas con Visión de Género (2015). Emergencia por violencia de género en la provincia de Buenos Aires: Exigimos respuestas concretas y eficientes a la Justicia. Buenos Aires, Argentina.

-Corte Suprema de Justicia de La Nación. Oficina de la Mujer (2017). Datos estadísticos del Poder Judicial sobre Femicidios. Buenos Aires, Argentina. Recuperado el 5 de febrero de 2019, de https://www.cij.gov.ar/nota-30470-La-Oficina-de-la-Mujer-de-laCorte-Suprema-presenta-el-Registro-de-Femicidios-de-la- usticia-Argentina.html.

-Cristeche, M. y Vértiz, F. (2013). Acceso a la justicia y marginación judicial. El caso del Departamento Judicial de La Plata a través de sus protagonistas. En M. González, Acceso a la justicia y conflictos intrafamiliares. Marginación y pobreza en el ámbito judicial, pp. 97-127. La Plata, Argentina: Imás.

-Cumbre Judicial Iberoamericana XIV (2008, 4-6 de marzo). Reglas de Brasilia sobre acceso a la Justicia de las personas en condición de vulnerabilidad. Brasilia, Brasil.

-Curiel, O. (2009). Descolonizando el feminismo: una perspectiva desde América Latina y el Caribe. Recuperado el 8/3/2019 de http://feministas.org/IMG/pdf/Ochy_Curiel.pdf.

-D’ Amico, M.L. (2018). Contener sin contención. En La pulseada, (159), pp. 6-11. La Plata, Argentina.

- De Beauvoir, S. (2011). El segundo sexo. Buenos Aires, Argentina: De bolsillo. -Defensoría del pueblo de la Provincia de santa Fé (2017). Ruta Crítica: trayectorias que siguen las mujeres en situación de violencia. Santa Fe, Argentina: De l'aire.

-Delmas, F. y Urtazún, M. (2012). Recorridos, vacíos institucionales y estrategias frente a la violencia contra las mujeres. Ponencia presentada en las VII Jornadas de Sociología de la UNLP, Argentina en el escenario latinoamericano actual: Debates desde las ciencias sociales. La Plata, Argentina. Recuperada el 12/03/2019 de http://www.memoria.fahce.unlp.edu.ar/trab_eventos/ev.1820/ev.1820.pdf 
-Dohmen M. (2006). Abordaje Interdisciplinario del Síndrome de la Mujer Maltratada. Proceso secuencial. En J. Corsi, Violencia Familiar, una mirada Interdisciplinaria sobre un grave problema social. Buenos Aires Argentina: Paidós.

-Equipo Latinoamericano de Justicia y Género-ELA (2012). Más allá de la denuncia. Los desafíos del acceso a la justicia. Investigaciones sobre violencia contra las mujeres. Buenos Aires, Argentina: ELA.

-(2014). Claroscuros en las políticas contra la violencia de género. A cinco años de la sanción de la Ley 26.485 de Protección Integral contra la Violencia es tiempo de promover la rendición de cuentas. Buenos Aires, Argentina: ELA.

-Facio Montejo, A. (1999). Cuando el género suena cambios trae (una metodología para el análisis de género del fenómeno legal). San José, Costa Rica: ILANUD.

-(2002). La carta magna de todas las mujeres. Recuperado el 28/02/2019 de http://convivejoven.semsys.itesi.edu.mx/cargas/Articulos/CARTA\%20MAGNA\%20DE \%20TODAS\%20LAS\%20MUJERES.pdf.

-Federici, S. (2010). Calibán y la bruja. Mujeres, cuerpo y acumulación originaria. Madrid, España: Traficantes de Sueños.

-Femenías M.L. (2011). Violencias del mundo global: inscripciones e identidades esencializadas. En M. Lagarde y A. Valcarcel (coord.), Feminismo, género e igualdad, pp. 85-107. Madrid, España: Pensamiento Iberoamericano.

-(2011). Acerca de los DDHH de las mujeres [apuntes de clase]. Seminario Filosofía Política Feminista y Teoría de Genero, Facultad de Humanidades y Ciencias de la Educación, UNLP.

-Femenías M.L. y Soza Rossi P. (2009). Poder y violencia sobre el cuerpo de las mujeres. En Sociologías, (21), p. 42-65. Porto Alegre, Brasil.

-Fernández Valle, M. (2018). Aproximación a las temáticas de género en la jurisprudencia interamericana. En Género y diversidad sexual. Revista Institucional de la Defensa Pública de la Ciudad Autónoma de Buenos Aires, (14), pp. 31-47. Buenos Aires, Argentina: Ministerio Público de la Defensa de la Ciudad Autónoma de Buenos Aires. 
-Ferreira G. (1992). Hombres Violentos, Mujeres Maltratadas: Aportes a la investigación y tratamiento de un problema social. Buenos Aires: Editorial Sudamericana.

-Gago, V. (15 de septiembre 2017). Teléfono descompuesto. Las 12. pp. 2-4.

-Gamba, S. (2007). Diccionario de estudios de género y feminismo. Buenos Aires: Biblos.

-García Muñoz S. (2001). La progresiva generización de la protección internacional de los derechos humanos. En Revista electrónica de estudios internacionales, (2).

Recuperado el 28/02/2019 de: http://reei.org/index.php/revista/num2/notas/progresiva-generizacion-proteccioninternacional-derechos-humanos

-(2009). Derechos Humanos de las mujeres en África y en América Latina: claves conceptuales y normativas. En E. Molina y Nava San Miguel (coords.), Buenas prácticas en derechos humanos de las mujeres. África y América latina, pp. 9 - 46. Madrid, España: Universidad autónoma de Madrid ediciones.

-Gherardi N. (2006). Notas sobre acceso a la justicia y servicios jurídicos gratuitos en experiencias comparadas: ¿Un espacio de asistencia posible para las mujeres? En Birgin, H. y Kohen, B. (comp.), Acceso a la justicia como garantía de igualdad. Instituciones, actores y experiencias comparadas. Buenos Aires, Argentina: Ed. Biblos. -Giberti, E. (2015, 14 de mayo). Violencia, ¿de género?. Diario Página/12. Recuperado el 1/3/2019 de https://www.pagina12.com.ar/diario/contratapa/13-272615-2015-0514.html

-González, M. (2015). La normativa vigente sobre violencia contra la mujer. En Revista Con X, (1), pp. 73-96. La Plata, Argentina: FPyCS-UNLP.

-González, M. y Barcaglioni, G. (2018). Violencia contra las mujeres y acceso a la justicia. En Revista Vía luris, (25), pp. 1-26. Recuperado a partir de https://revistas.libertadores.edu.co/index.php/Vialuris/article/view/848

-González, M.; Berto, V.; Sarmiento, C. y Veiga, V. (2017). Violencia de género y ruta crítica. ¿El Estado siempre presente? Una experiencia desde la Línea 144. 
-González, M. y Salanueva O. (2012). Las mujeres y el acceso a la justicia. En Revista Derecho y Ciencias Sociales, (6), pp. 91- 108. La Plata, Argentina: FCJ y S-UNLP.

-González, M., y Galletti, G. (2012). Las familias, sus conflictos y el rol de la Administración de Justicia. En Revista Punto Género, (2), pp. 143 - 159. doi:10.5354/0719-0417.2012.28368

- (2013). Tras los pasos de una administración de justicia proactiva. En M. González (comp.), Acceso a la justicia y conflictos intrafamiliares. Marginación y pobreza en el ámbito judicial, pp. 25-48. La Plata, Argentina: Imás.

- (2013). Las violencias contra las mujeres pobres en la pareja. El caso de la ciudad de La Plata. En M. González (comp.), Acceso a la justicia y conflictos intrafamiliares. Marginación y pobreza en el ámbito judicial, pp. 49-76. La Plata, Argentina: Imás.

- (2016). Dispositivos para el acceso a la justicia de las mujeres. En M. González (comp.), Violencia contra las mujeres, discurso y justicia, pp. 39-75. La Plata, Argentina: EDULP.

-Haraway, D. (1995). Ciencia, cyborgs y mujeres. Valencia, España: Ediciones Cátedra. -Hollweck M. y Urbancic Baxter M.(2006). Problemas actuales en la aplicación de la ley de protección contra la violencia familiar de la provincia de Buenos Aires. En Revista del Colegio de Magistrados y Funcionarios de la Provincia de Buenos Aires, (1), pp.7990.

-Hopp, C.M. (2017). Maternidad y delito: Una agenda para el feminismo. En Revista Argentina de Teoría Jurídica, (17). Recuperado de https://www.utdt.edu/ver_contenido.php?id_contenido=12835\&id_item_menu=5858 -Infocielo (2018, 31 de julio). En la fiscalía de violencia de género de La Plata se iniciaron ocho causas diarias. Recuperado el 10/3/2019 de: https://infocielo.com/nota/94190/en_la_fiscalia_de_violencia_de_genero_de_la_plat a_se_iniciaron_ocho_causas_diarias/

-Korol, C. (2013). Escribiendo nuestro camino. En Aquelarre, POP. Protocolo para organizaciones populares. Violencia contra las mujeres en relaciones de pareja. Violencia sexual. La Plata, Argentina: Pixel Editora. 
-(2018). El feminismo compañero de las feministas compañeras. En Pensaré cartoneras, A nuestras amigas. Sobre la amistad política entre mujeres. Colonia Nueva Maravilla.

-Lahera Parada, E. (2002). Introducción a las políticas públicas. Chile: Fondo de Cultura Económica.

-La Provincia planifica abrir 20 refugios para víctimas de violencia de género. En Diario El popular, 10 de enero 2017. Recuperado el 10/3/2019 de: http://www.elpopular.com.ar/eimpresa/251152/la-provincia-planifica-abrir-20 refugios-para-victimas-de-violencia-de-genero.

-Lugones, M. (2008). Colonialidad y género. En Tabula Rasa, (9), pp. 73-101. Recuperado el 29 de enero de 2019 de <http://www.redalyc.org/articulo.oa?id=39600906>

-Luzzi, F.; Haudemand, M. y Fernández, M.C. (2011). El trabajo en red de organizaciones vinculadas con la atención de casos de violencia familiar en La Plata. Ponencia presentada en el XI Congreso Iberoamericano de Extensión universitaria, Santa Fe, Argentina.

-Malacalza, L. (2018). Violencia contra las mujeres: un modelo de gestión securitario y privatista. En Género y diversidad sexual. Revista Institucional de la Defensa Pública de la Ciudad Autónoma de Buenos Aires, (14), pp. 237-244. Buenos Aires, Argentina: Ministerio Público de la Defensa de la Ciudad Autónoma de Buenos Aires.

-(2018). Alcances y dilemas sobre la especialización de la justicia en las causas de violencia familiar y violencia de género. En Revista Electrónica, Instituto de Investigaciones Ambrosio L. Gioja, (20), pp. 95-114. Buenos Aires, Argentina.

-Medina, D. (2017, 3 de enero). Vidal Visitó El Call Center De La Línea 144 De Llamadas De Violencia Contra Las Mujeres. El correo gráfico. Recuperado el 10/3/2019 de: http://elcorreografico.com.ar/vidal-vistito-el-call-center-de-la-linea-144-de-Ilamadasde-vionencia-contra-las-mujeres/.

-Medina Quiroga, C. (2005). Derechos humanos de la mujer: ¿Dónde estamos ahora en las Américas?. En 18 Ensayos. Justicia Transicional, Estado de Derecho y Democracia. Recuperado de: http://www.cdh.uchile.cl/media/publicaciones/pdf/18/54.pdf 
-Merino Sancho, V. (2007). Aportaciones conceptuales de la Relatora Especial sobre la Violencia Contra la Mujer. En Anuario de filosofía del derecho, (24), p.p. 387-408.

-MESECVI (2013). Indicadores de progreso para la medición de la implementación de la convención interamericana para prevenir, sancionar y erradicar la violencia contra la mujer "Convención De Belém Do Pará". Ciudad de México, México: OEA.

-(2017). Tercer Informe Hemisférico sobre la Implementación de la Convención de Belém do Pará. Prevención de la Violencia contra las Mujeres en las Américas. Caminos por Recorrer. Washington, Estados Unidos: OEA.

-(2018). Carta para el Presidente de la Corte Suprema de Justicia Argentina. 29 de noviembre de 2018.

-Minayo, M.C.S. (2016). El Desafío del Conocimiento. Investigación Cualitativa en

Salud. Recuperado el 12/3/2019 de https://www.researchgate.net/publication/31673891_El desafio del conocimiento i nvestigacion cualitativa en salud MC de Souza_Minayo

-Niken, P. (s.f.). El concepto de Derechos Humanos. Recuperado de http://www.derechoshumanos.unlp.edu.ar/assets/files/documentos/el-concepto-dederechos-humanos.pdf.

-Noe De Teitelbaum, S.; Ale, V.; Sampayo Guillaume, M. Y Hurtado, C. (s/f).Violencia de género: de la ruta crítica a la construcción de posibilidades. Recuperado el 1/3/2019 dehttps://sites.google.com/a/fundpsicsigmundfreud.org/trabajos-2do-congreso-deinvestigacion/home/noe-de-teitelbaum-susana---ale-veronica---sampayo-guillaumema-cecilia---hurtado-claudia

-Oficina del Alto Comisionado de las Naciones Unidas para los Derechos Humanos (2013). 20 años trabajando por tus derechos. Declaración y Programa de Acción de Viena. 1993. Conferencia mundial de derechos humanos. Departamento de Información Pública de las Naciones Unidas.

-ONU mujeres (2014). Declaración y Plataforma de Acción de Beijing. Declaración política y Documentos resultados de Beijing+5. Nueva York, Estados Unidos. 
-Observatorio de Violencia de Género de la Defensoría del Pueblo de la Provincia de Buenos Aire (2016). Monitoreo de políticas públicas y violencia de género. Informe 2014/2015. Buenos Aires, Argentina: OVG-DP.

-(2016). Diagnósticos sobre el funcionamiento de la justicia especializada en violencia familiar en la provincia de Buenos Aires. Aportes para la creación de un Fuero Unificado de justicia. Recuperado el 15/11/2018 de https://www.defensorba.org.ar/micrositios/ovg/pdfs/Diagnostico-sobre-elFuncionamiento-de-la-Justicia-Especializada-en-Violencia-Familiar-en-la-provincia-deBuenos-Aires.pdf

-Procuración General de la Suprema Corte de Justicia de la Provincia de Buenos Aires (2015). Informe en respuesta a la Nota 15089-15-6. Buenos Aires, Argentina.

-Raffin M. (2010). Concepto de políticas públicas [apuntes de clase]. Seminario Políticas públicas y Derechos humanos, Facultad de Ciencias Jurídicas y Sociales, UNLP. La Plata, Argentina.

-Relatora Especial sobre la violencia contra la mujer con inclusión de sus causas y consecuencias, Erturk Y. (2006). Integración de los derechos humanos de la mujer y la perspectiva de género: violencia contra la mujer. La norma de la debida diligencia como instrumento para la eliminación de la violencia contra la mujer.

-Relatora Especial sobre la violencia contra la mujer, con inclusión de sus causas y consecuencias, Coomaraswamy R. (1999). Integración de los derechos humanos de la mujer y la perspectiva de género: la violencia contra la mujer. La violencia contra la mujer en la familia.

-Repetto F. (2010). Experiencias comparadas de coordinación de políticas sociales en América Latina: aprendizajes para el caso argentino. Recuperado el 24/2/2019 de http://www.asociacionag.org.ar/pdfcap/6/REPETTO_FABIAN_EXPERIENCIAS.pdf.

-Rioseco Ortega, L. (1999). Mediación en casos de violencia doméstica. En A. Facio y L. Fries (eds.), Género y Derecho (pp. 575-611). Santiago de Chile, Chile: Lom editores. -(2005). Buenas Prácticas para la Erradicación de la Violencia Doméstica en la Región de América Latina y el Caribe. Santiago de Chile, Chile: Naciones Unidas. 
-Roberts, D. (2017). Maternidad y delito. En Revista Argentina de Teoría Jurídica, (17). Recuperado de: https://www.utdt.edu/ver_contenido.php?id_contenido=12835\&id_item_menu=5858 -Rodríguez, M. (2006). Violencia de género: una violación a los derechos humanos de las mujeres. En V. Abramovich y $\mathrm{CH}$. Courtis (comp.), La aplicación de los tratados sobre derechos humanos en el ámbito local. La experiencia de una década, pp. 581628. Ciudad Autónoma de Buenos Aires, Argentina: Editores del Puerto.

-Sagot, M. (2000). La ruta crítica de las mujeres afectadas por la violencia intrafamiliar en América Latina (Estudios de casos de diez países). Washington, Estados Unidos: Organización Panamericana de la Salud.

-Salvioli, F. (2007). El sistema interamericano de protección de los Derechos Humanos. En Instituto internacional de Derechos del Hombre, XXXVIII Session d'Enseignement, pp. 127-199. Estrasburgo, Francia.

-Secretaría de Derechos Humanos de la Provincia de Buenos Aires (2017). Informe de gestión. Buenos Aires. Argentina.

-Secretario General de la Organización de Naciones Unidas (2006). Estudio a fondo sobre todas las formas de violencia contra la mujer. ONU.

-Segato, R. (2011). Femi-geno-cidio como crimen en el fuero internacional de los Derechos Humanos: el derecho a nombrar el sufrimiento en el derecho. Recuperado el día 28/02/2019 de http://www.larevuelta.com.ar/pdf/Femi-geno-cidio-como-crimenSegato.pdf

-Sen, A. (2007). Identidad y Violencia. La ilusión del destino. Nueva York, Estados Unidos: Katz Editores.

-Servicio Nacional de la mujer (2007). Análisis y Evaluación de la Ruta Crítica en Mujeres Afectadas por Violencia en la Relación de Pareja. Santiago de Chile, Chile: SERNAM.

-Subsecretaría de Promoción de Derechos Humanos (2012). Mujeres y Derechos Humanos. Módulo 2: la perspectiva de género. Campus virtual. Dirección Nacional de Formación en Derechos Humanos. 
-Suprema Corte de Justicia de la Nación de México (2013). Protocolo para juzgar con perspectiva de género. Haciendo realidad el derecho a la igualdad. México DF, México. -Teodori, C. (2015). A los saltos buscando el cielo. Trayectorias de mujeres en situación de violencia familiar. Buenos Aires, Argentina: Biblos.

-Trabajadoras de la Línea 144 Nacional y Provincial, Cuerpo de delegdxs ATE DDHH, Delegadas INAM y ATE Capital (2018). No hay \#Ni una menos con trabajadoras despedidas.

-Unesco (1999). Recomendaciones para un uso no sexista del lenguaje. Recuperado el 5 de febrero de 2019 de: https://unesdoc.unesco.org/ark:/48223/pf0000114950.

-UNFPA, PNUD, UNICEF y ONU Mujeres (2012). Ampliando la mirada: la integración de los enfoques de género, interculturalidad y derechos humanos en la programación para el desarrollo. Santiago de Chile, Chile.

-Valcárcel, A. (1997). La política de las mujeres. Madrid, España: Ediciones Cátedra.

-Valle Rodríguez G. y Bueno Sánchez E. (2006). Las Políticas Públicas desde una perspectiva de género. En Novedades en Población, (4), La Habana, Cuba: Centro de Estudios Demográficos, Universidad de La Habana.

-Vázquez Camacho, S. (2011). El caso “Campo Algodonero" ante la Corte Interamericana de Derechos Humanos. En Anuario Mexicano de Derecho Internacional, vol. XI, (pp. 515-561). Ciudad de México, México: UNAM.

-Velazquez, S. (2003). Violencias cotidianas, violencia de género: Escuchar, comprender, ayudar. Buenos Aires, Argentina: Paidós.

-Viano, E. (1987). Violencia, victimización y cambio social. Opúsculos de derecho penal y criminología, (28). Córdoba, Argentina.

-Writh Mills C. (1959). La imaginacion sociologica. México, D.F.: Fondo de Cultura Económica.

-Yañez, S. (2013). La institución de la maternidad como bastión del heteropatriarcado. Reflexiones situadas y puntos de quiebre. Documento presentado en las XIV Jornadas Interescuelas/Departamentos de Historia. Facultad de Filosofía y Letras. Universidad Nacional de Cuyo, Mendoza. 
-(2017). Una genealogía feminista para abordar la maternidad como institución y como experiencia. El legado de Adrienne Rich. En La manzana de la discordia, vol. 12 (1), pp 61-76.

\section{Normativa Nacional y provincial:}

-Ley Nacional 26.485. Ley de protección integral para prevenir, sancionar y erradicar la violencia contra las mujeres en los ámbitos en que desarrollen sus relaciones interpersonales. Boletín Oficial № 31632, p. 1, Argentina, 14 de abril de 2009.

-Ley Nacional 24417. Régimen de Protección contra la violencia familiar. Boletín Oficial N 28052, p. 1, Argentina. 3 de enero de 1995.

-Decreto 1011/ 2010 reglamentario de la ley 26485. Boletín Oficial № 31947, p. 1, Argentina, 20 de julio de 2010.

-Ley Provincial 12.569. Ley de Violencia Familiar. Provincia de Buenos Aires. Boletín Oficial de la Provincia de Buenos Aires, 2 de enero de 2001.

-Ley Provincial 14407. Ley de declaración de emergencia pública en materia social por violencia de género. Boletín Oficial de la Provincia de Buenos Aires, 12 de diciembre de 2012.

-Decreto reglamentario 2.875. Actualizado por el Decreto 436/15, por el Dec. 686/16 y por el Dec. 165/18.

-Suprema Corte de Justicia de la Provincia de Buenos Aires (2010). Resolución 3488. -(2018). Resolución 2149.

-Procuración General del Ministerio Público de la Provincia de Buenos Aires (2014). Resolución 346.

\section{Normativa internacional:}

-Organización de Estados Americanos (1994). Convención Interamericana para Prevenir, Sancionar y Erradicar la violencia contra la mujer. Belem Do Para, Brasil. -Organización de Naciones Unidas (1979). Convención sobre la Eliminación de Todas las Formas de Discriminación contra la Mujer. 
-(1993). Declaración sobre la Eliminación de la Violencia contra la Mujer. 85ạ sesión plenaria, 20 de diciembre de 1993.

- (1999). Protocolo Facultativo a la CEDAW. 6 de octubre de 1999. 
